\author{
UNIVERSIDADE DE SÃO PAULO \\ FACULDADE DE FILOSOFIA, LETRAS E CIÊNCIAS HUMANAS \\ DEPARTAMENTO DE LINGÜÍSTICA
}

\title{
Percurso da Aquisição dos Encontros Consonantais, Fonemas e Estruturas Silábicas em Crianças de 2:1 a 3:0 Anos de Idade
}




\section{DANIELA EVARISTO DOS SANTOS GALEA}

Percurso da Aquisição dos Encontros Consonantais, Fonemas e Estruturas Silábicas em Crianças de 2:1 a 3:0 Anos de Idade

Tese apresentada ao programa de Pós-Graduação do Departamento de Linguística da Faculdade de Filosofia, Letras e Ciências Humanas da Universidade de São Paulo para obtenção do título de Doutor em Semiótica e Linguística Geral.

Orientador: Profa. Dra. Haydée Fiszbein Wertzner

São Paulo

2008 
AUTORIZO A REPRODUÇÃO E DIVULGAÇÃO TOTAL OU PARCIAL DESTE TRABALHO, POR QUALQUER MEIO CONVENCIONAL OU ELETRÔNICO, PARA FINS DE ESTUDO E PESQUISA, DESDE QUE CITADA A FONTE.

Catalogação na publicação

Programa de Semiótica e Lingüística Geral

Faculdade de Filosofia, Letras e Ciências Humanas

Galea, Daniela Evaristo dos Santos.

Percurso da Aquisição dos Encontros Consonantais, Fonemas e Estruturas Silábicas em Crianças de 2:1 a 3:0 Anos de Idade/ Daniela Evaristo dos Santos Galea; Orientadora Haydée Fiszbein Wertzner.

- - São Paulo, 2008.

$226 \mathrm{f}$.

Tese (Doutorado - Programa de Semiótica e Lingüística Geral) - Faculdade de Filosofia, Letras e Ciências Humanas da Universidade de São Paulo.

1. Desenvolvimento Infantil. 2. Testes de Articulação de Fala. 3. Medida da produção de Fala. 4. Fonética. 5. Distribuição por idade e sexo. 


\section{FOLHA DE APROVAÇÃO}

\section{Daniela Evaristo dos Santos Galea}

Percurso da Aquisição dos Encontros Consonantais, Fonemas e Estruturas Silábicas em Crianças de 2:1 a 3:0 Anos de ldade

Tese apresentada ao programa de Pós-Graduação do Departamento de Lingüística da Faculdade de Filosofia, Letras e Ciências Humanas da Universidade de São Paulo para obtenção do título de Doutor.

Área de Concentração: Semiótica e Lingüística Geral

Aprovado em:

\section{Banca Examinadora}

Prof. Dr.

Instituição:

Assinatura:

Prof. Dr.

Instituição:

Assinatura:

Prof. Dr.

Instituição:

Assinatura:

Prof. Dr.

Instituição:

Assinatura:

Prof. Dr.

Instituição: Assinatura: 
Aos meus queridos pais, que me deram a alegria da vida. Agradeço por todo o carinho, incentivo e amizade. 


\section{AGRADECIMENTOS}

Nestes anos de vida, todas as pessoas que passaram por mim, de certa forma, contribuíram para meu desenvolvimento como ser humano. Algumas ainda fazem parte diretamente do meu cotidiano, outras apesar de estarem ausentes, deixaram sua participação.

Seria um tanto extenso listar todos os nomes que durante estes anos estiveram ao meu lado. Porém, deixo registrados aqueles que estiveram mais próximos e que colaboraram para que este trabalho fosse realizado.

Primeiramente, agradeço a Deus por tudo o que tenho e pelas conquistas pessoais e profissionais.

Aos meus pais que, passando a lição de meus avós, conseguiram educar e formar não somente a mim, como a meus dois irmãos. Aos meus avós presentes e ausentes, aos meus novos avós e aos meus irmãos que tanto me apóiam e incentivam.

Nestes anos de estudo, graduei-me como fonoaudióloga pelo Curso de Fonoaudiologia da Faculdade de Medicina da USP e que, com o ensinamento de todas as professoras, foi possível minha formação acadêmica e a chegada até este momento.

Agradeço especialmente à $\operatorname{Prof}^{a}{ }^{a} r^{a}$ Haydée Fiszbein Wertzner, por quem tenho profunda admiração e gratidão. Durante dez anos tem me formado como pesquisadora e profissional, orientando-me na iniciação científica, capacitação técnica, mestrado e doutorado.

Às minhas amigas de faculdade, em especial Camila Rabelo, Patrícia Ideriha e Sandra Pires, por estarem sempre ao meu lado. Também, a todas as fonoaudiólogas do Laboratório de Fonologia. À Luciana Pagan, minha grande companheira durante o mestrado e doutorado, Adriana Gurgueira, Amália Rodrigues, Ana Carolina Papp, Vanessa Simões, Cristiane Rosal, por todo o carinho e amizade recebidos.

Não poderia deixar de citar a $\operatorname{Prof}^{\mathrm{a}} \mathrm{Dr}^{\mathrm{a}}$ Débora Maria Befi-Lopes que me auxiliou na análise do vocabulário e abriu caminho essencial para o início da coleta dos dados, as Prof ${ }^{\mathrm{a}} \mathrm{s} \mathrm{Dr}^{\mathrm{a}}$ Irenilde Pereira dos Santos e $\mathrm{Dr}^{\mathrm{a}}$ Clara Regina Brandão de Ávila por terem contribuído na minha qualificação e a $\operatorname{Prof}^{\underline{a}} \operatorname{Dr}^{\mathrm{a}}$ Carol Stoel-Gammon, 
profunda estudiosa de desenvolvimento fonológico, que me recebeu abertamente em seu laboratório em Seattle, colaborando com a análise dos dados de meu doutorado.

Agradeço a permissão das diretoras e coordenadoras das creches que tornaram meu trabalho viável, assim como a compreensão de todas as educadoras. Finalmente, às crianças que foram o alvo primordial do estudo.

À CNPq que possibilitou a realização da pesquisa por meio de bolsa de doutorado e, à CAPES, por ter fornecido bolsa sanduíche nos Estados Unidos. 


\section{RESUMO}

GALEA, D.E.S. - Percurso da Aquisição dos Encontros Consonantais, Fonemas e Estruturas Silábicas em Crianças de 2:1 a 3:0 anos de idade. 2008. 226 f. Tese (Doutorado) - Faculdade de Filosofia, Letras e Ciências Humanas, Universidade de São Paulo, São Paulo, 2008.

O objetivo geral do estudo foi descrever o percurso da aquisição dos encontros consonantais, fonemas e estruturas silábicas em crianças de 2:1 a 3:0 anos de idade. Foram sujeitos da pesquisa 88 crianças divididas de acordo com a idade e o sexo: Gl composto de dois grupos de crianças de 2:1 a 2:6 anos de idade, GI F-23 meninas e GI M - 18 meninos e, Gll composto de dois grupos de 2:7 a 3:0 anos de idade, Gll F - 24 meninas e Gll M - 24 meninos. Todas as crianças freqüentavam creches conveniadas à Prefeitura do Município de São Paulo e não apresentavam queixa de problema de linguagem, mais de três ocorrências de otite média e não eram bilíngües. A coleta de dados foi realizada por meio de três provas de fonologia: nomeação, imitação e fala espontânea. Todas as provas foram registradas em vídeo e audio. Os resultados mostraram que não havia diferença entre as posições de sílabas para encontros consonantais, mas em relação aos fonemas e estruturas silábicas foi encontrada diferença estatística em algumas situações. A comparação entre meninos e meninas da mesma faixa etária não mostrou diferença; assim, foram criados dois grupos: GI (2:1 a 2:6 anos) e Gll (2:7 a 3:0 anos). Os resultados mostraram que com o aumento da idade, houve melhora no desempenho de acertos totais em encontros consonantais, fonemas e estruturas silábicas em algumas posições de sílabas. Tal fato também foi observado ao analisar cada um dos encontros consonantais, fonemas e estruturas silábicas. As diferenças foram encontradas para: /fP/, /kP/, /d/, /b/, /m/, /z/, /s/, /f/, /Z/, / / /, /n/, /l/, $\mid \times /$, /X/, arquifonema $/ \mathrm{S} /$ e /R/, estrutura CV em trissílabos, CCV em dissílabos e CVC em dissílabos e trissílabos em determinadas posições de sílabas e provas. Alguns alvos foram mais omitidos, como o fonema /X/ e arquifonemas /S/ e /R/. Os demais tiveram mais substituições. Já as fricativas $/ \mathrm{s} / \mathrm{e} / \mathrm{z} /$, as plosivas linguodentais e as líquidas também apresentaram distorções acústicas e articulatórias. A estrutura silábica CCV apresentou com maior freqüência a omissão da segunda líquida, a CV omissão de fonema e de sílaba e a CVC, omissão do arquifonema. Não houve diferença entre o /s/ em onset e coda de sílaba, com exceção do Gll na sílaba final da imitação. Porém, as crianças apresentaram melhor desempenho do /P/ em onset que em coda. Quanto ao critério de aquisição, os encontros consonantais, fonemas e estruturas silábicas foram classificados como: não adquirido, em aquisição, produção habitual e adquirido. Até os 3:0 anos os fonemas /p/, /b/, /t/, /d/, / / /, /f/, /m/, $/ \mathrm{n} /, / \mathrm{N} /, / / /, / \mathrm{g} /, / \mathrm{X} /$ e arquifonema /S/ estão adquiridos em pelo menos uma posição de sílaba. A estrutura CV também está adquirida nesta faixa etária. A comparação entre as provas indicou que as crianças não mostraram desempenho diferente nas provas quanto aos encontros consonantais e estruturas CCV. Nas demais análises, os fonemas e estruturas silábicas apresentaram, em muitos momentos, diferenças entre as provas ao se verificar as posições das sílabas.

Palavras-Chave: Desenvolvimento Infantil, Testes de Articulação da Fala, Medida da Produção da Fala, Fonética, Distribuição por Idade e Sexo. 


\begin{abstract}
GALEA, D.E.S. - Course of Acquisition of Consonantal Clusters, Phonemes and Syllabic Structures in Children from 2:1 to 3:0 years old. 2008. $226 \mathrm{f}$. Thesis (Doctoral) - Faculdade de Filosofia, Letras e Ciências Humanas, Universidade de São Paulo, São Paulo, 2008.
\end{abstract}

The general purpose of this study was to describe the course of acquisition of consonantal clusters, phonemes and syllabic structure in children from 2:1 to 3:0 years old. The subjects of the research were 88 children divided according to age and gender: Gl was composed of two groups of children from 2:1 to 2:6 years old, GlF: 23 girls and GI-M: 18 boys and, Gll composed of 2 groups from 2:7 to 3:0 years old, GII-F: 24 girls and Gll-M: 24 boys. All children attended public day care centers linked to the São Paulo town hall and they did not have any language problems, more than three otitis media episodes, nor they were bilingual. Data collection was done through three phonology tests: picture naming, imitation and spontaneous speech. All the tests were recorded with a camera and a tape recorder. Results showed no differences between syllables in relation to consonantal clusters, although some differences were found regarding phonemes and syllabic structures. The comparison between girls and boys of the same age range did not show differences, thus, two groups were formed: Gl (2:1 to 2:6 years) e Gll (2:7 to 3:0 years). The results indicated that with the age growth, there was a better performance related to the correct production of consonantal clusters, phonemes and syllabic structures, in some syllables. This was also detected when analyzing each consonantal cluster, phoneme and syllabic structure separately. Differences were found for: $/ \mathrm{fP} /, / \mathrm{kP} /, / \mathrm{d} /$, $/ \mathrm{b} /, / \mathrm{m} /, / \mathrm{z} /, / \mathrm{s} /, / \mathrm{f} /, / \mathrm{Z} /, / \Sigma /, / \mathrm{n} /, / / /, / \times /, / \mathrm{X} /$, archiphonemes $/ \mathrm{S} /$ and $/ \mathrm{R} /$, CV structure in trisyllabic words, CCV structure in dissylabic words and CVC structure in trisyllabic and dissylabic words, in some syllables and tests. Some targets were more omitted like the $/ \mathrm{X} /$ phoneme and the archiphonemes $/ \mathrm{S} /$ and $/ \mathrm{R} /$; the others were more substituted. The fricatives $/ \mathrm{s} /$ and $/ \mathrm{z} /$, the dental plosives and the liquids also showed acoustical and articulatory distortions. The CCV syllable presented more omission of the liquid, the CV syllable more phoneme omission and the CVC syllable more omission of the archiphoneme. There was no difference between the $/ \mathrm{s} /$ in the onset and coda position of the syllable, with the exception of the final syllable of the imitation test in the Gll. However, children presented a better performance of the /R/ in the onset than in the coda of the syllable. The consonantal clusters, phonemes and syllabic structures were classified as the following criteria of acquisition: not acquired, in acquisition, customary production and acquired. Until the age of 3:0, the phonemes $/ \mathrm{p} /, / \mathrm{b} /, / \mathrm{t} /, / \mathrm{d} /, / \mathrm{k} /, / \mathrm{f} /, / \mathrm{m} /, / \mathrm{n} /, / \mathrm{l}, / / /, / \mathrm{g} /, / \mathrm{X} /$ and the archiphoneme $/ \mathrm{S} /$ were acquired in at least one syllable within the word. Also, the CV syllable was already acquired at that time. Comparison between tests indicated that children did not show different performance related to consonantal clusters and CCV syllable between them. On the other hand, phonemes and other syllabic structures showed differences within the tests according to some syllables of the word.

Key words: Child Development, Speech Articulation Tests, Speech Production Measurement, Phonetics, Age and Sex Distribution. 


\section{LISTA DE FIGURAS}

Figura 1: Acertos em encontros consonantais na prova de fala espontânea................................................................. 64

Figura 2: $\quad$ Acertos em encontros consonantais na prova de imitação. 64

Figura 3: Acertos em encontros consonantais na prova de nomeação.

Figura 4: $\quad$ Comparação da porcentagem de acerto em estrutura CV, entre as faixas etárias, na fala espontânea........................ 103

Figura 5: $\quad$ Comparação da porcentagem de acerto em estrutura CV, entre as faixas etárias, na imitação..................................... 105

Figura 6 : $\quad$ Comparação da porcentagem de acerto em estrutura CV, entre as faixas etárias, na nomeação................................ 106

Figura 7: Desempenho dos grupos quanto à estrutura CCV............. 107

Figura 8: $\quad$ Desempenho dos grupos quanto à estrutura CVC............. 110

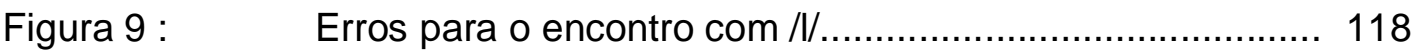

Figura 10: $\quad$ Erros para o encontro com /P/..................................... 119

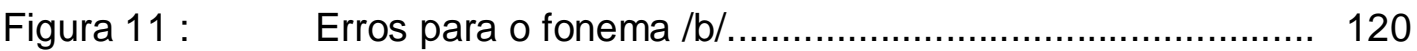

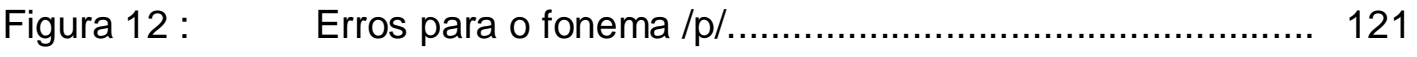

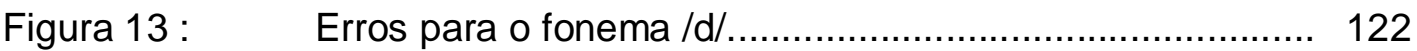

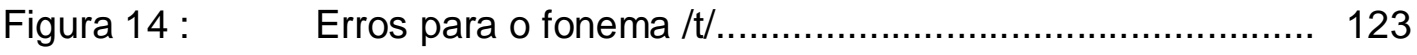

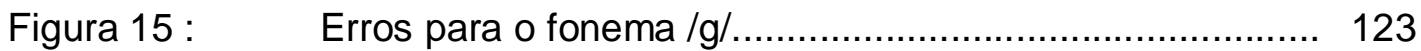

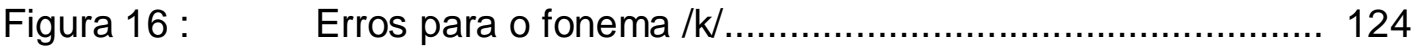

Figura 17: $\quad$ Erros para o fonema /z/ ........................................... 125

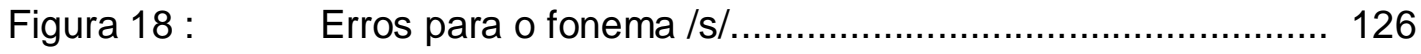

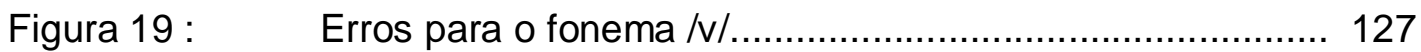

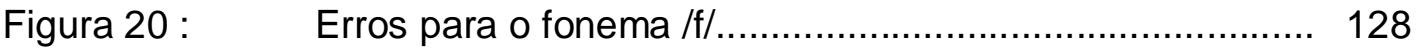

Figura 21: $\quad$ Erros para o fonema /Z/_.......................................... 129

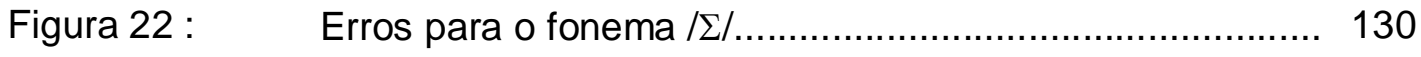




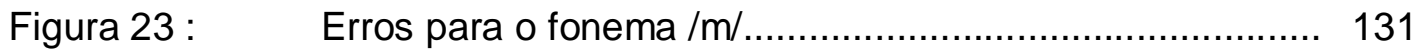

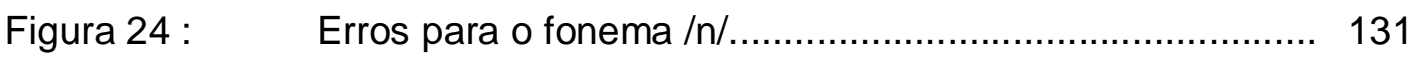

Figura 25: $\quad$ Erros para o fonema / $/$ /............................................. 132

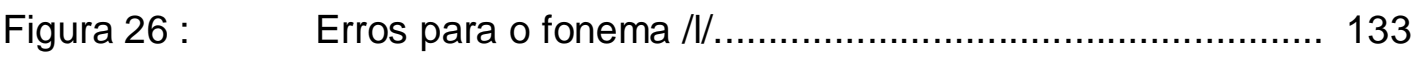

$\begin{array}{lllll}\text { Figura 27: } & \text { Erros } & \text { para } & 0 & \text { fonema } 133\end{array}$

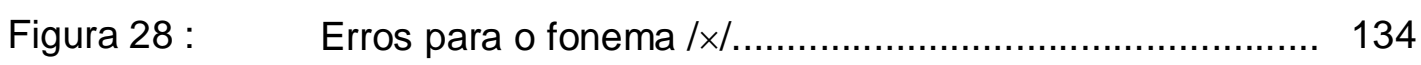

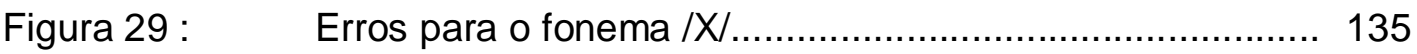

Figura 30: $\quad$ Erros para o arquifonema /R/..................................... 136

Figura 31: $\quad$ Erros para o arquifonema /S/..................................... 137 


\section{LISTA DE QUADROS}

Quadro 1: Exemplo dos fonemas, encontros consonantais e estruturas silábicas em cada posição de sílaba................. 56

Quadro 2: $\quad$ Critério de aquisição e adjetivo correspondente................. 57

Quadro 3: Definição dos tipos de erros para fonemas e encontros consonantais........................................................... 58

Quadro 4: $\quad$ Acerto nas estruturas silábicas analisadas..................... 59

Quadro 5: $\quad$ Erro das estruturas silábicas analisadas........................6 60

Quadro 6: $\quad$ Porcentagem de crianças com fonemas e encontros consonantais adquiridos em cada grupo na fala espontânea............................................................... 151

Quadro 7: $\quad$ Porcentagem de crianças com fonemas e encontros consonantais adquiridos em cada grupo na imitação......... 154

Quadro 8: $\quad$ Porcentagem de crianças com fonemas e encontros consonantais adquiridos em cada grupo na nomeação..... 157

Quadro 9 : $\quad$ Classificação de aquisição das estruturas silábicas........... 159 


\section{LISTA DE TABELAS}

Tabela 1: $\quad$ Distribuição dos Sujeitos nos Grupos................................ 51

Tabela 2: Comparação entre as posições de sílabas na fala espontânea para fonemas............................................. 65

Tabela 3: $\quad$ Comparação entre as posições de sílabas na imitação

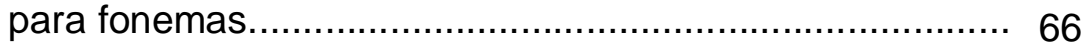

Tabela 4: $\quad$ Comparação entre as posições de sílabas na nomeação

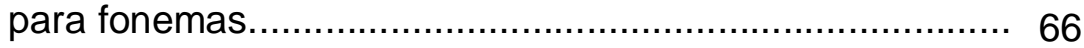

Tabela 5: $\quad$ Comparação entre posição de sílaba na estrutura CV na fala espontânea.............................................................. 67

Tabela 6: $\quad$ Comparação dois a dois entre as posições de sílaba na estrutura CV na fala espontânea..................................... 68

Tabela 7: $\quad$ Comparação entre posição de sílaba na estrutura CV na imitação....................................................................... 68

Tabela 8: $\quad$ Comparação entre as posições de sílabas na estrutura CV na nomeação......................................................... 69

Tabela 9 : $\quad$ Comparação entre posição de sílaba na estrutura CCV na fala espontânea............................................................. 69

Tabela 10: $\quad$ Comparação entre posição de sílaba na estrutura CCV na imitação..................................................................... 70

Tabela 11: $\quad$ Comparação entre posição de sílaba na estrutura CCV na nomeação.

Tabela 12: $\quad$ Comparação entre posição de sílaba na estrutura CVC na fala espontânea....................................................... 71

Tabela 13 : $\quad$ Comparação entre posição de sílaba na estrutura CVC na imitação..................................................................... 71

Tabela 14: $\quad$ Comparação entre posição de sílaba na estrutura CVC na

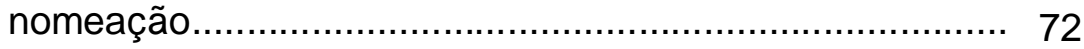

Tabela 15: Comparação entre os gêneros quanto aos encontros consonantais na fala espontânea..................................... 73

Tabela 16: Comparação entre os gêneros quanto aos encontros consonantais na imitação............................................... 74

Tabela 17: Comparação entre os gêneros quanto aos encontros consonantais na nomeação............................................ 74

Tabela 18: Comparação entre os gêneros quanto aos fonemas na fala espontânea............................................................. 75

Tabela 19: Comparação entre os gêneros quanto aos fonemas na

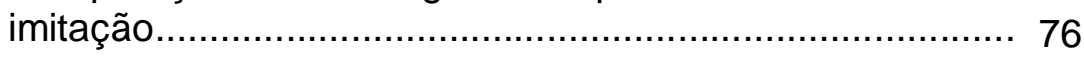

Tabela 20: $\quad$ Comparação entre os gêneros quanto aos fonemas na

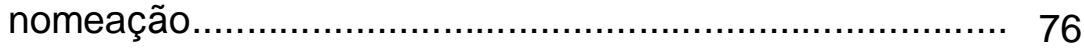

Tabela 21: $\quad$ Diferença entre os gêneros para a estrutura CV na fala espontânea................................................................... 77

Tabela 22: Diferença entre os gêneros para a estrutura CV na

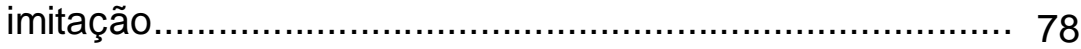


Tabela 23: Diferença entre os gêneros para a estrutura CV na nomeação........................................................... 78

Tabela 24 : Diferença entre os gêneros para a estrutura CCV na fala espontânea.............................................................. 79

Tabela 25: Diferença entre os gêneros para a estrutura CCV na imitação................................................................ 79

Tabela 26: Diferença entre os gêneros para a estrutura CCV na nomeação.......................................................... 80

Tabela 27: $\quad$ Diferença entre os gêneros para a estrutura CVC na fala espontânea............................................................. 80

Tabela 28: Diferença entre os gêneros para a estrutura CVC na imitação.............................................................. 81

Tabela 29: Diferença entre os gêneros para a estrutura CVC na nomeação............................................................... 81

Tabela 30: Comparação entre as faixas etárias para encontros consonantais na fala espontânea................................ 82

Tabela 31: $\quad$ Comparação entre as faixas etárias para cada encontro consonantal na fala espontânea.................................... 83

Tabela 32 : $\quad$ Comparação entre as faixas etárias para cada encontro consonantal na imitação........................................... 84

Tabela 33: $\quad$ Comparação entre as faixas etárias para encontros na nomeação........................................................... 85

Tabela 34 : $\quad$ Comparação entre as faixas etárias para cada encontro consonantal na nomeação......................................... 85

Tabela 35 : $\quad$ Comparação entre as faixas etárias para fonemas na fala espontânea............................................................. 86

Tabela 36 : $\quad$ Comparação entre as faixas etárias para plosivas na fala espontânea................................................................ 87

Tabela 37 : $\quad$ Comparação entre as faixas etárias para fricativas na fala espontânea............................................................. 88

Tabela 38 : $\quad$ Comparação entre as faixas etárias para nasais na fala espontânea............................................................. 90

Tabela 39 : $\quad$ Comparação entre as faixas etárias para líquidas na fala espontânea............................................................... 91

Tabela 40 : $\quad$ Comparação entre as faixas etárias para fricativa velar na fala espontânea.......................................................... 91

Tabela 41: $\quad$ Comparação entre as faixas etárias para arquifonemas na fala espontânea......................................................... 92

Tabela 42 : $\quad$ Comparação entre as faixas etárias para fonemas na imitação.................................................................... 92

Tabela 43: Comparação entre as faixas etárias para plosivas na imitação................................................................ 93

Tabela 44: $\quad$ Comparação entre as faixas etárias para fricativas na imitação..................................................................... 95

Tabela 45: $\quad$ Comparação entre as faixas etárias para nasais na imitação. 
Tabela 46: $\quad$ Comparação entre as faixas etárias para líquidas na imitação.................................................................. 96

Tabela 47 : $\quad$ Comparação entre as faixas etárias para a fricativa velar na imitação.

Tabela 48: $\quad$ Comparação entre as faixas etárias para arquifonemas na imitação.

Tabela 49: Comparação entre as faixas etárias para fonemas na nomeação.

Tabela 50: $\quad$ Comparação entre as faixas etárias para plosivas na nomeação.

Tabela 51: $\quad$ Comparação entre as faixas etárias para fricativas na nomeação.

Tabela 52: Comparação entre as faixas etárias para nasais na nomeação

Tabela 53: Comparação entre as faixas etárias para líquidas na nomeação.

Tabela 54 : $\quad$ Comparação entre as faixas etárias para a fricativa velar na nomeação............................................................ 102

Tabela 55: $\quad$ Comparação entre as faixas etárias para arquifonemas na nomeação........................................................... 103

Tabela 56: $\quad$ Comparação entre as faixas etárias quanto à estrutura CV na fala espontânea................................................ 104

Tabela 57: $\quad$ Comparação entre as faixas etárias quanto à estrutura CV na imitação......................................................... 105

Tabela 58: $\quad$ Comparação entre as faixas etárias quanto à estrutura CV na nomeação...................................................... 106

Tabela 59: $\quad$ Comparação entre as faixas etárias quanto à estrutura CCV na fala espontânea.............................................. 108

Tabela 60: $\quad$ Comparação entre as faixas etárias quanto à estrutura CCV na imitação.

Tabela 61: $\quad$ Comparação entre as faixas etárias quanto à estrutura CCV na nomeação...................................................... 109

Tabela 62: $\quad$ Comparação entre as faixas etárias quanto à estrutura CVC na fala espontânea.

Tabela 63: $\quad$ Comparação entre as faixas etárias quanto à estrutura CVC na imitação.

Tabela 64: $\quad$ Comparação entre as faixas etárias quanto à estrutura CVC na nomeação....................................................... 112

Tabela 65 : $\quad$ Comparação entre /s/ em onset e coda de sílaba na fala espontânea............................................................... 113

Tabela 66: $\quad$ Comparação entre /s/ em onset e coda de sílaba na imitação....................................................................... 114

Tabela 67: Comparação entre /s/ em onset e coda de sílaba na nomeação.................................................................. 114

Tabela 68: $\quad$ Comparação entre /P/ em onset e coda de sílaba na fala espontânea..... 
Tabela 69: $\quad$ Comparação entre /P/ em onset e coda de sílaba na imitação..................................................................... 116

Tabela 70: Comparação entre /P/ onset e coda de sílaba na nomeação................................................................ 116

Tabela 71: Comparação entre as faixas etárias para erros do encontro com $/ \mathrm{l} /$........................................................ 118

Tabela 72: Comparação entre as faixas etárias para erros do encontro com

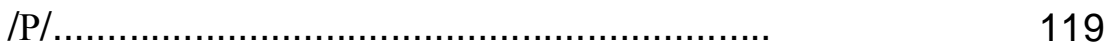

Tabela 73 : $\quad$ Comparação entre as faixas etárias para erros do fonema

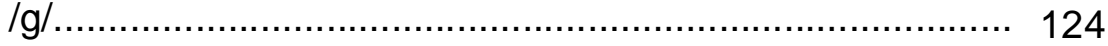

Tabela 74 : $\quad$ Comparação entre as faixas etárias para erros do fonema

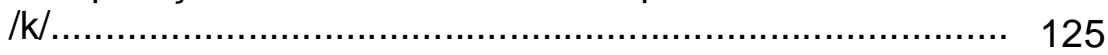

Tabela 75 : $\quad$ Comparação entre as faixas etárias para erros do fonema

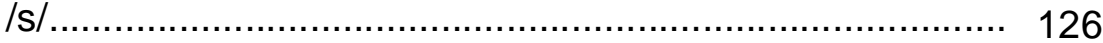

Tabela 76 : $\quad$ Comparação entre as faixas etárias para erros do fonema

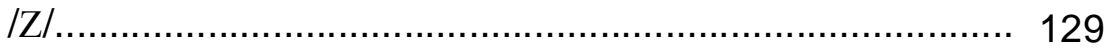

Tabela 77 : $\quad$ Comparação entre as faixas etárias para erros do fonema $/ \mathrm{P} /$.

Tabela 78 : $\quad$ Comparação entre as faixas etárias para erros do fonema $1 \times 1$.

Tabela 79 : $\quad$ Comparação entre as faixas etárias para erros do fonema /X/.....

Tabela 80: Comparação entre as faixas etárias para erros do arquifonema /R/......

Tabela 81: Comparação entre as faixas etárias para erros do arquifonema /S/ 138

Tabela 82 : $\quad$ Erros observados na estrutura CV em dissílabos............... 139

Tabela 83 : $\quad$ Erros observados na estrutura CV em trissílabos .............. 140

Tabela 84 : $\quad$ Erros observados na estrutura CV em polissílabos............ 141

Tabela 85: Comparação entre as faixas etárias para erros da estrutura CV.

Tabela 86 : $\quad$ Erros observados na estrutura CCV com $/ \mathrm{P} /$

Tabela 87: Comparação entre as faixas etárias para erros da estrutura CCV com /P/................................................ 144

Tabela 88 : $\quad$ Erros observados na estrutura CCV com $/ \mathrm{I} / \ldots \ldots \ldots \ldots \ldots \ldots \ldots . . . \ldots 145$

Tabela 89 : $\quad$ Erros observados na estrutura CVC com /S/................. 146

Tabela 90 : $\quad$ Erros observados na estrutura CVC com /R.................. 147 
Tabela 91: Comparação entre as faixas etárias para erros da estrutura CVC com /R/................................................ 148

Tabela 92: Comparação entre as provas para encontros

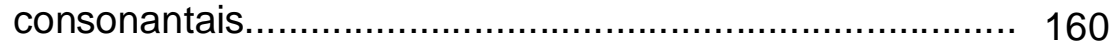

Tabela 93 : Comparação entre as provas para fonemas....................... 162

Tabela 94: $\quad$ Comparação múltipla entre as provas para fonemas.......... 162

Tabela 95: $\quad$ Comparação entre as provas para estrutura CV................ 163

Tabela 96 : $\quad$ Comparação múltipla entre as provas para estrutura CV... 164

Tabela 97: Comparação entre as provas para estrutura CCV.............. 164

Tabela 98: Comparação entre as provas para estrutura CVC.............. 165

Tabela 99: Comparação múltipla entre as provas para estrutura CVC, em sílaba final..................................................... 166 


\section{LISTA DE ANEXOS}

Anexo A: $\quad$ Aprovação da Comissão de Ética para Análise de Projetos de Pesquisa.

Anexo B : $\quad$ Creches na ordem em que foram utilizadas na pesquisa e número de crianças que passaram por cada uma das etapas.

Anexo C :

Anamnese

Anexo D : $\quad$ Termo de Consentimento Pós Informação.......................... 215

Anexo E : $\quad$ Carta de Encaminhamento às Creches.............................. 216

Anexo F a : $\quad$ Rodízio das provas no GI-F....................................... 217

Anexo F b : $\quad$ Rodízio das provas no Gl-M........................................ 218

Anexo F c : $\quad$ Rodízio das provas no Gll-F....................................... 219

Anexo F d : $\quad$ Rodízio das provas no Gll-M....................................... 220

Anexo G: $\quad$ Número possível de fonemas na prova de imitação e nomeação em sílaba medial............................................ 221

Anexo $\mathrm{H}$ : $\quad$ Número possível de cada estrutura silábica, na prova de imitação e nomeação. .................................................... 222

Anexo I a : $\quad$ Erro mais comum quanto a fonemas no Gl....................... 223

Anexo I b : $\quad$ Erro mais comum quanto a encontros consonantais no Gl 224

Anexo I c : $\quad$ Erro mais comum quanto a fonemas no Gll..................... 225

Anexo Id: $\quad$ Erro mais comum quanto a encontros consonantais no Gll....... 


\section{LISTA DE ABREVIATURAS}

GI F Crianças de 2;1 a 2;6 anos de idade do sexo feminino

GI M Crianças de 2;1 a 2;6 anos de idade do sexo masculino

GIl F Crianças de 2;7 a 3;0 anos de idade do sexo feminino

GII M Crianças de 2;7 a 3;0 anos de idade do sexo masculino

GI Crianças de 2;1 a 2;6 anos de idade

GIl Crianças de 2;7 a 3;0 anos de idade

I Sílaba inicial

M Sílaba medial

F Sílaba final

CV Estrutura silábica Consoante - Vogal

CCV Estrutura silábica Consoante - Consoante - Vogal

CVC Estrutura silábica Consoante - Vogal - Consoante

C Produção correta

Quanto aos erros:

OF Omissão de Fonema

OS Omissão de Sílaba

S Substituição por um determinado fonema

I Interdentalização

D Distorção

CA Ceceio anterior

CL Ceceio lateral 


\section{SUMÁRIO}

\section{APRESENTAÇÃO}

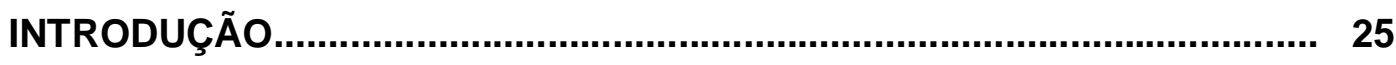

Estrutura silábica e aquisição dos fonemas........................................... 26

Fatores biológicos e Ambientais influentes na aquisição fonológica.......... 37

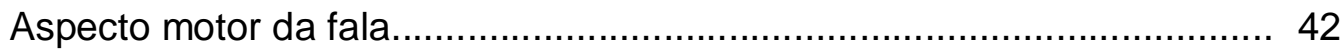

Coleta de dados de Fonologia......................................................... 45

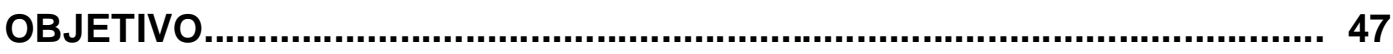

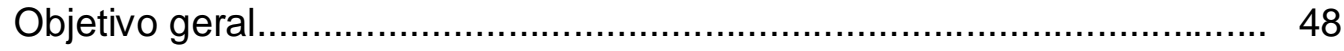

Objetivos Específicos................................................................. 48

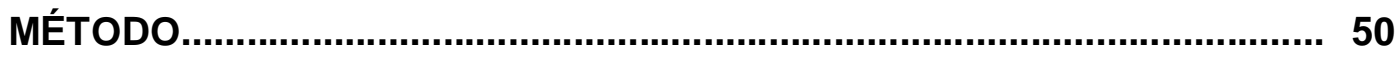

Sujeitos

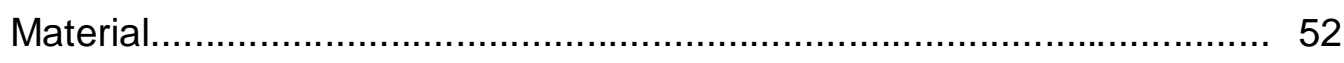

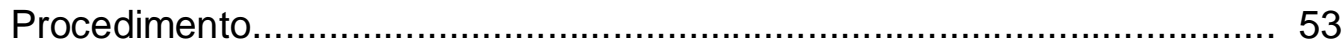

Seleção das creches....................................................................... 53

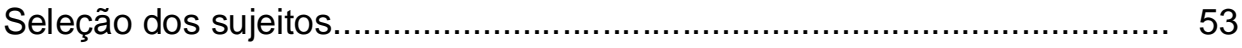

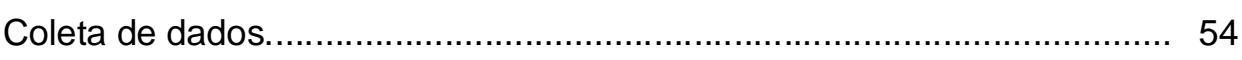

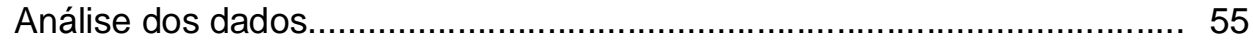

Método Estatístico ................................................................................ 61 
RESULTADOS..

Hipótese 1 - Não há diferença entre o acerto de encontros consonantais, fonemas e estruturas silábicas de acordo com as posições de sílaba inicial, medial e final.

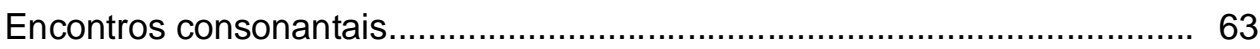

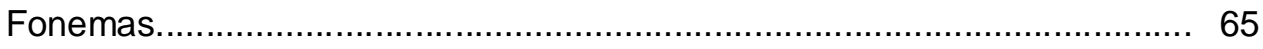

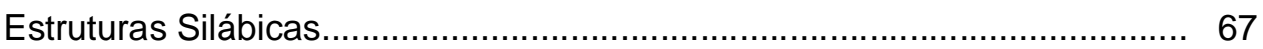

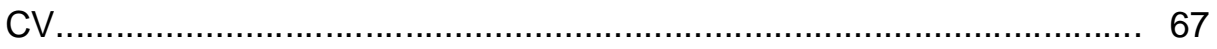

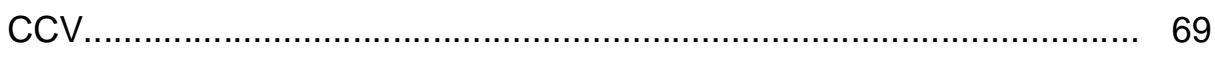

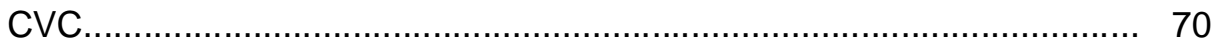

Hipótese 2 - Não há diferença na aquisição fonológica de meninos e meninas da mesma faixa etária quanto a encontros consonantais, fonemas e estruturas silábicas....................................................... 73

Encontros consonantais....................................................................... 73

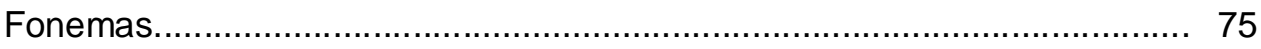

Estruturas Silábicas......................................................................... 77

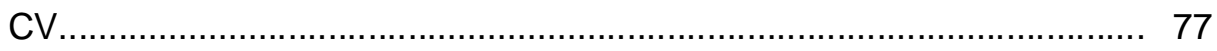

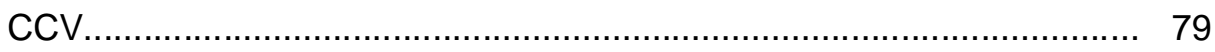

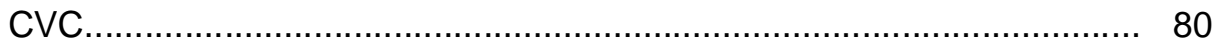

Hipótese 3 - Crianças mais velhas apresentam mais acertos que as mais novas em relação a encontros consonantais, fonemas e estruturas silábicas.

Encontros consonantais................................................................... 82

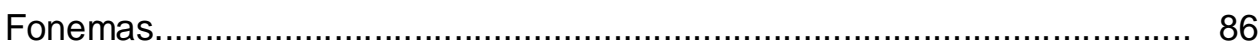

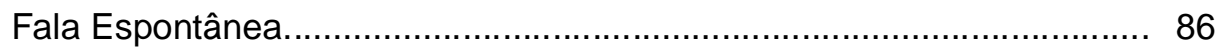

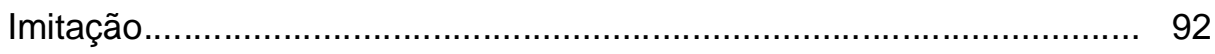

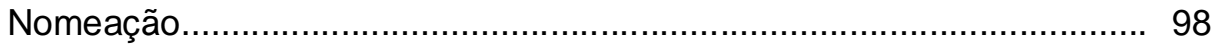


CV.

CCV.

CVC

Hipótese 4 - Há diferença no acerto do fonema /s/ em posição de onset e coda silábica. Ao contrário, não há diferença entre $0 / \mathrm{P} /$ em onset e coda de sílaba.

Comparação entre /s/ em onset e coda silábica.

Comparação entre /P/ em onset e coda silábica.

Hipótese 5 - Há diferentes tipos de erros predominantes: em encontros consonantais acontece em função do $/ \mathrm{P} /$ e $/ \mathrm{l} /$; nos fonemas cada um apresenta diferenças em função das categorias omissão, substituição e distorção e, nas estruturas silábicas a diversidade ocorre em função da extensão da palavra. Além disso, também se supõe que as crianças do Gl apresentem mais ocorrência de erros que as do Gll.

Encontros consonantais.

Fonemas.

Estruturas Silábicas.

CV.

CCV.

CVC

Hipótese 6 - Há diferença entre os encontros consonantais, fonemas e estruturas silábicas quanto à classificação de aquisição, indicando que as crianças do Gll apresentam maior porcentagem de aquisição para todos os fonemas.

Encontros consonantais e fonemas.

Fala Espontânea

Imitação.

Nomeação 
Hipótese 7 - As crianças das duas faixas etárias apresentam desempenho diferente nas três provas (nomeação, imitação e fala espontânea).

Encontros consonantais...................................................................... 160

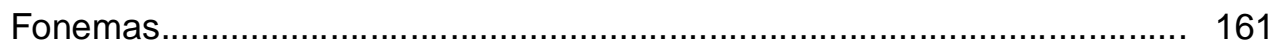

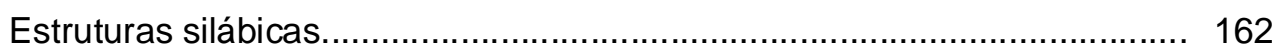

$\mathrm{CV}$

CCV

CVC

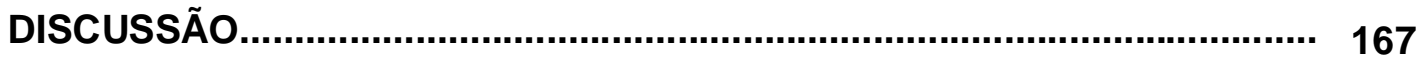

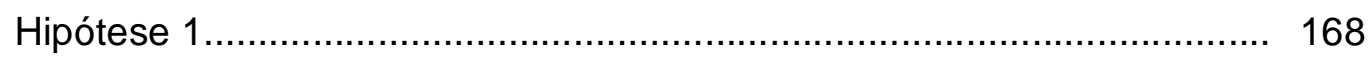

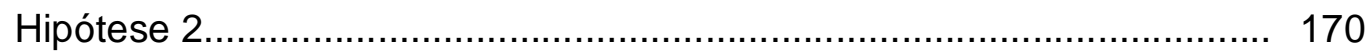

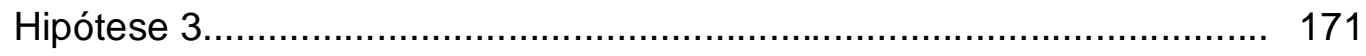

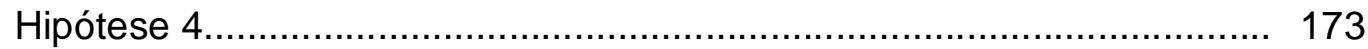

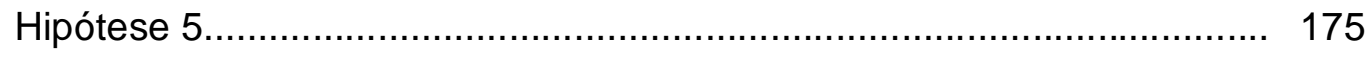

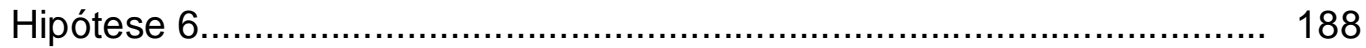

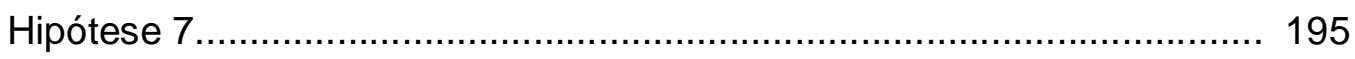

CONCLUSÃO

REFERÊNCIAS BIBLIOGRÁFICAS..................................................... 202

ANEXOS 
APRESENTAÇÃO 
A área de desenvolvimento de linguagem, especialmente a de fonologia, tem me atraído desde a época da minha graduação. $\mathrm{Na}$ ocasião, fui contemplada com bolsa de iniciação científica pela FAPESP, começando os estudos numa área pouco pesquisada no português brasileiro, principalmente com crianças no início da aquisição fonológica.

Posteriormente, tive oportunidade de desenvolver uma pesquisa de mestrado na mesma área, com bolsa da CAPES. Meu alvo, naquela época, foi analisar os processos fonológicos e dois índices de gravidade de fala em crianças de 2;1 a 3;0 anos de idade.

Atualmente, minha pesquisa de doutorado é a continuação do mestrado que foi defendido em novembro de 2003. Iniciei meus estudos do doutorado em fevereiro de 2004, com bolsa da CNPq e, de setembro a dezembro de 2005, a CAPES me concedeu bolsa de estágio no exterior. Nesta ocasião, tive a oportunidade de analisar e discutir os dados com a Prof $^{\text {a }}$ Carol Stoel-Gammon, da University of Washington. Além das orientações individuais, participei das reuniões do Child Speech Laboratory, com as demais alunas de doutorado da Prof ${ }^{\mathrm{a}}$ Carol, e realizei três disciplinas: Doctoral Research Fórum, American English Sounds e Critical Period for Second Language Acquisition.

Os dados que serão apresentados nesta pesquisa são oriundos do mesmo corpus coletado anteriormente, porém o enfoque é diferente. Com o intuito de entender ainda melhor o desenvolvimento das crianças, serão abordados os fonemas e encontros consonantais isoladamente, bem como a aquisição de três tipos diferentes de estruturas silábicas: consoante-vogal, consoante-vogal-consoante e consoante-consoante-vogal.

Como pelo menos $2,5 \%$ das crianças em idade pré-escolar apresentam transtorno fonológico, entender cada vez mais o desenvolvimento fonológico possibilita auxiliar a prática clínica. Cabe ao fonoaudiólogo avaliar as crianças com queixa e definir o diagnóstico. Assim, dados do desenvolvimento típico, ou seja, daquele considerado adequado para as diferentes idades, são necessários para que as decisões terapêuticas que propiciam o início do tratamento sejam tomadas o mais breve possível. Além disso, dados da normalidade também auxiliam na escolha dos sons-alvo e das estruturas silábicas para a terapia fonoaudiológica com ênfase na fonologia. 
A pesquisa aqui apresentada faz um recorte do percurso da aquisição fonológica dos 2:1 aos 3:0 anos de idade, em crianças falantes do português do Brasil, da região de São Paulo.

Primeiramente, será realizada revisão da literatura para situar o leitor sobre o tema da pesquisa. Ao final da introdução serão expostas as hipóteses, seguida dos objetivos e do método. Os resultados, bem como a discussão e conclusão, serão apresentados de acordo com as hipóteses para melhor entendimento do estudo. 
INTRODUÇÃO 
$\mathrm{Na}$ introdução, será enfatizada a aquisição dos fonemas e encontros consonantais, bem como das estruturas silábicas em crianças com desenvolvimento típico, isto é, aquelas com desenvolvimento fonológico adequado para a idade. Como há alguns fatores que influenciam a aquisição dos fonemas, estes também serão enfocados. Na terceira parte, será abordada a parte motora da fala e, por fim, serão apontadas as provas para coleta de dados de fonologia.

Vários estudos que serão abordados na introdução apontam acertos e erros fonológicos encontrados durante o desenvolvimento, sendo que erro é usado no sentido de produção não desejável do som alvo, ou seja, produção incorreta comparada à forma do adulto.

\section{- Estrutura silábica e aquisição fonemas}

As sílabas são constituídas de vogais $(\mathrm{V})$ e consoantes $(\mathrm{C})$. A vogal é sempre necessária, porém as consoantes podem ser opcionais (SILVA, 1999).

As consoantes podem ser pré-vocálicas ou pós-vocálicas. Se a sílaba apresenta um elemento pós-vocálico, ela é travada ou fechada, se não é considerada aberta ou livre (BECHARA, 1988; CÂMARA JR, 2001). Para o português, as sílabas livres predominam sobre as travadas (CÂMARA JR, 2001).

Há duas teorias sobre a estrutura da sílaba: a primeira que supõe camadas independentes, na qual a sílaba está ligada diretamente aos segmentos e, a segunda, que as sílabas são estruturadas. Nessa última, uma sílaba consiste de onset e rima e essa, de núcleo e coda. Qualquer categoria, exceto o núcleo, pode ser omitida. Na primeira teoria, os elementos apresentam relação igual entre si e, na segunda, há um relacionamento mais estreito entre a vogal (núcleo) e a consoante da coda do que entre a vogal e a consoante do onset (COLLINSCHONN, 2001a; MATZENAUER, 2004).

As sílabas também podem ser consideradas leves ou pesadas. De acordo com a segunda teoria, as sílabas pesadas têm rima ramificada. Outra proposta é a de que as sílabas são compostas por constituintes de peso, ou seja, as moras. Uma sílaba pesada consiste de duas moras, ao contrário, a leve consiste de apenas uma (BERNHARDT \& STEMBERGER, 2000; COLLINSCHONN, 2001a). Duas ou mais sílabas constituem o pé métrico, estabelecendo uma relação de dominância, sendo que uma delas é dominante e, as demais, recessivas (BERNHARDT \& 
STEMBERGER, 2000; BISOL, 2001). O pé troqueu é dissilábico e tem proeminência na sílaba inicial. Em contrapartida, o pé iambo tem proeminência final, o elemento mais forte fica à direita. A maioria das palavras do português brasileiro é paroxítona, ou seja, apresenta o pé troqueu (COLLINSCHONN, 2001b).

Além disso, a maior parte das palavras é polissilábica e a estrutura $\mathrm{CV}$ (consoante-vogal) a mais ocorrente (TEIXEIRA \& DAVIS, 2002; MATZENAUER, 2004).

Quanto às consoantes do português brasileiro, elas podem ser apresentadas nas seguintes posições da palavra: onset silábico em início de palavra, onset silábico dentro da palavra, coda silábica dentro da palavra, coda silábica no final da palavra e como segunda consoante pré-vocálica em início ou dentro da palavra (CÂMARA JR, 1975; SILVA, 1999; MATZENAUER, 2004).

$\mathrm{Na}$ posição de onset silábico em início de palavra, somente 16 consoantes aparecem no português. Porém, ao considerar a posição de onset silábico dentro da palavra, são 19 as consoantes que podem ser usadas nesta posição (SILVA, 1999).

A classificação proposta por BECHARA (1988) considera que as consoantes podem ser oclusivas e constritivas, sendo que esta se divide em fricativas, laterais, vibrantes e nasais. Para as oclusivas, têm-se as bilabiais $/ \mathrm{p} / \mathrm{e} / \mathrm{b} /$, as linguodentais $/ \mathrm{t} /$ e $/ d /$ e as velares $/ \mathrm{k} /$ e $/ \mathrm{g} /$. As fricativas são divididas em labiodentais $/ \mathrm{f} / \mathrm{e} / \mathrm{v} /$, alveolares $/ \mathrm{s} / \mathrm{e} / \mathrm{z} /$ e as palatais $/ \Sigma / \mathrm{e} / \mathrm{Z} /$. Como mostrado, cada par tem um elemento surdo e outro sonoro. As demais classes de consoantes são somente sonoras. As nasais são: bilabial $/ \mathrm{m} /$, linguodental $/ \mathrm{n} /$ e palatal $/ / /$. As outras consoantes além de serem sonoras, não têm a participação dos lábios na sua produção. São elas as laterais $/ / / \mathrm{e} / x /$, sendo a primeira alveolar e a segunda palatal e as vibrantes que são constituídas da simples /P/ ("r-brando") e da múltipla /X/ ("r forte").

Na língua portuguesa, o ponto coronal é o mais usado, seguido pelo labial. As plosivas são mais freqüentes, as fricativas e líquidas quase equivalentes a elas e, as nasais, aparecem em menor quantidade (TEIXEIRA \& DAVIS, 2002).

No estudo de TEIXEIRA \& DAVIS (2002) foi constatado que as duas crianças que tiveram sua fonologia analisada entre 1:0 e 3:0 anos produziram mais palavras dissilábicas, seguidas por monossilábicas e polissilábicas. A estrutura silábica mais encontrada foi CV. Apenas $12 \%$ das sílabas mostraram coda, sendo estas ocupadas, na maioria das vezes, por semi-vogais. O ponto coronal foi o mais 
freqüente, seguido de labial e velar. Quando os segmentos foram analisados separadamente, o / $/$ foi o mais ocorrente, seguido do /p/. Em posição final de sílaba as nasais foram as mais ocorrentes, seguidas das semi-vogais $/ \mathrm{w} / \mathrm{e} / \mathrm{j} /$.

Na língua inglesa, HAWKINS (1995) estudou 510 crianças de 3:0 a 6:0 anos em Edimburgo, Escócia. Os resultados mostraram que as plosivas e as nasais são adquiridas mais precocemente que as demais consoantes. As fricativas seguem as plosivas e nasais, mas se pode notar pelo menos uma fricativa durante os estágios iniciais da fala, sendo o /f/ e o /s/ as primeiras a aparecerem. O ponto de articulação preferido parece ser o labial e o alveolar, sendo então os sons mais precocemente adquiridos /p b t d m n/. Nos períodos iniciais, o vozeamento não é distinguido.

A pesquisa de STOEL-GAMMON \& PETER (no prelo) para o inglês americano mostrou que $60 \%$ das palavras eram monossilábicas, 36\% dissilábicas, $5 \%$ trissilábicas e $1 \%$ polissilábicas; A estrutura silábica mais comumente encontrada em ordem decrescente de freqüência foi: CVC (30\%), CVCV (9\%), CCVC (8\%), CVCC (7\%) e CV (6\%). Em 90\% das palavras a acentuação era na primeira sílaba. Estes dados foram retirados de palavras faladas por crianças de até 30 meses de idade do MacArthur Communicative Development.

Com relação aos segmentos, na posição inicial de palavra, as plosivas constituem a maior parte dos segmentos (43\%), seguidas de fricativas e africadas (29\%), nasais (7\%), líquidas (6\%) e semivogais (5\%). Em posição final, as plosivas ocorrem em $30 \%$ das palavras, vogais em $29 \%$, fricativas e africadas em $17 \%$, nasais em $13 \%$, e líquidas em $11 \%$. As bilabiais contam com $33 \%$ das palavras, as coronais, $40 \%$ e dorsais e glotais, 18\% (STOEL-GAMMON \& PETER, no prelo).

Um estudo sobre a aquisição de crianças falantes do árabe entre 14 e 24 meses mostrou que quase $50 \%$ das consoantes são plosivas. As fricativas são o segundo modo mais freqüente $(16,9 \%)$, seguido das semivogais $(12,5 \%)$, nasais $(11,6 \%)$, líquidas $(7,6 \%)$ e africadas $(1,8 \%)$. A proporção de plosivas diminuiu com 0 avanço da idade e as líquidas e fricativas aumentaram. Os pontos de articulação bilabial, dento-alveolar e glotal constituem quase $80 \%$ da amostra. Dentre estes, o dento-alveolar $(36,9 \%)$ predomina sobre glotal $(21,6 \%)$ e bilabial $(20,2 \%)$. Poucas dentais, uvulares ou labiodentais foram usadas, sendo somente $3,2 \%$ da amostra (AMAYREH \& DYSON, 2000). 
Para o português do Brasil, alguns estudos mostram as classes de fonemas estudadas e como ocorre o desenvolvimento, com os erros cometidos pelas crianças e a idade de aquisição.

FREITAS (2004) fez uma revisão de estudos do português do Brasil sobre aquisição de plosivas e nasais. Quanto às plosivas e às nasais $/ \mathrm{m} / \mathrm{e} / \mathrm{n} /$, constatou que são adquiridas entre 1:6 e 1:8 ano de idade. $\mathrm{O} /$ / tem aquisição mais tardia, sendo adquirido a partir de 1:7 ano.

Em relação às fricativas, WERTZNER \& CARVALHO (2000) realizaram pesquisa com crianças em desenvolvimento fonológico típico de 3:0 a 4:0 anos. Notaram que as crianças ainda realizaram omissão e substituição dos fonemas /f v s $z \Sigma \mathrm{Z} /$ mas, nesta faixa etária, eles estão adquiridos, com exceção do /Z/ em posição final e inicial.

Em estudo posterior, WERTZNER et al. (2002) analisaram a fonologia de 75 crianças de 2:1 a 5:6 anos de idade nas provas de nomeação e imitação. Os resultados mostraram que, nas duas provas, com o aumento da idade, o número de acertos aumentava e as substituições e omissões de fonemas diminuíam. Pode-se observar que as crianças realizavam mais substituições comparadas às omissões, sendo as últimas pouco observadas. Além disso, os fonemas /f, v, s, z/ são produzidos corretamente antes de $/ \Sigma, \mathrm{Z} /$.

OLIVEIRA (2003) estudou as fricativas /f, v, $\Sigma, \mathrm{Z} /$ em crianças de 1:0 a 3:9 anos de idade e verificou que a produção delas não é linear, mas gradual. Constatouse que o fonema /f/ é adquirido pela criança a partir de 1:9 ano, o /v/ a partir de 1:8 ano, o / $/ /$ a partir de 2:10 anos e o /Z/ a partir de 2:6 anos. Quanto à posição da sílaba na palavra, /f, v, $\Sigma /$ estabeleceram-se primeiro em sílaba medial e o /Z/ em sílaba inicial. Em relação às substituições, as crianças realizaram mais substituições do $/ \Sigma /$ e do /Z/ e menos do /f/ e do /V/, sendo que para o / $/ /$ e o /Z/ as substituições mais comuns são para o/s/ e o /z/, respectivamente.

A aquisição das fricativas coronais /s, z, $\Sigma, \mathrm{Z} /$ foi estudada por MATZENAUER (2003) em 72 crianças em desenvolvimento típico de 1:3 a 2:5 anos de idade, falantes do português. Verificou-se que durante a aquisição a criança pode escolher dois padrões: A (aquisição do /s/) ou B (aquisição do $/ \Sigma /$ ). Caso o escolhido seja o padrão $A$, o estágio seguinte é representado pela aquisição do /z/ ou do $/ \Sigma /$. Se o 
padrão B for escolhido, subseqüentemente, a aquisição seria do /Z/ ou do /s/. No estágio final, todas as fricativas estariam adquiridas.

OLIVEIRA (2004) reuniu dados de duas pesquisas sobre aquisição das fricativas e constatou que $0 / \mathrm{s} /$ é adquirido aos 2:6 e o /z/ aos 2:0. Em relação às substituições, o /s/ é mais substituído por $/ \Sigma /$ e o /z/ por /Z/. As fricativas palatais são mais substituídas pelas alveolares.

Sobre as consoantes líquidas, HERNADORENA \& LAMPRECHT (1997) realizaram estudo com 310 crianças da região de Pelotas e Porto Alegre com idade entre 2:0 e 7:1 anos. Os resultados mostraram que o /// em onset silábico em início de palavra era adquirido entre 2:8 e 2:9 anos e, dentro da palavra, entre 3:0 e 3:1 anos. Os fonemas $/ \times /$ e $/ \mathrm{P} /$, que aparecem somente em onset silábico dentro da palavra, foram adquiridos entre 4:0 e 4:1 anos e entre 4:2 e 4:3 anos, respectivamente.

WERTZNER (1998) notou que as crianças de 3:1 a 5:6 anos de idade ainda omitem ou substituem as líquidas, com diminuição dessas ocorrências conforme o aumento da idade. A substituição de uma liquida por outra ou pela semivogal/y/ foram os erros mais observados.

Em outra pesquisa, HERNANDORENA (1999) estudou a lateral $/ \times /$ e a nasal /N/ em 130 crianças de 2:0 a 4:1 anos de idade. Constatou que o / / já está adquirido aos dois anos, embora ainda seja omitido ou tenha outro segmento empregado em seu lugar, porém, em baixa ocorrência. $O / \times /$ é adquirido entre 2:6 e 2:7 anos, porém, até os 4:0/4:1, ele é ainda apagado ou substituído por outro segmento.

RIGATTI et al. (2001) analisaram as dificuldades de aquisição típica e desviante do /P/ comparando dados de duas pesquisas previamente realizadas: uma com 60 crianças normais de 2:6 a 5:0 anos de idade e outra com 20 crianças, sendo que dez produziam o fonema / $r /$ adequadamente, em todas as posições das palavras, e outras dez, com ausência de sua produção. Observou-se que, quando as crianças apresentavam dificuldade na aquisição deste fonema, elas o substituíam por /l/, /y/, /w/, /R/ ou o omitiam.

MEZZOMO \& RIBAS (2004) observaram que o /l/ é adquirido antes das demais líquidas, sendo adquirido em posição inicial de palavra aos 2:6 e, em onset silábico dentro da palavra, aos 3:0 anos de idade. Nesse percurso, os erros mais ocorrentes são a omissão do /// ou a semivocalização. O / x/ é dominado aos 3:6 
anos, sendo a semivocalização e a omissão deste segmento os erros mais encontrados no percurso de aquisição. A vibrante simples /P/ é adquirida aos 4:2 anos, sendo as substituições por /// e as semivocalizações mais observadas como erros.

Um estudo sobre as consoantes líquidas em crianças de 2:1 a 2:6 e de 2:7 a 3:0 anos de idade (GALEA \& WERTZNER, 2005a) mostrou que as crianças mais velhas apresentaram maior número de produções corretas destes fonemas. Nos dois grupos, o /// é o fonema produzido mais corretamente, o /P/ é o mais omitido e o / $/ x /$ é o mais substituído, com exceção das crianças mais velhas na imitação, em que o mais substituído é o /P/. Os fonemas /×, P/ são mais substituídos por /// na nomeação e imitação, nos dois grupos e o /// é mais substituído por /P/ com exceção do Gl, na imitação, no qual é mais substituído por /y/.

Alguns autores consideram o /X/ como vibrante (CUNHA, 1980; BECHARA, 1988; CÂMARA JR, 2001), outros como líquida (HERNANDORENA \& LAMPRECHT, 1997; MEZZOMO \& RIBAS, 2004) ou ainda fricativa velar (SILVA, 1999; WERTZNER et al., 2001a).

HERNADORENA \& LAMPRECHT (1997) em estudo com crianças de 2:0 a 7:1 anos, observaram que o /X/ é adquirido tanto no início como dentro da palavra entre 3:4 e 3:5 anos.

RAMOS (2000) mostrou que as crianças podem ter dificuldade na aquisição deste fonema por estar relacionado a origens fonéticas e fonológicas. Apontou que as crianças têm três possibilidades de percepção do $/ \mathrm{X} /$ : podem enfocar sua característica fonética e categorizá-lo como fricativa, podem enfocar seu funcionamento fonológico e categorizá-lo como líquida ou, na impossibilidade de categorizá-lo, omitem este fonema de seu sistema fonológico.

WERTZNER et al. (2001a) e GALEA (2003) estudaram crianças de 2:1 a 3:0 anos de idade e concluíram que até esta idade as crianças o omitem ou o substituem com grande freqüência. Porém, com o aumento da idade houve aumento nas emissões corretas e diminuição das omissões e substituições.

MEZZOMO \& RIBAS (2004) mostraram que a aquisição do /X/ ocorre aos 3:4/3:5 anos de idade. Os erros mais encontrados durante este percurso foram: substituição por /I/, não-produção, substituição por / $/ /$ ou /g/, substituição por /d/ ou /t/ e semivocalização. 
No sul do Brasil, são muito freqüentes as pesquisas com róticos. Alguns estudos desta região mostram que o /X/ é adquirido antes do /P/ (MALDANER \& RAMOS, 2001; MIRANDA, 2003).

$\mathrm{Na}$ literatura são encontrados alguns estudos que consideraram a aquisição de todos os fonemas. Dentre estes, no inglês, SMIT et al. (1990) pesquisaram a idade de aquisição dos fonemas e observaram se havia diferença entre meninos e meninas. Foram estudadas crianças de três a nove anos e os resultados indicaram que havia diferença estatística entre os gêneros em crianças de até seis anos de idade, sendo que as meninas adquiriram os fonemas mais precocemente que os meninos. $75 \%$ dos sujeitos teriam que ter o fonema adquirido para que este fosse considerado adquirido pelo grupo. Os fonemas $/ \mathrm{m} \mathrm{n} \mathrm{h} \mathrm{w} \mathrm{p} \mathrm{b} \mathrm{t} \mathrm{d} \mathrm{k} \mathrm{g/foram} \mathrm{adquiridos}$ aos 3:0 anos em ambos os gêneros; o /f/ foi adquirido aos 3:0 anos pelas meninas e aos 3:6 pelos meninos; o /v/ foi aos 4:0 pelas meninas e aos 4:6 pelos meninos; o /s/ foi aos 3:0 anos pelas meninas e aos 5:0 pelos meninos; o /z/ foi aos 5:0 pelas meninas e aos 6:0 pelos meninos; o /// foi aos 4:6 pelas meninas e aos 6:0 pelos meninos; o /P/ foi aos 6:0 pelas as meninas e aos 5:6 pelos meninos; o /Z/ foi aos 3:6 pelos meninos e meninas; o /// foi aos 5:6 pelas meninas e aos 6:0 pelos meninos; para $\circ / \Sigma /$ e $\circ / \mathrm{t} \Sigma /$ encontrou-se aos 4:0 anos para meninas e aos 5:0 anos para meninos; o /dZ/ foi adquirido aos 4:6 anos pelas meninas e aos 4:0 anos pelos meninos. Os encontros consonantais foram adquiridos posteriormente aos fonemas isolados

PORTER \& HODSON (2001) estudaram 520 crianças de 2:6 a 8:0 anos de idade em Riverside County, Estados Unidos. Os resultados mostraram que embora as crianças de até 3:5 anos apresentassem desvios em velares, estridentes e semivogais, estas classes de fonemas foram consideradas adquiridas, assim como as nasais, pois foram produzidas adequadamente em mais de $85 \%$ das oportunidades. Observou-se que as crianças com menos de 3:5 anos tinham adquirido todos os padrões do inglês com exceção das líquidas e dos encontros consonantais.

Estudo realizado com crianças falantes do inglês britânico separadas nas faixas etárias de 3:0 a 3:11, de 4:0 a 5:5 e de 5:6 a 7:0 indicaram que os fonemas $/ m, n, p, b, d, w /$ estão entre os primeiros a serem adquiridos, enquanto os fonemas /r, h, ठ/ foram uns dos últimos ( DODD et al., 2003). Além disso, a pesquisa mostrou que com o aumento da idade houve mais produção correta dos fonemas e que o 
gênero exerceu desempenho diferente apenas depois dos 5:6 anos. Desta idade até os sete anos as meninas cometeram menos redução de sílaba comparadas aos meninos, além de terem melhor desempenho nos fonemas interdentais surdos e sonoros.

Em estudo sobre o finlandês com 24 crianças aos dois anos de idade, KUNNARI et al. (2007) observaram relação entre léxico e inventário fonético. Além disso, mostraram que houve variação individual considerável tanto no número de consoantes como no léxico.

Para o português, o estudo de WERTZNER (1994) mostrou que aos 3:1 anos de idade os sujeitos já estavam com o sistema fonológico adquirido, com exceção apenas do arquifonema / $R /$ e dos encontros consonantais que foram dominados somente aos 6:1 anos. Ressalta-se que a autora considerou o fonema dominado pelo grupo quando $75 \%$ das crianças ou mais tinham o fonema adquirido.

Quanto à coda silábica, apenas as consoantes /S/, /R/, // e /N/ ocupam esta posição . Mesmo assim, há algumas restrições para estas consoantes. O /// em final de sílaba tende a uma vocalização, levando-o ao /u/, como na oposição entre "mal" e "mau", tornando-os homônimos (CÂMARA JR., 2001, SILVA, 1999). Este fato ocorre na maioria das regiões brasileiras. Porém, no sul do Brasil, o /// é considerado como consoante final, pois se observa a interrupção do fluxo do ar na cavidade oral pelo levantamento da ponta da língua junto aos dentes.

Como o estudo aqui proposto foi realizado na região de São Paulo, supôs-se que haveria vocalização do ///. Desta forma, não se adotou o /// como consoante de coda na análise da estrutura CVC.

No que se refere à consoante final $/ \mathrm{N} /$, alguns autores mostram que pode haver nasalização da vogal anterior, gerando doze vogais possíveis no português, sendo sete orais e cinco nasais (SILVA, 1999; CUNHA, 1980). Outros autores como CÂMARA JR (2001) argumentam que as vogais nasais do português consistem na junção de uma vogal oral com o arquifonema /N/. Assim, apenas de sete vogais é constituído o sistema fonético do português.

Para a pesquisa, foi considerado que as vogais sofrem nasalização conforme SILVA (1999) e CUNHA (1980). Portanto, somente serão estudadas as consoantes /R/ e /S/ em coda silábica. 
WERTZNER (1994) estudou crianças de 3:0 a 7:0 anos e observou que nesta idade $\mathrm{o}$ arquifonema /S/ já estava adquirido. Porém, o arquifonema /R/ foi adquirido posteriormente, aos 4:6 anos em sílaba final e, aos 6:0 anos em sílaba inicial.

MEZZOMO (2003) pesquisou crianças de 1:0 a 7:1 anos de idade durante a aquisição fonológica do português. Observou que há omissão do arquifonema antes da aquisição correta da sílaba CVC ou VC. A autora realizou análise acústica da vogal precedente, mostrando que ela era mais alongada. Este fato indica que as crianças possuem conhecimento a respeito da existência da coda antes de a produzirem.

Observando as idades de aquisição dos arquifonemas, MEZZOMO (2004) expôs que o /S/ é dominado em posição final de palavra aos 2:6 anos e em coda silábica dentro da palavra aos 3:0 anos. Além disso, durante a aquisição em posição de final de palavra, a palatalização e a epêntese são mais observadas que as omissões. Ao contrário, no meio da palavra, observam-se mais omissões.

Quanto ao /R/ em coda silábica, a aquisição ocorre tanto em posição medial como final de palavra aos 3:10 anos de idade. As omissões do /R/ são mais observadas em posição medial e as semivocalizações e as substituições por líquidas laterais em posição final de palavra (MEZZOMO, 2004).

As crianças de 2:1 a 3:0 anos falantes do português da região de São Paulo ainda comentem erros na estrutura CVC, marcados pela omissão da consoante final (GALEA \& WERTZNER, 2005b).

$\mathrm{Na}$ língua inglesa, o estudo de OWENS (1996) mostrou que as crianças em início de aquisição da consoante final realizam epêntese, prolongamento da vogal precedente e substituição por plosiva glotal.

Outro estudo de MEZZOMO (2007a) mostrou que crianças de 1:2 a 3:10 anos realizam metátese e epêntese somente na coda $/ S /$ e $/ R /$, demonstrando que o fonema é preservado, porém em outro local da palavra. A epêntese ocorreu apenas em sílaba final e a metátese foi mais freqüente em coda dentro da palavra com /R/ e /S/. Com o aumento da idade, há crescimento da produção correta dos fonemas, mas ele não é linear, verificando regressões em seu uso (MEZZOMO, 2007b). Neste estudo, os meninos tiveram maior porcentagem de acerto que as meninas no /N/, /S/ e /// dentro da palavra e do /// no final da palavra. No /R/ dentro da palavra, as meninas obtiveram porcentagem de acerto estatisticamente maior que os meninos. 
Os encontros consonantais são agrupamentos de consoantes num mesmo vocábulo. Os mais freqüentes do português são realizados por dois segmentos, uma obstruinte e uma líquida. As obstruintes que podem fazer parte do primeiro segmento são: /p,b,t,d,k,g,f,v/. O segundo segmento deve ser uma líquida /P,l/. Mas, nem todas as combinações destes segmentos são permitidas. Por exemplo, não há o encontro /vP/ em início de palavra nem /dl/ ou /vl/ em qualquer posição silábica. O uso de /tt/ é restrito a algumas palavras (SILVA, 1999; RIBAS, 2004). Há ainda encontros como /gn, mn, pn, pt, tm/ que não aparecem em muitos vocábulos (CUNHA, 1980; BECHARA, 1988).

No presente estudo, foram analisados apenas os encontros consonantais formados por obstruinte e líquida.

Para o português, WERTZNER (1994) constatou que os encontros consonantais com /P/ foram dominados entre 3:7 e 5:0 anos e, os encontros com /// entre 4:7 e 5:0 anos.

RIBAS $(2003,2004)$ estudou a aquisição dos encontros consonantais com /P/ e /// em crianças de 1:0 a 5:3 anos de idade. As primeiras produções corretas apareceram na fala das crianças aos 1:8 ano, apresentando oscilações até a produção correta aos 5:2 anos. Ambos os encontros foram considerados adquiridos no mesmo período. Observou-se que o erro mais freqüente foi a eliminação da líquida, produzindo estrutura silábica CV. Outros tipos de erros foram vistos e, para as crianças de 2:0 a 3:0 anos, os observados foram: substituição de líquida, metátese, substituição de obstruinte, epêntese, semivocalização, apagamento da sílaba CCV e coalescência.

Outro estudo (RIBAS et al., 2003) mostrou alguns tipos de erros cometidos pelas crianças durante a aquisição dos encontros consonantais: produção de CV, metátese e epêntese. Constatou-se que estes erros ocorrem mais freqüentemente quando as duas consoantes do encontro são coronais.

A metátese do /P/ foi estudada por MAGALHÃES (2003) tanto na estrutura CCV como na (C)VC. O autor discute estudos anteriormente realizados sobre a aquisição fonológica com base no pé de acentuação da palavra. Durante este período, as crianças realizam metátese deste fonema e, quando isso ocorre, tendem a manter o modelo troqueu das sílabas nas palavras. 
Num estudo abordado anteriormente (GALEA \& WERTZNER, 2005b), foi observada a estrutura CCV em crianças de 2:1 a 3:0 anos. Estas crianças ainda apresentaram erros de eliminação da líquida, ou seja o segundo elemento do encontro consonantal.

Para o inglês, SMIT (1993) relatou os erros realizados durante a aquisição dos encontros consonantais em posição inicial de sílaba. A omissão dos dois elementos do encontro é rara, mesmo em crianças no início de aquisição. Porém, a omissão de um dos elementos do encontro é mais freqüente. Como a língua inglesa permite várias combinações de consoantes para a formação de encontros consonantais e com número de elementos variável, os erros observados dependeram destes fatores.

Outro estudo para a língua inglesa foi realizado por MCLEOD et al. (2001a). Foram estudadas 16 crianças da Austrália de 2:0 a 2:11 anos de idade quanto aos encontros em início e final de palavra. Conforme o aumento da idade, o número e a diversidade de encontros consonantais nestas posições aumentaram. Observou-se que as crianças mais novas eliminaram um dos elementos do encontro e, à medida que a idade aumentou, as crianças deixaram de omitir os elementos, substituindo-os por outros.

Em revisão de estudos que envolviam a aquisição dos encontros consonantais em várias línguas, MCLEOD et al. (2001b) encontraram algumas características, sendo elas: 1) crianças de dois anos podem produzir encontros consonantais, sendo que estes não necessitam ter a mesma forma que a da própria língua; 2) encontros em posição final, geralmente, aparecem antes que em posição inicial; 3) encontros com duas consoantes são adquiridos antes de encontros com três consoantes; 4) encontros que possuem plosivas são adquiridos antes de encontros com fricativas; 5) crianças geralmente omitem um elemento (redução do encontro) e esta omissão pode ser explicada pelos princípios de marcação e sonoridade; 6) surgem alguns homônimos na tentativa de produção dos encontros; 7) existem outras realizações de produção do encontro como simplificação do encontro, epêntese, coalescência e metátese; 8) a aquisição do encontro é gradual e existe uma seqüência típica de aquisição; 9) há uma relação entre simplificação de encontro, redução de encontro e produção correta; e, 10) embora haja uma seqüência na aquisição, existem diferenças individuais. 
KIRK \& DEMUTH (2005) compararam a aquisição dos encontros consonantais em final e início de sílaba. Constataram que as crianças de dois anos de idade produzem os encontros de final de sílaba mais corretamente que os de início de sílaba.

A omissão da líquida do encontro consonantal e da coda silábica, além de omissão de fonema em onset silábico, afetam a estrutura da sílaba. Nas crianças em desenvolvimento típico de linguagem, um processo que afeta a estrutura da palavra é a omissão de sílaba.

Estudo com crianças falantes do catalão e espanhol com alterações de linguagem foram comparadas com crianças em desenvolvimento típico de 2:4 anos (AGUILAR-MEDIAVILLA et al., 2002). Ambos os grupos realizaram a omissão da sílaba átona, porém as com alteração cometeram com maior freqüência esta alteração, sendo observada omissão de mais de uma sílaba. Já as crianças em desenvolvimento típico, normalmente, excluem apenas uma sílaba, sendo esta a medial. As autoras apontaram que a omissão da primeira sílaba pode ser um fator desviante.

Em 2003, DODD et al. realizaram estudo com crianças falantes do inglês britânico de 3:0 a 6:11 anos e observaram que a omissão da sílaba átona era suprimida aos 4:0 anos de idade.

JAMES (2007) estudou 283 crianças falantes do inglês australiano entre 3:0 e 7:11 anos para verificar omissão de sílaba. Todas as vogais e consoantes apareciam nas diversas sílabas e as palavras variavam em extensão, acentuação e forma. A autora constatou que a eliminação da sílaba átona final era suprimida aos três anos, no entanto, a eliminação da sílaba átona em posição não final ocorria em baixa freqüência até os sete anos. Vários fatores contribuíam para a eliminação desta sílaba, como extensão da palavra e consoantes líquidas.

\section{- Fatores biológicos e ambientais influentes na aquisição fonológica}

Muitos fatores podem influenciar a aquisição dos fonemas pelas crianças. Alguns estudos enfocam a freqüência de aparecimento de um determinado som na língua como facilitador para a produção do som alvo.

TEIXEIRA \& DAVIS (2002) realizaram pesquisa longitudinal com duas crianças falantes do português brasileiro entre 1:0 e 3:0 anos comparando a 
aquisição de consoantes, vogais e estruturas silábicas com a freqüência de ocorrência dos segmentos e estruturas silábicas no português. Notaram que a influência da língua ambiente parece estar presente e deve ser levada em consideração na compreensão da aquisição fonológica das crianças estudadas.

A complexidade articulatória e a freqüência dos sons na língua foram estudadas em crianças de 10 a 27 meses falantes do cantonês (STOKES \& WONG, 2002). Os dados indicaram que dos 24 aos 27 meses a aquisição das vogais é influenciada tanto pela complexidade articulatória como pela freqüência de aparecimento delas na língua. Ao contrário, os ditongos pareceram sofrer mais influência da freqüência de ocorrência na língua.

STOKES \& SURENDRAN (2005) pesquisaram a freqüência do fonema na língua, a complexidade articulatória e o functional load, freqüência de algum contraste na língua, em crianças em desenvolvimento típico falantes do inglês, alemão e cantonês. Para o cantonês foram pesquisadas 51 crianças de 15 a 30 meses. Observou-se que consoantes que apareciam mais cedo eram aquelas de grande freqüência na língua e de pouca complexidade articulatória. Ao contrário, para as sete crianças de oito a 25 meses falantes do inglês, functional load e complexidade articulatória tiveram alta correlação com a aquisição dos sons. Quanto à acuidade de produção, os sons que tiveram alta porcentagem de acuidade para o inglês, em 40 crianças de 25 meses, tiveram alta relação com a complexidade articulatória. Para as cinco crianças falantes do alemão de 25 meses de idade, somente a freqüência dos sons na língua e a complexidade articulatória tiveram correlação com a produção dos fonemas.

Para o inglês, KIRK \& DEMUTH (2005) não constataram o efeito da freqüência de determinados encontros consonantais na língua e a produção correta de encontros consonantais. Além deste aspecto, verificaram as influências estruturais, morfológicas e a facilidade de produção na aquisição dos encontros consonantais. Somente a facilidade de produção teve relação com sua produção.

STOEL-GAMMON \& PETER (no prelo) observaram o modo de articulação e os segmentos mais freqüentemente encontrados em início de palavras em 16 crianças de 11 a 31 meses. Comparam estes resultados com as palavras usadas pelos cuidadores quando se dirigiam às crianças e com o vocabulário adulto baseado em dados de dicionário. Verificaram que, nas três situações, bilabiais apareciam em $36 \%$ dos tipos de palavras, coronais em $45 \%$ e glotais em $19 \%$. 
Quanto ao segmento mais utilizado em início de palavra, encontrou-se o /b/ na fala das crianças e o /p/ na dos cuidadores. Houve um declínio da porcentagem de uso do /b/ dos 11 aos 30 meses, principalmente em conseqüência do aparecimento de outros fonemas em posição inicial de palavra. O extenso uso de /b/ confirmou a noção de seleção lexical, indicando que as crianças escolhem as palavras de seu vocabulário, ao menos em parte, devido a características fonológicas das palavrasalvo.

Para o português, não há ênfase em estudos que mostram a freqüência dos fonemas na língua, seja em coleta de fala de adultos e crianças ou em pesquisas de materiais escritos.

ALBANO (2001) relatou a freqüência relativa de fonemas do português do Brasil com base em duas amostras: o Minidicionário Aurélio e transcrições de fala de adultos (Projeto NURC). No primeiro, os fonemas, do mais freqüente para o menos freqüente foram: /t/, /n/ (coda), /P/, /a/, /d/, /k/, /s/, /Y/, / $/, / \mathrm{p} /, / \mathrm{e} /, / \mathrm{i} /, / / /, / \mathrm{S} /$ (coda), /m/, /R/ (coda), /n/, /b/, /v/, /o/, /I/, /z/, /f/, /g/, /w/ (coda), /X/, /l/ (coda), /j/ (coda), /Z/, /E/, /u/, / $\square /, / \Sigma /, / \times /, /$ /. Na base de dados de fala do adulto, foram, do mais freqüente para o menos freqüente: /t/, /n/ (coda), /d/, /k/, /s/, /e/, /P/, /m/, /a/, /S/ (coda), /p/, /n/, / $\square /, / \mathrm{Y} /, / \mathrm{l} /, / \mathrm{o} /$, /w/ (coda), /i/, /R/ (coda), /v/, /I/, /E/, /z/, /f/, /j/ (coda), /b/, /g/, /u/, / $\square /$, /Z/, /X/, /l/ (coda), / /, / / /, / /.

CASTRO \& WERTZNER (2003) observaram os contextos que os fonemas /P, $\times$, I/ mais ocorrem, tanto na fala de crianças de 5:0 a 8:0 anos, como em livros didáticos e de histórias. Todos apareceram mais em palavras trissilábicas, com exceção do /// em livros didáticos, que ocorreu mais em dissílabos. Todos aparecem mais em sílabas CV e em sílaba final de palavra. Porém, nas entrevistas com as crianças, o fonema /// ocorre mais em sílaba medial. Quanto às vogais que seguem mais freqüentemente estas consoantes, o /// é mais observado com /a, E, i/, o /P/ com / a, E, i, o/ e o / $/$ com /a, o/.

Outro fator que parece influenciar a aquisição dos fonemas e encontros consonantais é o ambiente fonético da palavra.

EDWARDS et al. (1997) comentaram sobre pesquisas anteriormente publicadas a respeito da aquisição de plosivas alveolares e velares em posição inicial de palavra. Os autores mostraram que sempre são encontradas diferenças acústicas ou articulatórias entre um alvo alveolar e a consoante alveolar cujo alvo 
seria uma velar. Comentaram também sobre o /g/ ser auditivamente considerado mais correto quando seguido pela vogal /u/ que por /a/, pois a primeira vogal abaixa o spectrum do /g/ para uma região percebida mais como o /g/ do adulto.

A análise das sílabas CV realizada sob a perspectiva da teoria da moldura/constituinte, em que a moldura seria a sílaba e os constituintes os segmentos que a compõem, indica que as consoantes bilabiais estariam associadas a vogais mediais, consoantes coronais a vogais anteriores e consoantes dorsais a vogais posteriores (MCNEILAGE, 1998; MCNEILAGE \& DAVIS, 2000; 2001).

STOEL-GAMMON \& PETER (no prelo) realizaram análise de palavras faladas por crianças de até 30 meses no MacArthur Communicative Development e não encontraram dados que condiziam com a teoria de moldura/constituinte. Nenhuma seqüência CV ocorreu consistentemente na amostra de palavras, além de outras seqüências não previstas pelas teorias terem aparecido em grande ocorrência. Este fato pode ter ocorrido devido às autoras terem analisado somente o tipo de palavra e não levarem em consideração a produção das palavras das crianças.

Estudos no português brasileiro como o de HERNADORENA \& LAMPRECHT (1997) observaram que o /// é favorecido tanto em onset silábico em início de palavra como no meio da palavra pelas vogais seguintes /a, i, u/. Quanto à tonicidade, dentro da palavra, é favorecido pelas vogais anteriores /a, E/. O / $/$ / é favorecido pela vogal seguinte /a/ e precedentes /i, e/ e em situação pós-tônica. O /P/ não pareceu ser favorecido por nenhuma das vogais, tanto precedentes como seguintes, mas pela situação pós-tônica.

TEIXEIRA \& DAVIS (2002) queriam observar se esta relação estava presente em duas crianças falantes do português do Brasil de 1:0 a 3:0 anos em um estudo longitudinal. As autoras encontraram esta relação em apenas uma das crianças. $\mathrm{Na}$ outra, apenas a relação consoante dorsal e vogal posterior foi vista, também ocorrendo associação entre consoante labial e vogal anterior e consoante coronal e vogal posterior.

PAGAN (2003) notou que a vogal /i/ não se mostrou facilitadora da produção das consoantes líquidas laterais e vibrante simples em crianças em desenvolvimento típico de 6:0 a 9:11 anos.

CASTRO (2004) estudou a estimulabilidade das consoantes líquidas laterais e da vibrante simples em crianças em desenvolvimento típico, de 5 a 11:6 anos. Constatou que todas as vogais subseqüentes ao /l/ facilitavam sua produção, não 
encontrando erro na emissão das seqüências de sílabas e palavras. Quanto ao /P/, as vogais /E/ e / $\square /$, em contexto posterior a esta consoante, facilitavam sua produção. $\mathrm{O} / \times /$ teve sua produção facilitada pelas vogais seguintes /o/, / $\square / \mathrm{e} / \mathrm{u} /$.

Outro estudo sobre o ambiente fonético como facilitador na aquisição das líquidas é o de MEZZOMO \& RIBAS (2004). As autoras escreveram artigo de revisão, mostrando que em alguns estudos o /l/ é favorecido pela situação póstonicidade e, em outros, que a sílaba tônica é a favorecedora. $O / \times \mid$ é mais preservado em sílaba pós-tônica e o /P/ é mais favorecido quando a vogal antecedente ou a seguinte é o /i/ e quando se encontra na sílaba tônica.

Em relação ao /X/, HERNADORENA \& LAMPRECHT (1997) constataram que em início de palavra a vogal / $\square /$ favorece sua produção se ele estiver precedendo ou seguindo. Dentro de palavra, as vogais seguintes /a/ e /u/ são facilitadoras. Quanto à tonicidade, há maior facilidade de produção quando o /X/ encontra-se em sílaba tônica.

MEZZOMO \& RIBAS (2004) mostraram que o contexto que propicia a produção do $/ X /$ é as vogais antecedentes /i, e, E/, as vogais seguintes arredondadas e a posição de onset silábico dentro de palavra, em situação tônica ou pós-tônica.

Para as plosivas, as vogais altas /i/ e /u/ favorecem a não ocorrência da dessonorização (FREITAS, 2004).

Quanto ao ambiente ideal de produção das fricativas, há indicação de que para o /f/ é a situação pós-tônica e, para o /v/, palavras monossilábicas. Quando ocorre omissão das fricativas coronais, as sílabas mais atingidas são as pré-tônicas e as tônicas. O ambiente fonético que favorece a produção do /s/ é a vogal seguinte /e/ e/ou a precedente /E/. O /z/ e / $/$ / são mais favorecidos quando se encontram em coda silábica dentro de palavra. O /Z/ é favorecido pela vogal seguinte /u/ (OLIVEIRA, 2004).

Para os arquifonemas em posição final de palavra, as vogais /e, o, a/, as palavras dissilábicas e a posição pós-tônica são mais propícias para a realização do /s/. Dentro da palavra, a produção é mais correta quando a vogal antecedente é /e, a, E/, a consoante seguinte tem ponto coronal, as palavras são dissilábicas e a sílaba é tônica. $\mathrm{O} / \mathrm{R} /$ tem como melhor ambiente fonético a sílaba tônica da palavra, 
para as duas posições, além das vogais precedentes /e,a/ para a posição final (MEZZOMO, 2004).

Quanto ao contexto facilitador de produção dos encontros consonantais, a obstruinte com a líquida lateral é produzida mais corretamente quando o núcleo silábico contém a vogal /a/ e quando a obstruinte contém a plosiva labial surda /p/. Para a obstruinte com líquida não-lateral, os ambientes propícios para a produção são: obstruintes labiais e sonoras, sílaba com CCV em posição medial de palavra com a vogal /o/ antecedente, sílaba átona e /i, /u/ ou /a/ como vogal do núcleo CCV (RIBAS, 2004).

\section{- Aspecto motor da fala}

Até o momento, foi mostrada a parte fonológica da aquisição dos fonemas. Porém, a fonologia mantém forte relação com os processos motores da fala.

As crianças, além de estarem em processo de aquisição da fonologia, também se encontram em fase de crescimento e maturação do sistema motor oral. Assim, alguns fonemas são mais facilmente produzidos do que outros e algumas seqüências de sons facilitam a adequação da produção dos sons. Neste desenvolvimento, observa-se que alguns sons são menos precisos (STOELGAMMON \& DUNN, 1985).

O controle motor dos movimentos da língua é de grande importância no aprendizado dos sons da fala. A criança deve aprender a controlá-la para atingir necessidades de mobilidade e forma simultaneamente (KENT, 1992).

O trato vocal da criança não é somente uma miniatura daquele do adulto. Ela tem a árdua tarefa de aprender a fala usando o aparato que está passando por mudanças. Esta maturação do controle motor da fala é um processo que continua até a puberdade e, provavelmente, até a adolescência. Durante o desenvolvimento, ocorre o mapeamento sensório motor que é estabelecido e refinado durante o desenvolvimento. Assim, não é estático, já que tem que ser ajustado ao crescimento e desenvolvimento do sistema de produção de fala (KENT \& VORPERIAN, 2006).

Um estudo de MUNSON (2004) mostrou que as crianças produzem a fricativa /s/ com maior variação espectral que os adultos, indicando que a diferença é um indício da imaturidade das crianças na produção da fala. 
SOSA \& STOEL-GAMMON (2006) mostraram que crianças de 1:0 a 2:0 anos ainda têm grande variabilidade na produção da mesma palavra. Discutem que isto pode estar relacionado à maturação do sistema neuromotor.

A distorção é uma alteração fonética caracterizada por alguma dificuldade motora envolvendo a produção dos sons como ponto, tempo, tonicidade e velocidade de fala (WERTZNER et al., 2005).

WERTZNER (1994) estudou crianças de 3:0 a 7:0 anos e notou que ocorrem distorções principalmente dos fonemas /s/ e /z/, por interposição anterior de língua. Estas distorções diminuíam entre os $5: 1$ e os 6:7 anos de idade, porém, aumentavam aos 6:7 anos. A autora justifica o aumento pelo fato das crianças estudadas estarem trocando os dentes decíduos, o que facilitava a interposição anterior de língua.

JUNQUEIRA \& GUILHERME (1996) estudaram crianças de 3:0 a 8:0 anos de escola pública e particular com o objetivo de detectar a presença de ceceio no fonema /s/. Notaram que o sigmatismo diminuiu conforme a idade aumentou. Observaram ainda diferença entre os gêneros apenas na faixa etária de 5:1 a 6:0 anos, em escola particular, sendo que os meninos apresentaram maior porcentagem de distorção que as meninas.

Outro estudo abordou as distorções em 50 crianças de três a dez anos de idade na produção do fonema /s/ em coda silábica, no início e no meio da palavra. Foi constatado que $52 \%$ das crianças apresentaram distorção, entre elas a tipologia de interdental anterior, dental anterior, palatal e lateral, sendo que as duas primeiras corresponderam à $88,4 \%$ dos casos. Houve diminuição das distorções com 0 aumento da idade (PEREIRA et al., 2003).

TOMÉ et al. (2004) também estudaram a distorção em fricativas. Foram estudadas crianças de três a seis anos quanto aos fonemas /z/ e /s/. Os resultados mostraram que há diferença estatística entre os gêneros quanto à presença de distorção, sendo que os meninos apresentaram maior porcentagem que as meninas. A maior ocorrência de ceceio ocorreu nas faixas etárias de quatro e cinco anos, diminuindo na faixa etária de três e de seis anos de idade.

CASTRO (2004) observou que as crianças de 5:0 a 11:6 anos em desenvolvimento fonológico típico não apresentam distorção das laterais $/ / /$ e $/ \times /$ e da vibrante $/ \mathrm{P} /$. 
Outro estudo que relata a distorção dos fonemas líquidos em crianças em aquisição é o de GALEA \& WERTZNER (2005a). Para a coleta dos dados, as autoras utilizaram as provas de nomeação e imitação do ABFW (WERTZNER, 2000). O fonema mais distorcido nas crianças mais novas (2:1 a 2:6 anos) é o / $\times /$ e, nas mais velhas (2:7 a 3:0 anos), o /P/ na nomeação e o /l/ na imitação. Com o aumento da idade as distorções tendem a diminuir.

WERTZNER et al. (2005) verificaram a presença de distorção nos fonemas do português brasileiro em crianças em desenvolvimento típico de 5:0 a 9:9 anos. A distorção mais comumente observada foi nos fonemas /s, Z, $\Sigma, Z$ /. Embora as distorções tenham ocorrido em crianças ao longo desta faixa etária, elas diminuíram com o aumento da idade.

Um estudo com 200 crianças de três a sete anos observou os fonemas /s/ e /z/ em onset silábico (FONSECA et al., 2005) e concluiu que 35,5\% das crianças cometeram ceceio anterior na sua produção. Mostrou que a faixa etária com mais ceceio é a de três anos e a de cinco e a de sete anos as de menor ocorrência. Apesar deste fato, não houve diferença estatística significante, indicando que com o aumento da idade o ceceio diminui. Além disso, as autoras observaram que houve mais meninas que meninos com esta alteração, embora não tenha indícios estatísticos desta diferença.

AMARO (2006) analisou a distorção dos fonemas líquidos e fricativos em três grupos de crianças em desenvolvimento fonológico típico, cada um composto por dez crianças. No grupo de crianças de 5:1 a 5:11 anos, dois sujeitos apresentaram distorções, sendo que os dois distorceram o /s/, um o /z/ e o outro o ///. No grupo de 6:1 a 6:11 anos, apenas uma criança apresentou distorção nos fonemas /s/ e / $/ \Sigma /$. Quatro crianças de 7:0 a 7:11 anos apresentaram distorção, sendo que todas distorceram o /s/ e o /z/ e somente uma também distorceu o ///. 


\section{- Coleta de dados de fonologia}

As formas mais conhecidas e usadas na literatura sobre coleta de dados para amostra de fala são as provas de nomeação, imitação e fala espontânea.

Alguns autores demonstram que cada uma possui suas vantagens e desvantagens. MICCIO (2006) argumenta que as provas que propiciam a produção da palavra são diferentes da fala encadeada, mostrando pouca informação sobre inteligibilidade e nenhuma informação sobre padrão fonológico ao nível da frase.

O desempenho de crianças em idade pré-escolar é melhor nas provas de imitação e nomeação que em fala espontânea. Nesta, as crianças têm que organizar tarefas mais complexas como parte de uma narrativa (HOFFMAN \& NORRIS, 2002; GOLDSTEIN et al., 2004).

No entanto, a imitação pode propiciar mais acerto que a fala espontânea por haver o padrão do adulto. Porém, é diferente de um ambiente natural da criança. $\mathrm{Na}$ fala espontânea, as crianças podem evitar sons e estruturas silábicas que não sabem produzir, causando desempenho acima do esperado (STOEL-GAMMON \& DUNN, 1985).

WERTZNER (1992) notou que não há diferença estatística entre as provas de imitação e nomeação ao analisar dados de crianças de três a sete anos quanto aos acertos em fonemas.

JONHSON et al (2004) compararam índices de fala em crianças com transtorno fonológico em provas de imitação de sentenças e de fala espontânea. Os resultados mostraram que uma forma foneticamente balanceada de produção de sentenças, com complexidade lingüística controlada, pode fornecer informações que são estatisticamente e clinicamente iguais a amostras de conversação.

GALEA \& WERTZNER (2005c) estudaram crianças em desenvolvimento típico entre 2:1 e 3:0 anos de idade. As autoras verificaram que a porcentagem de ocorrência de processos fonológicos na nomeação é similar tanto à fala espontânea quanto à imitação. Porém, na imitação as crianças demonstraram melhor desempenho comparado à fala espontânea.

Outra comparação quanto ao uso de processos fonológicos nas provas de imitação e nomeação foi realizado, porém com crianças com transtorno fonológico, de quatro a doze anos (WERTZNER et al., 2006). Os resultados mostraram associação e concordância entre as provas. 
Desta forma, pode-se dizer que a avaliação de fonologia deve se basear na análise dos três tipos de provas. Sendo assim, este estudo as utilizou para que fossem realizadas as análises dos encontros consonantais, fonemas e estruturas sílabas da presente pesquisa.

Assim, a presente pesquisa apresenta as seguintes hipóteses:

1) Não há diferença entre o acerto de encontros consonantais, fonemas e estruturas silábicas de acordo com as posições de sílaba inicial, medial e final;

2) Não há diferença na aquisição fonológica de meninos e meninas da mesma faixa etária quanto a encontros consonantais, fonemas e estruturas silábicas;

3) Crianças mais velhas apresentam mais acertos que as mais novas em relação aos encontros consonantais, fonemas e estruturas silábicas;

4) Há diferença intragrupo no acerto do fonema /s/ em posição de onset e coda silábica. Ao contrário, não há diferença entre o /P/ em onset e coda de sílaba;

5) Há diferentes tipos de erros predominantes intragrupo: em encontros consonantais isso acontece em função do /P/ e /l/; nos fonemas cada um apresenta diferenças em função das categorias omissão, substituição e distorção e, nas estruturas silábicas, a diversidade ocorre em função da extensão da palavra. Além disso, também se supõem que as crianças mais novas apresentem mais ocorrência de erros que as mais velhas;

6) Há diferença entre os encontros consonantais, fonemas e estruturas silábicas quanto à classificação de aquisição, indicando que as crianças mais velhas apresentam maior porcentagem de aquisição para todos os fonemas;

7) As crianças das duas faixas etárias apresentam desempenho diferente nas três provas (nomeação, imitação e fala espontânea). 
OBJETIVO 


\section{Objetivo Geral:}

* Descrever o percurso da aquisição dos encontros consonantais, fonemas e estruturas silábicas de crianças de 2:1 a 3:0 anos de idade.

\section{Objetivos Específicos:}

* verificar a diferença entre as sílabas inicial, medial e final quanto aos fonemas, aos encontros consonantais e às estruturas silábicas CV, CVC e CCV, nas três provas aplicadas;

× verificar a diferença intragrupos quanto ao gênero no que concerne aos fonemas, aos encontros consonantais e às estruturas silábicas CV, CVC e CCV, nas três provas aplicadas;

× verificar a diferença entre grupos quanto à idade no que se refere à cada um dos fonemas, encontros consonantais e às estruturas silábicas CV, CVC e CCV, nas três provas aplicadas;

× verificar os erros mais freqüentes dos fonemas, encontros consonantais e estruturas silábicas, omissões, substituições e distorções, de crianças de 2:1 a 3:0 anos de idade;

× verificar se há diferença intragrupo entre a porcentagem de acertos em onset e coda de sílaba dos fonemas /s/ e/P/, nas provas aplicadas. 
× identificar as diferentes fases de aquisição - não adquirido, em aquisição, produção habitual ou adquirido - em que se encontram as crianças, em função da idade, para o uso de encontros consonantais, fonemas e estruturas silábicas.

× verificar a diferença intragrupo entre as provas de nomeação, imitação e fala espontânea quanto aos fonemas, encontros consonantais e às estruturas silábicas. 
MÉTODO 
Esta pesquisa foi aprovada pela Comissão de Ética para Análise de Projetos de Pesquisa - CAPPesq da Diretoria Clínica do Hospital das Clínicas e da Faculdade de Medicina da Universidade de São Paulo no 358/01, em 9 de agosto de 2001 (Anexo A).

$\underline{\text { Suieitos }}$

Os sujeitos da pesquisa foram 88 crianças, de idade entre 2:1 e 3:0 anos, divididas em quatro grupos de acordo com o sexo e a idade (Tabela 1).

Todos foram selecionados e avaliados durante o ano escolar de 2002.

Tabela 1 - Distribuição dos Sujeitos nos Grupos

\begin{tabular}{|c|c|c|}
\hline grupo & idade & número de sujeitos \\
\hline \multirow{6}{*}{$\begin{array}{c}\text { GI - F } \\
\text { (sexo feminino) } \\
\text { Total: } 23 \text { crianças }\end{array}$} & $2: 1$ & 4 \\
\hline & $2: 2$ & 4 \\
\hline & $2: 3$ & 3 \\
\hline & $2: 4$ & 4 \\
\hline & $2: 5$ & 4 \\
\hline & $2: 6$ & 4 \\
\hline \multirow{4}{*}{$\begin{array}{c}\text { GI - M } \\
\text { (sexo masculino) }\end{array}$} & $2: 1$ & 1 \\
\hline & $2: 2$ & 2 \\
\hline & $2: 3$ & 3 \\
\hline & $2: 4$ & 4 \\
\hline \multirow[t]{2}{*}{ Total: 18 crianças } & $2: 4$ & 4 \\
\hline & $2: 6$ & 4 \\
\hline \multirow{3}{*}{$\begin{array}{c}\text { Gll - F } \\
\text { (sexo feminino) }\end{array}$} & $2: 7$ & 4 \\
\hline & $2: 8$ & 4 \\
\hline & $2: 9$ & 4 \\
\hline \multirow{3}{*}{ Total: 24 crianças } & $2: 10$ & 4 \\
\hline & $2: 11$ & 4 \\
\hline & $3: 0$ & 4 \\
\hline \multirow{4}{*}{$\begin{array}{c}\text { Gll - M } \\
\text { (sexo masculino) }\end{array}$} & $2: 7$ & 4 \\
\hline & $2: 8$ & 3 \\
\hline & $2: 9$ & 4 \\
\hline & $2: 10$ & 4 \\
\hline \multirow[t]{2}{*}{ Total: 23 crianças } & $2: 11$ & 4 \\
\hline & $3: 0$ & 4 \\
\hline
\end{tabular}

As crianças que apresentavam, segundo relato dos responsáveis na anamnese realizada, queixas de problema de linguagem ou audição, três ou mais ocorrências de otite média e bilingüismo, não participaram da pesquisa. Além disso, as crianças deveriam ter desempenho adequado na prova de vocabulário do Teste de Linguagem Infantil - ABFW (BEFI-LOPES, 2000). 
Todas as crianças da pesquisa freqüentavam creches conveniadas à Prefeitura da Cidade de São Paulo. Ao todo, seis creches da região Pinheiros Butantã participaram da pesquisa. No Anexo B encontram-se os dados das creches, considerando o número de crianças que foram recrutadas em cada etapa da pesquisa.

\section{Material}

Para a aplicação da prova de vocabulário do Teste de Linguagem Infantil ABFW (BEFI-LOPES, 2000), empregado para selecionar as crianças de acordo com - critério de inclusão estabelecido, utilizou-se um álbum elaborado pela pesquisadora com figuras de programas de computador, pois na época em que se iniciou a pesquisa, não tinham sido publicadas as figuras do teste em questão. Além disso, foi utilizado o respectivo protocolo para a anotação da resposta da criança no momento da avaliação.

Para a coleta dos dados foram utilizadas as provas de fonologia do Teste de Linguagem Infantil - ABFW (WERTZNER, 2000), sendo que, para a prova de nomeação, adaptou-se o uso de objetos no lugar de figuras, como proposto por HODSON (1986). Também foi aplicada uma prova de fala espontânea em forma de rotina (SHRIBERG \& KWIATKOWSKI, 1985), na qual a criança brincava durante 15 minutos com miniaturas de objetos: móveis de diversos cômodos da casa, bonecos e carrinhos.

As provas de fonologia foram registradas no protocolo do teste no momento da aplicação. Realizou-se também gravação para posterior conferência dos dados.

Utilizou-se um protocolo de anamnese aplicado aos pais a fim de se obter dados de desenvolvimento da criança (Anexo $C$ ) e um termo de consentimento pósinformação para a realização da pesquisa (Anexo D).

Os dados das provas de fonologia, nomeação, imitação e fala espontânea tiveram som e imagem registrados. Para tal, foram utilizadas fitas cassetes de 90 minutos da marca Maxwell UR, um microfone de lapela e um gravador Sony TCM353V. As imagens foram captadas por uma câmera digital Sony CCD-TR 315, com fitas Sony $8 \mathrm{~mm}$ de 120 minutos. 


\section{Procedimento}

\section{- seleção das creches}

Foram selecionadas seis creches da Região Pinheiros - Butantã conveniadas à Prefeitura da Cidade de São Paulo. Em cada uma delas, fez-se contato anterior com a diretora ou coordenadora pedagógica, visando explicar a pesquisa a ser desenvolvida e obter autorização por meio de uma carta que apresentava o detalhamento do processo de trabalho (Anexo E). Elaborou-se também um plano para seleção e aplicação dos testes, de forma a atender as necessidades de cada instituição.

Quando obtida a autorização para a realização da pesquisa, todas as crianças da creche, cujas idades compreendiam de dois anos e um mês a três anos, foram listadas.

\section{- seleção dos sujeitos}

Após a listagem das crianças, de acordo com o gênero e a idade, foi realizada entrevista com seus pais ou responsáveis para descrição explicativa da pesquisa e assinatura do termo de consentimento pós-informação (Anexo D). A folha de consentimento foi preenchida e assinada em duas vias para que uma ficasse com a avaliadora e a outra com o responsável.

Em seguida, foi aplicada a anamnese (Anexo C) que continha dados sobre o desenvolvimento da criança, para verificar alguma intercorrência e possível impedimento na participação da criança na pesquisa.

As entrevistas com os pais ocorreram no período de entrada ou saída da creche. Em alguns casos, como não era o pai ou responsável a levar a criança fezse o contato de outras duas formas: ou se enviava uma convocação para o comparecimento à creche em um determinado dia e horário, ou se conversava com ele pelo telefone. Em ambos os casos, dava-se a explicação sobre a pesquisa, realizava-se $o$ preenchimento do consentimento pós-informação e aplicava-se a anamnese. $\mathrm{Na}$ impossibilidade do comparecimento do responsável à creche, as duas vias do consentimento pós-informação eram enviadas para os pais assinarem e devolverem no dia seguinte. 
Como foi estabelecido anteriormente, nos critérios de inclusão dos sujeitos, aquele cujos responsáveis relataram três ou mais ocorrências de problemas de orelha média ou queixa de audição foram descartados da pesquisa. Esse critério está de acordo com vários autores (SHRIBERG, 1999; PEÑA-BROOKS \& HEDGE, 2000) que consideram a presença de otites de repetição uma possível causa do transtorno fonológico.

Da mesma forma, foram incluídas no estudo, as crianças que apresentaram desempenho adequado na prova de vocabulário do Teste de Linguagem Infantil ABFW (BEFI-LOPES, 2000), de acordo com os critérios estabelecidos para sujeitos normais da faixa etária de 2:0 a 2:11 por BEFI-LOPES \& FERREIRA (2000) e de 3:0 a 3:11 por BEFI-LOPES \& SERRA (2000).

Se a criança não atingisse a porcentagem de designação usual (DU) para sua faixa etária, conforme orientação do teste, deveria ser feita análise qualitativa, realizada por meio dos processos de substituições (PS), para os quais há também padronização pela faixa etária (BEFI-LOPES \& FERREIRA, 2000; BEFI-LOPES \& SERRA, 2000). Para a criança ser incluída na pesquisa, ela deveria ter sete ou mais dos nove campos semânticos com os PS esperados.

As crianças que atingiram os critérios do teste de vocabulário foram submetidas às provas de fonologia. As que não atingiram o desempenho esperado para a prova de vocabulário ou apresentaram fala ininteligível foram excluídas da pesquisa e encaminhadas para um serviço específico de fonoaudiologia.

\section{- coleta de dados}

Para evitar viés na pesquisa, as provas de fonologia foram aplicadas em ordem diferente para os sujeitos dentro dos grupos. No Anexo F, encontram-se os dados dos quatro grupos com a ordem de aplicação das provas para cada criança. A coleta de dados foi realizada em duas sessões, sendo que o intervalo entre elas foi de quatro a doze dias. Na primeira sessão, eram aplicadas duas provas e, na segunda, somente uma. Na prova de fala espontânea, a avaliadora interagia com a criança durante 15 minutos em situação de brincadeira, com miniaturas de objetos, a fim de coletar 15 minutos de amostra de fala (SHRIBERG \& KWIATKOWSKI, 1985).

Na prova de nomeação, da parte de Fonologia do Teste de Linguagem Infantil - ABFW (WERTZNER, 2000), foram utilizados objetos como proposto por HODSON 
(1986), ao invés de figuras. Quando a criança não sabia, o nome do objeto era falado pela avaliadora e, após apresentação de cinco outros objetos, retornava-se a ele para a criança nomeá-lo. Caso, mais uma vez, ela não soubesse o nome, este era descartado da análise.

$\mathrm{Na}$ prova de imitação do mesmo teste, quando a criança deixava de imitar algum vocábulo, este era novamente apresentado ao final da prova.

Todas as crianças que participaram da pesquisa eram avaliadas na própria creche. Retirava-se a criança da classe e, em uma sala separada, eram aplicadas todas as provas.

\section{- análise dos dados}

Para melhor fidedignidade dos dados, foi realizado acordo entre a pesquisadora e um juiz, fonoaudióloga, cursando especialização, para a transcrição fonética das fitas dos dados de duas crianças sorteadas da pesquisa. O pareamento mostrou $85,71 \%$ de acordo na nomeação e $87,5 \%$ na imitação.

A transcrição das provas de imitação e nomeação foi realizada durante a coleta e novamente confirmada com as gravações. Na prova de fala espontânea, a examinadora repetia o que a criança dizia para facilitar a posterior transcrição das fitas (SHRIBERG \& KWIATKOWSKI, 1985).

Todas as transcrições foram armazenadas em planilhas, disponibilizadas no computador, a fim de facilitar a análise dos dados. Apesar das provas de nomeação e imitação (WERTZNER, 2000) já terem o número de palavras estipulado em 34 e 39, respectivamente, este diferiu entre os sujeitos. Na nomeação, algumas crianças não conheciam os objetos ou não queriam nomeá-los. Na imitação, às vezes, as crianças não queriam repetir o que era pedido.

É importante ressaltar que, na prova de imitação, eliminou-se a palavra "ônibus", pois um grande número e diversidade de erros foram cometidos pelas crianças. Assim, o número máximo de palavras nesta prova foi 38.

Na fala espontânea, não havia um número exato de vocábulos que poderiam ser ditos, visto que era uma situação de 15 minutos de brincadeira. Nesta prova, foram descartados os primeiros e os últimos dois minutos e meio. Sendo assim, a análise baseou-se no período de 10 minutos intermediários da gravação. Somente 
os substantivos foram analisados e, a não ser que a mesma palavra fosse emitida de forma diferente, cada substantivo desta prova era contado apenas uma vez.

Com base nas transcrições das fitas, foi realizada análise de todos os fonemas e encontros consonantais do português brasileiro. Da mesma forma, foram analisadas as estruturas silábicas nas três provas. Assim, foram demonstrados os acertos e os erros de cada alvo.

Tanto os fonemas como os encontros consonantais e estruturas silábicas foram analisados nas posições de sílaba inicial, medial e final. Nesta pesquisa, sempre que houver referência a essas posições de sílaba serão utilizados os termos sílaba inicial, sílaba medial e sílaba final, respectivamente. Também será utilizada a abreviatura I para sílaba inicial, M para medial e F para final. O Quadro 1 mostra exemplo destas posições de sílaba em palavras do teste de fonologia do ABFW (WERTZNER, 2000).

Quadro 1 - Exemplo dos fonemas, encontros consonantais e estruturas silábicas em cada posição de sílaba.

\begin{tabular}{|c|c|c|}
\hline \multicolumn{1}{|c|}{ Exemplo } & sílaba & palavra \\
\hline \multirow{4}{*}{ Fonema em... } & $\ldots$ sílaba inicial & palde \\
\cline { 2 - 3 } & $\ldots$ sílaba medial & dedo \\
\cline { 2 - 3 } & $\ldots$ sílaba final & pasta \\
\hline \multirow{2}{*}{ Arquifonema em... } & $\ldots$ sílaba inicial & trator \\
\cline { 2 - 3 } & $\ldots$ sílaba final & palhaço \\
\hline \multirow{2}{*}{ Estrutura CV em... } & $\ldots$ sílaba inicial & tigela \\
\cline { 2 - 3 } & $\ldots$ sílaba medial & cachorro \\
\cline { 2 - 3 } & $\ldots$ sílaba final & $\underline{\text { clube }}$ \\
\hline \multirow{2}{*}{ Estrutura CCV em... } & $\ldots$ sílaba inicial & livro \\
\cline { 2 - 3 } & $\ldots$ sílaba final & $\underline{\text { garfo }}$ \\
\hline \multirow{2}{*}{ Estrutura CVC em... } & $\ldots$ sílaba inicial & nariz \\
\cline { 2 - 3 } & $\ldots$ sílaba final & \\
\cline { 2 - 3 }
\end{tabular}

Além disso, foi estabelecido critério para classificação da aquisição dos fonemas, encontros consonantais e estruturas silábicas. A criança deveria produzir o alvo com $75 \%$ de acerto para que ele fosse considerado adquirido. Também para um alvo obter a classificação de adquirido no grupo, mais de $75 \%$ das crianças teriam que ter dominado o fonema, encontro consonantal ou estrutura silábica. Para esta 
classificação foram estabelecidos adjetivos de aquisição para demonstrar o grau de aquisição (Quadro 2). Nota-se que a acuidade da classificação mostra a porcentagem de crianças com determinado alvo adquirido e seu adjetivo de aquisição correspondente.

Quadro 2 - Critério de aquisição e adjetivo correspondente.

\begin{tabular}{|c|c|}
\hline Critério de acerto & Definição \\
\hline $0 \%$ a $24 \%$ & não adquirido \\
\hline $25 \%$ a $49 \%$ & em aquisição \\
\hline $50 \%$ a $74 \%:$ & produção habitual \\
\hline $75 \%$ a $100 \%$ & adquirido \\
\hline
\end{tabular}

Para que o alvo fosse analisado de acordo com este critério de aquisição em um determinado grupo, foi estabelecido que a análise somente seria realizada quando mais de $50 \%$ das crianças o produzissem em uma determinada posição de sílaba.

1. análise por fonema e encontro consonantal

Cada fonema foi observado quanto aos seus acertos e erros em posição de onset silábico nas sílabas inicial, medial e final das palavras. Os fonemas $/ \mathrm{P} / \mathrm{e} / \mathrm{s} /$ também foram analisados em posição de coda silábica, considerando a posição da sílaba na palavra. Observar-se-á, na análise estatística, se há diferença na produção dos fonemas e encontros consonantais nas três sílabas testadas. Para a análise das provas de imitação e nomeação foram respeitadas as ocorrências previstas no teste de fonologia do teste de linguagem infantil ABFW (WERTZNER, 2000). Como nesse teste não há análise das sílabas mediais, no presente estudo, foi realizada contagem nesta posição para as provas de imitação e nomeação (Anexo G). Entretanto, o número de alvos por sujeito diferiu nas provas, pois algumas crianças não imitaram alguns vocábulos e não nomearam algumas figuras. Na fala espontânea, o número de palavras de cada sujeito era variável. Assim, a possibilidade de cada fonema e encontro consonantal variou. 
$\mathrm{Na}$ fala espontânea, quando havia uma palavra monossilábica, esta era contada como sílaba inicial. Quando a palavra era polissilábica, as sílabas mediais eram todas computadas na categoria de sílaba medial.

Os erros analisados compreenderam as omissões, substituições e distorções dos fonemas e encontros consonantais. Algumas regras foram estipuladas para maior esclarecimento da análise (Quadro 3).

Quadro 3 - Definição dos tipos de erros para fonemas e encontros consonantais

\begin{tabular}{|c|c|c|}
\hline Erro & Definição & Exemplo \\
\hline Omissão de sílaba & Omissão completa da sílaba & /pe'tEka/ - ['tEka] \\
\hline $\begin{array}{l}\text { Omissão de fonema ou } \\
\text { encontro consonantal }\end{array}$ & $\begin{array}{l}\text { Omissão do fonema ou } \\
\text { encontro consonantal } \\
\text { analisado }\end{array}$ & $\begin{array}{l}\text { /pa'xasu/ - [pa'asu] } \\
\text { /'brasu/ - ['asu] }\end{array}$ \\
\hline & $\begin{array}{l}\text { Substituição de um fonema } \\
\text { por outro }\end{array}$ & /'mixu/ - ['milu] \\
\hline Substituição de fonema & $\begin{array}{l}\text { Substituição de um fonema } \\
\text { por um encontro consonantal. } \\
\text { Geralmente, este tipo de erro } \\
\text { era observado quando havia } \\
\text { metátese. de um elemento do } \\
\text { encontro para a sílaba de um } \\
\text { fonema simples }\end{array}$ & /'brãku/ - ['bãkru] \\
\hline Substituição de encontro & $\begin{array}{c}\text { Substituição do encontro } \\
\text { consonantal por um fonema } \\
\text { simples }\end{array}$ & /'livru/ - ['lifu] \\
\hline & $\begin{array}{l}\text { Substituição de um ou ambos } \\
\text { os elementos do encontro }\end{array}$ & $\begin{array}{l}\text { /'kravu/ - ['klavu] } \\
\text { /'bluza/ - ['pPuza] }\end{array}$ \\
\hline & $\begin{array}{l}\text { Substituição do arquifonema } \\
\text { por outro fonema }\end{array}$ & /'poRku/ - ['poyku] \\
\hline Substituição do arquifonema & $\begin{array}{c}\text { Substituição do arquifonema } \\
\text { por outro tipo de estrutura } \\
\text { silábica }\end{array}$ & /'nariS/ - [na'Pisi] ou [na'Pizi] \\
\hline Distorção & \multicolumn{2}{|c|}{$\begin{array}{l}\text { Qualquer tipo de distorção acústica e articulatória como } \\
\text { ceceio anterior, ceceio lateral, interdentalização e outras. }\end{array}$} \\
\hline Aglutinação de duas sílabas & $\begin{array}{l}\text { A sílaba que permanecia era } \\
\text { a que continha a consoante. }\end{array}$ & $\begin{array}{l}\text { /eSkoxega'doR/ - [eskoxe'go]: } \\
\text { omissão da sílaba /doR/ }\end{array}$ \\
\hline
\end{tabular}

Em relação às omissões, quando uma sílaba era omitida da palavra, as demais eram analisadas na mesma posição que se encontravam na palavra alvo. Por exemplo: "sapato" - se a criança produzisse ['patu], o fonema /p/ era analisado como sendo medial.

Ou, ao contrário, quando uma sílaba era acrescentada à palavra, como /na'riS/ para [na'risa], a consoante em onset silábico da sílaba final da palavra, /r/, continuava sendo considerada como final e não medial. 


\section{2. estrutura silábica}

As estruturas silábicas CV, CVC e CCV que apareceram nas provas de nomeação, imitação e fala espontânea foram analisadas. No Anexo $H$, encontram-se os tipos de estruturas silábicas das palavras das provas de nomeação e imitação, de acordo com a posição da sílaba. Como mencionado anteriormente, as palavras da fala espontânea variaram em cada sujeito. Da mesma forma que os fonemas e encontros consonantais, as estruturas foram analisadas nas sílabas inicial, medial e final.

Para cada tipo de estrutura silábica, foi observado se elas tinham sido produzidas corretamente (Quadro 4) e, se houvesse erro, este foi demonstrado, como indica o Quadro 5. Destaca-se que as categorias de erros foram criadas a partir da análise das estruturas. Cada sílaba foi analisada com base nos erros que nela ocorriam, independentemente se estes foram influenciados pelas demais sílabas da palavra, como no exemplo (Quadro 5) sobre epêntese.

Nota-se que o uso de distorção não interferiu na análise das estruturas silábicas.

Quadro 4- Acerto nas estruturas silábicas analisadas

\begin{tabular}{|c|c|c|}
\hline & Acerto & Exemplo \\
\hline CV & $\begin{array}{c}\text { Troca de um dos elementos da estrutura CV, } \\
\text { permanecendo como C+V, mesmo quando há } \\
\text { aglutinação de sílabas. }\end{array}$ & $\begin{array}{c}\text { /ka'fE/ - [ka'vE] } \\
\text { /eSkoxega'doR/ - [koxe'go] }\end{array}$ \\
\hline CCV & $\begin{array}{c}\text { Troca de um ou ambos os elementos, permanecendo a } \\
\text { estrutura CCV. }\end{array}$ & $\begin{array}{c}\text { /'bl } \square \mathrm{ku} / \text { - [pP }[\mathrm{ku}] \\
\text { /'plãta/ - ['pPãta] }\end{array}$ \\
\hline CVC & $\begin{array}{c}\text { Troca de uma consoante da estrutura, geralmente a } \\
\text { primeira. }\end{array}$ & /tãboR/ - [tã'poP] \\
\hline
\end{tabular}


Quadro 5 - Erro das estruturas silábicas analisadas

\begin{tabular}{|c|c|c|c|}
\hline & Erro & Definição & Exemplo \\
\hline \multirow{6}{*}{ CV } & Omissão da sílaba & Omissão completa da sílaba: CV & /sa'patu/ - ['patu] \\
\hline & $\begin{array}{l}\text { Omissão de um dos } \\
\text { elementos da sílaba }\end{array}$ & $\begin{array}{c}\text { Foi observada apenas a omissão da } \\
\text { consoante: } \mathrm{CV} \rightarrow \mathrm{V}\end{array}$ & /'selu/ - ['seu] \\
\hline & Epêntese & $\begin{array}{l}\text { Inserção de um fonema na estrutura } \\
\text { CV, tornando-a CVC ou CCV. }\end{array}$ & /'fraku/ - ['fakPu] \\
\hline & VV & A sílaba CV torna-se VV & /'zEru/ - ['zEyu] \\
\hline & CVV & $\begin{array}{c}\text { Há epêntese de uma vogal na } \\
\text { estrutura CV }\end{array}$ & /'globu/ - ['gobio] \\
\hline & CVC & $\begin{array}{l}\text { Há epêntese de uma consoante na } \\
\text { estrutura CV }\end{array}$ & /'plaStiku/ - ['pakistu] \\
\hline \multirow{7}{*}{ CCV } & Omissão da sílaba & $\begin{array}{c}\text { Omissão completa da sílaba: CCV } \rightarrow \\
\mathrm{O}\end{array}$ & /tra'toR/ - ['to] \\
\hline & $\begin{array}{l}\text { Omissão de } \\
\text { consoantes }\end{array}$ & $\begin{array}{l}\text { Omissão de ambas as consoantes da } \\
\text { estrutura CCV }\end{array}$ & /'brasu/ - ['asu] \\
\hline & CV & $\begin{array}{l}\text { Omissão da líquida formando estrutura } \\
\text { CV }\end{array}$ & /'livru/ - ['livu] ou ['lifu] \\
\hline & $\begin{array}{l}\text { Metátese na mesma } \\
\text { sílaba }\end{array}$ & $\begin{array}{l}\text { O elemento do encontro é deslocado } \\
\text { para outra posição na sílaba, podendo } \\
\text { ser substituído por uma outra líquida. }\end{array}$ & /'pratu/ - ['paPtu] \\
\hline & $\begin{array}{c}\text { Metátese para a } \\
\text { sílaba seguinte ou } \\
\text { anterior }\end{array}$ & $\begin{array}{l}\text { O elemento do encontro é transferido } \\
\text { para a outra sílaba da palavra. Pode } \\
\text { haver ou não mudança da líquida. A } \\
\text { sílaba CCV torna-se CV. }\end{array}$ & $\begin{array}{l}\text { /'bl } \square \mathrm{ku} / \text { - ['b } \square \mathrm{kPu}] \\
/ \text { pratu/ - ['patPu] }\end{array}$ \\
\hline & Epêntese & $\begin{array}{c}\text { Há inserção de um fonema na } \\
\text { estrutura CCV, geralmente a } \\
\text { tendência de criança de tornar sílaba } \\
\text { CCV em CV }\end{array}$ & /'klubi/ - [ku'lubi] \\
\hline & Metátese + Epêntese & $\begin{array}{l}\text { Há metátese para a sílaba seguinte ou } \\
\text { anterior além de acréscimo de fonema }\end{array}$ & /'klubi/ - ['kubili] \\
\hline \multirow{8}{*}{ CVC } & Omissão da sílaba & $\begin{array}{c}\text { Omissão completa da sílaba: CVC } \rightarrow \\
\text { O, mesmo havendo aglutinação }\end{array}$ & $\begin{array}{l}\text { /eSkoxega'doR/ - } \\
{[\text { koxe'go] }}\end{array}$ \\
\hline & $\begin{array}{l}\text { Omissão de } \\
\text { consoantes }\end{array}$ & $\begin{array}{c}\text { Omissão das duas consoantes da } \\
\text { estrutura CVC }\end{array}$ & /koR'tina/ - [o't $\Sigma$ ina] \\
\hline & CV & $\begin{array}{c}\text { Omissão do arquifonema formando } \\
\text { uma estrutura CV }\end{array}$ & /tã'boR/ - [tã'bo] \\
\hline & Epêntese & $\begin{array}{c}\text { Adição de um fonema, tendendo à } \\
\text { estrutura CV }\end{array}$ & /na'riS/ - [na'Pisi] \\
\hline & $\begin{array}{l}\text { Metátese para a } \\
\text { mesma síalaba }\end{array}$ & $\begin{array}{l}\text { O arquifonema é transferido para outra } \\
\text { posição da sílaba formando estrutura } \\
\text { CCV }\end{array}$ & /'gaRfu/ - [gPafu] \\
\hline & $\begin{array}{c}\text { Metátese para a } \\
\text { sílaba seguinte ou } \\
\text { anterior }\end{array}$ & $\begin{array}{l}\text { O arquifonema é transferido para a } \\
\text { sílaba seguinte ou anterior }\end{array}$ & $\begin{array}{l}\text { /'paSta/ - ['pataS] } \\
\text { /'poRku/ - ['pokPu] }\end{array}$ \\
\hline & ogal & $\begin{array}{l}\text { Há troca do arquifonema R para uma } \\
\text { semivogal }\end{array}$ & /koR'tina/ - [koy't $\Sigma$ ina] \\
\hline & $\begin{array}{l}\mathrm{CV}+\underset{\text { semivogal }+}{\text { arqui } \mathrm{S}} \\
\end{array}$ & $\begin{array}{l}\text { Além de haver troca da líquida pela } \\
\text { semivogal, há epêntese de arqui S }\end{array}$ & /a'moR/ - [a'moyS] \\
\hline
\end{tabular}

Assim como na análise dos fonemas e encontros consonantais, quando uma sílaba era omitida da palavra, as demais eram analisadas na mesma posição que se encontravam na palavra alvo. 
Quando ocorria aglutinação de dois elementos de sílabas distintas, a sílaba que permanecia era a que continha a consoante. Então, na palavra "escorregador", se a criança emitiu como [escoxe'go], a última sílaba CVC foi considerada como omitida e a sílaba CV referente à parte "ga" foi analisada.

\section{- Método estatístico}

A análise estatística desta pesquisa foi realizada com base no percentual de acerto produzido em relação ao número de possibilidades do alvo aparecer para cada criança. Para que o alvo pudesse ser analisado, o número de casos com percentual calculado deveria ser superior a dez para que a comparação tivesse alguma confiabilidade ao ser realizada.

A primeira análise proposta foi a comparação entre as sílabas inicial, medial e final. Assim, primeiramente, todos os encontros, bem como os fonemas isolados e cada tipo de estrutura silábica, ou seja, CV, CVC ou CCV, foram agrupados de acordo com a posição da sílaba na palavra.

Quando havia comparação de apenas duas posições de sílabas foi usado o teste t. Em momentos em que a comparação envolvia as três sílabas, foi utilizada a ANOVA. Nas situações em que foi constatada diferença entre as provas, foi realizada comparação duas a duas por meio da comparação múltipla de Bonferroni.

$\mathrm{Na}$ comparação entre meninos e meninas da mesma faixa etária, entre as faixas etárias e quanto aos fonemas /s/ e /P/, em onset e coda de sílaba, foi utilizado o teste t.

Além disso, foi feita comparação dos tipos de erros realizados em cada fonema, encontro e estrutura silábica. Assim, quando havia pelo menos dez erros de um mesmo tipo em um dos grupos, foi usado o teste de proporção.

Outra análise realizada nesta pesquisa foi a comparação do desempenho das crianças nas provas de imitação, nomeação e fala espontânea, utilizando a ANOVA. Nos momentos em que foi constatada diferença entre as provas, foi realizada comparação duas a duas por meio da comparação múltipla de Bonferroni.

Em todos os testes estatísticos usados foi estabelecido o valor de $95 \%$ de confiança (n. sig. 0,05). 
RESULTADOS 


\title{
HIPÓTESE 1 - NÃO HÁ DIFERENÇA ENTRE O ACERTO DE ENCONTROS CONSONANTAIS, FONEMAS E ESTRUTURAS SILÁBICAS DE ACORDO COM AS POSIÇÕES DE SÍLABA INICIAL, MEDIAL E FINAL.
}

\author{
ENCONTROS CONSONANTAIS: HIPÓTESE CONFIRMADA \\ FONEMAS: HIPÓTESE PARCIALMENTE CONFIRMADA \\ ESTRUTURAS SILÁBICAS: HIPÓTESE PARCIALMETE CONFIRMADA
}

Para esta análise, assim como para todas as realizadas nesta pesquisa, o teste estatístico foi aplicado somente quando havia pelo menos dez ocorrências de análise dos dados. Além disso, em muitas posições de sílaba, o alvo não foi observado.

- Encontros consonantais

Primeiramente, foi realizada em cada uma das três provas de fonologia a comparação entre as sílabas inicial, medial e final para cada um dos grupos separadamente, considerando todos os encontros consonantais.

$\mathrm{Na}$ fala espontânea, não foi possível comparar os encontros consonantais nas diferentes posições silábicas. A Figura 1 mostra os grupos e posições de sílabas em que mais de dez alvos foram analisados. Nestas posições de sílabas, o GI-F obteve maior média de acerto em sílaba inicial, mas também maior desvio padrão. Ressaltase que o Gl-M teve número de alvo suficiente apenas na sílaba medial, apresentando baixa porcentagem de acerto.

$\mathrm{Na}$ imitação, os encontros consonantais aparecem somente em sílaba inicial, também não sendo possível comparação entre as sílabas (Figura 2). Nota-se, porém, que as crianças mais velhas apresentam mais acerto que as mais novas. 
Figura 1 - Acertos em encontros consonantais na prova de fala espontânea.

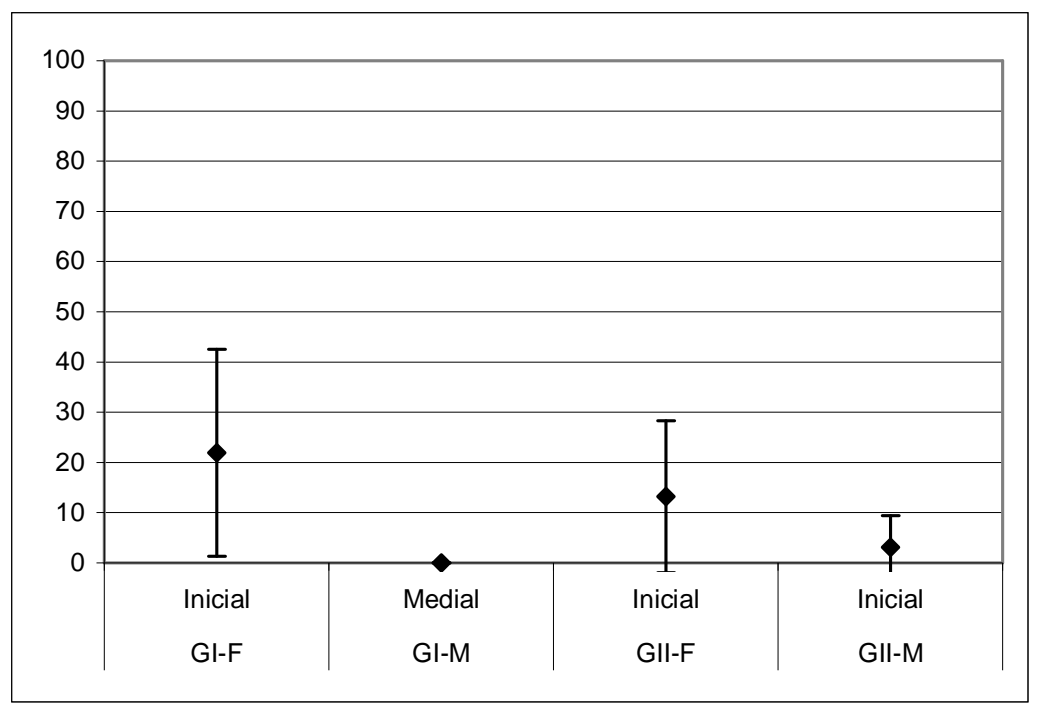

Figura 2 - Acertos em encontros consonantais na prova de imitação.

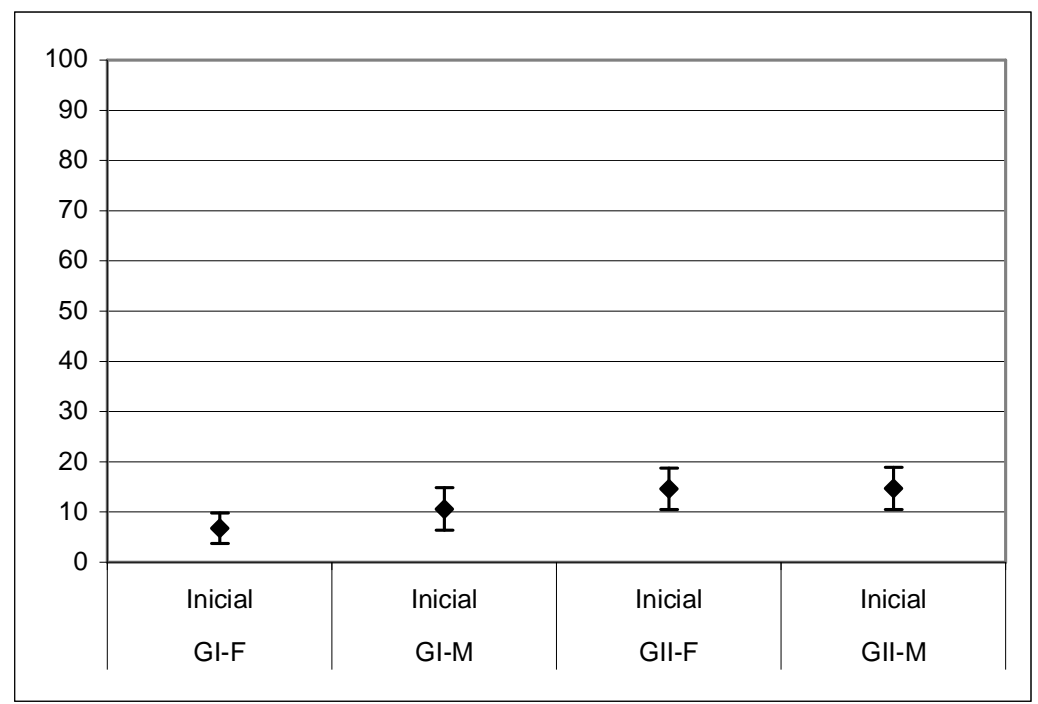

Na nomeação, apesar de aparecem palavras com encontro em sílaba inicial e final, para o Gl-F, a possibilidade de encontro em sílaba final era apenas de sete, não sendo realizada comparação. Mesmo assim, a Figura 3 mostra todos os dados de sílaba inicial e final nos grupos.

Para os demais grupos, foi usado o teste $t$ (n. sig. 0,05) e observou-se que a porcentagem de acerto em sílaba inicial é igual à de sílaba final: GI-M: $p=0,302$; GII$F: p=0,804 ;$ GII-M: $p=0,356$. 
Figura 3 - Acertos em encontros consonantais na prova de nomeação.

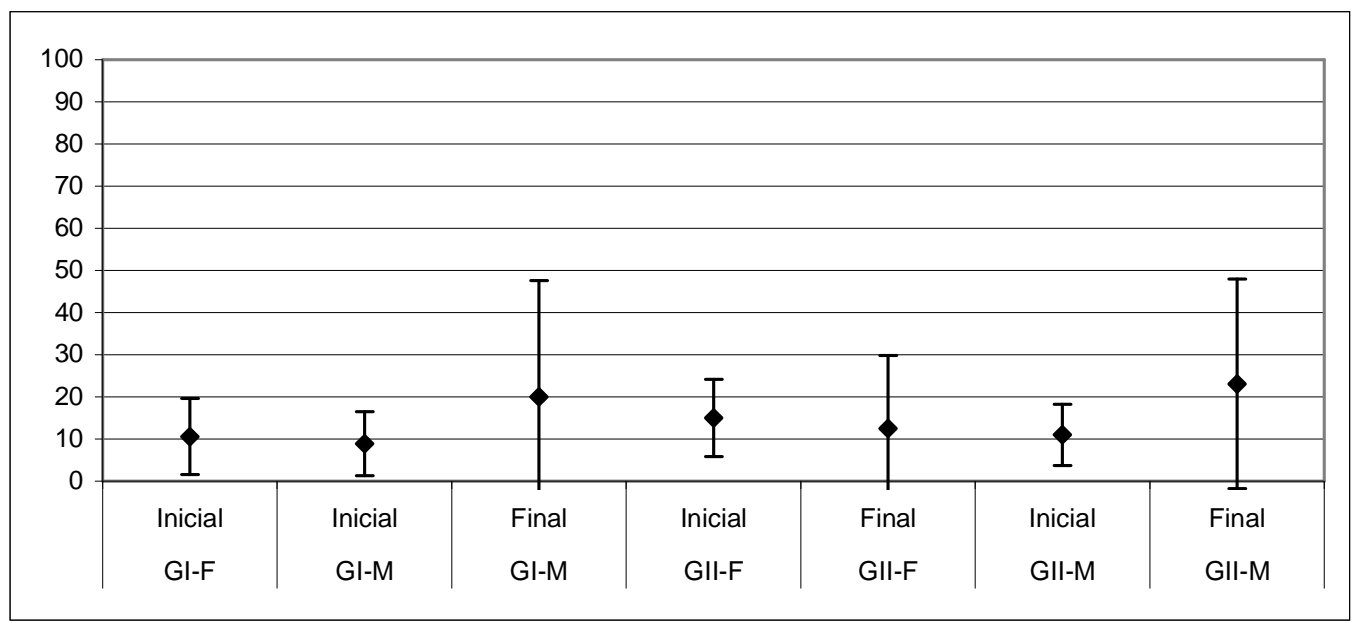

\section{- Fonemas}

Para os fonemas foi possível comparar as três posições silábicas nas três provas, usando a ANOVA (n. sig. 0,05).

$\mathrm{Na}$ fala espontânea, a porcentagem de acerto dos fonemas foi igual para sílaba inicial, medial e final, com exceção do GI-M. Assim, foi realizada comparação dois a dois por meio da comparação múltipla de Bonferroni para ANOVA (n. sig $0,05)$. Neste caso, a sílaba medial tem porcentagem igual à final $(p=1,000)$, mas a inicial tem porcentagem de acerto estatisticamente maior que as duas $(\mathrm{I} \times \mathrm{M}: \mathrm{p}=$ 0,055 e I x F: $p=0,041$ ) (Tabela 2).

Tabela 2 - Comparação entre as posições de sílabas na fala espontânea para fonemas.

\begin{tabular}{|c|c|c|c|c|c|}
\hline Grupo & estatística & Sílaba Inicial & Sílaba Medial & Sílaba Final & \multirow{2}{*}{ ANOVA } \\
\hline \multirow{3}{*}{ GI - F } & Média & 76,4 & 68,9 & 68,3 & \multirow{2}{*}{$\mathrm{p}=0,209$} \\
\cline { 2 - 5 } & Desvio-padrão & 37,9 & 43,6 & 44,2 & \\
\cline { 2 - 5 } & $\mathrm{n}$ & 128 & 122 & 191 & \\
\hline \multirow{3}{*}{ GI-M } & Média & 82,1 & 67,3 & 68,5 & \multirow{2}{*}{$\mathrm{p}=0,023^{*}$} \\
\cline { 2 - 5 } & Desvio-padrão & 35,1 & 44,5 & 44,0 & \\
\cline { 2 - 5 } & $\mathrm{n}$ & 93 & 88 & 154 & \\
\hline \multirow{3}{*}{ GII - F } & Média & 84,4 & 81,4 & 78,1 & \multirow{2}{*}{$\mathrm{p}=0,256$} \\
\cline { 2 - 5 } & Desvio-padrão & 33,8 & 37,3 & 39,0 & \\
\cline { 2 - 5 } GII - M & $\mathrm{n}$ & 155 & 187 & 241 & \\
\cline { 2 - 5 } & Média & 77,7 & 81,8 & 74,5 & \multirow{2}{*}{$\mathrm{p}=0,235$} \\
\cline { 2 - 5 } & Desvio-padrão & 39,4 & 36,9 & 41,7 & \\
\cline { 2 - 5 } & $\mathrm{n}$ & 148 & 136 & 232 & \\
\hline
\end{tabular}


$\mathrm{Na}$ imitação, apenas para as meninas, tanto para o $\mathrm{Gl}-\mathrm{F}$ como para o Gll-F, os fonemas nas diferentes sílabas tiveram o mesmo percentual de acerto (Tabela 3). No GI-M, foi encontrada diferença, verificando-se que a sílaba medial tem mesma porcentagem de acerto que a final $(p=0,522)$ e que a inicial é estatisticamente menor que as duas $(\mathrm{I} \times \mathrm{M}: \mathrm{p}=0,001 ; \mathrm{I} \times \mathrm{F}: \mathrm{p}=0,028)$ (comparações múltiplas de Bonferroni para ANOVA). No GII-M, as sílabas também foram diferentes, sendo que a inicial é igual à final $(p=1,000)$ e ambas têm porcentagem de acerto estatisticamente menor que a medial ( $x \mathrm{M}: \mathrm{p}=0,001 ; \mathrm{M} \times \mathrm{F}: \mathrm{p}=0,007)$.

Tabela 3 - Comparação entre as posições de sílabas na imitação para fonemas.

\begin{tabular}{|c|c|c|c|c|c|}
\hline Grupo & estatística & Sílaba Inicial & Sílaba Medial & Sílaba Final & \multirow{2}{*}{ ANOVA (p) } \\
\hline \multirow{3}{*}{ GI - F } & Média & 57,1 & 65,3 & 60,4 & \multirow{2}{*}{$\mathrm{p}=0,090$} \\
\cline { 2 - 5 } & Desvio-padrão & 47,2 & 46,2 & 45,9 & \\
\cline { 2 - 5 } & $\mathrm{n}$ & 411 & 248 & 474 & \\
\hline \multirow{3}{*}{ GI-M } & Média & 55,3 & 69,9 & 64,4 & \multirow{3}{*}{$\mathrm{p}=0,001$ * } \\
\cline { 2 - 5 } & Desvio-padrão & 47,5 & 45,0 & 45,0 & \\
\cline { 2 - 5 } & $\mathrm{n}$ & 323 & 195 & 375 & \\
\hline \multirow{3}{*}{ GII - F } & Média & 73,6 & 73,1 & 70,3 & \multirow{2}{*}{$\mathrm{p}=0,459$} \\
\cline { 2 - 5 } & Desvio-padrão & 41,2 & 43,5 & 42,9 & \\
\cline { 2 - 5 } & $\mathrm{n}$ & 432 & 264 & 504 & \\
\hline \multirow{3}{*}{ Gll - M } & Média & 66,2 & 78,5 & 68,1 & \multirow{2}{*}{$\mathrm{p}=0,001$ * } \\
\cline { 2 - 5 } & Desvio-padrão & 45,1 & 40,1 & 44,3 & \\
\cline { 2 - 5 } & $\mathrm{n}$ & 413 & 253 & 479 & \\
\hline
\end{tabular}

$\mathrm{Na}$ nomeação, em todos os grupos, a comparação mostrou que a porcentagem de acerto é igual em todas as sílabas (Tabela 4).

Tabela 4 - Comparação entre as posições de sílabas na nomeação para fonemas.

\begin{tabular}{|c|c|c|c|c|c|}
\hline Grupo & Estatística & Sílaba Inicial & Sílaba Medial & Sílaba Final & Comparativo \\
\hline \multirow{3}{*}{ GI - F } & Média & 62,8 & 64,6 & 64,9 & \multirow{2}{*}{$\mathrm{p}=0,864$} \\
\cline { 2 - 5 } & Desvio-padrão & 47,2 & 48,0 & 46,1 & \\
\cline { 2 - 5 } & $\mathrm{n}$ & 245 & 144 & 281 & \\
\hline \multirow{3}{*}{ GI-M } & Média & 66,9 & 63,1 & 65,8 & \multirow{2}{*}{$\mathrm{p}=0,762$} \\
\cline { 2 - 5 } & Desvio-padrão & 45,7 & 47,4 & 45,9 & \\
\cline { 2 - 5 } & $\mathrm{n}$ & 213 & 126 & 246 & \\
\hline \multirow{3}{*}{ GII - F } & Média & 74,5 & 70,5 & 75,1 & \multirow{2}{*}{$\mathrm{p}=0,488$} \\
\cline { 2 - 5 } & Desvio-padrão & 42,0 & 45,1 & 42,0 & \\
\cline { 2 - 5 } & $\mathrm{n}$ & 304 & 173 & 352 & \multirow{2}{*}{$\mathrm{p}=0,950$} \\
\hline \multirow{3}{*}{ GII - M } & Média & 69,5 & 70,6 & 69,4 & \\
\cline { 2 - 5 } & Desvio-padrão & 44,3 & 45,5 & 44,5 & \\
\cline { 2 - 5 } & $\mathrm{n}$ & 310 & 182 & 360 & \\
\hline
\end{tabular}


O desempenho das crianças nas sílabas inicial, medial e final foi comparado nas estruturas CCV, CV e CVC.

$\underline{\mathrm{CV}}$

Na fala espontânea, com exceção do Gll-M, todos os grupos evidenciaram diferenças significantes na comparação da estrutura silábica CV nas diferentes posições de sílabas (ANOVA, n. sig. 0,05). Destaca-se que o Gll-M apresentou o valor de p próximo do nível de significância, indicando tendência à diferença (Tabela 5).

Tabela 5 - Comparação entre posição de sílaba na estrutura CV na fala espontânea.

\begin{tabular}{|c|c|c|c|c|c|}
\hline Grupo & Estatística & Sílaba Inicial & Sílaba Medial & Sílaba Final & ANOVA (p) \\
\hline \multirow{3}{*}{ Gl - F } & Média & 98,3 & 87,1 & 97,1 & \multirow{3}{*}{$\mathrm{p}<0,001$ * } \\
\hline & Desvio-padrão & 7,1 & 20,8 & 10,8 & \\
\hline & $\mathrm{n}$ & 55 & 33 & 54 & \\
\hline \multirow{3}{*}{ GI-M } & Média & 95,5 & 80,3 & 97,7 & \multirow{3}{*}{$\mathrm{p}=0,001$ * } \\
\hline & Desvio-padrão & 17,4 & 34,7 & 8,6 & \\
\hline & $\mathrm{n}$ & 44 & 31 & 45 & \\
\hline \multirow{3}{*}{ Gll - F } & Média & 99,1 & 92,3 & 98,9 & \multirow{3}{*}{$\mathrm{p}<0,001^{*}$} \\
\hline & Desvio-padrão & 5,3 & 14,3 & 5,8 & \\
\hline & $\mathrm{n}$ & 63 & 41 & 63 & \\
\hline \multirow{3}{*}{ GII - M } & Média & 96,7 & 91,2 & 98,3 & \multirow{3}{*}{$p=0,055$} \\
\hline & Desvio-padrão & 14,5 & 20,8 & 5,3 & \\
\hline & $\mathrm{n}$ & 55 & 36 & 56 & \\
\hline
\end{tabular}

Ao se aplicar a comparação múltipla de Bonferroni para ANOVA, há indícios de que a sílaba inicial foi estatisticamente igual à final, porém, ambas apresentaram porcentagem de acerto maior que a medial (Tabela 6). 
Tabela 6 - Comparação dois a dois entre as posições de sílaba na estrutura CV na fala espontânea.

\begin{tabular}{|c|c|}
\hline Grupo & Bonferroni (p) \\
\hline GI-F & $\begin{array}{l}\mathrm{I} \times \mathrm{MP} P<0,001 \text { * } \\
\mathrm{I} \times \mathrm{F} p=1,000 \\
\mathrm{M} \times \mathrm{Fp}=0,002 \text { * }\end{array}$ \\
\hline GI-M & $\begin{array}{l}\mathrm{I} \times \mathrm{MP}=0,009^{*} \\
\mathrm{I} \times \mathrm{F}=1,000 \\
\mathrm{M} \times \mathrm{Fp}=0,002 \text { * }\end{array}$ \\
\hline GII-F & $\begin{array}{l}\mathrm{I} \times \mathrm{M} \mathrm{p}<0,001 \text { * } \\
\mathrm{I} \times \mathrm{Fp}=1,000 \\
\mathrm{M} \times \mathrm{Fp}=0,001 \text { * }\end{array}$ \\
\hline
\end{tabular}

Na imitação, a estrutura CV teve porcentagem de acerto igual para os grupos, com exceção do Gl-F (Tabela 7).

Ao se aplicar a comparação múltipla de Bonferroni neste grupo, observa-se que a sílaba medial é estatisticamente igual à inicial $(p=0,523)$ e à final $(p=1,000)$, porém, a final obteve porcentagem de acerto estatisticamente maior que a inicial $(p=$ 0,042).

Tabela 7 - Comparação entre posição de sílaba na estrutura CV na imitação.

\begin{tabular}{|c|c|c|c|c|c|}
\hline Grupo & Estatística & Sílaba Inicial & Sílaba Medial & Sílaba Final & ANOVA (p) \\
\hline \multirow{3}{*}{ GI - F } & Média & 90,0 & 93,6 & 95,3 & \multirow{2}{*}{$\mathrm{p}=0,045^{*}$} \\
\cline { 2 - 5 } & Desvio-padrão & 14,5 & 5,0 & 6,4 & \\
\cline { 2 - 5 } & $\mathrm{n}$ & 46 & 23 & 46 & \\
\hline \multirow{3}{*}{ GI-M } & Média & 85,7 & 92,9 & 94,6 & \multirow{2}{*}{$\mathrm{p}=0,062$} \\
\cline { 2 - 5 } & Desvio-padrão & 24,4 & 6,7 & 6,7 & \\
\cline { 2 - 5 } & $\mathrm{n}$ & 36 & 18 & 36 & \\
\hline \multirow{3}{*}{ GII - F } & Média & 95,6 & 95,8 & 96,4 & \multirow{2}{*}{$\mathrm{p}=0,813$} \\
\cline { 2 - 5 } & Desvio-padrão & 6,5 & 5,1 & 5,3 & \\
\cline { 2 - 5 } & $\mathrm{n}$ & 48 & 24 & 48 & \multirow{2}{*}{$\mathrm{p}=0,419$} \\
\hline \multirow{3}{*}{ GII - M } & Média & 92,0 & 95,3 & 94,2 & \\
\cline { 2 - 5 } & Desvio-padrão & 15,0 & 4,5 & 5,9 & \\
\cline { 2 - 5 } & $\mathrm{n}$ & 46 & 23 & 46 & \\
\hline
\end{tabular}

Na nomeação, em todos os grupos, a porcentagem de acerto na estrutura CV foi estatisticamente igual em todas as sílabas (Tabela 8) 
Tabela 8 - Comparação entre as posições de sílabas na estrutura CV na nomeação.

\begin{tabular}{|c|c|c|c|c|c|}
\hline Grupo & Estatística & Sílaba Inicial & Sílaba Medial & Sílaba Final & ANOVA $(\mathrm{p})$ \\
\hline \multirow{3}{*}{ GI - F } & Média & 92,3 & 92,5 & 90,2 & \multirow{2}{*}{$\mathrm{p}=0,720$} \\
\cline { 2 - 5 } & Desvio-padrão & 12,4 & 12,0 & 15,6 & \\
\cline { 2 - 5 } & $\mathrm{n}$ & 46 & 23 & 46 & \\
\hline \multirow{3}{*}{ GI-M } & Média & 94,1 & 88,3 & 91,4 & \multirow{2}{*}{$\mathrm{p}=0,269$} \\
\cline { 2 - 5 } & Desvio-padrão & 10,8 & 13,8 & 13,2 & \\
\cline { 2 - 5 } & $\mathrm{n}$ & 36 & 18 & 36 & \\
\hline \multirow{3}{*}{ GII - F } & Média & 97,5 & 94,5 & 96,4 & \multirow{2}{*}{$\mathrm{p}=0,319$} \\
\cline { 2 - 5 } & Desvio-padrão & 6,4 & 9,3 & 8,7 & \\
\cline { 2 - 5 } & $\mathrm{n}$ & 48 & 24 & 48 & \multirow{2}{*}{$\mathrm{p}=0,075$} \\
\hline \multirow{3}{*}{ GII - M } & Média & 95,2 & 87,7 & 91,7 & \\
\cline { 2 - 5 } & Desvio-padrão & 9,9 & 14,0 & 15,0 & \\
\cline { 2 - 5 } & $\mathrm{n}$ & 46 & 23 & 46 & \\
\hline
\end{tabular}

$\underline{\text { CCV }}$

Na fala espontânea, não foi possível a comparação das estruturas CCV em nenhum dos grupos por não apresentarem número de alvos suficiente para o teste estatístico (Tabela 9).

Tabela 9 - Comparação entre posição de sílaba na estrutura CCV na fala espontânea.

\begin{tabular}{|c|c|c|c|c|c|}
\hline Grupo & Estatística & Sílaba Inicial & Sílaba Medial & Sílaba Final & Comparativo \\
\hline \multirow{3}{*}{ Gl - F } & Média & 15,0 & 0,0 & --- & \multirow{3}{*}{ não analisado } \\
\hline & Desvio-padrão & 36,6 & --- & --- & \\
\hline & $\mathrm{n}$ & 20 & 1 & --- & \\
\hline \multirow{3}{*}{ GI-M } & Média & 11,1 & --- & --- & \multirow{3}{*}{ não analisado } \\
\hline & Desvio-padrão & 30,0 & --- & --- & \\
\hline & $n$ & 15 & --- & --- & \\
\hline \multirow{3}{*}{ Gll - F } & Média & 16,7 & 0,0 & --- & \multirow{3}{*}{ não analisado } \\
\hline & Desvio-padrão & 36,5 & --- & --- & \\
\hline & $\mathrm{n}$ & 21 & 1 & --- & \\
\hline \multirow{3}{*}{ GII - M } & Média & 9,5 & 0,0 & 50,0 & \multirow{3}{*}{ não analisado } \\
\hline & Desvio-padrão & 26,1 & --- & 70,7 & \\
\hline & $\mathrm{n}$ & 21 & 1 & 2 & \\
\hline
\end{tabular}

Na imitação, a estrutura CCV aparece apenas em sílaba inicial, também não sendo possível comparação entre sílabas (Tabela 10). 
Tabela 10 - Comparação entre posição de sílaba na estrutura CCV na imitação.

\begin{tabular}{|c|c|c|c|}
\hline Grupo & Estatística & Sílaba Inicial & Comparativo \\
\hline \multirow{3}{*}{ Gl - F } & Média & 8,4 & \multirow{3}{*}{ não analisado } \\
\cline { 2 - 3 } & Desvio-padrão & 21,3 & \\
\cline { 2 - 3 } & $\mathrm{n}$ & 68 & \\
\hline \multirow{3}{*}{ GI-M } & Média & 13,5 & \multirow{3}{*}{ não analisado } \\
\cline { 2 - 3 } & Desvio-padrão & 27,8 & \\
\cline { 2 - 3 } & $\mathrm{n}$ & 54 & \\
\hline \multirow{3}{*}{ GII - F } & Média & 16,7 & \multirow{2}{*}{ não analisado } \\
\cline { 2 - 3 } & Desvio-padrão & 29,5 & \\
\cline { 2 - 3 } & $\mathrm{n}$ & 72 & \\
\hline \multirow{3}{*}{ GII - M } & Média & 20,0 & \multirow{3}{*}{ não analisado } \\
\cline { 2 - 3 } & Desvio-padrão & 33,5 & \\
\cline { 2 - 3 } & $\mathrm{n}$ & 69 & \\
\hline
\end{tabular}

Na nomeação, a estrutura CCV aparece em sílaba inicial e final. Porém, nos grupos de crianças mais novas (GI-F e Gl-M) não foi possível a comparação. No entanto, para o Gll-F e Gll-M, a sílaba inicial foi estatisticamente igual à final, utilizando-se o teste $\mathrm{t}$ (Tabela 11).

Tabela 11 - Comparação entre posição de sílaba na estrutura CCV na nomeação.

\begin{tabular}{|c|c|c|c|c|}
\hline Grupo & Estatística & Sílaba Inicial & Sílaba Final & Teste $t(p)$ \\
\hline \multirow{3}{*}{ Gl - F } & Média & 8,1 & 42,9 & \multirow{3}{*}{ não analisado } \\
\hline & Desvio-padrão & 26,1 & 53,5 & \\
\hline & $\mathrm{n}$ & 31 & 7 & \\
\hline \multirow{3}{*}{ GI-M } & Média & 13,7 & 22,2 & \multirow{3}{*}{ não analisado } \\
\hline & Desvio-padrão & 34,0 & 44,1 & \\
\hline & $\mathrm{n}$ & 34 & 9 & \\
\hline \multirow{3}{*}{ GII - F } & Média & 22,2 & 20,0 & \multirow{3}{*}{$p=0,856$} \\
\hline & Desvio-padrão & 38,8 & 41,4 & \\
\hline & $\mathrm{n}$ & 36 & 15 & \\
\hline \multirow{3}{*}{ Gll - M } & Média & 12,4 & 23,1 & \multirow{3}{*}{$p=0,427$} \\
\hline & Desvio-padrão & 30,5 & 43,9 & \\
\hline & $\mathrm{n}$ & 39 & 13 & \\
\hline
\end{tabular}

$\underline{\mathrm{CVC}}$

Para esta análise, as estruturas CVC com arquifonema $\mathrm{S}$ e $\mathrm{R}$ foram agrupadas.

$\mathrm{Na}$ fala espontânea, somente para o Gll-F foi possível fazer comparação entre as sílabas inicial e final. $O$ teste $t(n$. sig. 0,05$)$ mostrou que elas são estatisticamente diferentes, sendo que a sílaba inicial teve porcentagem maior de acerto que a final (Tabela 12). 
Nos demais grupos, não foi possível comparação, pois em algumas posições de sílaba não houve número suficiente de alvos.

Tabela 12 - Comparação entre posição de sílaba na estrutura CVC na fala espontânea.

\begin{tabular}{|c|c|c|c|c|c|}
\hline Grupo & Estatística & Sílaba Inicial & Sílaba Medial & Sílaba Final & \multirow{2}{*}{ Comparativo } \\
\hline \multirow{3}{*}{ GI - F } & Média & 14,3 & 0,0 & 0,0 & \multirow{3}{*}{ não analisado } \\
\cline { 2 - 5 } & Desvio-padrão & 37,8 & 0,0 & 0,0 & \\
\cline { 2 - 5 } & $\mathrm{n}$ & 7 & 2 & 20 & \\
\hline \multirow{3}{*}{ GI-M } & Média & 50,0 & 0,0 & 11,1 & \multirow{3}{*}{ não analisado } \\
\cline { 2 - 5 } & Desvio-padrão & 70,7 & --- & 32,3 & \\
\cline { 2 - 5 } & $\mathrm{n}$ & 2 & 1 & 18 & \\
\hline \multirow{3}{*}{ GII - F } & Média & 60,0 & 14,3 & 10,3 & \multirow{3}{*}{$\mathrm{p}=0,015^{*}$} \\
\cline { 2 - 5 } & Desvio-padrão & 51,6 & 37,8 & 25,0 & \\
\cline { 2 - 5 } & $\mathrm{n}$ & 10 & 7 & 21 & \\
\hline \multirow{3}{*}{ Gll - M } & Média & 22,2 & 50,0 & 10,5 & \multirow{3}{*}{ não analisado } \\
\cline { 2 - 5 } & Desvio-padrão & 36,3 & 57,7 & 31,5 & \\
\cline { 2 - 5 } & $\mathrm{n}$ & 9 & 4 & 19 & \\
\hline
\end{tabular}

$\mathrm{Na}$ imitação, houve comparação entre as sílabas inicial e final em todos os grupos por meio do teste $t$ (n. sig. 0,05). No GI-F, a sílaba inicial teve porcentagem de acerto menor que a final. Vale ressaltar que nos outros grupos, apesar das sílabas serem estatisticamente iguais, a sílaba inicial sempre obteve porcentagem de acerto menor que a final (Tabela 13).

Tabela 13 - Comparação entre posição de sílaba na estrutura CVC na imitação.

\begin{tabular}{|c|c|c|c|c|}
\hline Grupo & Estatística & Sílaba Inicial & Sílaba Final & Teste t $(\mathrm{p})$ \\
\hline \multirow{3}{*}{ GI - F } & Média & 7,5 & 29,5 & \multirow{2}{*}{$\mathrm{p}=0,005^{*}$} \\
\cline { 2 - 4 } & Desvio-padrão & 26,5 & 46,2 & \\
\cline { 2 - 4 } & $\mathrm{n}$ & 67 & 44 & \multirow{2}{*}{$\mathrm{p}=0,412$} \\
\hline \multirow{3}{*}{ GI-M } & Média & 13,0 & 19,4 & \\
\cline { 2 - 4 } & Desvio-padrão & 33,9 & 40,1 & \multirow{2}{*}{$\mathrm{p}=0,132$} \\
\cline { 2 - 4 } & $\mathrm{n}$ & 54 & 36 & \\
\hline \multirow{3}{*}{ GII - F - M } & Média & 31,9 & 45,8 & \multirow{2}{*}{$\mathrm{p}=0,161$} \\
\cline { 2 - 4 } & Desvio-padrão & 47,0 & 50,4 & \\
\cline { 2 - 4 } & $\mathrm{n}$ & 72 & 48 & \\
\cline { 2 - 4 } & Desvio-padrão & 46,1 & 50,1 & \\
\cline { 2 - 4 } & $\mathrm{n}$ & 67 & 44 & \\
\hline
\end{tabular}

Na nomeação, a comparação entre posição de sílaba foi realizada apenas no GII-M (teste t, n. sig. 0,05). Neste, a sílaba inicial foi comparada com a final e não foi observada diferença estatística entre elas (Tabela 14). 
Tabela 14 - Comparação entre posição de sílaba na estrutura CVC na nomeação.

\begin{tabular}{|c|c|c|c|c|}
\hline Grupo & estatística & Sílaba Inicial & Sílaba Final & Teste $\mathrm{t}(\mathrm{p})$ \\
\hline \multirow{3}{*}{ GI - F } & Média & 13,6 & 0,0 & \multirow{2}{*}{ não analisado } \\
\cline { 2 - 4 } & Desvio-padrão & 35,1 & 0,0 & \\
\cline { 2 - 4 } & $\mathrm{n}$ & 22 & 4 & \\
\hline \multirow{3}{*}{ GI-M } & Média & 23,5 & 0,0 & \multirow{3}{*}{ não analisado } \\
\cline { 2 - 4 } & Desvio-padrão & 43,7 & 0,0 & \\
\cline { 2 - 4 } & $\mathrm{n}$ & 17 & 8 & \\
\hline \multirow{3}{*}{ GII - F } & Média & 35,1 & 11,1 & \multirow{3}{*}{ não analisado } \\
\cline { 2 - 4 } & Desvio-padrão & 48,4 & 33,3 & \\
\cline { 2 - 4 } & $\mathrm{n}$ & 37 & 9 & \\
\hline \multirow{3}{*}{ GII - M } & Média & 29,7 & 10,0 & \multirow{2}{*}{$\mathrm{p}=0,067$} \\
\cline { 2 - 4 } & Desvio-padrão & 46,3 & 28,0 & \\
\cline { 2 - 4 } & $\mathrm{n}$ & 37 & 15 & \\
\hline
\end{tabular}

Como houve diferença entre algumas posições de sílabas e em alguns casos não houve alvo ou não havia número de amostra suficiente para comparação, as posições de sílabas foram analisadas separadamente neste trabalho. Assim, as próximas análises serão realizadas separadamente para sílaba inicial, medial e final. 


\section{HIPÓTESE 2 - NÃO HÁ DIFERENÇA NA AQUISIÇÃO FONOLÓGICA DE MENINOS E MENINAS DA MESMA FAIXA ETÁRIA QUANTO A ENCONTROS CONSONANTAIS, FONEMAS E ESTRUTURAS SILÁBICAS.}

\section{HIPÓTESE CONFIRMADA}

Para esse estudo foram realizadas comparações entre meninas e meninos da mesma faixa etária, ou seja, GI-F x GI-M e GII-F x GII-M, para cada variável, nas três posições silábicas, nas diferentes provas.

\section{- Encontros consonantais}

$\mathrm{Na}$ fala espontânea, foi possível realizar comparações entre os grupos apenas para meninos e meninas da faixa etária mais velha em sílaba inicial. Nesta, não houve diferença estatística entre os gêneros. Nas demais comparações, não havia número suficiente de alvos para a análise estatística (Tabela 15).

Tabela 15 - Comparação entre os gêneros quanto aos encontros consonantais na fala espontânea.

\begin{tabular}{|c|c|c|c|c|c|}
\hline Sílaba & Grupo & estatística & Feminino & Masculino & teste $t(p)$ \\
\hline \multirow{3}{*}{ Inicial } & \multirow{3}{*}{ GI-F x GI-M } & Média & 21,9 & 11,1 & \multirow{3}{*}{ não analisado } \\
\hline & & Desvio-padrão & 40,7 & 27,2 & \\
\hline & & $\mathrm{n}$ & 16 & 6 & \\
\hline \multirow{3}{*}{ Inicial } & \multirow{3}{*}{ GII-F x Gll-M } & Média & 13,2 & 3,1 & \multirow{3}{*}{0,256} \\
\hline & & Desvio-padrão & 32,7 & 12,5 & \\
\hline & & $\mathrm{n}$ & 19 & 16 & \\
\hline \multirow{3}{*}{ Medial } & \multirow{3}{*}{ GI-F x GI-M } & Média & 0,0 & 0,0 & \multirow{3}{*}{ não analisado } \\
\hline & & Desvio-padrão & 0,0 & 0,0 & \\
\hline & & $\mathrm{n}$ & 5 & 10 & \\
\hline \multirow{3}{*}{ Medial } & \multirow{3}{*}{ GII-F x Gll-M } & Média & 0,0 & 11,1 & \multirow{3}{*}{ não analisado } \\
\hline & & Desvio-padrão & 0,0 & 33,3 & \\
\hline & & $\mathrm{n}$ & 3 & 9 & \\
\hline \multirow{3}{*}{ Final } & \multirow{3}{*}{ GI-F x GI-M } & Média & 0,0 & 0,0 & \multirow{3}{*}{ não analisado } \\
\hline & & Desvio-padrão & 0,0 & 0,0 & \\
\hline & & $\mathrm{n}$ & 0 & 0 & \\
\hline \multirow{3}{*}{ Final } & \multirow{3}{*}{ GII-F x GII-M } & Média & 0,0 & 50,0 & \multirow{3}{*}{ não analisado } \\
\hline & & Desvio-padrão & --- & 70,7 & \\
\hline & & $\mathrm{n}$ & 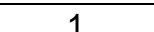 & 2 & \\
\hline
\end{tabular}


$\mathrm{Na}$ imitação (Tabela 16), os encontros consonantais aparecem apenas em sílaba inicial. Tanto para as crianças mais novas, como para as mais velhas, não houve diferença estatística entre os gêneros.

Tabela 16 - Comparação entre os gêneros quanto aos encontros consonantais na imitação.

\begin{tabular}{|c|c|c|c|c|c|}
\hline Sílaba & Grupo & estatística & Feminino & Masculino & teste t $(\mathrm{p})$ \\
\hline \multirow{3}{*}{ Inicial } & \multirow{3}{*}{ GI-F x GI-M } & Média & 6,8 & 10,6 & \multirow{2}{*}{0,135} \\
\cline { 3 - 5 } & & Desvio-padrão & 25,2 & 30,9 & \\
\cline { 3 - 5 } & $\mathrm{n}$ & 266 & 207 & \\
\hline \multirow{2}{*}{ Inicial } & \multirow{2}{*}{ GII-F x GII-M } & Média & 14,6 & 14,7 & \multirow{2}{*}{0,981} \\
\cline { 3 - 5 } & & Desvio-padrão & 35,4 & 35,5 & \multirow{2}{*}{$\mathrm{n}$} \\
\cline { 3 - 4 } & & 287 & 272 & \\
\hline
\end{tabular}

Na nomeação (Tabela 17), não foi possível a realização de comparação em sílaba final entre as crianças mais novas. Quanto à sílaba inicial para os grupos de crianças mais velhas e mais novas, e à sílaba final no grupo mais velho, não houve diferença entre meninos e meninas quanto aos acertos dos encontros consonantais.

Tabela 17 - Comparação entre os gêneros quanto aos encontros consonantais na nomeação.

\begin{tabular}{|c|c|c|c|c|c|}
\hline Sílaba & Grupo & estatística & Feminino & Masculino & teste $t(p)$ \\
\hline \multirow{3}{*}{ Inicial } & \multirow{3}{*}{ GI-F x Gl-M } & Média & 10,6 & 8,9 & \multirow{3}{*}{0,773} \\
\hline & & Desvio-padrão & 31,2 & 28,8 & \\
\hline & & $\mathrm{n}$ & 47 & 56 & \\
\hline \multirow{3}{*}{ Inicial } & \multirow{3}{*}{ Gll-F x Gll-M } & Média & 15,0 & 11,0 & \multirow{3}{*}{0,134} \\
\hline & & Desvio-padrão & 36,0 & 31,5 & \\
\hline & & $\mathrm{n}$ & 60 & 73 & \\
\hline \multirow{3}{*}{ Final } & \multirow{3}{*}{ GI-F x GI-M } & Média & 42,9 & 20,0 & \multirow{3}{*}{ não analisado } \\
\hline & & Desvio-padrão & 53,5 & 42,2 & \\
\hline & & $\mathrm{n}$ & 7 & 10 & \\
\hline \multirow{3}{*}{ Final } & \multirow{3}{*}{ Gll-F x Gll-M } & Média & 12,5 & 23,1 & \multirow{3}{*}{0,471} \\
\hline & & Desvio-padrão & 34,2 & 43,9 & \\
\hline & & $\mathrm{n}$ & 16 & 13 & \\
\hline
\end{tabular}


- Fonemas

Na fala espontânea, não houve diferença entre meninos e meninas da mesma faixa etária, quanto aos acertos dos fonemas, em nenhuma posição silábica (Tabela 18).

Tabela 18 - Comparação entre os gêneros quanto aos fonemas na fala espontânea.

\begin{tabular}{|c|c|c|c|c|c|}
\hline Sílaba & Grupo & estatística & Feminino & Masculino & teste $t(p)$ \\
\hline \multirow{3}{*}{ Inicial } & \multirow{3}{*}{ GI-F x Gl-M } & Média & 76,4 & 82,1 & \multirow{3}{*}{0,257} \\
\hline & & Desvio-padrão & 37,9 & 35,1 & \\
\hline & & $\mathrm{n}$ & 128 & 93 & \\
\hline \multirow{3}{*}{ Inicial } & \multirow{3}{*}{ GII-F x Gll-M } & Média & 84,4 & 77,7 & \multirow{3}{*}{0,114} \\
\hline & & Desvio-padrão & 33,8 & 39,4 & \\
\hline & & $\mathrm{n}$ & 155 & 148 & \\
\hline \multirow{3}{*}{ Medial } & \multirow{3}{*}{ GI-F x GI-M } & Média & 68,9 & 67,3 & \multirow{3}{*}{0,796} \\
\hline & & Desvio-padrão & 43,6 & 44,5 & \\
\hline & & $\mathrm{n}$ & 122 & 88 & \\
\hline \multirow{3}{*}{ Medial } & \multirow{3}{*}{ Gll-F x Gll-M } & Média & 81,4 & 81,8 & \multirow{3}{*}{0,925} \\
\hline & & Desvio-padrão & 37,3 & 36,9 & \\
\hline & & $\mathrm{n}$ & 187 & 136 & \\
\hline \multirow{3}{*}{ Final } & \multirow{3}{*}{ GI-F x GI-M } & Média & 68,3 & 68,5 & \multirow{3}{*}{0,974} \\
\hline & & Desvio-padrão & 44,2 & 44,0 & \\
\hline & & $\mathrm{n}$ & 191 & 154 & \\
\hline \multirow{3}{*}{ Final } & \multirow{3}{*}{ GII-F x GII-M } & Média & 78,1 & 74,5 & \multirow{3}{*}{0,329} \\
\hline & & Desvio-padrão & 39,0 & 41,7 & \\
\hline & & $\mathrm{n}$ & 241 & 232 & \\
\hline
\end{tabular}

Em relação à imitação, houve diferença estatística entre os gêneros apenas em sílaba inicial no grupo mais velho, sendo que as meninas apresentaram porcentagem de acerto maior que os meninos (Tabela 19).

$\mathrm{Na}$ nomeação, os meninos e as meninas de ambos os grupos apresentaram porcentagem de acerto igual, quanto à produção dos fonemas, em todas as posições silábicas (Tabela 20). 
Tabela 19 - Comparação entre os gêneros quanto aos fonemas na imitação.

\begin{tabular}{|c|c|c|c|c|c|}
\hline Sílaba & Grupo & estatística & Feminino & Masculino & teste $t(p)$ \\
\hline \multirow{3}{*}{ Inicial } & \multirow{3}{*}{ GI-F x GI-M } & Média & 57,1 & 55,3 & \multirow{3}{*}{0,621} \\
\hline & & Desvio-padrão & 47,2 & 47,5 & \\
\hline & & $\mathrm{n}$ & 411 & 323 & \\
\hline \multirow{3}{*}{ Inicial } & \multirow{3}{*}{ GII-F x GII-M } & Média & 73,6 & 66,2 & \multirow{3}{*}{$0,013^{*}$} \\
\hline & & Desvio-padrão & 41,2 & 45,1 & \\
\hline & & $\mathrm{n}$ & 432 & 413 & \\
\hline \multirow{3}{*}{ Medial } & \multirow{3}{*}{ GI-F x GI-M } & Média & 65,3 & 69,9 & \multirow{3}{*}{0,287} \\
\hline & & Desvio-padrão & 46,2 & 45,0 & \\
\hline & & $n$ & 248 & 195 & \\
\hline \multirow{3}{*}{ Medial } & \multirow{3}{*}{ GII-F x GII-M } & Média & 73,1 & 78,5 & \multirow{3}{*}{0,142} \\
\hline & & Desvio-padrão & 43,5 & 40,1 & \\
\hline & & $\mathrm{n}$ & 264 & 253 & \\
\hline \multirow{3}{*}{ Final } & \multirow{3}{*}{ GI-F x Gl-M } & Média & 60,4 & 64,4 & \multirow{3}{*}{0,202} \\
\hline & & Desvio-padrão & 45,9 & 45,0 & \\
\hline & & $\mathrm{n}$ & 474 & 375 & \\
\hline \multirow{3}{*}{ Final } & \multirow{3}{*}{ GII-F x Gll-M } & Média & 70,3 & 68,1 & \multirow{3}{*}{0,420} \\
\hline & & Desvio-padrão & 42,9 & 44,3 & \\
\hline & & $n$ & 504 & 479 & \\
\hline
\end{tabular}

Tabela 20 - Comparação entre os gêneros quanto aos fonemas na nomeação.

\begin{tabular}{|c|c|c|c|c|c|}
\hline Sílaba & Grupo & estatística & Feminino & Masculino & teste t $(p)$ \\
\hline \multirow{3}{*}{ Inicial } & \multirow{3}{*}{ GI-F x GI-M } & Média & 62,8 & 66,9 & \multirow{3}{*}{0,346} \\
\hline & & Desvio-padrão & 47,2 & 45,7 & \\
\hline & & $\mathrm{n}$ & 245 & 213 & \\
\hline \multirow{3}{*}{ Inicial } & \multirow{3}{*}{ GII-F x GII-M } & Média & 74,5 & 69,5 & \multirow{3}{*}{0,153} \\
\hline & & Desvio-padrão & 42,0 & 44,3 & \\
\hline & & $\mathrm{n}$ & 304 & 310 & \\
\hline \multirow{3}{*}{ Medial } & \multirow{3}{*}{ GI-F x GI-M } & Média & 64,6 & 63,1 & \multirow{3}{*}{0,798} \\
\hline & & Desvio-padrão & 48,0 & 47,4 & \\
\hline & & $\mathrm{n}$ & 144 & 126 & \\
\hline \multirow{3}{*}{ Medial } & \multirow{3}{*}{ GII-F x GII-M } & Média & 70,5 & 70,6 & \multirow{3}{*}{0,986} \\
\hline & & Desvio-padrão & 45,1 & 45,5 & \\
\hline & & $\mathrm{n}$ & 173 & 182 & \\
\hline \multirow{3}{*}{ Final } & \multirow{3}{*}{ GI-F x GI-M } & Média & 64,9 & 65,8 & \multirow{3}{*}{0,832} \\
\hline & & Desvio-padrão & 46,1 & 45,9 & \\
\hline & & $\mathrm{n}$ & 281 & 246 & \\
\hline \multirow{3}{*}{ Final } & \multirow{3}{*}{ GII-F x GII-M } & Média & 75,1 & 69,4 & \multirow{3}{*}{0,075} \\
\hline & & Desvio-padrão & 42,0 & 44,5 & \\
\hline & & $\mathrm{n}$ & 352 & 360 & \\
\hline
\end{tabular}




\section{- Estruturas silábicas}

Para a comparação entre as sílabas quanto ao gênero, foi usado o teste t com nível de significância 0,05.

$\underline{\mathrm{CV}}$

Em todas as provas e posição de sílabas testadas, a porcentagem de acerto na estrutura CV foi igual entre meninos e meninas da mesma faixa etária (Tabelas 21 a 23).

Tabela 21 - Diferença entre os gêneros para a estrutura CV na fala espontânea.

\begin{tabular}{|c|c|c|c|c|c|}
\hline Sílaba & Grupo & estatística & Feminino & Masculino & teste $t(p)$ \\
\hline \multirow{3}{*}{ Inicial } & \multirow{3}{*}{ GI-F x GI-M } & Média & 98,3 & 95,5 & \multirow{3}{*}{0,315} \\
\hline & & Desvio-padrão & 7,1 & 17,4 & \\
\hline & & $\mathrm{n}$ & 55 & 44 & \\
\hline \multirow{3}{*}{ Inicial } & \multirow{3}{*}{ GII-F x GII-M } & Média & 99,1 & 96,7 & \multirow{3}{*}{0,241} \\
\hline & & Desvio-padrão & 5,3 & 14,5 & \\
\hline & & $\mathrm{n}$ & 63 & 55 & \\
\hline \multirow{3}{*}{ Medial } & \multirow{3}{*}{ GI-F x GI-M } & Média & 87,1 & 80,3 & \multirow{3}{*}{0,356} \\
\hline & & Desvio-padrão & 20,8 & 34,7 & \\
\hline & & $\mathrm{n}$ & 33 & 31 & \\
\hline \multirow{3}{*}{ Medial } & \multirow{3}{*}{ GII-F x GII-M } & Média & 92,3 & 91,2 & \multirow{3}{*}{0,774} \\
\hline & & Desvio-padrão & 14,3 & 20,8 & \\
\hline & & $\mathrm{n}$ & 41 & 36 & \\
\hline \multirow{3}{*}{ Final } & \multirow{3}{*}{ GI-F x GI-M } & Média & 97,1 & 97,7 & \multirow{3}{*}{0,737} \\
\hline & & Desvio-padrão & 10,8 & 8,6 & \\
\hline & & $\mathrm{n}$ & 54 & 45 & \\
\hline \multirow{3}{*}{ Final } & \multirow{3}{*}{ GII-F x GII-M } & Média & 98,9 & 98,3 & \multirow{3}{*}{0,531} \\
\hline & & Desvio-padrão & 5,8 & 5,3 & \\
\hline & & $\mathrm{n}$ & 63 & 56 & \\
\hline
\end{tabular}


Tabela 22 - Diferença entre os gêneros para a estrutura CV na imitação.

\begin{tabular}{|c|c|c|c|c|c|}
\hline Sílaba & Grupo & estatística & Feminino & Masculino & teste $t(p)$ \\
\hline \multirow{3}{*}{ Inicial } & \multirow{3}{*}{ GI-F x GI-M } & Média & 90,0 & 85,7 & \multirow{3}{*}{0,328} \\
\hline & & Desvio-padrão & 14,5 & 24,4 & \\
\hline & & $n$ & 46 & 36 & \\
\hline \multirow{3}{*}{ Inicial } & \multirow{3}{*}{ GII-F x GII-M } & Média & 95,6 & 92,0 & \multirow{3}{*}{0,132} \\
\hline & & Desvio-padrão & 6,5 & 15,0 & \\
\hline & & $\mathrm{n}$ & 48 & 46 & \\
\hline \multirow{3}{*}{ Medial } & \multirow{3}{*}{ GI-F x GI-M } & Média & 93,6 & 92,9 & \multirow{3}{*}{0,719} \\
\hline & & Desvio-padrão & 5,0 & 6,7 & \\
\hline & & $\mathrm{n}$ & 23 & 18 & \\
\hline \multirow{3}{*}{ Medial } & \multirow{3}{*}{ GII-F x GII-M } & Média & 95,8 & 95,3 & \multirow{3}{*}{0,714} \\
\hline & & Desvio-padrão & 5,1 & 4,5 & \\
\hline & & $\mathrm{n}$ & 24 & 23 & \\
\hline \multirow{3}{*}{ Final } & \multirow{3}{*}{ Gl-F x GI-M } & Média & 95,3 & 94,6 & \multirow{3}{*}{0,633} \\
\hline & & Desvio-padrão & 6,4 & 6,7 & \\
\hline & & $\mathrm{n}$ & 46 & 36 & \\
\hline \multirow{3}{*}{ Final } & \multirow{3}{*}{ GII-F x GII-M } & Média & 96,4 & 94,2 & \multirow{3}{*}{0,058} \\
\hline & & Desvio-padrão & 5,3 & 5,9 & \\
\hline & & $\mathrm{n}$ & 48 & 46 & \\
\hline
\end{tabular}

Tabela 23 - Diferença entre os gêneros para a estrutura CV na nomeação

\begin{tabular}{|c|c|c|c|c|c|}
\hline Sílaba & Grupo & estatística & Feminino & Masculino & teste $t(p)$ \\
\hline \multirow{3}{*}{ Inicial } & \multirow{3}{*}{ GI-F x GI-M } & Média & 92,3 & 94,1 & \multirow{3}{*}{0,496} \\
\hline & & Desvio-padrão & 12,4 & 10,8 & \\
\hline & & $\mathrm{n}$ & 46 & 36 & \\
\hline \multirow{3}{*}{ Inicial } & \multirow{3}{*}{ GII-F x Gll-M } & Média & 97,5 & 95,2 & \multirow{3}{*}{0,185} \\
\hline & & Desvio-padrão & 6,4 & 9,9 & \\
\hline & & $\mathrm{n}$ & 48 & 46 & \\
\hline \multirow{3}{*}{ Medial } & \multirow{3}{*}{ Gl-F x Gl-M } & Média & 92,5 & 88,3 & \multirow{3}{*}{0,302} \\
\hline & & Desvio-padrão & 12,0 & 13,8 & \\
\hline & & $\mathrm{n}$ & 23 & 18 & \\
\hline \multirow{3}{*}{ Medial } & \multirow{3}{*}{ GII-F x Gll-M } & Média & 94,5 & 87,7 & \multirow{3}{*}{0,058} \\
\hline & & Desvio-padrão & 9,3 & 14,0 & \\
\hline & & $\mathrm{n}$ & 24 & 23 & \\
\hline \multirow{3}{*}{ Final } & \multirow{3}{*}{ GI-F x GI-M } & Média & 90,2 & 91,4 & \multirow{3}{*}{0,072} \\
\hline & & Desvio-padrão & 15,6 & 13,2 & \\
\hline & & $\mathrm{n}$ & 46 & 36 & \\
\hline \multirow{3}{*}{ Final } & \multirow{3}{*}{ GII-F x GII-M } & Média & 96,4 & 91,7 & \multirow{3}{*}{0,070} \\
\hline & & Desvio-padrão & 8,7 & 15,0 & \\
\hline & & $\mathrm{n}$ & 48 & 46 & \\
\hline
\end{tabular}




\section{$\underline{\mathrm{CCV}}$}

Apesar de haver alvo em quase todas as posições de sílaba na fala espontânea, somente em sílaba inicial, foi possível comparação. Não houve diferença entre meninos e meninas, das duas faixas etárias, quanto à porcentagem de acerto (Tabela 24).

Tabela 24 - Diferença entre os gêneros para a estrutura CCV na fala espontânea.

\begin{tabular}{|c|c|c|c|c|c|}
\hline Sílaba & Grupo & estatística & Feminino & Masculino & teste $t(p)$ \\
\hline Inicial & GI-F x GI-M & $\begin{array}{c}\text { Média } \\
\text { Desvio-padrão } \\
\mathrm{n}\end{array}$ & $\begin{array}{c}15,0 \\
36,6 \\
20\end{array}$ & $\begin{array}{c}11,1 \\
30,0 \\
15\end{array}$ & 0,740 \\
\hline Inicial & GII-F x GII-M & $\begin{array}{c}\text { Média } \\
\text { Desvio-padrão } \\
\mathrm{n}\end{array}$ & $\begin{array}{c}16,7 \\
36,5 \\
21\end{array}$ & $\begin{array}{c}9,5 \\
26,1 \\
21\end{array}$ & 0,470 \\
\hline Medial & GI-F x GI-M & $\begin{array}{c}\text { Média } \\
\text { Desvio-padrão } \\
\mathrm{n}\end{array}$ & $\begin{array}{c}0,0 \\
-- \\
1\end{array}$ & $\begin{array}{c}0,0 \\
0,0 \\
0\end{array}$ & não analisado \\
\hline Medial & GII-F x Gll-M & $\begin{array}{c}\text { Média } \\
\text { Desvio-padrão } \\
\mathrm{n}\end{array}$ & $\begin{array}{c}0,0 \\
-- \\
1\end{array}$ & $\begin{array}{c}0,0 \\
--- \\
1\end{array}$ & não analisado \\
\hline Final & GI-F x GI-M & $\begin{array}{c}\text { Média } \\
\text { Desvio-padrão } \\
\mathrm{n}\end{array}$ & $\begin{array}{c}0,0 \\
0,0 \\
0\end{array}$ & $\begin{array}{c}0,0 \\
0,0 \\
0\end{array}$ & não analisado \\
\hline Final & GII-F x Gll-M & $\begin{array}{c}\text { Média } \\
\text { Desvio-padrão } \\
n\end{array}$ & $\begin{array}{c}0,0 \\
0,0 \\
0\end{array}$ & $\begin{array}{c}50,0 \\
70,7 \\
2\end{array}$ & não analisado \\
\hline
\end{tabular}

$\mathrm{Na}$ imitação (Tabela 25), os gêneros foram comparados apenas em sílaba inicial, ressaltando-se que, nesta prova, os encontros consonantais apareciam apenas nesta posição. Do mesmo modo, na fala espontânea, a porcentagem de acerto foi estatisticamente igual entre meninos e meninas nas duas faixas etárias.

Tabela 25 - Diferença entre os gêneros para a estrutura CCV na imitação.

\begin{tabular}{|c|c|c|c|c|c|}
\hline Sílaba & Grupo & estatística & Feminino & Masculino & teste $t(p)$ \\
\hline \multirow{3}{*}{ Inicial } & \multirow{3}{*}{ GI-F x GI-M } & Média & 8,4 & 13,5 & \multirow{3}{*}{0,256} \\
\hline & & Desvio-padrão & 21,3 & 27,8 & \\
\hline & & $\mathrm{n}$ & 68 & 54 & \\
\hline \multirow{3}{*}{ Inicial } & \multirow{3}{*}{ GII-F x Gll-M } & Média & 16,7 & 20,0 & \multirow{3}{*}{0,525} \\
\hline & & Desvio-padrão & 29,5 & 33,5 & \\
\hline & & $\mathrm{n}$ & 72 & 69 & \\
\hline
\end{tabular}


Em relação à nomeação, os gêneros foram comparados em sílaba inicial nas duas faixas etárias e, em final, nas crianças mais velhas (Tabela 26). Também não foi observada diferença estatística entre meninos e meninas.

Tabela 26 - Diferença entre os gêneros para a estrutura CCV na nomeação.

\begin{tabular}{|c|c|c|c|c|c|}
\hline Sílaba & Grupo & estatística & Feminino & Masculino & teste $t(p)$ \\
\hline \multirow{3}{*}{ Inicial } & \multirow{3}{*}{ GI-F x GI-M } & Média & 8,1 & 13,7 & \multirow{3}{*}{0,457} \\
\hline & & Desvio-padrão & 26,1 & 34,0 & \\
\hline & & $\mathrm{n}$ & 31 & 34 & \\
\hline \multirow{3}{*}{ Inicial } & \multirow{3}{*}{ GII-F x Gll-M } & Média & 22,2 & 12,4 & \multirow{3}{*}{0,230} \\
\hline & & Desvio-padrão & 38,8 & 30,5 & \\
\hline & & $\mathrm{n}$ & 36 & 39 & \\
\hline \multirow{3}{*}{ Final } & \multirow{3}{*}{ GI-F x GI-M } & Média & 42,9 & 22,2 & \multirow{3}{*}{ não analisado } \\
\hline & & Desvio-padrão & 53,5 & 44,1 & \\
\hline & & $\mathrm{n}$ & 7 & 9 & \\
\hline \multirow{3}{*}{ Final } & \multirow{3}{*}{ GII-F x GII-M } & Média & 20,0 & 23,1 & \multirow{3}{*}{0,850} \\
\hline & & Desvio-padrão & 41,4 & 43,9 & \\
\hline & & $\mathrm{n}$ & 15 & 13 & \\
\hline
\end{tabular}

$\underline{\text { CVC }}$

Na estrutura CVC em fala espontânea (Tabela 27), a comparação foi realizada apenas em sílaba final. Nesta, meninos e meninas obtiveram porcentagem de acerto estatisticamente igual, tanto no grupo mais velho, como no mais novo.

Tabela 27 - Diferença entre os gêneros para a estrutura CVC na fala espontânea

\begin{tabular}{|c|c|c|c|c|c|}
\hline Sílaba & Grupo & estatística & Feminino & Masculino & teste t $(p)$ \\
\hline \multirow{3}{*}{ Inicial } & \multirow{3}{*}{ GI-F x Gl-M } & Média & 14,3 & 50,0 & \multirow{3}{*}{ não analisado } \\
\hline & & Desvio-padrão & 37,8 & 70,7 & \\
\hline & & $\mathrm{N}$ & 7 & 2 & \\
\hline \multirow{3}{*}{ Inicial } & \multirow{3}{*}{ GII-F x GII-M } & Média & 60,0 & 22,2 & \multirow{3}{*}{ não analisado } \\
\hline & & Desvio-padrão & 51,6 & 36,3 & \\
\hline & & $\mathrm{N}$ & 10 & 9 & \\
\hline \multirow{3}{*}{ Medial } & \multirow{3}{*}{ GI-F x Gl-M } & Média & 0,0 & 0,0 & \multirow{3}{*}{ não analisado } \\
\hline & & Desvio-padrão & 0,0 & -- & \\
\hline & & $\mathrm{N}$ & 2 & 1 & \\
\hline \multirow{3}{*}{ Medial } & \multirow{3}{*}{ GII-F x Gll-M } & Média & 14,3 & 50,0 & \multirow{3}{*}{ não analisado } \\
\hline & & Desvio-padrão & 37,8 & 57,7 & \\
\hline & & $\mathrm{N}$ & 7 & 4 & \\
\hline \multirow{3}{*}{ Final } & \multirow{3}{*}{ GI-F x Gl-M } & Média & 0,0 & 11,1 & \multirow{3}{*}{0,163} \\
\hline & & Desvio-padrão & 0,0 & 32,3 & \\
\hline & & $\mathrm{N}$ & 20 & 18 & \\
\hline \multirow{3}{*}{ Final } & \multirow{3}{*}{ GII-F x GII-M } & Média & 10,3 & 10,5 & \multirow{3}{*}{0,982} \\
\hline & & Desvio-padrão & 25,0 & 31,5 & \\
\hline & & $\mathrm{N}$ & 21 & 19 & \\
\hline
\end{tabular}


$\mathrm{Na}$ imitação, tanto em sílaba inicial como em final, crianças de gêneros diferentes da mesma faixa etária obtiveram porcentagem de acerto igual (Tabela 28).

Tabela 28 - Diferença entre os gêneros para a estrutura CVC na imitação.

\begin{tabular}{|c|c|c|c|c|c|}
\hline Sílaba & Grupo & estatística & Feminino & Masculino & teste $t(p)$ \\
\hline \multirow{3}{*}{ Inicial } & \multirow{3}{*}{ GI-F x Gl-M } & Média & 7,5 & 13,0 & \multirow{3}{*}{0,331} \\
\hline & & Desvio-padrão & 26,5 & 33,9 & \\
\hline & & $\mathrm{N}$ & 67 & 54 & \\
\hline \multirow{3}{*}{ Inicial } & \multirow{3}{*}{ GII-F x GII-M } & Média & 31,9 & 29,9 & \multirow{3}{*}{0,791} \\
\hline & & Desvio-padrão & 47,0 & 46,1 & \\
\hline & & $\mathrm{N}$ & 72 & 67 & \\
\hline \multirow{3}{*}{ Final } & \multirow{3}{*}{ GI-F x Gl-M } & Média & 29,5 & 19,4 & \multirow{3}{*}{0,299} \\
\hline & & Desvio-padrão & 46,2 & 40,1 & \\
\hline & & $\mathrm{N}$ & 44 & 36 & \\
\hline \multirow{3}{*}{ Final } & \multirow{3}{*}{ Gll-F x Gll-M } & Média & 45,8 & 43,2 & \multirow{3}{*}{0,801} \\
\hline & & Desvio-padrão & 50,4 & 50,1 & \\
\hline & & $\mathrm{N}$ & 48 & 44 & \\
\hline
\end{tabular}

Na nomeação (Tabela 29), havia alvo em sílaba inicial e final. Porém, em sílaba final não pôde ser realizada comparação devido ao número insuficiente de alvos. Na sílaba inicial, para as duas faixas etárias, não houve diferença entre os gêneros.

Tabela 29 - Diferença entre os gêneros para a estrutura CVC, nomeação.

\begin{tabular}{|c|c|c|c|c|c|}
\hline Sílaba & Grupo & estatística & Feminino & Masculino & teste $t(p)$ \\
\hline \multirow{3}{*}{ Inicial } & \multirow{3}{*}{ Gl-F x Gl-M } & Média & 13,6 & 23,5 & \multirow{3}{*}{0,438} \\
\hline & & Desvio-padrão & 35,1 & 43,7 & \\
\hline & & $\mathrm{N}$ & 22 & 17 & \\
\hline \multirow{3}{*}{ Inicial } & \multirow{3}{*}{ Gll-F x Gll-M } & Média & 35,1 & 29,7 & \multirow{3}{*}{0,625} \\
\hline & & Desvio-padrão & 48,4 & 46,3 & \\
\hline & & $\mathrm{N}$ & 37 & 37 & \\
\hline \multirow{3}{*}{ Final } & \multirow{3}{*}{ GI-F x GI-M } & Média & 0,0 & 0,0 & \multirow{3}{*}{ não analisado } \\
\hline & & Desvio-padrão & 0,0 & 0,0 & \\
\hline & & $\mathrm{N}$ & 4 & 8 & \\
\hline \multirow{3}{*}{ Final } & \multirow{3}{*}{ GII-F x Gll-M } & Média & 11,1 & 10,0 & \multirow{3}{*}{ não analisado } \\
\hline & & Desvio-padrão & 33,3 & 28,0 & \\
\hline & & $\mathrm{N}$ & 9 & 15 & \\
\hline
\end{tabular}

Como os resultados não evidenciaram diferenças significantes entre os gêneros da mesma faixa etária, o GI-F foi agrupado com o Gl-M e o Gll-F com o GllM. Assim, as análises que seguem nesta pesquisa serão realizadas apenas com dois grupos de faixas etárias diferentes, crianças mais novas (GI), de 2:1 a 2:6 anos e crianças mais velhas (GII), de 2:7 a 3:0 anos. 


\section{HIPÓTESE 3 - CRIANÇAS MAIS VELHAS APRESENTAM MAIS ACERTOS QUE AS MAIS NOVAS EM RELAÇÃO A ENCONTROS CONSONANTAIS, FONEMAS E ESTRUTURAS SILÁBICAS.}

\section{HIPÓTESE PARCIALMENTE CONFIRMADA}

Para a comparação entre as faixas etárias, foram realizados dois tipos de análise. O primeiro comparou os dois grupos quanto aos acertos totais em encontros consonantais, fonemas e estruturas silábicas, CV, CCV e CVC. Num segundo momento, os grupos foram comparados para acertos em cada um dos encontros consonantais, fonemas e estruturas silábicas. Para esta última análise, as comparações foram realizadas, considerando a extensão da palavra e na estrutura CCV, se o alvo era com líquida /// ou /P/ e na estrutura CVC, se era com arquifonema /S/ ou /R/.

\section{- Encontros consonantais}

Quanto aos encontros consonantais, em fala espontânea, crianças mais novas tiveram porcentagem de acerto estatisticamente igual às mais velhas, nas sílabas inicial e medial. Em sílaba final, não houve número de alvo suficiente para comparação (Tabela 30).

Tabela 30 - Comparação entre as faixas etárias para encontros consonantais na fala espontânea.

\begin{tabular}{|c|c|c|c|c|}
\hline sílaba & estatística & Gl & Gll & teste t $(p)$ \\
\hline \multirow{3}{*}{ Inicial } & Média & 18,9 & 8,6 & \multirow{2}{*}{0,260} \\
\cline { 2 - 4 } & Desvio-padrão & 37,2 & 25,7 & \\
\cline { 2 - 4 } & $\mathrm{n}$ & 22 & 35 & \\
\hline \multirow{3}{*}{ Medial } & Média & 0,0 & 8,3 & \multirow{2}{*}{0,339} \\
\cline { 2 - 4 } & Desvio-padrão & 0,0 & 28,9 & \multirow{2}{*}{ não analisado } \\
\cline { 2 - 4 } & $\mathrm{n}$ & 15 & 12 & \\
\hline \multirow{3}{*}{ Final } & Média & --- & 33,3 & \multicolumn{2}{|c}{} \\
\cline { 2 - 4 } & Desvio-padrão & --- & 57,7 & \\
\cline { 2 - 4 } & $\mathrm{n}$ & --- & 3 & \\
\hline
\end{tabular}

Analisando os encontros consonantais separadamente, apenas os encontros /bP/ e /pP/, em sílaba inicial, e /kl/, em sílaba medial, tiveram comparação entre o Gl 
e o Gll. Em todas estas análises, os grupos tiveram porcentagem de acerto estatisticamente igual (Tabela 31).

Tabela 31 - Comparação entre as faixas etárias para cada encontro consonantal na fala espontânea.

\begin{tabular}{|c|c|c|c|c|c|}
\hline Encontro & sílaba & estatística & $\mathrm{Gl}$ & GII & Teste t (p) \\
\hline \multirow{9}{*}{ br } & \multirow{3}{*}{ Inicial } & Média & 18,75 & 0,00 & \multirow{3}{*}{ não analisado } \\
\hline & & Desvio-padrão & 37,20 & 0,00 & \\
\hline & & $\mathrm{n}$ & 8 & 12 & \\
\hline & \multirow{3}{*}{ Medial } & Média & 0,00 & 0,00 & \multirow{3}{*}{ não analisado } \\
\hline & & Desvio-padrão & --- & --- & \\
\hline & & $\mathrm{n}$ & 1 & 1 & \\
\hline & \multirow{3}{*}{ Final } & Média & --- & 100,00 & \multirow{3}{*}{ não analisado } \\
\hline & & Desvio-padrão & --- & --- & \\
\hline & & $\mathrm{n}$ & --- & 1 & \\
\hline \multirow{6}{*}{ dr } & \multirow{3}{*}{ Medial } & Média & --- & 0,00 & \multirow{3}{*}{ não analisado } \\
\hline & & Desvio-padrão & --- & --- & \\
\hline & & $\mathrm{n}$ & --- & 1 & \\
\hline & \multirow{3}{*}{ Final } & Média & --- & 0,00 & \multirow{3}{*}{ não analisado } \\
\hline & & Desvio-padrão & --- & --- & \\
\hline & & $\mathrm{n}$ & --- & 1 & \\
\hline \multirow{3}{*}{$\mathrm{fl}$} & \multirow{3}{*}{ Inicial } & Média & 25,00 & 0,00 & \multirow{3}{*}{ não analisado } \\
\hline & & Desvio-padrão & 50,00 & 0,00 & \\
\hline & & $\mathrm{n}$ & 4 & 2 & \\
\hline \multirow{3}{*}{$\mathrm{kl}$} & \multirow{3}{*}{ Medial } & Média & 0,00 & 10,00 & \multirow{3}{*}{0,343} \\
\hline & & Desvio-padrão & 0,00 & 31,62 & \\
\hline & & $\mathrm{n}$ & 14 & 10 & \\
\hline \multirow{3}{*}{$\mathrm{kr}$} & \multirow{3}{*}{ Inicial } & Média & --- & 0,00 & \multirow{3}{*}{ não analisado } \\
\hline & & Desvio-padrão & --- & --- & \\
\hline & & $\mathrm{n}$ & --- & 1 & \\
\hline \multirow{3}{*}{ pl } & \multirow{3}{*}{ Inicial } & Média & --- & 0,00 & \multirow{3}{*}{ não analisado } \\
\hline & & Desvio-padrão & --- & --- & \\
\hline & & $\mathrm{n}$ & --- & 1 & \\
\hline \multirow{3}{*}{ pr } & \multirow{3}{*}{ Inicial } & Média & 16,67 & 17,65 & \multirow{3}{*}{0,946} \\
\hline & & Desvio-padrão & 36,00 & 35,09 & \\
\hline & & $\mathrm{n}$ & 10 & 17 & \\
\hline \multirow{6}{*}{$\operatorname{tr}$} & & Média & --- & 0,00 & \\
\hline & Inicial & Desvio-padrão & --- & 0,00 & não analisado \\
\hline & & $\mathrm{n}$ & --- & 2 & \\
\hline & & Média & --- & 0,00 & \\
\hline & Final & Desvio-padrão & --- & --- & não analisado \\
\hline & & $\mathrm{n}$ & --- & 1 & \\
\hline
\end{tabular}

$\mathrm{Na}$ prova de imitação havia alvo apenas em sílaba inicial, sendo que as crianças mais velhas tiveram, estatisticamente, maior número de acerto que as mais novas $(p=0,002)$. 
Em todas as comparações realizadas entre o Gl e o Gll quanto aos encontros separadamente, os grupos foram estatisticamente iguais, com exceção do /fP/. Nesta, as crianças do Gl tiveram média de acerto estatisticamente menor que as do Gll (Tabela 32).

Tabela 32 - Comparação entre as faixas etárias para cada encontro consonantal na imitação.

\begin{tabular}{|c|c|c|c|c|c|}
\hline Encontro & sílaba & estatística & GI & GII & Teste t (p) \\
\hline \multirow{3}{*}{$\mathrm{bl}$} & \multirow{3}{*}{ Inicial } & Média & 7,50 & 12,77 & \multirow{3}{*}{0,427} \\
\hline & & Desvio-padrão & 26,67 & 33,73 & \\
\hline & & $\mathrm{n}$ & 40 & 47 & \\
\hline \multirow{3}{*}{$\mathrm{br}$} & \multirow{3}{*}{ Inicial } & Média & 17,07 & 21,28 & \multirow{3}{*}{0,623} \\
\hline & & Desvio-padrão & 38,09 & 41,37 & \\
\hline & & $\mathrm{n}$ & 41 & 47 & \\
\hline \multirow{3}{*}{$\mathrm{dr}$} & \multirow{3}{*}{ Inicial } & Média & 7,50 & 19,15 & \multirow{3}{*}{0,108} \\
\hline & & Desvio-padrão & 26,67 & 39,77 & \\
\hline & & $\mathrm{n}$ & 40 & 47 & \\
\hline \multirow{3}{*}{$\mathrm{fl}$} & \multirow{3}{*}{ Inicial } & Média & 2,63 & 2,17 & \multirow{3}{*}{0,893} \\
\hline & & Desvio-padrão & 16,22 & 14,74 & \\
\hline & & $\mathrm{n}$ & 38 & 46 & \\
\hline \multirow{3}{*}{$\mathrm{fr}$} & \multirow{3}{*}{ Inicial } & Média & 2,56 & 21,28 & \multirow{3}{*}{0,006 * } \\
\hline & & Desvio-padrão & 16,01 & 41,37 & \\
\hline & & $\mathrm{n}$ & 39 & 47 & \\
\hline \multirow{3}{*}{ gl } & \multirow{3}{*}{ Inicial } & Média & 10,26 & 19,57 & \multirow{3}{*}{0,230} \\
\hline & & Desvio-padrão & 30,74 & 40,11 & \\
\hline & & $\mathrm{n}$ & 39 & 46 & \\
\hline \multirow{3}{*}{ gr } & \multirow{3}{*}{ Inicial } & Média & 17,95 & 14,89 & \multirow{3}{*}{0,706} \\
\hline & & Desvio-padrão & 38,88 & 35,99 & \\
\hline & & $\mathrm{n}$ & 39 & 47 & \\
\hline \multirow{3}{*}{$\mathrm{kl}$} & \multirow{3}{*}{ Inicial } & Média & 7,89 & 10,87 & \multirow{3}{*}{0,649} \\
\hline & & Desvio-padrão & 27,33 & 31,47 & \\
\hline & & $\mathrm{n}$ & 38 & 46 & \\
\hline \multirow{3}{*}{$\mathrm{kr}$} & \multirow{3}{*}{ Inicial } & Média & 2,56 & 17,02 & \multirow{3}{*}{0,021 * } \\
\hline & & Desvio-padrão & 16,01 & 37,99 & \\
\hline & & $\mathrm{n}$ & 39 & 47 & \\
\hline \multirow{3}{*}{$\mathrm{pl}$} & & Média & 5,26 & 6,67 & \\
\hline & Inicial & Desvio-padrão & 22,63 & 25,23 & 0,792 \\
\hline & & $\mathrm{n}$ & 38 & 45 & \\
\hline & & Média & 14,63 & 21,28 & \\
\hline $\mathrm{pr}$ & Inicial & Desvio-padrão & 35,78 & 41,37 & 0,426 \\
\hline & & $\mathrm{n}$ & 41 & 47 & \\
\hline & & Média & 4,88 & 8,51 & \\
\hline $\operatorname{tr}$ & Inicial & Desvio-padrão & 21,81 & 28,21 & 0,506 \\
\hline & & $\mathrm{n}$ & 41 & 47 & \\
\hline
\end{tabular}

Já na nomeação (Tabela 33), nas sílabas inicial e final, as crianças de faixas etárias diferentes tiveram porcentagem de acerto estatisticamente igual. Vale 
ressaltar que a média de acerto das crianças mais novas na sílaba final foi maior que a das mais velhas.

Tabela 33 - Comparação entre as faixas etárias para encontros na nomeação.

\begin{tabular}{|c|c|c|c|c|}
\hline sílaba & estatística & Gl & Gll & teste $t(p)$ \\
\hline \multirow{3}{*}{ Inicial } & Média & 9,7 & 12,8 & \multirow{2}{*}{0,464} \\
\cline { 2 - 4 } & Desvio-padrão & 29,8 & 33,5 & \\
\cline { 2 - 4 } & $\mathrm{n}$ & 103 & 133 & \\
\hline \multirow{3}{*}{ Final } & Média & 29,4 & 17,2 & \multirow{2}{*}{0,345} \\
\cline { 2 - 4 } & Desvio-padrão & 47,0 & 38,4 & \multirow{2}{*}{29} \\
\cline { 2 - 4 } & $\mathrm{n}$ & 17 & 29 \\
\hline
\end{tabular}

Analisando cada encontro consonantal, as crianças das duas faixas etárias tiveram média de acerto estatisticamente igual em todos (Tabela 34).

Tabela 34 - Comparação entre as faixas etárias para cada encontro consonantal na nomeação.

\begin{tabular}{|c|c|c|c|c|c|}
\hline Encontro & sílaba & estatística & GI & GII & Teste $t(p)$ \\
\hline \multirow{3}{*}{ bl } & & Média & 7,69 & 11,76 & \multirow{3}{*}{0,724} \\
\hline & Inicial & Desvio-padrão & 27,74 & 33,21 & \\
\hline & & $n$ & 13 & 17 & \\
\hline \multirow{6}{*}{$\mathrm{br}$} & & Média & 10,00 & 16,67 & \multirow{3}{*}{0,427} \\
\hline & Inicial & Desvio-padrão & 30,51 & 37,72 & \\
\hline & & $\mathrm{n}$ & 30 & 42 & \\
\hline & & Média & 50,00 & 0,00 & \multirow{3}{*}{ não analisado } \\
\hline & Final & Desvio-padrão & 70,71 & -- & \\
\hline & & $\mathrm{n}$ & 2 & 1 & \\
\hline \multirow{3}{*}{$\mathrm{kr}$} & & Média & --- & 0,00 & \multirow{3}{*}{ não analisado } \\
\hline & Inicial & Desvio-padrão & --- & 0,00 & \\
\hline & & $\mathrm{n}$ & --- & 3 & \\
\hline \multirow{3}{*}{$\mathrm{pl}$} & & Média & 16,67 & 9,52 & \multirow{3}{*}{0,476} \\
\hline & Inicial & Desvio-padrão & 37,90 & 30,08 & \\
\hline & & $\mathrm{n}$ & 30 & 21 & \\
\hline \multirow{3}{*}{ pr } & & Média & 4,76 & 12,50 & \multirow{3}{*}{0,355} \\
\hline & Inicial & Desvio-padrão & 21,82 & 33,60 & \\
\hline & & $\mathrm{n}$ & 21 & 32 & \\
\hline \multirow{3}{*}{$\operatorname{tr}$} & & Média & 0,00 & 11,11 & \multirow{3}{*}{ não analisado } \\
\hline & Inicial & Desvio-padrão & 0,00 & 32,34 & \\
\hline & & $\mathrm{n}$ & 9 & 18 & \\
\hline \multirow{3}{*}{$\mathrm{vr}$} & & Média & 26,67 & 17,86 & \multirow{3}{*}{0,510} \\
\hline & Final & Desvio-padrão & 45,77 & 39,00 & \\
\hline & & $\mathrm{n}$ & 15 & 28 & \\
\hline
\end{tabular}


- Fonemas

Nesta parte, os resultados serão apresentados por prova e por classe de fonemas.

\section{Fala espontânea}

As crianças mais novas apresentam porcentagem de acerto estatisticamente menor que as mais velhas em sílaba medial e final (Tabela 35).

Tabela 35 - Comparação entre as faixas etárias para fonemas na fala espontânea.

\begin{tabular}{|c|c|c|c|c|}
\hline sílaba & estatística & Gl & Gll & teste $t(p)$ \\
\hline \multirow{3}{*}{ Inicial } & Média & 78,8 & 81,1 & \multirow{3}{*}{0,480} \\
\hline & Desvio-padrão & 36,8 & 36,7 & \\
\hline & $\mathrm{n}$ & 221 & 303 & \\
\hline \multirow{3}{*}{ Medial } & Média & 68,3 & 81,6 & \multirow{3}{*}{$<0,001$ * } \\
\hline & Desvio-padrão & 43,9 & 37,1 & \\
\hline & $\mathrm{n}$ & 210 & 323 & \\
\hline \multirow{3}{*}{ Final } & Média & 68,4 & 76,3 & \multirow{3}{*}{0,008 * } \\
\hline & Desvio-padrão & 44,0 & 40,4 & \\
\hline & $\mathrm{n}$ & 345 & 473 & \\
\hline
\end{tabular}

Os dados a seguir mostram a comparação para cada um dos fonemas isoladamente.

- plosivas

Para todas as plosivas surdas e sonoras, o Gl teve porcentagem de acerto estatisticamente igual ao Gll, com exceção do fonema /d/, para o qual as crianças mais novas tiveram porcentagem de acerto estatisticamente menor que as mais velhas nas sílabas medial e final, únicas que tiveram comparação (Tabela 36). 
Tabela 36 - Comparação entre as faixas etárias para plosivas na fala espontânea.

\begin{tabular}{|c|c|c|c|c|c|}
\hline fonema & sílaba & estatística & $\mathrm{Gl}$ & GII & Teste t $(p)$ \\
\hline \multirow{6}{*}{ b } & \multirow{3}{*}{ Inicial } & Média & 83,25 & 92,14 & \multirow{3}{*}{0,083} \\
\hline & & Desvio-padrão & 22,93 & 19,65 & \\
\hline & & $\mathrm{n}$ & 35 & 37 & \\
\hline & \multirow{3}{*}{ Medial } & Média & 100,00 & 100,00 & \multirow{3}{*}{ não analisado } \\
\hline & & Desvio-padrão & 0,00 & 0,00 & \\
\hline & & $\mathrm{n}$ & 2 & 6 & \\
\hline \multirow{9}{*}{$\mathrm{p}$} & \multirow{3}{*}{ Inicial } & Média & 97,62 & 96,43 & \multirow{3}{*}{0,798} \\
\hline & & Desvio-padrão & 10,91 & 18,90 & \\
\hline & & $\mathrm{n}$ & 21 & 28 & \\
\hline & \multirow{3}{*}{ Medial } & Média & 100,00 & 100,00 & \multirow{3}{*}{1,000} \\
\hline & & Desvio-padrão & 0,00 & 0,00 & \\
\hline & & $\mathrm{n}$ & 10 & 21 & \\
\hline & \multirow{3}{*}{ Final } & Média & 88,89 & 97,62 & \multirow{3}{*}{ não analisado } \\
\hline & & Desvio-padrão & 33,33 & 10,91 & \\
\hline & & $\mathrm{n}$ & 9 & 21 & \\
\hline \multirow{9}{*}{ d } & \multirow{3}{*}{ Inicial } & Média & 100,00 & 100,00 & \multirow{3}{*}{ não analisado } \\
\hline & & Desvio-padrão & & 0,00 & \\
\hline & & $\mathrm{n}$ & 1 & 8 & \\
\hline & \multirow{3}{*}{ Medial } & Média & 71,18 & 94,12 & \multirow{3}{*}{0,021 * } \\
\hline & & Desvio-padrão & 41,77 & 23,88 & \\
\hline & & $\mathrm{n}$ & 24 & 34 & \\
\hline & \multirow{3}{*}{ Final } & Média & 78,40 & 95,04 & \multirow{3}{*}{0,048 * } \\
\hline & & Desvio-padrão & 39,71 & 17,24 & \\
\hline & & $\mathrm{n}$ & 27 & 41 & \\
\hline \multirow{9}{*}{$\mathrm{t}$} & \multirow{3}{*}{ Inicial } & Média & 77,27 & 87,50 & \multirow{3}{*}{0,487} \\
\hline & & Desvio-padrão & 41,01 & 34,16 & \\
\hline & & $\mathrm{n}$ & 11 & 16 & \\
\hline & \multirow{3}{*}{ Medial } & Média & 75,00 & 81,25 & \multirow{3}{*}{ não analisado } \\
\hline & & Desvio-padrão & 43,30 & 37,20 & \\
\hline & & $\mathrm{n}$ & 5 & 8 & \\
\hline & \multirow{3}{*}{ Final } & Média & 89,29 & 96,19 & \\
\hline & & Desvio-padrão & 28,41 & 17,66 & 0,267 \\
\hline & & $\mathrm{n}$ & 28 & 35 & \\
\hline & & Média & 66,67 & 100,00 & \\
\hline & Inicial & Desvio-padrão & 57,74 & 0,00 & não analisado \\
\hline & & $\mathrm{n}$ & 3 & 4 & \\
\hline & & Média & 64,29 & 72,22 & \\
\hline $\mathrm{g}$ & Medial & Desvio-padrão & 37,80 & 46,09 & não analisado \\
\hline & & $\mathrm{n}$ & 7 & 18 & \\
\hline & & Média & 95,45 & 92,86 & \\
\hline & Final & Desvio-padrão & 15,08 & 26,73 & 0,776 \\
\hline & & $n$ & 11 & 14 & \\
\hline
\end{tabular}


Continuação Tabela 36 - Comparação entre as faixas etárias para plosivas na fala espontânea

\begin{tabular}{|c|c|c|c|c|c|}
\hline fonema & sílaba & estatística & Gl & GII & Teste $\mathrm{t}(\mathrm{p})$ \\
\hline \multirow{9}{*}{ k } & \multirow{3}{*}{ Inicial } & Média & 90,49 & 89,27 & \multirow{3}{*}{0,820} \\
\hline & & Desvio-padrão & 22,55 & 25,43 & \\
\hline & & $\mathrm{n}$ & 38 & 45 & \\
\hline & \multirow{3}{*}{ Medial } & Média & 94,79 & 94,09 & \multirow{3}{*}{0,903} \\
\hline & & Desvio-padrão & 14,55 & 20,43 & \\
\hline & & $\mathrm{n}$ & 16 & 31 & \\
\hline & \multirow{3}{*}{ Final } & Média & 96,55 & 95,71 & \multirow{3}{*}{0,858} \\
\hline & & Desvio-padrão & 18,57 & 18,67 & \\
\hline & & $\mathrm{n}$ & 29 & 35 & \\
\hline
\end{tabular}

- fricativas

Somente para o fonema /z/ em sílaba final, houve diferença entre as faixas etárias, sendo que o Gl obteve porcentagem de acerto menor que o Gll (Tabela 37).

Tabela 37 - Comparação entre as faixas etárias para fricativas na fala espontânea.

\begin{tabular}{|c|c|c|c|c|c|}
\hline fonema & sílaba & estatística & GI & GII & Teste $t(p)$ \\
\hline \multirow{9}{*}{$\mathrm{v}$} & \multirow{3}{*}{ Inicial } & Média & 100,00 & 100,00 & \multirow{3}{*}{ não analisado } \\
\hline & & Desvio-padrão & 0,00 & 0,00 & \\
\hline & & $\mathrm{n}$ & 3 & 5 & \\
\hline & \multirow{3}{*}{ Medial } & Média & 75,00 & 100,00 & \multirow{3}{*}{ não analisadc } \\
\hline & & Desvio-padrão & 50,00 & 0,00 & \\
\hline & & $\mathrm{n}$ & 4 & 4 & \\
\hline & \multirow{3}{*}{ Final } & Média & 79,17 & 87,93 & \multirow{3}{*}{0,460} \\
\hline & & Desvio-padrão & 39,65 & 31,78 & \\
\hline & & $\mathrm{n}$ & 12 & 29 & \\
\hline \multirow{9}{*}{$f$} & \multirow{3}{*}{ Inicial } & Média & 90,91 & 89,58 & \multirow{3}{*}{0,893} \\
\hline & & Desvio-padrão & 20,23 & 29,41 & \\
\hline & & $\mathrm{n}$ & 11 & 24 & \\
\hline & \multirow{3}{*}{ Medial } & Média & --- & 100,00 & \multirow{3}{*}{ não analisadc } \\
\hline & & Desvio-padrão & --- & 0,00 & \\
\hline & & $\mathrm{n}$ & --- & 2 & \\
\hline & \multirow{3}{*}{ Final } & Média & 100,00 & 100,00 & \multirow{3}{*}{ não analisadc } \\
\hline & & Desvio-padrão & 0,00 & 0,00 & \\
\hline & & $\mathrm{n}$ & 8 & 11 & \\
\hline \multirow{6}{*}{ z } & \multirow{3}{*}{ Medial } & Média & 47,62 & 52,08 & \multirow{3}{*}{ não analisado } \\
\hline & & Desvio-padrão & 50,40 & 48,64 & \\
\hline & & $\mathrm{n}$ & 7 & 16 & \\
\hline & \multirow{3}{*}{ Final } & Média & 32,14 & 70,67 & \multirow{3}{*}{$0,007^{*}$} \\
\hline & & Desvio-padrão & 37,82 & 43,11 & \\
\hline & & $n$ & 14 & 25 & \\
\hline
\end{tabular}

continua 
Continuação Tabela 37 - Comparação entre as faixas etárias para fricativas na fala espontânea.

\begin{tabular}{|c|c|c|c|c|c|}
\hline fonema & sílaba & estatística & $\mathrm{Gl}$ & GII & Teste $t(p)$ \\
\hline \multirow{9}{*}{$\mathrm{s}$} & \multirow{3}{*}{ Inicial } & Média & $\begin{array}{ll}63,64 \\
\end{array}$ & 62,50 & \multirow{3}{*}{0,951} \\
\hline & & Desvio-padrão & 50,45 & 48,33 & \\
\hline & & $\mathrm{n}$ & 11 & 20 & \\
\hline & \multirow{3}{*}{ Medial } & Média & 43,33 & 63,16 & \multirow{3}{*}{0,211} \\
\hline & & Desvio-padrão & 49,52 & 41,04 & \\
\hline & & $\mathrm{n}$ & 15 & 19 & \\
\hline & \multirow{3}{*}{ Final } & Média & 75,00 & 77,65 & \multirow{3}{*}{0,849} \\
\hline & & Desvio-padrão & 42,74 & 38,78 & \\
\hline & & $n$ & 14 & 22 & \\
\hline \multirow{9}{*}{ Z } & \multirow{3}{*}{ Inicial } & Média & 50,00 & 75,00 & \multirow{3}{*}{ não analisado } \\
\hline & & Desvio-padrão & 50,00 & 50,00 & \\
\hline & & $n$ & 3 & 4 & \\
\hline & \multirow{3}{*}{ Medial } & Média & --- & 100,00 & \multirow{3}{*}{ não analisado } \\
\hline & & Desvio-padrão & --- & --- & \\
\hline & & $\mathrm{n}$ & --- & 1 & \\
\hline & \multirow{3}{*}{ Final } & Média & 25,00 & 60,71 & \multirow{3}{*}{ não analisado } \\
\hline & & Desvio-padrão & 41,83 & 44,63 & \\
\hline & & $\mathrm{n}$ & 6 & 14 & \\
\hline \multirow{9}{*}{$\Sigma$} & \multirow{3}{*}{ Inicial } & Média & 78,57 & 79,41 & \multirow{3}{*}{0,953} \\
\hline & & Desvio-padrão & 37,80 & 39,76 & \\
\hline & & $\mathrm{n}$ & 14 & 17 & \\
\hline & \multirow{3}{*}{ Medial } & Média & 100,00 & 100,00 & \multirow{3}{*}{ não analisado } \\
\hline & & Desvio-padrão & -- & -- & \\
\hline & & $\mathrm{n}$ & 1 & 1 & \\
\hline & \multirow{3}{*}{ Final } & Média & 80,00 & 84,62 & \multirow{3}{*}{0,746} \\
\hline & & Desvio-padrão & 41,40 & 31,52 & \\
\hline & & $\mathrm{n}$ & 15 & 13 & \\
\hline
\end{tabular}

- nasais

Para as nasais (Tabela 38), dentre as possíveis comparações realizadas entre Gl e Gll, somente o /n/, em sílaba medial, mostrou diferença entre os grupos, sendo que o grupo mais novo obteve porcentagem de acerto menor que o grupo mais velho. 
Tabela 38 - Comparação entre as faixas etárias para nasais na fala espontânea.

\begin{tabular}{|c|c|c|c|c|c|}
\hline fonema & sílaba & estatística & GI & GII & Teste $t(p)$ \\
\hline \multirow{9}{*}{$\mathrm{m}$} & \multirow{3}{*}{ Inicial } & Média & 96,00 & 100,00 & \multirow{3}{*}{0,327} \\
\hline & & Desvio-padrão & 20,00 & 0,00 & \\
\hline & & $\mathrm{n}$ & 25 & 33 & \\
\hline & \multirow{3}{*}{ Medial } & Média & 100,00 & 100,00 & \multirow{3}{*}{1,000} \\
\hline & & Desvio-padrão & 0,00 & 0,00 & \\
\hline & & $\mathrm{n}$ & 24 & 30 & \\
\hline & \multirow{3}{*}{ Final } & Média & 100,00 & 100,00 & \multirow{3}{*}{1,000} \\
\hline & & Desvio-padrão & 0,00 & 0,00 & \\
\hline & & $\mathrm{n}$ & 20 & 17 & \\
\hline \multirow{9}{*}{$\mathrm{n}$} & \multirow{3}{*}{ Inicial } & Média & 100,00 & 100,00 & \multirow{3}{*}{ não analisado } \\
\hline & & Desvio-padrão & 0,00 & 0,00 & \\
\hline & & $\mathrm{n}$ & 9 & 9 & \\
\hline & \multirow{3}{*}{ Medial } & Média & 77,22 & 96,25 & \multirow{3}{*}{0,014 * } \\
\hline & & Desvio-padrão & 38,53 & 13,33 & \\
\hline & & $\mathrm{n}$ & 30 & 36 & \\
\hline & \multirow{3}{*}{ Final } & Média & 100,00 & 100,00 & \multirow{3}{*}{1,000} \\
\hline & & Desvio-padrão & 0,00 & 0,00 & \\
\hline & & $\mathrm{n}$ & 12 & 19 & \\
\hline \multirow{6}{*}{$\mathrm{N}$} & \multirow{3}{*}{ Medial } & Média & 43,75 & 91,67 & \multirow{3}{*}{ não analisado } \\
\hline & & Desvio-padrão & 49,55 & 28,87 & \\
\hline & & $\mathrm{n}$ & 8 & 12 & \\
\hline & \multirow{3}{*}{ Final } & Média & 94,29 & 99,44 & \multirow{3}{*}{0,222} \\
\hline & & Desvio-padrão & 21,68 & 3,33 & \\
\hline & & $\mathrm{n}$ & 28 & 36 & \\
\hline
\end{tabular}

\section{- líquidas}

A única diferença estatística encontrada para as liquidas foi em relação ao /// em sílaba medial, na qual as crianças do Gl tiveram porcentagem de acerto menor que as do Gll (Tabela 39). 
Tabela 39 - Comparação entre as faixas etárias para líquidas na fala espontânea.

\begin{tabular}{|c|c|c|c|c|c|}
\hline fonema & sílaba & estatística & GI & GII & Teste $t(p)$ \\
\hline \multirow{9}{*}{1} & \multirow{3}{*}{ Inicial } & Média & 83,33 & 100,00 & \multirow{3}{*}{ não analisado } \\
\hline & & Desvio-padrão & 40,82 & 0,00 & \\
\hline & & $\mathrm{n}$ & 6 & 2 & \\
\hline & \multirow{3}{*}{ Medial } & Média & 73,02 & 95,83 & \multirow{3}{*}{0,039 * } \\
\hline & & Desvio-padrão & 44,25 & 20,41 & \\
\hline & & $\mathrm{n}$ & 21 & 24 & \\
\hline & \multirow{3}{*}{ Final } & Média & 88,24 & 96,83 & \multirow{3}{*}{0,332} \\
\hline & & Desvio-padrão & 33,21 & 14,55 & \\
\hline & & $\mathrm{n}$ & 17 & 21 & \\
\hline \multirow{6}{*}{$x$} & \multirow{3}{*}{ Medial } & Média & 0,00 & 20,83 & \multirow{3}{*}{ não analisado } \\
\hline & & Desvio-padrão & 0,00 & 39,65 & \\
\hline & & $\mathrm{n}$ & 3 & 12 & \\
\hline & \multirow{3}{*}{ Final } & Média & 15,52 & 15,67 & \multirow{3}{*}{0,985} \\
\hline & & Desvio-padrão & 30,19 & 32,45 & \\
\hline & & $\mathrm{n}$ & 29 & 30 & \\
\hline \multirow{6}{*}{$\mathrm{P}$} & \multirow{3}{*}{ Medial } & Média & 30,00 & 55,95 & \multirow{3}{*}{0,183} \\
\hline & & Desvio-padrão & 42,16 & 47,86 & \\
\hline & & $\mathrm{n}$ & 10 & 14 & \\
\hline & \multirow{3}{*}{ Final } & Média & 48,78 & 41,16 & \multirow{3}{*}{0,516} \\
\hline & & Desvio-padrão & 39,23 & 46,30 & \\
\hline & & $\mathrm{n}$ & 24 & 33 & \\
\hline
\end{tabular}

- fricativa velar

Houve comparação apenas em sílaba medial na fala espontânea. Apesar de 0 Gll ter tido média de acerto do /X/ superior ao Gl, não houve diferença estatística entre os grupos (Tabela 40).

Tabela 40 - Comparação entre as faixas etárias para fricativa velar na fala espontânea.

\begin{tabular}{|c|c|c|c|c|c|}
\hline fonema & sílaba & estatística & $\mathrm{Gl}$ & GII & Teste $t(p)$ \\
\hline \multirow{9}{*}{$x$} & \multirow{3}{*}{ Inicial } & Média & 60,00 & 33,33 & \multirow{3}{*}{ não analisado } \\
\hline & & Desvio-padrão & 54,77 & 51,64 & \\
\hline & & $\mathrm{n}$ & 5 & 6 & \\
\hline & \multirow{3}{*}{ Medial } & Média & 40,00 & 64,58 & \multirow{3}{*}{0,096} \\
\hline & & Desvio-padrão & 47,57 & 47,73 & \\
\hline & & $\mathrm{n}$ & 20 & 24 & \\
\hline & \multirow{3}{*}{ Final } & Média & 50,00 & 71,43 & \multirow{3}{*}{ não analisado } \\
\hline & & Desvio-padrão & 54,77 & 46,88 & \\
\hline & & $\mathrm{n}$ & 6 & 14 & \\
\hline
\end{tabular}


Não foram observadas diferenças estatísticas entre as crianças do Gl e do GII em nenhuma das comparações realizadas (Tabela 41).

Tabela 41 - Comparação entre as faixas etárias para arquifonemas na fala espontânea.

\begin{tabular}{|c|c|c|c|c|c|}
\hline arquifonema & sílaba & estatística & Gl & GII & Teste t (p) \\
\hline \multirow{9}{*}{$\mathrm{R}$} & \multirow{3}{*}{ Inicial } & Média & 14,29 & 22,81 & \multirow{3}{*}{0,523} \\
\hline & & Desvio-padrão & 36,31 & 38,17 & \\
\hline & & $\mathrm{n}$ & 14 & 19 & \\
\hline & \multirow{3}{*}{ Medial } & Média & 0,00 & 30,00 & \multirow{3}{*}{ não analisado } \\
\hline & & Desvio-padrão & 0,00 & 48,30 & \\
\hline & & $n$ & 3 & 10 & \\
\hline & \multirow{3}{*}{ Final } & Média & 0,86 & 7,50 & \multirow{3}{*}{0,120} \\
\hline & & Desvio-padrão & 4,64 & 22,36 & \\
\hline & & $\mathrm{n}$ & 29 & 30 & \\
\hline \multirow{6}{*}{$\mathrm{s}$} & \multirow{3}{*}{ Inicial } & Média & 27,50 & 48,91 & \multirow{3}{*}{0,184} \\
\hline & & Desvio-padrão & 38,10 & 47,36 & \\
\hline & & $\mathrm{n}$ & 10 & 23 & \\
\hline & \multirow{3}{*}{ Final } & Média & 75,00 & 70,00 & \multirow{3}{*}{ não analisado } \\
\hline & & Desvio-padrão & 50,00 & 42,16 & \\
\hline & & $\mathrm{n}$ & 4 & 10 & \\
\hline
\end{tabular}

\section{Imitação}

Nesta prova, agrupando todos os fonemas, as crianças do Gl tiveram desempenho estatisticamente pior que as do Gll em todas as posições de sílabas (Tabela 42) .

Tabela 42 - Comparação entre as faixas etárias para fonemas na imitação.

\begin{tabular}{|c|c|c|c|c|}
\hline sílaba & estatística & Gl & GII & teste $t(p)$ \\
\hline \multirow{3}{*}{ Inicial } & Média & 56,3 & 70,0 & \multirow{3}{*}{$<0,001$ * } \\
\hline & Desvio-padrão & 47,3 & 43,3 & \\
\hline & $\mathrm{n}$ & 734 & 845 & \\
\hline \multirow{3}{*}{ Medial } & Média & 67,3 & 75,8 & \multirow{3}{*}{0,003 * } \\
\hline & Desvio-padrão & 45,7 & 41,9 & \\
\hline & $\mathrm{n}$ & 443 & 517 & \\
\hline \multirow{3}{*}{ Final } & Média & 62,2 & 69,3 & \multirow{3}{*}{0,001 * } \\
\hline & Desvio-padrão & 45,5 & 43,6 & \\
\hline & $\mathrm{n}$ & 849 & 983 & \\
\hline
\end{tabular}


Os dados a seguir referem-se aos fonemas analisados separadamente.

- plosivas

Para todas as plosivas surdas e sonoras, o Gl teve porcentagem de acerto estatisticamente igual ao Gll, com exceção do fonema /b/, em sílaba inicial. Nesta, as crianças mais novas tiveram porcentagem de acerto estatisticamente menor que o Gll (Tabela 43).

Tabela 43 - Comparação entre as faixas etárias para plosivas na imitação.

\begin{tabular}{|c|c|c|c|c|c|}
\hline fonema & sílaba & estatística & $\mathrm{Gl}$ & GII & Teste $t(p)$ \\
\hline \multirow{9}{*}{ b } & \multirow{3}{*}{ inicial } & Média & 70,73 & 89,36 & \multirow{3}{*}{$0,007^{*}$} \\
\hline & & Desvio-padrão & 37,04 & 23,16 & \\
\hline & & $\mathrm{n}$ & 41 & 47 & \\
\hline & \multirow{3}{*}{ medial } & Média & 90,24 & 95,74 & \multirow{3}{*}{0,326} \\
\hline & & Desvio-padrão & 30,04 & 20,40 & \\
\hline & & $\mathrm{n}$ & 41 & 47 & \\
\hline & \multirow{3}{*}{ final } & Média & 73,08 & 72,83 & \multirow{3}{*}{0,976} \\
\hline & & Desvio-padrão & 37,78 & 39,02 & \\
\hline & & $\mathrm{n}$ & 39 & 46 & \\
\hline \multirow{9}{*}{$p$} & \multirow{3}{*}{ inicial } & Média & 82,93 & 89,36 & \multirow{3}{*}{0,215} \\
\hline & & Desvio-padrão & 28,01 & 18,53 & \\
\hline & & $\mathrm{n}$ & 41 & 47 & \\
\hline & \multirow{3}{*}{ medial } & Média & 94,74 & 97,87 & \multirow{3}{*}{0,442} \\
\hline & & Desvio-padrão & 22,63 & 14,59 & \\
\hline & & $\mathrm{n}$ & 38 & 47 & \\
\hline & \multirow{3}{*}{ final } & Média & 97,50 & 97,83 & \multirow{3}{*}{0,921} \\
\hline & & Desvio-padrão & 15,81 & 14,74 & \\
\hline & & $\mathrm{n}$ & 40 & 46 & \\
\hline \multirow{9}{*}{ d } & \multirow{3}{*}{ inicial } & Média & 73,17 & 76,60 & \multirow{3}{*}{0,715} \\
\hline & & Desvio-padrão & 44,86 & 42,80 & \\
\hline & & $\mathrm{n}$ & 41 & 47 & \\
\hline & \multirow{3}{*}{ medial } & Média & 72,50 & 87,23 & \multirow{3}{*}{0,094} \\
\hline & & Desvio-padrão & 45,22 & 33,73 & \\
\hline & & $\mathrm{n}$ & 40 & 47 & \\
\hline & \multirow{3}{*}{ final } & Média & 73,17 & 82,98 & \multirow{3}{*}{0,276} \\
\hline & & Desvio-padrão & 44,86 & 37,99 & \\
\hline & & $\mathrm{n}$ & 41 & 47 & \\
\hline \multirow{9}{*}{$\mathrm{t}$} & \multirow{3}{*}{ inicial } & Média & 75,61 & 87,23 & \multirow{3}{*}{0,170} \\
\hline & & Desvio-padrão & 43,48 & 33,73 & \\
\hline & & $\mathrm{n}$ & 41 & 47 & \\
\hline & \multirow{3}{*}{ medial } & Média & 63,82 & 75,89 & \multirow{3}{*}{0,072} \\
\hline & & Desvio-padrão & 32,04 & 30,06 & \\
\hline & & $\mathrm{n}$ & 41 & 47 & \\
\hline & \multirow{3}{*}{ final } & Média & 83,05 & 90,35 & \multirow{3}{*}{0,165} \\
\hline & & Desvio-padrão & 26,34 & 22,62 & \\
\hline & & $\mathrm{n}$ & 41 & 47 & \\
\hline
\end{tabular}

continua 
Continuação Tabela 43 - Comparação entre as faixas etárias para plosivas na imitação.

\begin{tabular}{|c|c|c|c|c|c|}
\hline fonema & sílaba & estatística & GI & GII & Teste $t(p)$ \\
\hline \multirow{9}{*}{ g } & \multirow{3}{*}{ inicial } & Média & 60,00 & 63,83 & \multirow{3}{*}{0,718} \\
\hline & & Desvio-padrão & 49,61 & 48,57 & \\
\hline & & $n$ & 40 & 47 & \\
\hline & \multirow{3}{*}{ medial } & Média & 67,50 & 82,98 & \multirow{3}{*}{0,101} \\
\hline & & Desvio-padrão & 47,43 & 37,99 & \\
\hline & & $\mathrm{n}$ & 40 & 47 & \\
\hline & \multirow{3}{*}{ final } & Média & 71,95 & 79,79 & \multirow{3}{*}{0,282} \\
\hline & & Desvio-padrão & 37,16 & 30,68 & \\
\hline & & $\mathrm{n}$ & 41 & 47 & \\
\hline \multirow{9}{*}{$\mathrm{k}$} & \multirow{3}{*}{ inicial } & Média & 86,99 & 89,36 & \multirow{3}{*}{0,627} \\
\hline & & Desvio-padrão & 23,43 & 22,10 & \\
\hline & & $n$ & 41 & 47 & \\
\hline & \multirow{3}{*}{ medial } & Média & 97,56 & 95,74 & \multirow{3}{*}{0,644} \\
\hline & & Desvio-padrão & 15,62 & 20,40 & \\
\hline & & $\mathrm{n}$ & 41 & 47 & \\
\hline & \multirow{3}{*}{ final } & Média & 91,67 & 90,71 & \multirow{3}{*}{0,801} \\
\hline & & Desvio-padrão & 17,28 & 18,03 & \\
\hline & & $\mathrm{n}$ & 41 & 47 & \\
\hline
\end{tabular}

- fricativas

Foram encontradas diferenças entre os grupos em sílaba inicial para os fonemas /s/, /f/ e /Z/, sendo que o Gl teve média de acerto menor que o Gll (Tabela 44). 
Tabela 44 - Comparação entre as faixas etárias para fricativas na imitação.

\begin{tabular}{|c|c|c|c|c|c|}
\hline fonema & sílaba & estatística & $\mathrm{Gl}$ & GII & Teste $\mathrm{t}(\mathrm{p})$ \\
\hline \multirow{9}{*}{ v } & \multirow{3}{*}{ inicial } & Média & 82,50 & 85,11 & \\
\hline & & Desvio-padrão & 38,48 & 35,99 & 0,745 \\
\hline & & $\mathrm{n}$ & 40 & 47 & \\
\hline & \multirow{3}{*}{ medial } & Média & 60,98 & 59,57 & \\
\hline & & Desvio-padrão & 49,39 & 49,61 & 0,895 \\
\hline & & $\mathrm{n}$ & 41 & 47 & \\
\hline & \multirow{3}{*}{ final } & Média & 70,73 & 76,60 & \\
\hline & & Desvio-padrão & 33,50 & 35,89 & 0,433 \\
\hline & & $\mathrm{n}$ & 41 & 47 & \\
\hline \multirow{9}{*}{$f$} & \multirow{3}{*}{ inicial } & Média & 55,00 & 82,98 & \\
\hline & & Desvio-padrão & 50,38 & 37,99 & $0,005^{*}$ \\
\hline & & $\mathrm{n}$ & 40 & 47 & \\
\hline & \multirow{3}{*}{ medial } & Média & 76,32 & 89,36 & \\
\hline & & Desvio-padrão & 43,09 & 31,17 & 0,122 \\
\hline & & $\mathrm{n}$ & 38 & 47 & \\
\hline & \multirow{3}{*}{ final } & Média & 97,50 & 93,62 & \\
\hline & & Desvio-padrão & 15,81 & 24,71 & 0,395 \\
\hline & & $\mathrm{n}$ & 40 & 47 & \\
\hline \multirow{6}{*}{ z } & \multirow{3}{*}{ inicial } & Média & 41.46 & 48.94 & \multirow{3}{*}{0.488} \\
\hline & & Desvio-padrão & 49.88 & 50.53 & \\
\hline & & $\mathrm{n}$ & 41 & 47 & \\
\hline & \multirow{3}{*}{ final } & Média & 26.32 & 40.43 & \multirow{3}{*}{0.172} \\
\hline & & Desvio-padrão & 44.63 & 49.61 & \\
\hline & & $\mathrm{n}$ & 38 & 47 & \\
\hline \multirow{6}{*}{$\mathrm{s}$} & \multirow{3}{*}{ inicial } & Média & 24.39 & 48.94 & \multirow{3}{*}{0,016 * } \\
\hline & & Desvio-padrão & 43.48 & 50.53 & \\
\hline & & $\mathrm{n}$ & 41 & 47 & \\
\hline & \multirow{3}{*}{ final } & Média & 41,67 & 51,06 & \multirow{3}{*}{0,275} \\
\hline & & Desvio-padrão & 38,10 & 41,69 & \\
\hline & & $\mathrm{n}$ & 41 & 47 & \\
\hline \multirow{9}{*}{ Z } & \multirow{3}{*}{ inicial } & Média & 36,59 & 63,83 & \multirow{3}{*}{0,010 * } \\
\hline & & Desvio-padrão & 48,77 & 48,57 & \\
\hline & & $\mathrm{n}$ & 41 & 47 & \\
\hline & \multirow{3}{*}{ medial } & Média & 36,59 & 36,17 & \\
\hline & & Desvio-padrão & 48,77 & 48,57 & 0,968 \\
\hline & & $\mathrm{n}$ & 41 & 47 & \\
\hline & & Média & 27,50 & 21,28 & \\
\hline & final & Desvio-padrão & 45,22 & 41,37 & 0,505 \\
\hline & & $\mathrm{n}$ & 40 & 47 & \\
\hline & & Média & 60,98 & 68,09 & \\
\hline & inicial & Desvio-padrão & 49,39 & 47,12 & 0,492 \\
\hline & & $n$ & 41 & 47 & \\
\hline & & Média & 60,98 & 53,19 & \\
\hline$\Sigma$ & medial & Desvio-padrão & 49,39 & 50,44 & 0,468 \\
\hline & & $\mathrm{n}$ & 41 & 47 & \\
\hline & & Média & 58,54 & 53,19 & \\
\hline & final & Desvio-padrão & 49,88 & 50,44 & 0,619 \\
\hline & & $\mathrm{n}$ & 41 & 47 & \\
\hline
\end{tabular}


- nasais

Somente para o fonema $/ \mathrm{m} /$, em sílaba inicial, as crianças do Gl obtiveram estatisticamente mais erros que as do Gll. Em todas as demais comparações, as duas faixas etárias tiveram porcentagem de acerto estatisticamente igual (Tabela 45).

Tabela 45 - Comparação entre as faixas etárias para nasais na imitação.

\begin{tabular}{|c|c|c|c|c|c|}
\hline fonema & sílaba & estatística & GI & GII & Teste $t(p)$ \\
\hline \multirow{6}{*}{$\mathrm{m}$} & \multirow[t]{3}{*}{ inicial } & Média & 73,17 & 91,49 & \multirow{3}{*}{$0,027^{*}$} \\
\hline & & Desvio-padrão & 44,86 & 28,21 & \\
\hline & & $\mathrm{n}$ & 41 & 47 & \\
\hline & \multirow[t]{3}{*}{ final } & Média & 95,12 & 95,74 & \multirow{3}{*}{0,842} \\
\hline & & Desvio-padrão & 15,02 & 14,10 & \\
\hline & & $\mathrm{n}$ & 41 & 47 & \\
\hline \multirow{6}{*}{$\mathrm{n}$} & \multirow[t]{3}{*}{ inicial } & Média & 81,71 & 91,49 & \multirow{3}{*}{0,055} \\
\hline & & Desvio-padrão & 26,82 & 18,99 & \\
\hline & & $\mathrm{n}$ & 41 & 47 & \\
\hline & \multirow[t]{3}{*}{ final } & Média & 92,68 & 100,00 & \multirow{3}{*}{0,083} \\
\hline & & Desvio-padrão & 26,37 & 0,00 & \\
\hline & & $\mathrm{n}$ & 41 & 47 & \\
\hline \multirow{3}{*}{$\mathrm{N}$} & \multirow{3}{*}{ Final } & Média & 94,87 & 97,87 & \multirow{3}{*}{0,456} \\
\hline & & Desvio-padrão & 22,35 & 14,59 & \\
\hline & & $\mathrm{n}$ & 39 & 47 & \\
\hline
\end{tabular}

- líquidas

Não foram observadas diferenças estatísticas entre o Gl e o Gll, na prova de imitação, para nenhuma das líquidas (Tabela 46).

Tabela 46 - Comparação entre as faixas etárias para líquidas na imitação.

\begin{tabular}{|c|c|c|c|c|c|}
\hline fonema & sílaba & estatística & $\mathrm{Gl}$ & GII & Teste t $(p)$ \\
\hline \multirow{6}{*}{ I } & \multirow{3}{*}{ inicial } & Média & 68,29 & 82,98 & \multirow{3}{*}{0,115} \\
\hline & & Desvio-padrão & 47,11 & 37,99 & \\
\hline & & $\mathrm{n}$ & 41 & 47 & \\
\hline & \multirow{3}{*}{ final } & Média & 80,49 & 85,11 & \multirow{3}{*}{0,491} \\
\hline & & Desvio-padrão & 33,31 & 29,33 & \\
\hline & & $n$ & 41 & 47 & \\
\hline \multirow{3}{*}{$x$} & \multirow{3}{*}{ final } & Média & 26,83 & 44,68 & \multirow{3}{*}{0,082} \\
\hline & & Desvio-padrão & 44,86 & 50,25 & \\
\hline & & $\mathrm{n}$ & 41 & 47 & \\
\hline \multirow{3}{*}{$\mathrm{P}$} & \multirow{3}{*}{ final } & Média & 21,95 & 33,33 & \multirow{3}{*}{0,137} \\
\hline & & Desvio-padrão & 32,15 & 38,07 & \\
\hline & & $\mathrm{n}$ & 41 & 47 & \\
\hline
\end{tabular}


- fricativa velar

Em relação ao fonema /X/ (Tabela 47), em todas as posições de sílabas, as crianças do Gl obtiveram porcentagem de acerto estatisticamente menor que as do GII.

Tabela 47 - Comparação entre as faixas etárias para a fricativa velar na imitação.

\begin{tabular}{|c|c|c|c|c|c|}
\hline fonema & sílaba & estatística & $\mathrm{Gl}$ & GII & Teste $\mathrm{t}(\mathrm{p})$ \\
\hline \multirow{9}{*}{$\mathrm{x}$} & \multirow{3}{*}{ inicial } & Média & 28,05 & 45,74 & \multirow{3}{*}{0,036 * } \\
\hline & & Desvio-padrão & 35,44 & 41,48 & \\
\hline & & $\mathrm{n}$ & 41 & 47 & \\
\hline & \multirow{3}{*}{ medial } & Média & 21,95 & 59,57 & \multirow{3}{*}{$<0,001$ * } \\
\hline & & Desvio-padrão & 41,91 & 49,61 & \\
\hline & & $\mathrm{n}$ & 41 & 47 & \\
\hline & \multirow{3}{*}{ final } & Média & 36,59 & 65,96 & \multirow{3}{*}{0,006 * } \\
\hline & & Desvio-padrão & 48,77 & 47,90 & \\
\hline & & $\mathrm{n}$ & 41 & 47 & \\
\hline
\end{tabular}

- arquifonemas

Tanto para o arquifonema /R/ como para o /S/, as crianças mais velhas tiveram porcentagem de acerto estatisticamente maior que as mais novas (Tabela 48).

Tabela 48 - Comparação entre as faixas etárias para arquifonemas na imitação.

\begin{tabular}{|c|c|c|c|c|c|}
\hline arquifonema & sílaba & estatística & Gl & GII & Teste $t(p)$ \\
\hline \multirow{6}{*}{$\mathrm{R}$} & \multirow{3}{*}{ inicial } & Média & 1,22 & 14,89 & \multirow{3}{*}{0,002 * } \\
\hline & & Desvio-padrão & 7,81 & 27,42 & \\
\hline & & $\mathrm{n}$ & 41 & 47 & \\
\hline & \multirow{3}{*}{ final } & Média & 0,00 & 8,89 & \multirow{3}{*}{$0,044^{*}$} \\
\hline & & Desvio-padrão & 0,00 & 28,78 & \\
\hline & & $\mathrm{n}$ & 40 & 45 & \\
\hline \multirow{6}{*}{$S$} & \multirow{3}{*}{ inicial } & Média & 10,00 & 39,13 & \multirow{3}{*}{$<0,001$ * } \\
\hline & & Desvio-padrão & 23,20 & 39,32 & \\
\hline & & $\mathrm{n}$ & 40 & 46 & \\
\hline & \multirow{3}{*}{ final } & Média & 42,50 & 70,21 & \multirow{3}{*}{0,009 * } \\
\hline & & Desvio-padrão & 50,06 & 46,23 & \\
\hline & & $\mathrm{n}$ & 40 & 47 & \\
\hline
\end{tabular}




\section{Nomeação}

$\mathrm{Na}$ nomeação, as crianças do Gl também tiveram média de acerto significativamente menor nas sílabas inicial e final ao se comparar todos os fonemas juntamente (Tabela 49).

Tabela 49 - Comparação entre as faixas etárias para fonemas na nomeação.

\begin{tabular}{|c|c|c|c|c|}
\hline sílaba & estatística & Gl & Gll & teste t $(p)$ \\
\hline \multirow{3}{*}{ inicial } & Média & 64,7 & 71,9 & \multirow{2}{*}{0,010 * } \\
\cline { 2 - 4 } & Desvio-padrão & 46,5 & 43,2 & \\
\cline { 2 - 4 } & $\mathrm{n}$ & 458 & 614 & \\
\hline \multirow{3}{*}{ medial } & Média & 63,9 & 70,6 & \multirow{2}{*}{0,077} \\
\cline { 2 - 4 } & Desvio-padrão & 47,6 & 45,3 & \\
\cline { 2 - 4 } final & $\mathrm{n}$ & 270 & 355 & \\
\cline { 2 - 4 } & Média & 65,3 & 72,2 & \multirow{2}{*}{0,007 * } \\
\cline { 2 - 4 } & Desvio-padrão & 46,0 & 43,3 & \\
\cline { 2 - 4 } & $\mathrm{n}$ & 527 & 712 & \\
\hline
\end{tabular}

Os dados a seguir referem-se aos fonemas analisados separadamente na nomeação.

- plosivas

Para todas as plosivas surdas e sonoras, o Gl teve porcentagem de acerto estatisticamente igual ao Gll (Tabela 50). 
Tabela 50 - Comparação entre as faixas etárias para plosivas na nomeação.

\begin{tabular}{|c|c|c|c|c|c|}
\hline fonema & sílaba & estatística & GI & GII & Teste $t(p)$ \\
\hline \multirow{9}{*}{ b } & \multirow{3}{*}{ inicial } & Média & 96,15 & 95,34 & \multirow{3}{*}{0,823} \\
\hline & & Desvio-padrão & 17,71 & 14,69 & \\
\hline & & $\mathrm{n}$ & 39 & 43 & \\
\hline & \multirow{3}{*}{ medial } & Média & 100,00 & 100,00 & \multirow{3}{*}{1,000} \\
\hline & & Desvio-padrão & 0,00 & 0,00 & \\
\hline & & $\mathrm{n}$ & 25 & 33 & \\
\hline & \multirow{3}{*}{ final } & Média & 75,00 & 100,00 & \multirow{3}{*}{ não analisado } \\
\hline & & Desvio-padrão & 50,00 & 0,00 & \\
\hline & & $\mathrm{n}$ & 4 & 9 & \\
\hline \multirow{9}{*}{$p$} & \multirow{3}{*}{ inicial } & Média & 94,02 & 97,52 & \multirow{3}{*}{0,316} \\
\hline & & Desvio-padrão & 19,68 & 9,82 & \\
\hline & & $\mathrm{n}$ & 39 & 47 & \\
\hline & \multirow{3}{*}{ medial } & Média & 100,00 & 100,00 & \multirow{3}{*}{1,000} \\
\hline & & Desvio-padrão & 0,00 & 0,00 & \\
\hline & & $\mathrm{n}$ & 39 & 44 & \\
\hline & \multirow{3}{*}{ final } & Média & 90,48 & 90,91 & \multirow{3}{*}{0,958} \\
\hline & & Desvio-padrão & 30,08 & 29,19 & \\
\hline & & $\mathrm{n}$ & 21 & 33 & \\
\hline \multirow{9}{*}{ d } & \multirow{3}{*}{ inicial } & Média & 85,29 & 84,61 & \multirow{3}{*}{0,937} \\
\hline & & Desvio-padrão & 35,95 & 36,55 & \\
\hline & & $\mathrm{n}$ & 34 & 39 & \\
\hline & \multirow{3}{*}{ medial } & Média & 76,47 & 92,68 & \multirow{3}{*}{0,061} \\
\hline & & Desvio-padrão & 43,06 & 26,36 & \\
\hline & & $\mathrm{n}$ & 34 & 41 & \\
\hline & \multirow{3}{*}{ final } & Média & 78,95 & 87,78 & \multirow{3}{*}{0,252} \\
\hline & & Desvio-padrão & 37,90 & 30,44 & \\
\hline & & $\mathrm{n}$ & 38 & 45 & \\
\hline \multirow{6}{*}{$t$} & & Média & 69,23 & 78,95 & \\
\hline & inicial & Desvio-padrão & 47,07 & 41,31 & 0,398 \\
\hline & & $\mathrm{n}$ & 26 & 38 & \\
\hline & & Média & 78,78 & 87,94 & \\
\hline & final & Desvio-padrão & 33,07 & 26,85 & 0,162 \\
\hline & & $\mathrm{n}$ & 41 & 47 & \\
\hline & & Média & 80,00 & 68,75 & \\
\hline & inicial & Desvio-padrão & 38,51 & 41,89 & 0,254 \\
\hline$g$ & & $\mathrm{n}$ & 30 & 40 & \\
\hline & & Média & 92,31 & 94,12 & \\
\hline & final & Desvio-padrão & 27,73 & 23,88 & 0,825 \\
\hline & & $n$ & 13 & 34 & \\
\hline & & Média & 88,62 & 90,58 & \\
\hline & inicial & Desvio-padrão & 23,99 & 24,00 & 0,704 \\
\hline & & $\mathrm{n}$ & 41 & 46 & \\
\hline & & Média & 100,00 & 75,00 & \\
\hline $\mathrm{k}$ & medial & Desvio-padrão & 0,00 & 44,72 & não analisado \\
\hline & & $\mathrm{n}$ & 6 & 16 & \\
\hline & & Média & 97,14 & 97,73 & \\
\hline & final & Desvio-padrão & 16,90 & 15,07 & 0,872 \\
\hline & & $\mathrm{n}$ & 35 & 44 & \\
\hline
\end{tabular}


- fricativas

Quanto ao fonema /s/, foram encontradas diferenças em sílaba inicial e final. Para o fonema $/ \Sigma /$, houve diferença entre os grupos em sílaba final. Ao contrário do /s/, as crianças do Gl tiveram porcentagem de acerto maior que o Gll para o fonema $/ \Sigma /$ (Tabela 51). Nas demais possíveis comparações, ambos os grupos tiveram porcentagem de acerto estatisticamente igual.

Tabela 51 - Comparação entre as faixas etárias para fricativas na nomeação.

\begin{tabular}{|c|c|c|c|c|c|}
\hline fonema & sílaba & estatística & Gl & GII & Teste $t(p)$ \\
\hline \multirow{6}{*}{ v } & \multirow{3}{*}{ inicial } & Média & 47,06 & 65,12 & \multirow{3}{*}{0,117} \\
\hline & & Desvio-padrão & 50,66 & 48,22 & \\
\hline & & $\mathrm{n}$ & 34 & 43 & \\
\hline & \multirow{3}{*}{ final } & Média & 50,00 & 100,00 & \multirow{3}{*}{ não analisado } \\
\hline & & Desvio-padrão & 70,71 & 0,00 & \\
\hline & & $\mathrm{n}$ & 2 & 3 & \\
\hline \multirow{6}{*}{$f$} & \multirow{3}{*}{ inicial } & Média & 83,33 & 84,78 & \multirow{3}{*}{0,846} \\
\hline & & Desvio-padrão & 33,81 & 33,11 & \\
\hline & & $\mathrm{n}$ & 36 & 46 & \\
\hline & \multirow{3}{*}{ final } & Média & 94,12 & 89,19 & \multirow{3}{*}{0,547} \\
\hline & & Desvio-padrão & 24,25 & 30,00 & \\
\hline & & $n$ & 17 & 37 & \\
\hline \multirow{9}{*}{ z } & \multirow{3}{*}{ inicial } & Média & 50,00 & 0,00 & \multirow{3}{*}{ não analisado } \\
\hline & & Desvio-padrão & 70,71 & --- & \\
\hline & & $\mathrm{n}$ & 2 & 1 & \\
\hline & \multirow{3}{*}{ medial } & Média & 25,00 & 42,50 & \multirow{3}{*}{0,151} \\
\hline & & Desvio-padrão & 44,23 & 50,06 & \\
\hline & & $\mathrm{n}$ & 24 & 40 & \\
\hline & \multirow{3}{*}{ final } & Média & 34,72 & 40,91 & \multirow{3}{*}{0,563} \\
\hline & & Desvio-padrão & 46,01 & 48,55 & \\
\hline & & $n$ & 36 & 44 & \\
\hline \multirow{9}{*}{$\mathrm{s}$} & \multirow{3}{*}{ inicial } & Média & 21,54 & 52,53 & \multirow{3}{*}{0,001 * } \\
\hline & & Desvio-padrão & 37,13 & 43,88 & \\
\hline & & $\mathrm{n}$ & 41 & 46 & \\
\hline & \multirow{3}{*}{ medial } & Média & 32,35 & 58,14 & \multirow{3}{*}{0,024 * } \\
\hline & & Desvio-padrão & 47,48 & 49,92 & \\
\hline & & $\mathrm{n}$ & 34 & 43 & \\
\hline & \multirow{3}{*}{ final } & Média & 48,78 & 51,77 & \multirow{3}{*}{0,758} \\
\hline & & Desvio-padrão & 46,90 & 43,71 & \\
\hline & & $\mathrm{n}$ & 41 & 47 & \\
\hline \multirow{6}{*}{ Z } & \multirow{3}{*}{ inicial } & Média & 33,33 & 61,54 & \multirow{3}{*}{ não analisado } \\
\hline & & Desvio-padrão & 57,73 & 50,64 & \\
\hline & & $\mathrm{n}$ & 3 & 13 & \\
\hline & \multirow{3}{*}{ final } & Média & 43,59 & 47,83 & \\
\hline & & Desvio-padrão & 50,23 & 50,50 & 0,700 \\
\hline & & $\mathrm{n}$ & 39 & 46 & \\
\hline
\end{tabular}


Continuação Tabela 51 - Comparação entre as faixas etárias para fricativas na nomeação.

\begin{tabular}{|c|c|c|c|c|c|}
\hline fonema & sílaba & estatística & Gl & Gll & \multirow{2}{*}{ Teste t $(\mathrm{p})$} \\
\hline \multirow{4}{*}{$\Sigma$} & \multirow{3}{*}{ inicial } & Média & 50,00 & 75,00 & \multirow{3}{*}{ não analisado } \\
\cline { 3 - 5 } & & Desvio-padrão & 54,77 & 44,72 & \\
\cline { 3 - 5 } & \multirow{3}{*}{ medial } & $\mathrm{n}$ & 6 & 16 & \\
\cline { 3 - 5 } & & Média & 72,97 & 64,29 & \multirow{2}{*}{0,414} \\
\cline { 3 - 5 } & & Desvio-padrão & 45,02 & 48,50 & \\
\cline { 3 - 5 } & \multirow{3}{*}{ final } & $\mathrm{n}$ & 37 & 42 & \multirow{2}{*}{0,047 * } \\
\cline { 3 - 5 } & & Média & 81,82 & 60,98 & \\
\cline { 3 - 5 } & & Desvio-padrão & 39,17 & 49,39 & \\
\cline { 3 - 4 } & & $\mathrm{n}$ & 33 & 41 & \\
\hline
\end{tabular}

- nasais

Dentre as possíveis comparações realizadas para nasais, o grupo de crianças mais velhas foi estatisticamente igual ao das mais novas (Tabela 52).

Tabela 52 - Comparação entre as faixas etárias para nasais na nomeação.

\begin{tabular}{|c|c|c|c|c|c|}
\hline fonema & sílaba & estatística & $\mathrm{Gl}$ & GII & Teste $t(p)$ \\
\hline \multirow{6}{*}{$\mathrm{m}$} & \multirow{3}{*}{ inicial } & Média & 96,97 & 97,73 & \multirow{3}{*}{0.813} \\
\hline & & Desvio-padrão & 17,41 & 10,53 & \\
\hline & & $\mathrm{n}$ & 33 & 44 & \\
\hline & \multirow{3}{*}{ final } & Média & 100,00 & 100,00 & \multirow{3}{*}{1.000} \\
\hline & & Desvio-padrão & 0,00 & 0,00 & \\
\hline & & $\mathrm{n}$ & 35 & 45 & \\
\hline \multirow{6}{*}{$\mathrm{n}$} & \multirow{3}{*}{ inicial } & Média & 100,00 & 100,00 & \multirow{3}{*}{ não analisado } \\
\hline & & Desvio-padrão & 0,00 & 0,00 & \\
\hline & & $\mathrm{n}$ & 2 & 3 & \\
\hline & \multirow{3}{*}{ final } & Média & 90,48 & 94,29 & \multirow{3}{*}{0.600} \\
\hline & & Desvio-padrão & 30,08 & 23,55 & \\
\hline & & $\mathrm{n}$ & 21 & 35 & \\
\hline \multirow{3}{*}{ | } & \multirow{3}{*}{ final } & Média & 95,65 & 100,00 & \multirow{3}{*}{0.328} \\
\hline & & Desvio-padrão & 20,85 & 0,00 & \\
\hline & & $\mathrm{n}$ & 23 & 33 & \\
\hline
\end{tabular}

\section{- líquidas}

Quanto às líquidas, foi observada diferença estatística entre as crianças mais novas e as mais velhas em relação ao fonema $/ \times /$ em sílaba medial, ressaltando que as crianças do Gl obtiveram mais erros que as do Gll (Tabela 53). 
Tabela 53 - Comparação entre as faixas etárias para líquidas na nomeação.

\begin{tabular}{|c|c|c|c|c|c|}
\hline fonema & sílaba & estatística & Gl & GII & Teste t (p) \\
\hline \multirow{9}{*}{ I } & \multirow{3}{*}{ inicial } & Média & 71,43 & 85,71 & \multirow{3}{*}{0,327} \\
\hline & & Desvio-padrão & 46,88 & 35,63 & \\
\hline & & $\mathrm{n}$ & 14 & 28 & \\
\hline & \multirow{3}{*}{ medial } & Média & 73,08 & 81,91 & \multirow{3}{*}{0,286} \\
\hline & & Desvio-padrão & 41,11 & 35,24 & \\
\hline & & $n$ & 39 & 47 & \\
\hline & \multirow{3}{*}{ final } & Média & 73,08 & 87,88 & \multirow{3}{*}{0,169} \\
\hline & & Desvio-padrão & 45,23 & 33,14 & \\
\hline & & $\mathrm{n}$ & 26 & 33 & \\
\hline \multirow{6}{*}{$x$} & \multirow{3}{*}{ medial } & Média & 6,90 & 27,78 & \multirow{3}{*}{0,023 * } \\
\hline & & Desvio-padrão & 25,79 & 45,43 & \\
\hline & & $\mathrm{n}$ & 29 & 36 & \\
\hline & \multirow{3}{*}{ final } & Média & 26,67 & 20,83 & \multirow{3}{*}{0,684} \\
\hline & & Desvio-padrão & 45,77 & 41,49 & \\
\hline & & $\mathrm{n}$ & 15 & 24 & \\
\hline \multirow{6}{*}{$\mathrm{P}$} & \multirow{3}{*}{ medial } & Média & 66,67 & 46,15 & \multirow{3}{*}{ não analisado } \\
\hline & & Desvio-padrão & 57,73 & 51,89 & \\
\hline & & $\mathrm{n}$ & 3 & 13 & \\
\hline & \multirow{3}{*}{ final } & Média & 32,67 & 38,22 & \multirow{3}{*}{0,540} \\
\hline & & Desvio-padrão & 39,91 & 42,15 & \\
\hline & & $\mathrm{n}$ & 38 & 46 & \\
\hline
\end{tabular}

- fricativa velar

$\mathrm{Na}$ comparação entre os grupos para o fonema $/ x /$, realizada em sílabas inicial e final, as crianças mais novas apresentaram estatisticamente mais erros comparadas às mais velhas (Tabela 54).

Tabela 54 - Comparação entre as faixas etárias para a fricativa velar na nomeação.

\begin{tabular}{|c|c|c|c|c|c|}
\hline fonema & sílaba & estatística & GI & GII & Teste t (p) \\
\hline \multirow{6}{*}{$\mathrm{x}$} & \multirow{3}{*}{ inicial } & Média & 15,38 & 43,48 & \multirow{3}{*}{$0,004^{*}$} \\
\hline & & Desvio-padrão & 36,55 & 50,12 & \\
\hline & & $\mathrm{n}$ & 39 & 46 & \\
\hline & \multirow{3}{*}{ final } & Média & 24,32 & 69,05 & \multirow{3}{*}{$<0,001$ * } \\
\hline & & Desvio-padrão & 43,49 & 46,79 & \\
\hline & & $\mathrm{n}$ & 37 & 42 & \\
\hline
\end{tabular}


- arquifonemas

A comparação entre os grupos para o arquifonema /R/, em sílaba inicial, mostrou que as crianças mais novas apresentaram porcentagem de acerto estatisticamente menor que as mais velhas (Tabela 55).

Tabela 55 - Comparação entre as faixas etárias para arquifonemas na nomeação.

\begin{tabular}{|c|c|c|c|c|c|}
\hline arquifonema & sílaba & estatística & GI & GII & Teste $t(p)$ \\
\hline \multirow{6}{*}{$\mathrm{R}$} & \multirow{3}{*}{ inicial } & Média & 0,00 & 11,11 & \multirow{3}{*}{0,044 * } \\
\hline & & Desvio-padrão & 0,00 & 31,87 & \\
\hline & & $\mathrm{n}$ & 17 & 36 & \\
\hline & \multirow{3}{*}{ final } & Média & 0,00 & 10,42 & \multirow{3}{*}{0.096} \\
\hline & & Desvio-padrão & 0,00 & 29,41 & \\
\hline & & $\mathrm{n}$ & 12 & 24 & \\
\hline \multirow{3}{*}{$S$} & \multirow{3}{*}{ Inicial } & Média & 22,73 & 44,87 & \multirow{3}{*}{0.074} \\
\hline & & Desvio-padrão & 42,89 & 49,73 & \\
\hline & & & 22 & 39 & \\
\hline
\end{tabular}

- Estruturas silábicas

$\underline{\mathrm{CV}}$

Observa-se alta porcentagem de acerto nas três posições de sílabas, na fala espontânea. A sílaba em que as crianças apresentaram mais erro foi a medial (Figura 4). Não houve diferença entre os grupos na sílaba inicial $(p=0,539)$, bem como na medial $(p=0,052)$ e final $(p=0,259)$.

Figura 4 - Comparação da porcentagem de acerto em estrutura CV, entre as faixas etárias, na fala espontânea.

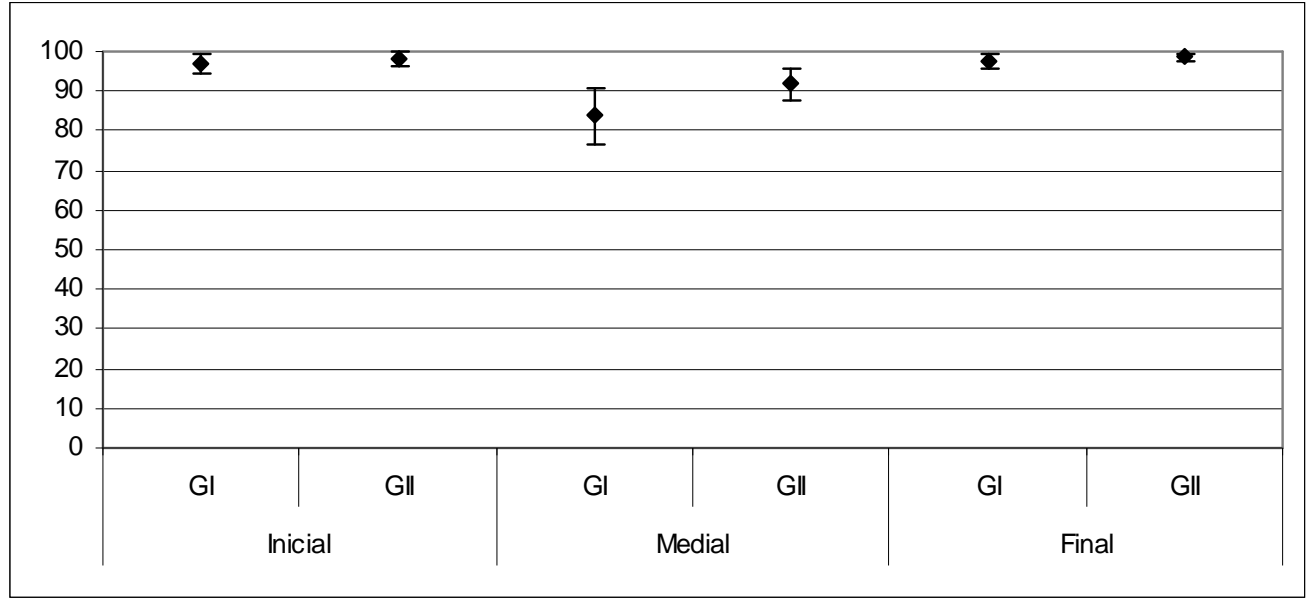


Separando a estrutura CV de acordo com a extensão da palavra, a porcentagem de acerto foi estatisticamente igual nas duas faixas etárias, em palavras dissilábicas, trissilábicas e polissilábicas em todas as posições de sílaba (Tabela 56).

Tabela 56 - Comparação entre as faixas etárias quanto à estrutura CV na fala espontânea.

\begin{tabular}{|c|c|c|c|c|c|}
\hline extensão da palavra & sílaba & estatística & GI & GII & Teste $t(p)$ \\
\hline \multirow{6}{*}{ DISSILÁBICA } & \multirow{3}{*}{ inicial } & Média & 98,43 & 99,20 & \multirow{3}{*}{0,552} \\
\hline & & Desvio-padrão & 7,39 & 4,03 & \\
\hline & & $n$ & 38 & 44 & \\
\hline & \multirow{3}{*}{ final } & Média & 97,77 & 98,33 & \multirow{3}{*}{0,732} \\
\hline & & Desvio-padrão & 8,93 & 5,52 & \\
\hline & & $\mathrm{n}$ & 37 & 44 & \\
\hline \multirow{9}{*}{ TRISSILÁBICA } & \multirow{3}{*}{ inicial } & Média & 98,60 & 98,58 & \multirow{3}{*}{0,986} \\
\hline & & Desvio-padrão & 5,26 & 5,55 & \\
\hline & & $\mathrm{n}$ & 37 & 43 & \\
\hline & \multirow{3}{*}{ medial } & Média & 89,19 & 92,32 & \multirow{3}{*}{0,407} \\
\hline & & Desvio-padrão & 19,18 & 14,81 & \\
\hline & & $\mathrm{n}$ & 38 & 44 & \\
\hline & \multirow{3}{*}{ final } & Média & 95,29 & 97,92 & \multirow{3}{*}{0,270} \\
\hline & & Desvio-padrão & 12,92 & 7,27 & \\
\hline & & $\mathrm{n}$ & 38 & 44 & \\
\hline \multirow{9}{*}{ POLISSILÁBICA } & \multirow{3}{*}{ inicial } & Média & 92,36 & 95,48 & \multirow{3}{*}{0,585} \\
\hline & & Desvio-padrão & 23,04 & 19,12 & \\
\hline & & $\mathrm{n}$ & 24 & 31 & \\
\hline & \multirow{3}{*}{ medial } & Média & 75,92 & 91,09 & \multirow{3}{*}{0,070} \\
\hline & & Desvio-padrão & 37,10 & 20,92 & \\
\hline & & $\mathrm{n}$ & 26 & 33 & \\
\hline & \multirow{3}{*}{ final } & Média & 100,00 & 100,00 & \multirow{3}{*}{1,000} \\
\hline & & Desvio-padrão & 0,00 & 0,00 & \\
\hline & & $\mathrm{n}$ & 24 & 31 & \\
\hline
\end{tabular}

$\mathrm{Na}$ imitação, também pode-se observar alta porcentagem de acerto na estrutura CV (Figura 5). As crianças mais novas tiveram pior desempenho que as mais velhas em sílaba inicial $(p=0,020)$ e medial $(p=0,044)$. Na sílaba final, ambos os grupos foram considerados estatisticamente similares $(p=0,765)$. 
Figura 5 - Comparação da porcentagem de acerto em estrutura CV, entre as faixas etárias, na imitação.

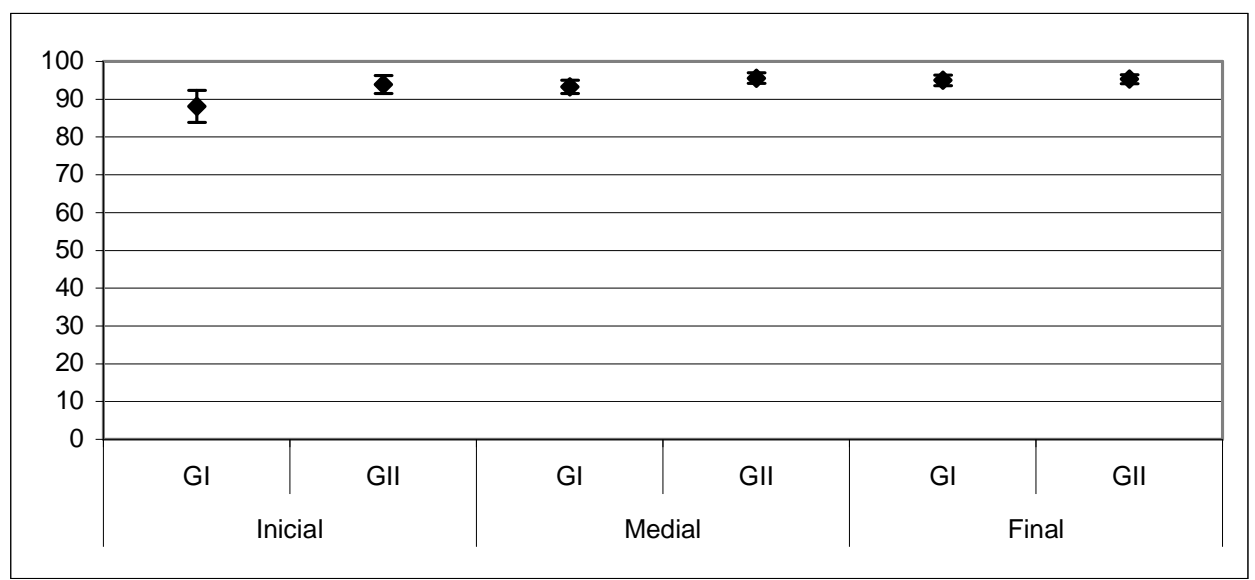

Analisando com base na extensão da palavra, as crianças mais novas são estatisticamente iguais às mais velhas quanto à estrutura CV apenas em palavras dissilábicas e na sílaba final dos palavras trissilábicas. Em relação às sílabas inicial e medial de palavras trissilábicas, as crianças mais velhas apresentaram porcentagem de acerto significantemente maior que as mais novas (Tabela 57).

Tabela 57 - Comparação entre as faixas etárias quanto à estrutura CV na imitação.

\begin{tabular}{|c|c|c|c|c|c|}
\hline extensão da palavra & sílaba & estatística & Gl & GII & Teste $t(p)$ \\
\hline \multirow{6}{*}{ DISSILÁBICA } & \multirow{3}{*}{ inicial } & Média & 96,18 & 97,87 & \multirow{3}{*}{0,232} \\
\hline & & Desvio-padrão & 7,08 & 6,06 & \\
\hline & & $n$ & 41 & 47 & \\
\hline & \multirow{3}{*}{ final } & Média & 94,05 & 94,37 & \multirow{3}{*}{0,793} \\
\hline & & Desvio-padrão & 5,61 & 5,78 & \\
\hline & & $\mathrm{n}$ & 41 & 47 & \\
\hline \multirow{9}{*}{ TRISSILÁBICA } & \multirow{3}{*}{ inicial } & Média & 80,01 & 89,89 & \multirow{3}{*}{0,025 * } \\
\hline & & Desvio-padrão & 24,14 & 14,19 & \\
\hline & & $\frac{\mathrm{r}}{\mathrm{n}}$ & 41 & 47 & \\
\hline & \multirow{3}{*}{ medial } & Média & 93,26 & 95,55 & \multirow{3}{*}{$0,047^{*}$} \\
\hline & & Desvio-padrão & 5,75 & 4,77 & \\
\hline & & $\frac{1}{n}$ & 41 & 47 & \\
\hline & \multirow{3}{*}{ final } & Média & 95,98 & 96,21 & \multirow{3}{*}{0,867} \\
\hline & & Desvio-padrão & 7,28 & 5,55 & \\
\hline & & $n$ & 41 & 47 & \\
\hline
\end{tabular}

A alta porcentagem de acerto na estrutura CV também é observada na nomeação (Figura 6). As crianças mais novas obtiveram porcentagem de acerto estatisticamente menor que as mais velhas apenas em sílaba inicial $(p=0,035)$. As 
demais foram consideradas estatisticamente iguais, apesar da média do GI ser menor que a do GII (medial: $p=0,856$ e final: $p=0,106$ ).

Figura 6 - Comparação da porcentagem de acerto em estrutura CV, entre as faixas etárias, na nomeação.

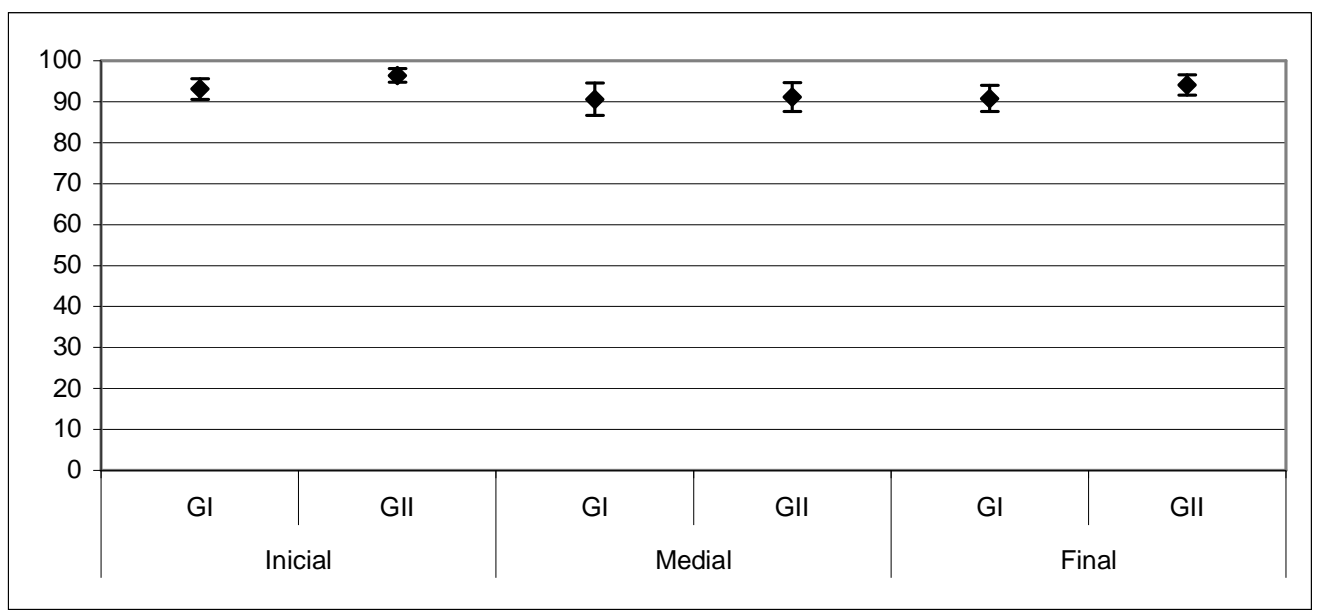

Da mesma forma, a estrutura CV foi separada para análise de acordo com a extensão da palavra. As crianças mais novas tiveram média de acerto significativamente menor que as mais velhas apenas em sílaba inicial de palavras trissilábicas (Tabela 58).

Tabela 58 - Comparação entre as faixas etárias quanto à estrutura CV na nomeação.

\begin{tabular}{|c|c|c|c|c|c|}
\hline extensão da palavra & sílaba & estatística & Gl & Gll & Teste $\mathrm{t}(\mathrm{p})$ \\
\hline \multirow{6}{*}{ DISSILÁBICA } & \multirow{3}{*}{ inicial } & Média & 98,29 & 98,63 & \multirow{3}{*}{0,779} \\
\hline & & Desvio-padrão & 6,46 & 4,64 & \\
\hline & & $\mathrm{n}$ & 41 & 47 & \\
\hline & \multirow{3}{*}{ final } & Média & 99,33 & 99,37 & \multirow{3}{*}{0,959} \\
\hline & & Desvio-padrão & 4,26 & 2,09 & \\
\hline & & $\mathrm{n}$ & 41 & 47 & \\
\hline \multirow{9}{*}{ TRISSILÁBICA } & \multirow{3}{*}{ inicial } & Média & 87,81 & 94,09 & \multirow{3}{*}{$0,017^{*}$} \\
\hline & & Desvio-padrão & 13,38 & 10,40 & \\
\hline & & $\mathrm{n}$ & 41 & 47 & \\
\hline & \multirow{3}{*}{ medial } & Média & 90,65 & 91,13 & \multirow{3}{*}{0,856} \\
\hline & & Desvio-padrão & 12,81 & 12,22 & \\
\hline & & $\mathrm{n}$ & 41 & 47 & \\
\hline & \multirow{3}{*}{ final } & Média & 82,17 & 88,80 & \multirow{3}{*}{0,054} \\
\hline & & Desvio-padrão & 16,04 & 15,71 & \\
\hline & & $\mathrm{n}$ & 41 & 47 & \\
\hline
\end{tabular}




\section{$\underline{\mathrm{CCV}}$}

A Figura 7 mostra o desempenho de cada grupo para a estrutura CCV nas provas de fonologia. Observa-se que as crianças mais novas apresentaram melhor desempenho que as mais velhas na fala espontânea, em sílaba inicial, e na nomeação, em sílaba final. Porém, esta diferença entre os grupos não foi estatisticamente significante nem na fala espontânea $(p=0,975)$ nem na nomeação $(p=0,481)$.

Na sílaba inicial da nomeação, os grupos também não tiveram resultados diferentes $(p=0,272)$. Na imitação, também em sílaba inicial, as crianças do Gl apresentaram porcentagem de acerto estatisticamente menor que as do Gll $(p=0,027)$.

Figura 7 - Desempenho dos grupos quanto à estrutura CCV.

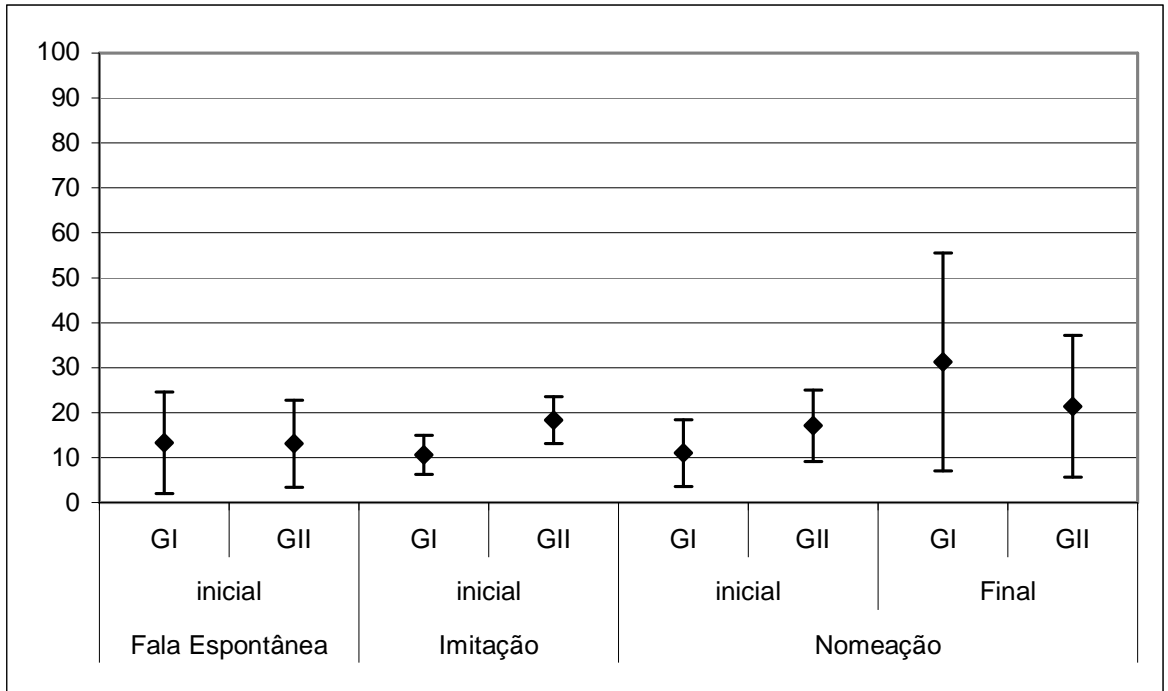

Considerando a estrutura CCV, foram comparados os encontros com /// separadamente dos encontros com /P/. Assim, na fala espontânea, a comparação entre os grupos mostrou que nas estruturas com número de alvos suficiente, as crianças dos dois grupos apresentaram porcentagem de acerto estatisticamente igual.

Vale ressaltar que a comparação foi realizada apenas em sílaba inicial, de palavras dissilábicas e trissilábicas e medial, de palavras polissilábicas com encontro com /P/ (Tabela 59). 
Tabela 59 - Comparação entre as faixas etárias quanto à estrutura CCV na fala espontânea.

\begin{tabular}{|c|c|c|c|c|c|}
\hline Estrutura & sílaba & estatística & Gl & Gll & Teste t (p) \\
\hline \multirow{3}{*}{ DISSÍLABO ENC /l/ } & \multirow{3}{*}{ inicial } & Média & --- & 0,00 & \multirow{3}{*}{ não analisado } \\
\hline & & Desvio-padrão & --- & --- & \\
\hline & & $\mathrm{n}$ & --- & 1 & \\
\hline \multirow{6}{*}{ DISSÍLABO ENC /P/ } & \multirow{3}{*}{ inicial } & Média & 16,67 & 17,86 & \multirow{3}{*}{0,938} \\
\hline & & Desvio-padrão & 36,00 & 37,25 & \\
\hline & & $\mathrm{n}$ & 10 & 14 & \\
\hline & \multirow{3}{*}{ final } & Média & --- & 50,00 & \multirow{3}{*}{ não analisado } \\
\hline & & Desvio-padrão & --- & 70,71 & \\
\hline & & $\mathrm{n}$ & --- & 2 & \\
\hline \multirow{3}{*}{ POLISSÍLABO ENC /// } & \multirow{3}{*}{ medial } & Média & 7,14 & 12,12 & \multirow{3}{*}{0,669} \\
\hline & & Desvio-padrão & 26,73 & 30,81 & \\
\hline & & $\mathrm{n}$ & 14 & 11 & \\
\hline \multirow{6}{*}{ POLISSÍLABO ENC /P/ } & \multirow{3}{*}{ inicial } & Média & 0,00 & 0,00 & \multirow{3}{*}{ não analisado } \\
\hline & & Desvio-padrão & --- & 0,00 & \\
\hline & & $\mathrm{n}$ & 1 & 2 & \\
\hline & \multirow{3}{*}{ medial } & Média & --- & 0,00 & \multirow{3}{*}{ não analisado } \\
\hline & & Desvio-padrão & --- & --- & \\
\hline & & $\mathrm{n}$ & --- & 1 & \\
\hline \multirow{6}{*}{ TRISSÍLABO ENC /P/ } & \multirow{3}{*}{ inicial } & Média & 20,00 & 11,90 & \multirow{3}{*}{0,592} \\
\hline & & Desvio-padrão & 42,16 & 30,96 & \\
\hline & & $\mathrm{n}$ & 10 & 14 & \\
\hline & \multirow{3}{*}{ medial } & Média & 0,00 & 0,00 & \multirow{3}{*}{ não analisado } \\
\hline & & Desvio-padrão & --- & --- & \\
\hline & & $\mathrm{n}$ & 1 & 1 & \\
\hline
\end{tabular}

Legenda: ENC: encontro consonantal

$\mathrm{Na}$ imitação (Tabela 60), os encontros aparecem apenas em sílaba inicial. As faixas etárias são estatisticamente iguais em palavras dissilábicas com encontro com $/ / /(p=0,141)$ e palavras trissilábicas com encontros com /P/ $(p=0,839)$. Nota-se que apesar de não haver diferença estatisticamente significante, as crianças mais novas apresentam porcentagem de acerto menor que as mais velhas. Em palavras dissilábicas com encontro com $/ \mathrm{P} /$, houve diferença estatística significante entre as duas faixas etárias $(p=0,036)$. 
Tabela 60 - Comparação entre as faixas etárias quanto à estrutura CCV na imitação.

\begin{tabular}{|c|c|c|c|c|c|}
\hline estrutura & sílaba & estatística & $\mathrm{Gl}$ & GII & Teste $t(p)$ \\
\hline \multirow{3}{*}{ DISSÍLABO ENC /I/ } & \multirow{3}{*}{ inicial } & Média & 13,33 & 21,98 & \multirow{3}{*}{0,141} \\
\hline & & Desvio-padrão & 24,81 & 28,89 & \\
\hline & & $\mathrm{n}$ & 40 & 47 & \\
\hline \multirow{3}{*}{ DISSÍLABO ENC /P/ } & \multirow{3}{*}{ inicial } & Média & 11,30 & 24,47 & \multirow{3}{*}{0,036 * } \\
\hline & & Desvio-padrão & 22,17 & 35,07 & \\
\hline & & $n$ & 41 & 47 & \\
\hline \multirow{3}{*}{ TRISSÍLABO ENC /P/ } & \multirow{3}{*}{ inicial } & Média & 7,32 & 8,51 & \multirow{3}{*}{0,839} \\
\hline & & Desvio-padrão & 26,37 & 28,21 & \\
\hline & & $\mathrm{n}$ & 41 & 47 & \\
\hline
\end{tabular}

Legenda: ENC: encontro consonantal

As comparações entre as faixas etárias na nomeação (Tabela 61) mostram que os grupos apresentaram porcentagem de acerto estatisticamente igual. Observa-se, entretanto que as crianças mais novas apresentaram porcentagem de acerto maior que as mais velhas em sílaba final, de dissílabos com /P/.

Tabela 61 - Comparação entre as faixas etárias quanto à estrutura CCV na nomeação.

\begin{tabular}{|c|c|c|c|c|c|}
\hline estrutura & sílaba & estatística & Gl & GII & Teste t $(p)$ \\
\hline \multirow{3}{*}{ DISSÍLABO ENC /// } & \multirow{3}{*}{ inicial } & Média & 12,50 & 20,69 & \multirow{3}{*}{0,397} \\
\hline & & Desvio-padrão & 33,60 & 41,23 & \\
\hline & & $n$ & 32 & 29 & \\
\hline \multirow{6}{*}{ DISSÍLABO ENC /P/ } & \multirow{3}{*}{ inicial } & Média & 9,60 & 14,86 & \multirow{3}{*}{0,432} \\
\hline & & Desvio-padrão & 27,33 & 30,48 & \\
\hline & & $\mathrm{n}$ & 33 & 46 & \\
\hline & \multirow{3}{*}{ final } & Média & 31,25 & 21,43 & \multirow{3}{*}{0,481} \\
\hline & & Desvio-padrão & 47,87 & 41,79 & \\
\hline & & $n$ & 16 & 28 & \\
\hline
\end{tabular}

Legenda: ENC: encontro consonantal.

\section{$\underline{\mathrm{CVC}}$}

Quanto à estrutura CVC, as crianças do Gl tiveram menos acertos comparadas às do Gll (Figura 8). Apenas para a sílaba final foi aplicada a comparação entre Gl e Gll na fala espontânea, sendo que as duas faixas etárias foram consideradas estatisticamente iguais $(p=0,375)$. Nas sílabas inicial e medial não houve número suficiente de alvo no Gl para comparação com o Gll. 
Na imitação, a comparação ocorreu apenas em sílaba inicial e final. Houve evidências de que as crianças do Gl apresentaram porcentagem de acerto estatisticamente menor que as mais velhas tanto em sílaba inicial $(p<0,001)$ como final $(p=0,007)$.

$\mathrm{Na}$ nomeação, apesar das crianças do Gl terem mostrado porcentagem de acerto menor que as do Gll, em sílaba inicial e final, esta diferença não foi estatisticamente comprovada (inicial: $p=0,084$ e final $p=0,096$ ).

Figura 8 - Desempenho dos grupos quanto à estrutura CVC.

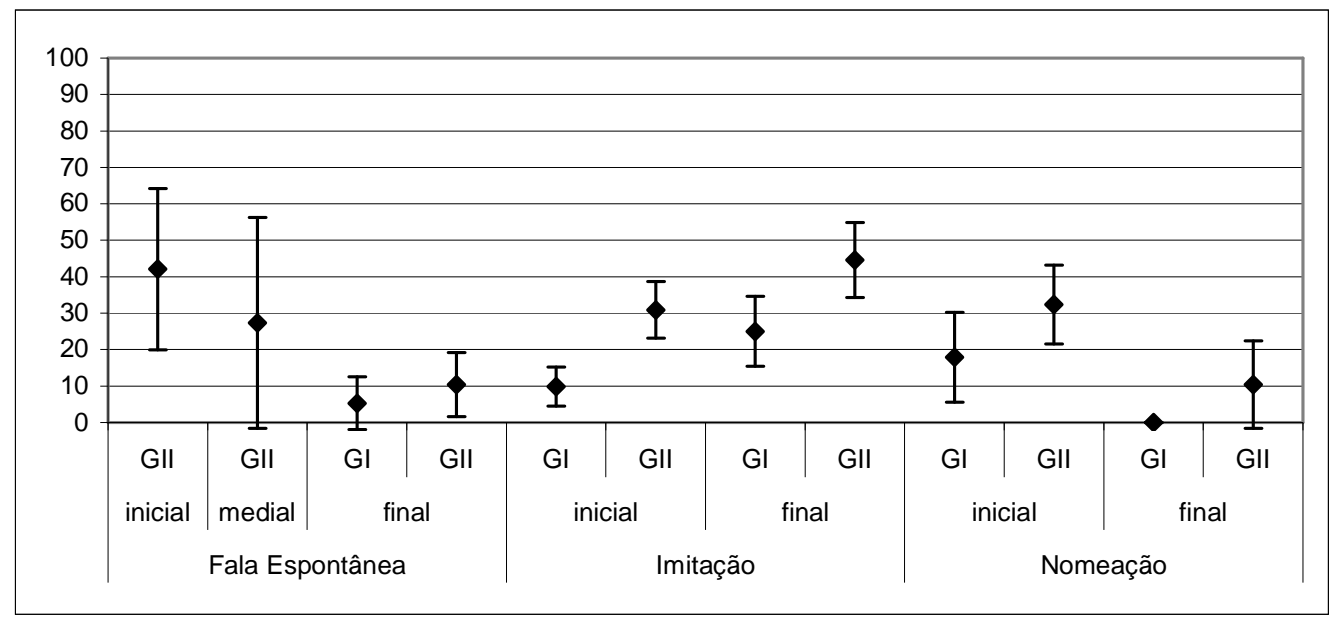

$\mathrm{Na}$ estrutura CVC, os arquifonemas /S/ e /R/ foram analisados separadamente nas diferentes extensões de palavras.

Para a fala espontânea (Tabela 62), houve comparação apenas nas palavras dissilábicas com arquifonema /R/ em sílaba final, na qual não houve diferença entre as duas faixas etárias $(p=0,329)$. 
Tabela 62 - Comparação entre as faixas etárias quanto à estrutura CVC na fala espontânea.

\begin{tabular}{|c|c|c|c|c|c|}
\hline Estrutura & sílaba & estatística & Gl & Gll & Teste $t(p)$ \\
\hline \multirow{6}{*}{ DISSÍLABO ARQUI /R/ } & \multirow{3}{*}{ inicial } & Média & 14,29 & 22,22 & \multirow{3}{*}{ não analisado } \\
\hline & & Desvio-padrão & 37,80 & 44,10 & \\
\hline & & $\mathrm{n}$ & 7 & 9 & \\
\hline & \multirow{3}{*}{ final } & Média & 0,00 & 1,59 & \multirow{3}{*}{0,329} \\
\hline & & Desvio-padrão & 0,00 & 7,27 & \\
\hline & & $\mathrm{n}$ & 30 & 21 & \\
\hline \multirow{6}{*}{ DISSÍLABO ARQUI /S/ } & \multirow{3}{*}{ inicial } & Média & 0,00 & 100,00 & \multirow{3}{*}{ não analisado } \\
\hline & & Desvio-padrão & --- & --- & \\
\hline & & $\mathrm{n}$ & 1 & 1 & \\
\hline & \multirow{3}{*}{ final } & Média & 100,00 & 6,25 & \multirow{3}{*}{ não analisado } \\
\hline & & Desvio-padrão & 0,00 & 17,68 & \\
\hline & & $\mathrm{n}$ & 2 & 8 & \\
\hline \multirow{9}{*}{ POLISSÍLABO ENC /R/ } & \multirow{3}{*}{ inicial } & Média & --- & 0,00 & \multirow{3}{*}{ não analisado } \\
\hline & & Desvio-padrão & --- & --- & \\
\hline & & $\mathrm{n}$ & --- & 1 & \\
\hline & \multirow{3}{*}{ medial } & Média & 0,00 & 30,00 & \multirow{3}{*}{ não analisado } \\
\hline & & Desvio-padrão & 0,00 & 48,30 & \\
\hline & & $\mathrm{n}$ & 3 & 10 & \\
\hline & \multirow{3}{*}{ final } & Média & 0,00 & 25,93 & \multirow{3}{*}{ não analisado } \\
\hline & & Desvio-padrão & 0,00 & 43,39 & \\
\hline & & $\mathrm{n}$ & 5 & 9 & \\
\hline \multirow{6}{*}{ TRISSÍLABO ARQUI /S/ } & \multirow{3}{*}{ inicial } & Média & --- & 100,00 & \multirow{3}{*}{ não analisado } \\
\hline & & Desvio-padrão & --- & 0,00 & \\
\hline & & $\mathrm{n}$ & --- & 2 & \\
\hline & \multirow{3}{*}{ final } & Média & --- & 100,00 & \multirow{3}{*}{ não analisado } \\
\hline & & Desvio-padrão & --- & --- & \\
\hline & & $\mathrm{n}$ & --- & 1 & \\
\hline \multirow{9}{*}{ TRISSÍLABO ENC /R/ } & \multirow{3}{*}{ inicial } & Média & 100,00 & 50,00 & \multirow{3}{*}{ não analisado } \\
\hline & & Desvio-padrão & --- & 44,72 & \\
\hline & & $\mathrm{n}$ & 1 & 6 & \\
\hline & \multirow{3}{*}{ medial } & Média & --- & 0,00 & \\
\hline & & Desvio-padrão & --- & --- & não analisado \\
\hline & & $\mathrm{n}$ & --- & 1 & \\
\hline & & Média & --- & 0,00 & \\
\hline & final & Desvio-padrão & --- & --- & não analisado \\
\hline & & $\mathrm{n}$ & --- & 1 & \\
\hline & & Média & 0,00 & --- & \\
\hline TRISSÍLABO ARQUI /S/ & final & Desvio-padrão & --- & --- & não analisado \\
\hline & & $\mathrm{n}$ & 1 & --- & \\
\hline
\end{tabular}

Legenda: ENC: encontro consonantal, ARQUI: arquifonema

Todas as comparações realizadas na prova de imitação, entre os grupos, mostraram diferença estatística significante, sendo que as crianças mais novas apresentaram porcentagem de acerto menor que as mais velhas (Tabela 63). 
Tabela 63 - Comparação entre as faixas etárias quanto à estrutura CVC na imitação.

\begin{tabular}{|c|c|c|c|c|c|}
\hline Estrutura & & estatística & Gl & GII & Teste t (p) \\
\hline \multirow{6}{*}{ DISSÍLABO ARQUI /R/ } & \multirow{3}{*}{ inicial } & Média & 2,50 & 21,74 & \multirow{3}{*}{0,005 * } \\
\hline & & Desvio-padrão & 15,81 & 41,70 & \\
\hline & & $\mathrm{n}$ & 40 & 46 & \\
\hline & \multirow{3}{*}{ final } & Média & 0,00 & 8,89 & \multirow{3}{*}{0,044 * } \\
\hline & & Desvio-padrão & 0,00 & 28,78 & \\
\hline & & $\mathrm{n}$ & 40 & 45 & \\
\hline \multirow{6}{*}{ DISSÍLABO ARQUI /S/ } & \multirow{3}{*}{ inicial } & Média & 27,50 & 56,52 & \multirow{3}{*}{0,006 * } \\
\hline & & Desvio-padrão & 45,22 & 50,12 & \\
\hline & & $\mathrm{n}$ & 40 & 46 & \\
\hline & \multirow{3}{*}{ final } & Média & 50,00 & 78,72 & \multirow{3}{*}{0,005 * } \\
\hline & & Desvio-padrão & 50,64 & 41,37 & \\
\hline & & $\mathrm{n}$ & 40 & 47 & \\
\hline \multirow{3}{*}{ TRISSÍLABO ARQUI /R/ } & \multirow{3}{*}{ inicial } & Média & 0,00 & 14,89 & \multirow{3}{*}{$0,007^{*}$} \\
\hline & & Desvio-padrão & 0,00 & 35,99 & \\
\hline & & $n$ & 41 & 47 & \\
\hline
\end{tabular}

Legenda: ARQUI: arquifonema

Quanto à prova de nomeação (Tabela 64), os arquifonemas aparecem somente em palavras dissilábicas. Houve diferença estatística entre as faixas etárias apenas em sílaba inicial, com arquifonema $/ R /(p=0,044)$. Em sílaba final, com arquifonema /R/, e sílaba inicial, com arquifonema /S/, apesar de não haver diferença estatística, as crianças mais novas apresentaram menor porcentagem de acerto que as mais velhas.

Tabela 64 - Comparação entre as faixas etárias quanto à estrutura CVC na nomeação.

\begin{tabular}{|c|c|c|c|c|c|}
\hline Estrutura & sílaba & estatística & GI & Gll & Teste $t(p)$ \\
\hline \multirow{6}{*}{ DISSÍLABO ARQUI /R/ } & \multirow{3}{*}{ inicial } & Média & 0,00 & 11,11 & \multirow{3}{*}{0,044 * } \\
\hline & & Desvio-padrão & 0,00 & 31,87 & \\
\hline & & $\mathrm{n}$ & 17 & 36 & \\
\hline & \multirow{3}{*}{ final } & Média & 0,00 & 10,42 & \multirow{3}{*}{0,096} \\
\hline & & Desvio-padrão & 0,00 & 29,41 & \\
\hline & & $\mathrm{n}$ & 12 & 24 & \\
\hline \multirow{3}{*}{ DISSÍLABO ARQUI /S/ } & \multirow{3}{*}{ inicial } & Média & 31,82 & 52,63 & \multirow{3}{*}{0,118} \\
\hline & & Desvio-padrão & 47,67 & 50,60 & \\
\hline & & $\mathrm{n}$ & 22 & 38 & \\
\hline
\end{tabular}

Legenda: ARQUI: arquifonema 


\section{HIPÓTESE 4 - HÁ DIFERENÇA NO ACERTO DO FONEMA /S/ EM POSIÇÃO DE ONSET E CODA SILÁBICA. AO CONTRÁRIO, NÃO HÁ DIFERENÇA ENTRE O /P/ EM ONSET E CODA DE SÍLABA.}

\section{HIPÓTESE NÃO CONFIRMADA}

Como mencionado na introdução, os arquifonemas $/ S /$ e $/ R /$ são os únicos considerados na presente pesquisa a ocupar a posição de coda silábica na estrutura CVㅡ. Os fonemas /s/ e /P/ também podem aparecer em posição de onset de sílaba em estrutura $\underline{\mathrm{C} V}$ ou $\underline{\mathrm{C} V C}$. Portanto, esta parte dos resultados baseia-se na comparação destes fonemas nas duas posições que eles podem ocupar dentro de uma sílaba.

\section{Comparação entre /s/ em onset e coda silábica}

$\mathrm{Na}$ fala espontânea, houve comparação apenas em sílaba inicial nos dois grupos e em sílaba final no Gll. Nota-se que a média de acerto das crianças no /s/ em onset de sílaba é maior comparada ao acerto em coda silábica, porém esta diferença não é significante (Tabela 65).

Tabela 65 - Comparação entre /s/ em onset e coda de sílaba na fala espontânea.

\begin{tabular}{|c|c|c|c|c|c|}
\hline Grupo & Sílaba & Estatística & coda & onset & Teste $t(p)$ \\
\hline \multirow{9}{*}{ GI } & \multirow{3}{*}{ Inicial } & Média & 27.50 & 63.64 & \multirow{3}{*}{0.082} \\
\hline & & Desvio-padrão & 38.10 & 50.45 & \\
\hline & & $\mathrm{n}$ & 10 & 11 & \\
\hline & \multirow{3}{*}{ Medial } & Média & --- & 43.33 & \multirow{3}{*}{ não analisado } \\
\hline & & Desvio-padrão & --- & 49.52 & \\
\hline & & $\mathrm{n}$ & --- & 15 & \\
\hline & \multirow{3}{*}{ Final } & Média & 75.00 & 75.00 & \multirow{3}{*}{ não analisado } \\
\hline & & Desvio-padrão & 50.00 & 42.74 & \\
\hline & & $\mathrm{n}$ & 4 & 14 & \\
\hline \multirow{9}{*}{ GII } & \multirow{3}{*}{ Inicial } & Média & 48.40 & 62.50 & \multirow{3}{*}{0.312} \\
\hline & & Desvio-padrão & 44.78 & 48.33 & \\
\hline & & $\mathrm{n}$ & 26 & 20 & \\
\hline & \multirow{3}{*}{ Medial } & Média & --- & 63.16 & \multirow{3}{*}{ não analisado } \\
\hline & & Desvio-padrão & --- & 41.04 & \\
\hline & & $\mathrm{n}$ & --- & 19 & \\
\hline & \multirow{3}{*}{ Final } & Média & 70.00 & 77.65 & \multirow{3}{*}{0.618} \\
\hline & & Desvio-padrão & 42.16 & 38.78 & \\
\hline & & $\mathrm{n}$ & 10 & 22 & \\
\hline
\end{tabular}

$\mathrm{Na}$ imitação, as crianças não apresentaram diferença estatística quanto ao /s/ em onset e coda de sílaba, com exceção do Gll na sílaba final. Nesta, as crianças 
tiveram porcentagem de acerto estatisticamente mais baixa em onset que em coda silábica. Ressalta-se que no Gl o /s/ em onset de sílaba também teve menos acertos que em coda de sílaba, mas a diferença não foi estatisticamente comprovada (Tabela 66).

Tabela 66 - Comparação entre /s/ em onset e coda de sílaba na imitação.

\begin{tabular}{|c|c|c|c|c|c|}
\hline Grupo & Sílaba & Estatística & coda & onset & Teste $t(p)$ \\
\hline \multirow{6}{*}{ Gl } & \multirow{3}{*}{ Inicial } & Média & 10.00 & 24.39 & \multirow{3}{*}{0.067} \\
\hline & & Desvio-padrão & 23.20 & 43.48 & \\
\hline & & $\mathrm{n}$ & 40 & 41 & \\
\hline & \multirow{3}{*}{ Final } & Média & 42.50 & 41.67 & \multirow{3}{*}{0.933} \\
\hline & & Desvio-padrão & 50.06 & 38.10 & \\
\hline & & $\mathrm{n}$ & 40 & 41 & \\
\hline \multirow{6}{*}{ Gll } & \multirow{3}{*}{ Inicial } & Média & 39.13 & 48.94 & \multirow{3}{*}{0.299} \\
\hline & & Desvio-padrão & 39.32 & 50.53 & \\
\hline & & $\mathrm{n}$ & 46 & 47 & \\
\hline & \multirow{3}{*}{ Final } & Média & 70.21 & 51.06 & \multirow{3}{*}{0,038 * } \\
\hline & & Desvio-padrão & 46.23 & 41.69 & \\
\hline & & $n$ & 47 & 47 & \\
\hline
\end{tabular}

$\mathrm{Na}$ nomeação, houve comparação apenas em sílaba inicial. Não houve diferença entre o /s/ em onset e coda de sílaba, embora no GI, as crianças tenham apresentado mais acerto no /s/ em coda que em onset silábico (Tabela 67).

Tabela 67 - Comparação entre /s/ em onset e coda de sílaba na nomeação

\begin{tabular}{|c|c|c|c|c|c|}
\hline Grupo & Sílaba & Estatística & coda & onset & Teste $t(p)$ \\
\hline \multirow{9}{*}{ GI } & \multirow{3}{*}{ Inicial } & Média & 22.73 & 21.54 & \multirow{3}{*}{0.909} \\
\hline & & Desvio-padrão & 42.89 & 37.13 & \\
\hline & & $\mathrm{n}$ & 22 & 41 & \\
\hline & \multirow{3}{*}{ Medial } & Média & --- & 32.35 & \multirow{3}{*}{ não analisado } \\
\hline & & Desvio-padrão & --- & 47.49 & \\
\hline & & $\mathrm{n}$ & --- & 34 & \\
\hline & \multirow{3}{*}{ Final } & Média & --- & 48.78 & \multirow{3}{*}{ não analisado } \\
\hline & & Desvio-padrão & --- & 46.90 & \\
\hline & & $\mathrm{n}$ & --- & 41 & \\
\hline \multirow{9}{*}{ Gll } & \multirow{3}{*}{ Inicial } & Média & 44.87 & 52.54 & \multirow{3}{*}{0.457} \\
\hline & & Desvio-padrão & 49.73 & 43.88 & \\
\hline & & $\mathrm{n}$ & 39 & 46 & \\
\hline & \multirow{3}{*}{ Medial } & Média & --- & 58.14 & \multirow{3}{*}{ não analisado } \\
\hline & & Desvio-padrão & --- & 49.92 & \\
\hline & & $\mathrm{n}$ & --- & 43 & \\
\hline & \multirow{3}{*}{ Final } & Média & --- & 51.77 & \multirow{3}{*}{ não analisado } \\
\hline & & Desvio-padrão & --- & 43.72 & \\
\hline & & $\mathrm{n}$ & --- & 47 & \\
\hline
\end{tabular}

\section{Comparação entre /P/ em onset e coda silábica}


Na fala espontânea (Tabela 68), a comparação entre o /P/ em onset e coda de sílaba, nos dois grupos, mostrou diferença significante entre as duas posições do fonema em sílaba final. Observa-se que em onset, houve mais acerto que coda. No grupo de crianças mais velhas, também foi realizada comparação em sílaba medial. Porém, não houve diferença entre o /P/ em coda e onset de sílaba, apesar deste fonema ter tido mais acerto em onset.

Tabela 68 - Comparação entre /P/ em onset e coda de sílaba na fala espontânea.

\begin{tabular}{|c|c|c|c|c|c|}
\hline Grupo & Sílaba & Estatística & coda & onset & Teste $t(p)$ \\
\hline \multirow{9}{*}{ Gl } & \multirow{3}{*}{ Inicial } & Média & 14.29 & --- & \multirow{3}{*}{ não analisado } \\
\hline & & Desvio-padrão & 36.31 & --- & \\
\hline & & $\mathrm{n}$ & 14 & --- & \\
\hline & \multirow{3}{*}{ Medial } & Média & 0.00 & 30.00 & \multirow{3}{*}{ não analisado } \\
\hline & & Desvio-padrão & 0.00 & 42.16 & \\
\hline & & $\mathrm{n}$ & 3 & 10 & \\
\hline & \multirow{3}{*}{ Final } & Média & 0.86 & 48.78 & \multirow{3}{*}{$<0,001$ * } \\
\hline & & Desvio-padrão & 4.64 & 39.23 & \\
\hline & & $\mathrm{n}$ & 29 & 24 & \\
\hline \multirow{9}{*}{ Gll } & \multirow{3}{*}{ Inicial } & Média & 22.81 & --- & \multirow{3}{*}{ não analisado } \\
\hline & & Desvio-padrão & 38.17 & --- & \\
\hline & & $\mathrm{n}$ & 19 & --- & \\
\hline & \multirow{3}{*}{ Medial } & Média & 30.00 & 55.95 & \multirow{3}{*}{0.205} \\
\hline & & Desvio-padrão & 48.30 & 47.86 & \\
\hline & & $\mathrm{n}$ & 10 & 14 & \\
\hline & \multirow{3}{*}{ Final } & Média & 7.50 & 41.16 & \multirow{3}{*}{0,001 * } \\
\hline & & Desvio-padrão & 22.36 & 46.30 & \\
\hline & & $\mathrm{n}$ & 30 & 33 & \\
\hline
\end{tabular}

Nas provas de imitação (Tabela 69) e nomeação (Tabela 70) foi realizada comparação apenas em sílaba final. Os dados constataram que o desempenho do fonema /P/ foi significantemente maior em onset que em coda silábica. 
Tabela 69 - Comparação entre /P/ em onset e coda de sílaba na imitação

\begin{tabular}{|c|c|c|c|c|c|}
\hline Grupo & Sílaba & Estatística & coda & onset & Teste $t(p)$ \\
\hline \multirow{6}{*}{ GI } & \multirow{3}{*}{ Inicial } & Média & 1.22 & --- & \multirow{3}{*}{ não analisado } \\
\hline & & Desvio-padrão & 7.81 & --- & \\
\hline & & $\mathrm{n}$ & 41 & --- & \\
\hline & \multirow{3}{*}{ Final } & Média & 0.00 & 21.95 & \multirow{3}{*}{$<0,001^{*}$} \\
\hline & & Desvio-padrão & 0.00 & 32.16 & \\
\hline & & $\mathrm{N}$ & 40 & 41 & \\
\hline \multirow{6}{*}{ GII } & \multirow{3}{*}{ Inicial } & Média & 14.89 & --- & \multirow{3}{*}{ não analisado } \\
\hline & & Desvio-padrão & 27.42 & --- & \\
\hline & & $\mathrm{n}$ & 47 & --- & \\
\hline & \multirow{3}{*}{ Final } & Média & 8.89 & 33.33 & \multirow{3}{*}{0,001 * } \\
\hline & & Desvio-padrão & 28.78 & 38.07 & \\
\hline & & $\mathrm{n}$ & 45 & 47 & \\
\hline
\end{tabular}

Tabela 70 - Comparação entre /P/ onset e coda de sílaba na nomeação

\begin{tabular}{|c|c|c|c|c|c|}
\hline Grupo & Sílaba & Estatística & coda & onset & Teste t $(p)$ \\
\hline \multirow{9}{*}{ Gl } & \multirow{3}{*}{ Inicial } & Média & 0.00 & --- & \multirow{3}{*}{ não analisado } \\
\hline & & Desvio-padrão & 0.00 & --- & \\
\hline & & $\mathrm{n}$ & 17 & --- & \\
\hline & \multirow{3}{*}{ Medial } & Média & --- & 66.67 & \multirow{3}{*}{ não analisado } \\
\hline & & Desvio-padrão & --- & 57.74 & \\
\hline & & $\mathrm{n}$ & --- & 3 & \\
\hline & \multirow{3}{*}{ Final } & Média & 0.00 & 32.67 & \multirow{3}{*}{$<0,001^{*}$} \\
\hline & & Desvio-padrão & 0.00 & 39.91 & \\
\hline & & $n$ & 12 & 38 & \\
\hline \multirow{9}{*}{ Gll } & \multirow{3}{*}{ Inicial } & Média & 11.11 & --- & \multirow{3}{*}{ não analisado } \\
\hline & & Desvio-padrão & 31.87 & --- & \\
\hline & & $\mathrm{n}$ & 36 & --- & \\
\hline & \multirow{3}{*}{ Medial } & Média & --- & 46.15 & \multirow{3}{*}{ não analisado } \\
\hline & & Desvio-padrão & --- & 51.89 & \\
\hline & & $\mathrm{N}$ & --- & 13 & \\
\hline & \multirow{3}{*}{ Final } & Média & 10.42 & 38.23 & \multirow{3}{*}{0,002 * } \\
\hline & & Desvio-padrão & 29.41 & 42.15 & \\
\hline & & $\mathrm{N}$ & 24 & 46 & \\
\hline
\end{tabular}


HIPÓTESE 5 - HÁ DIFERENTES TIPOS DE ERROS PREDOMINANTES: EM ENCONTROS CONSONANTAIS ACONTECE EM FUNÇÃO DO /P/ E /l/; NOS FONEMAS CADA UM APRESENTA DIFERENÇAS EM FUNÇÃO DAS CATEGORIAS OMISSÃO, SUBSTITUIÇÃO E DISTORCCÃO E, NAS ESTRUTURAS SILÁBICAS A DIVERSIDADE OCORRE EM FUNÇÃO DA EXTENSÃO DA PALAVRA. ALÉM DISSO, TAMBÉM SE SUPÕE QUEE AS CRIANÇAS DO GI APRESENTEM MAIS OCORRÊNCIA DE ERROS QUE AS DO GII.

HIPÓTESE CONFIRMADA

Esse estudo refere-se à análise dos erros observados em crianças dos dois grupos, nas provas de nomeação, imitação e fala espontânea, por posição silábica. Para a análise qualitativa, estabeleceu-se que o alvo somente seria analisado quando pelo menos metade dos sujeitos do grupo o tivessem emitido.

Além de uma analise qualitativa que aponta os erros mais observados em cada encontro consonantal, fonema e estrutura silábica, foi realizada comparação estatística entre os dois grupos de crianças quando um tipo de erro excedeu o valor de dez ocorrências em pelo menos um dos grupos, a fim de verificar se havia diferença entre as faixas etárias quanto ao tipo de erro cometido. Para esta comparação foi usado teste de proporção com nível de significância 0,05.

Para a representação da porcentagem de acerto, foi usado "C" que indica produção correta. Os tipos de erros que serão abordados são: OF: omissão de fonema, OS: omissão de sílaba, S: substituição, D: distorção, CA: ceceio anterior, CL: ceceio lateral, I: interdentalização.

- Encontros consonantais

Quanto aos encontros consonantais com //, a maior parte dos erros foi de substituição (Figura 9). Dentre estes erros, o mais freqüente foi a substituição pelo primeiro segmento, ou seja, eliminação da líquida. Nos encontros com /bl/, /pl/ nos dois grupos e no/fl/ no grupo de crianças mais velhas, o segundo erro mais freqüente foi para $/ \mathrm{bP} /$, $/ \mathrm{pP} /$ e $/ \mathrm{fP} /$, respectivamente. No encontro com $/ \mathrm{gl} /$, as crianças do Gl também substituíram por /d/ e as do Gll por /b/. No encontro /kl/ os dois grupos substituíram por /t/ e no /fl/ nas crianças mais novas para /p/. 
Figura 9 - Erros para o encontro com ///.

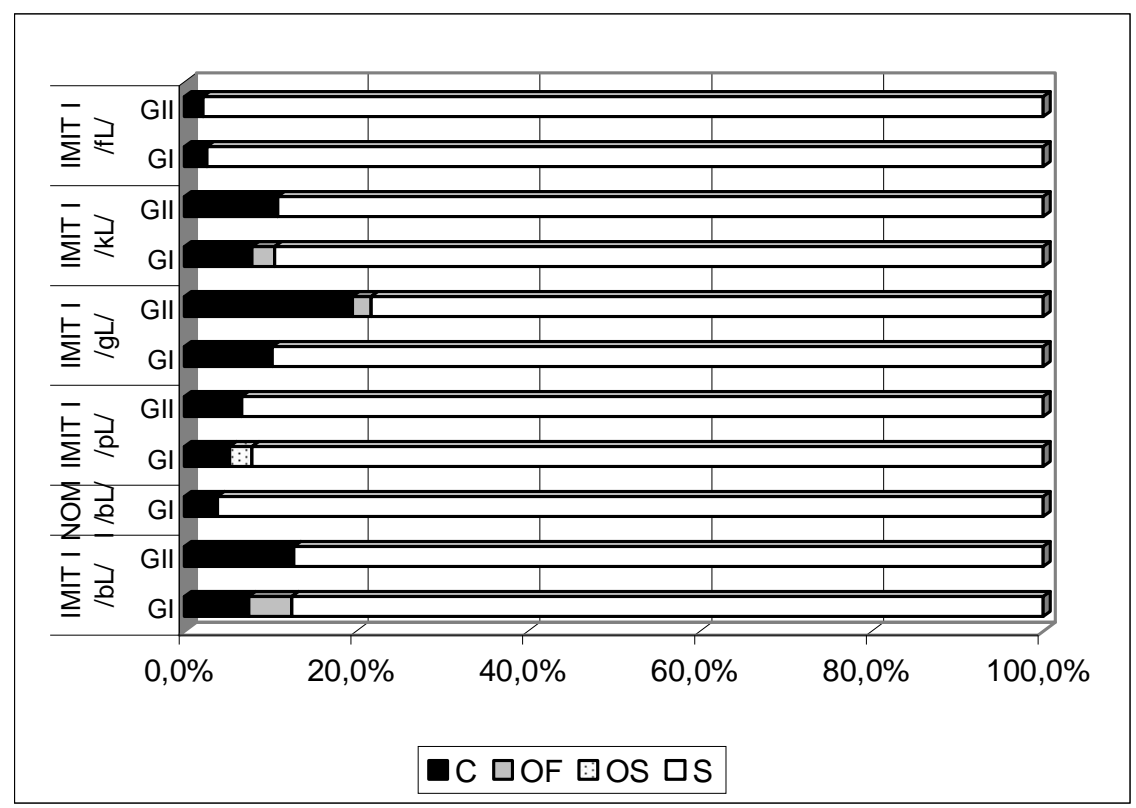

A comparação entre os erros mais freqüentes dos dois grupos por meio do teste de proporção (n. sig. 0,05$)$ indicou que não houve diferença entre as faixas etárias para os erros cometidos (Tabela 71).

Tabela 71- Comparação entre as faixas etárias para erros do encontro com ///.

\begin{tabular}{|c|c|c|c|c|c|c|c|c|c|}
\hline \multirow[b]{2}{*}{ prova } & \multirow[b]{2}{*}{$\begin{array}{c}\text { encontro/ } \\
\text { sílaba }\end{array}$} & \multirow[b]{2}{*}{ tipo erro } & \multicolumn{3}{|c|}{$\mathrm{Gl}$} & \multicolumn{3}{|c|}{ GII } & \multirow[b]{2}{*}{$\begin{array}{l}\text { Teste de } \\
\text { proporção }\end{array}$} \\
\hline & & & $\begin{array}{c}\text { № } \\
\text { erros }\end{array}$ & $\begin{array}{l}\text { possibi- } \\
\text { lidade }\end{array}$ & $\%$ & $\begin{array}{c}\text { № } \\
\text { erros }\end{array}$ & $\begin{array}{l}\text { possibi- } \\
\text { lidade. }\end{array}$ & $\%$ & \\
\hline \multirow{5}{*}{ imitação } & bl inicial & $\mathrm{S} / \mathrm{b} /$ & 24 & 40 & 60.0 & 33 & 47 & 70.2 & 0.3179 \\
\hline & pl inicial & $\mathrm{S} / \mathrm{p} /$ & 31 & 38 & 81.6 & 36 & 45 & 80.0 & 0.8558 \\
\hline & gl inicial & $\mathrm{S} / \mathrm{g} /$ & 28 & 39 & 71.8 & 29 & 146 & 19.9 & 0.3926 \\
\hline & $\mathrm{kl}$ inicial & $\mathrm{S} / \mathrm{k} /$ & 25 & 38 & 65.8 & 35 & 46 & 76.1 & 0.2984 \\
\hline & fl inicial & $\mathrm{S} / \mathrm{f} /$ & 27 & 38 & 71.1 & 36 & 46 & 78.3 & 0.4476 \\
\hline \multirow{2}{*}{ nomeação } & bl inicial & $\mathrm{S} / \mathrm{b} /$ & 22 & 26 & 84.6 & 15 & 17 & 88.2 & 0.738 \\
\hline & pl inicial & $\mathrm{S} / \mathrm{p} /$ & 14 & 17 & 82.4 & 16 & 21 & 76.2 & 0.643 \\
\hline
\end{tabular}

Legenda: S: substituição por um determinado fonema

Em relação ao encontro com $/ \mathrm{P} /$, a maior parte dos erros é de substituição (Figura 10), sendo que esta ocorre para o primeiro segmento, havendo eliminação da líquida. Demais erros englobam substituição da líquida /P/ para /// no grupo mais velho. Nos encontros com $/ \mathrm{kP} /$ e $/ \mathrm{gP} /$, é comum ter substituição para $/ \mathrm{t} / \mathrm{e} / \mathrm{d} /$, respectivamente e, nos encontros com $/ \mathrm{tP} /$ e $/ \mathrm{dP} /$, para $/ \mathrm{k} /$ e $/ \mathrm{g} /$, respectivamente. Isso foi observado nos dois grupos. 
Figura 10- Erros para o encontro com /P/.

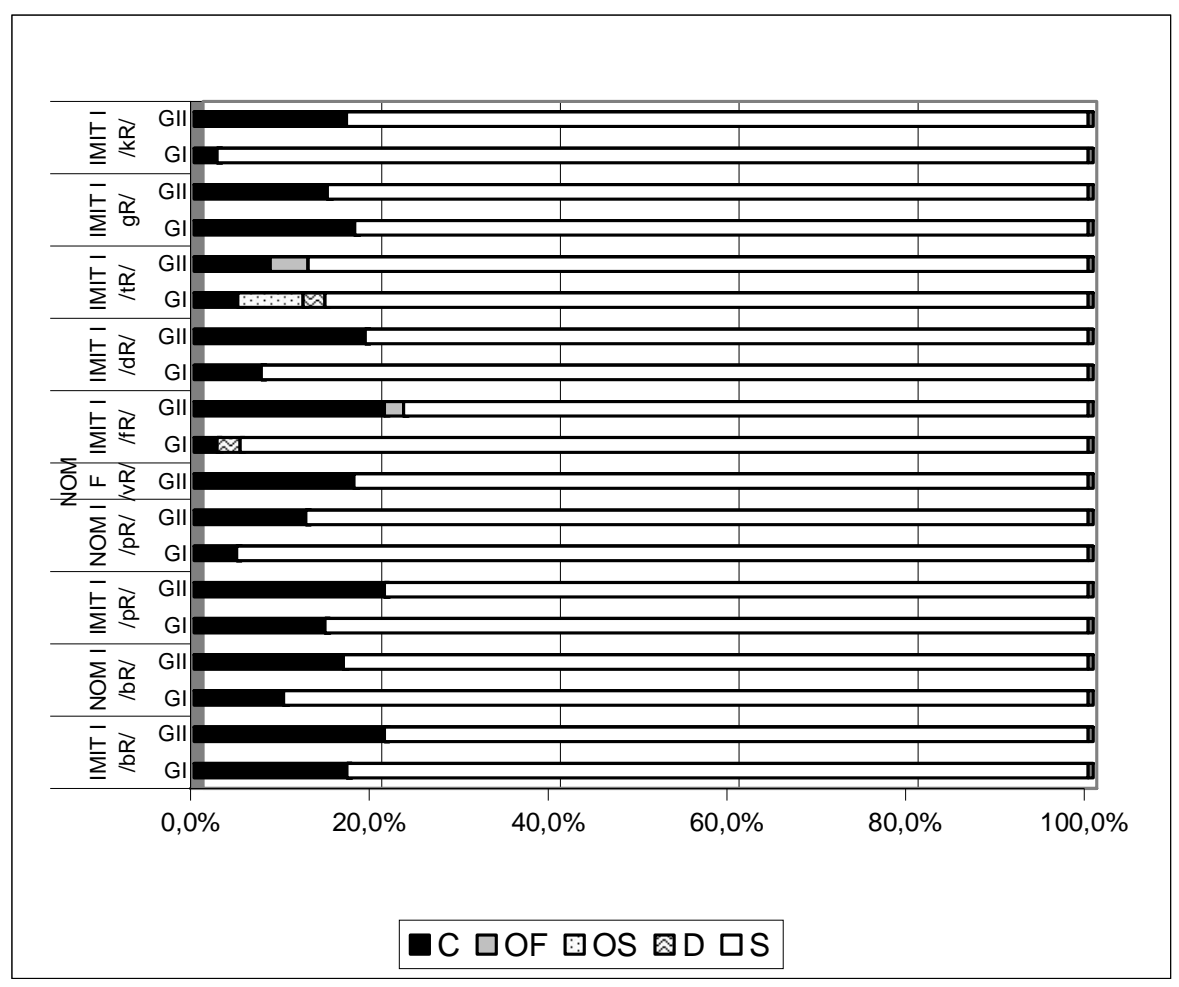

Porém, o teste de proporção não mostrou diferença entre os grupos para nenhum tipo de erro, com exceção do encontro com /fP/ na imitação em sílaba inicial (Tabela 72).

Tabela 72 - Comparação entre as faixas etárias para erros do encontro com /P/.

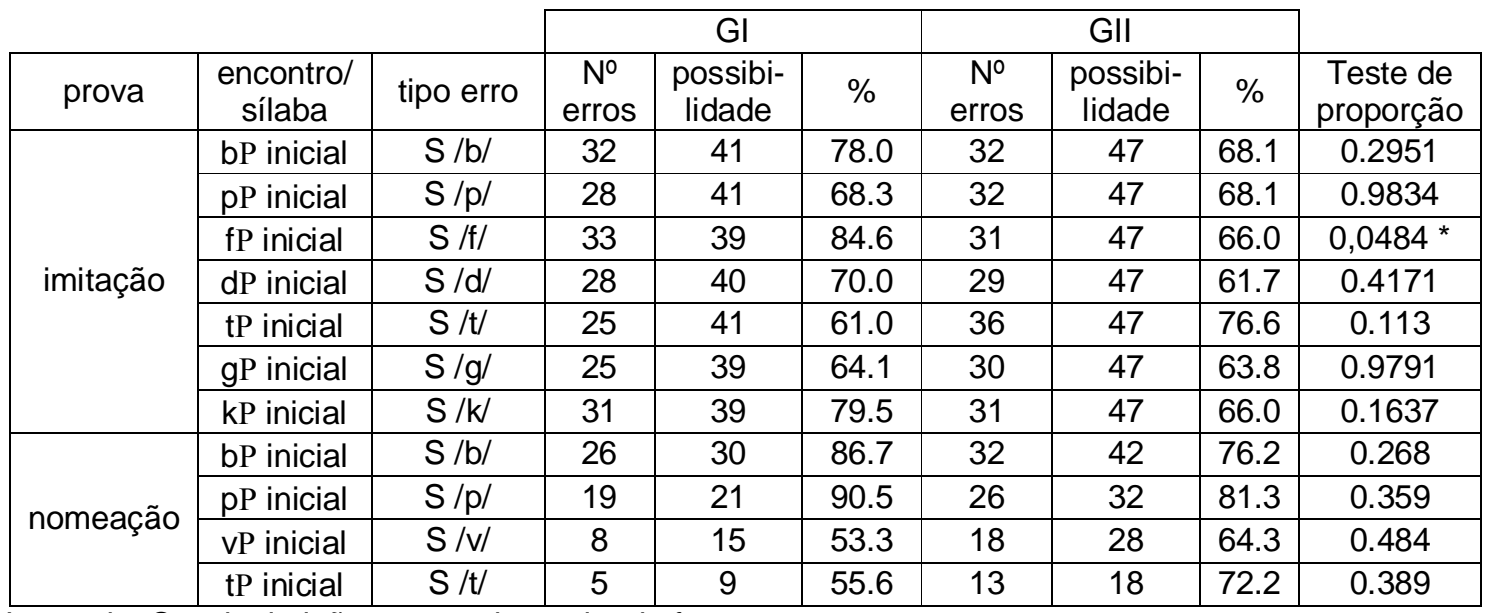

Legenda: S: substituição por um determinado fonema 
- Fonemas

plosivas

Nota-se que em todas as provas e posições silábicas predominou o acerto no fonema /b/ (Figura 11). O erro mais freqüente cometido pelo Gll, na fala espontânea, e pelo Gl, em sílaba inicial, da imitação, foi omissão de sílaba. Nas outras situações, o erro mais freqüente foi de substituição por $/ p /$, nos dois grupos. Somente na imitação em sílaba final, o /b/ foi mais substituído por /bP/.

Figura 11- Erros para o fonema /b/.

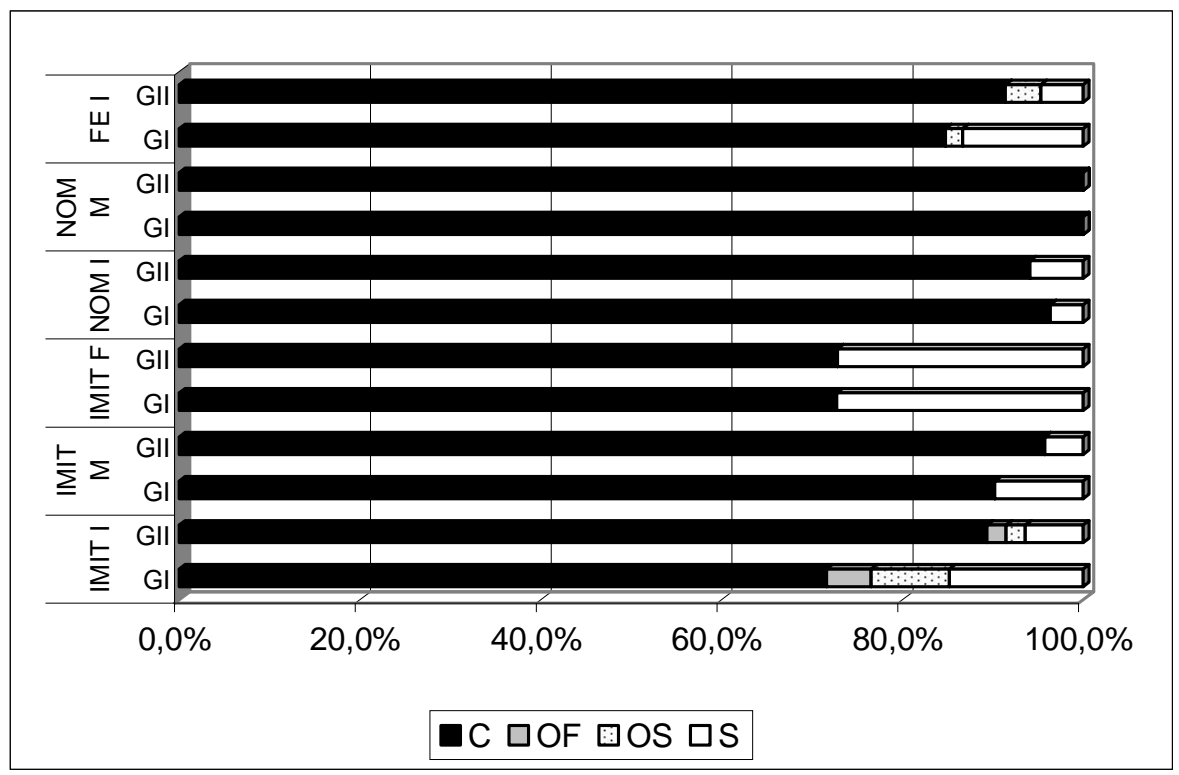

O teste de proporção foi realizado na imitação apenas em sílaba final, quanto ao tipo de erro de substituição para /bP/. Não houve diferença estatística entre os dois grupos $(p=0,1367)$, apesar do Gll ter apresentado maior média deste erro.

O fonema / $/$ / também teve alta porcentagem de acerto (Figura 12), sendo que na nomeação, em sílaba medial, não apresentou erros. A maior parte dos erros é de substituição por outro fonema. No Gl, em sílaba inicial da imitação, a omissão de sílaba foi mais freqüente quando comparada a qualquer tipo de substituição.

Não houve substituição mais freqüente para um determinado fonema (Anexo I). Pode-se dizer, no entanto, que a única substituição realizada por ambos os grupos na nomeação, em sílaba final, foi de /p/ para o / $/$. 
O teste de proporção não foi realizado para nenhum tipo de erro do fonema $/ \mathrm{p} /$.

Figura 12- Erros para o fonema /p/.

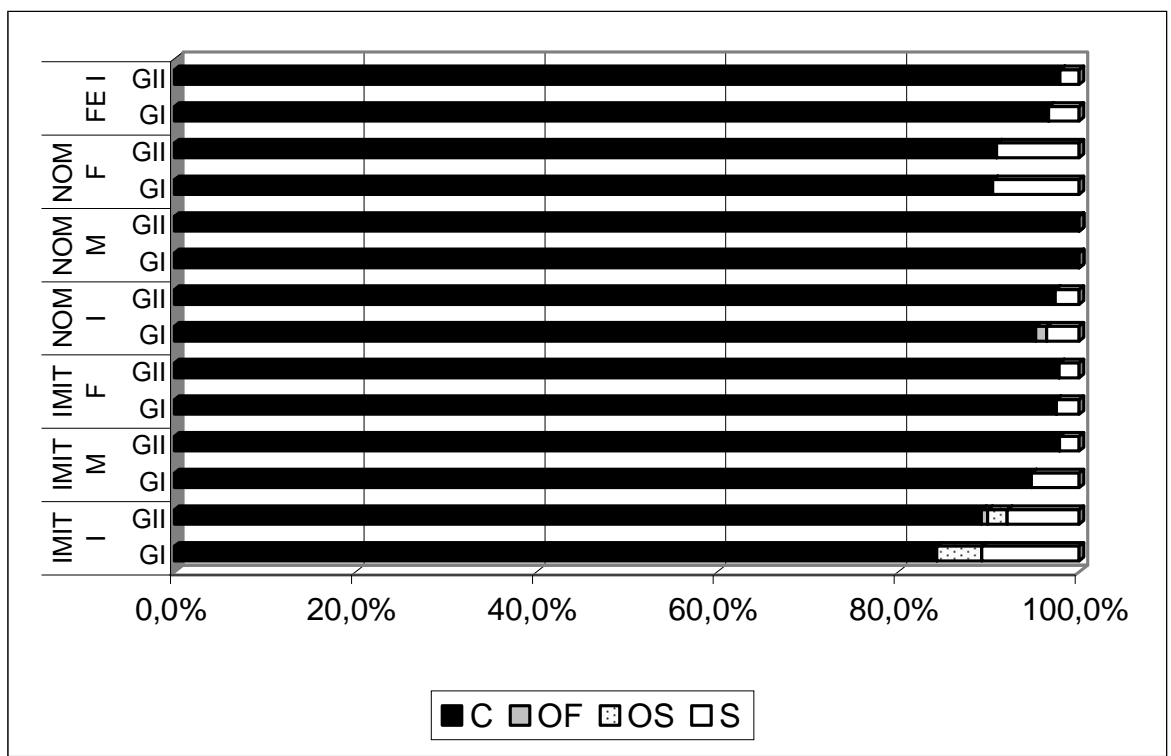

Quanto ao fonema /d/, os erros mais freqüentes foram de substituição e de interdentalização (Figura 13). Considerando cada tipo de substituição separadamente, na imitação o erro mais comum foi de substituição do /d/ para /t/ e, na nomeação e fala espontânea, a interdentalização (Anexo I).

Também não houve comparação entre os erros para o fonema /d/, mostrando que nenhum tipo de erro apresentou dez ou mais ocorrências. 
Figura 13- Erros para o fonema /d/.

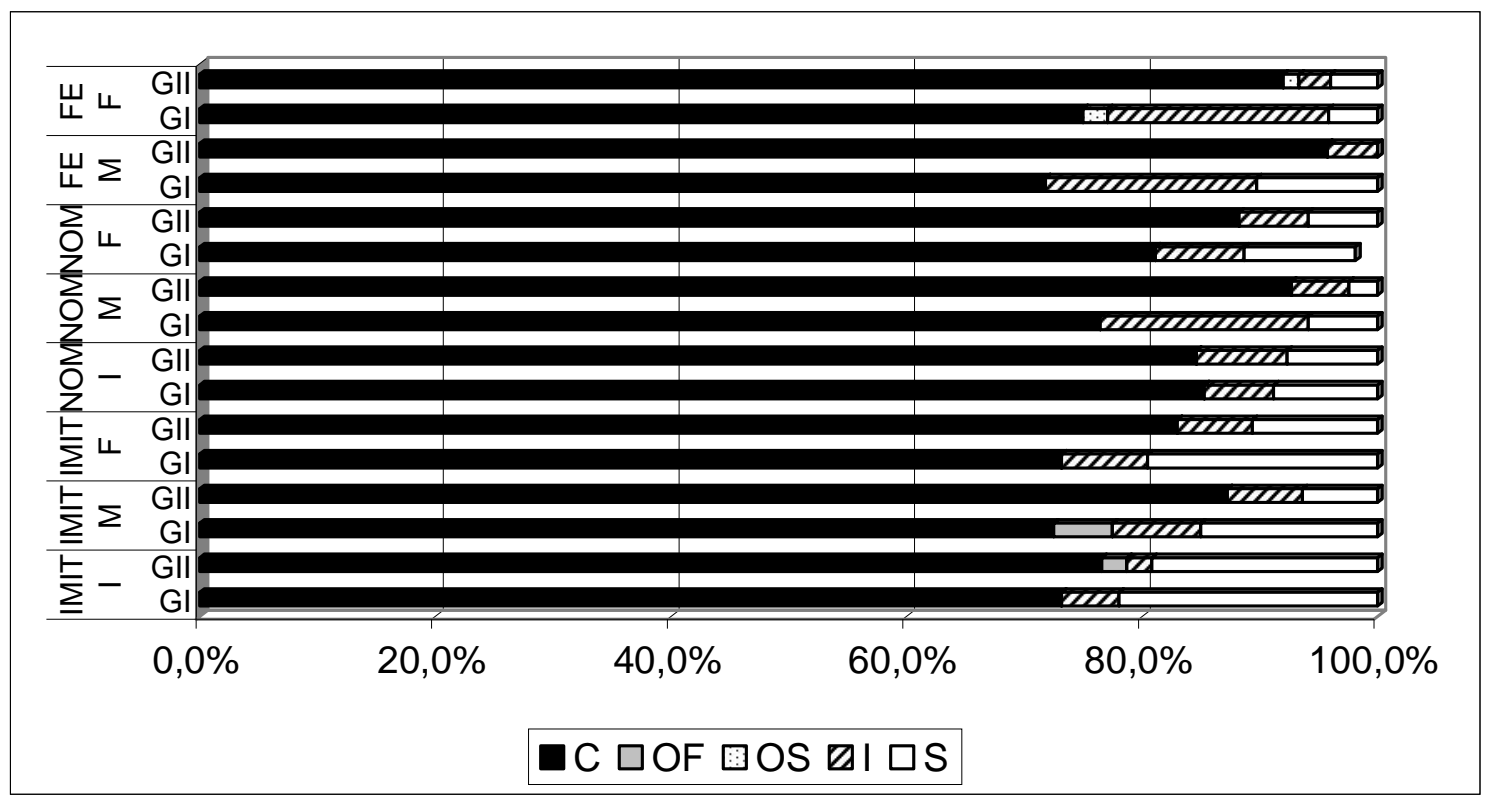

No fonema /t/ as crianças mais novas apresentaram mais erro de omissão de sílaba, na imitação, em sílaba inicial. A interdentalização foi o erro mais observado na sílaba final, das três provas, nas duas faixas etárias (Figura 14). Nas demais provas e sílabas, os mais freqüentes foram substituição do /t/ para $/ \Sigma /$, seguido da substituição por/s/ (Anexo l).

Foi realizada comparação entre a ocorrência de interdentalização, por meio do teste de proporção (n. sig. 0,05), na imitação e nomeação, em sílaba final. Não houve diferença estatística entre este tipo de erro para os dois grupos $(p=0,2165$ e $\mathrm{p}=0,198$, imitação e nomeação, respectivamente), sendo que o $\mathrm{Gl}$ apresentou maior porcentagem de ocorrência. 
Figura 14 - Erros para o fonema /t/.

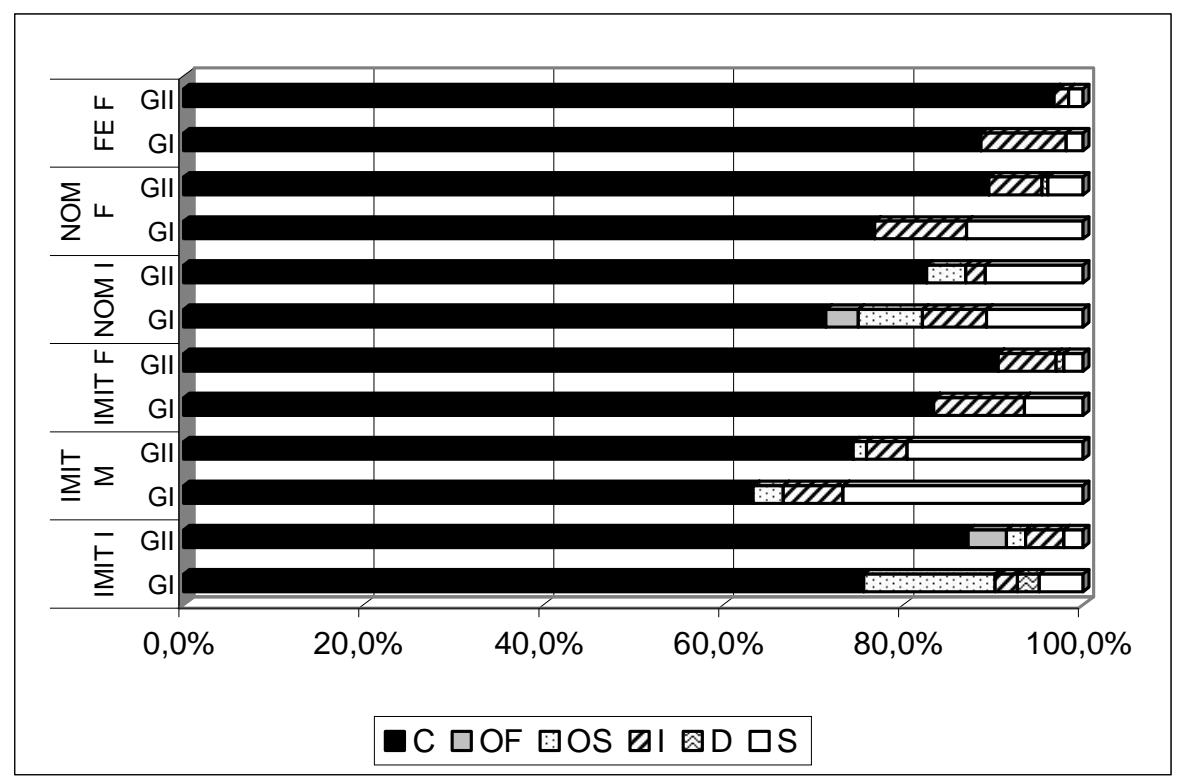

O fonema $/ \mathrm{g} /$ apresentou como único tipo de erro a substituição (Figura 15). As substituições mais freqüentes do $/ g /$ foram para os fonemas $/ \mathrm{k} /$ e $/ \mathrm{t} /$ nos dois grupos (Anexo I), sendo que elas são as únicas apresentadas pelas crianças na sílaba inicial, do Gl e do Gll, e medial, do Gll, na imitação. Na sílaba final do Gll na nomeação, houve substituição somente para /d/.

Figura 15- Erros para o fonema /g/.

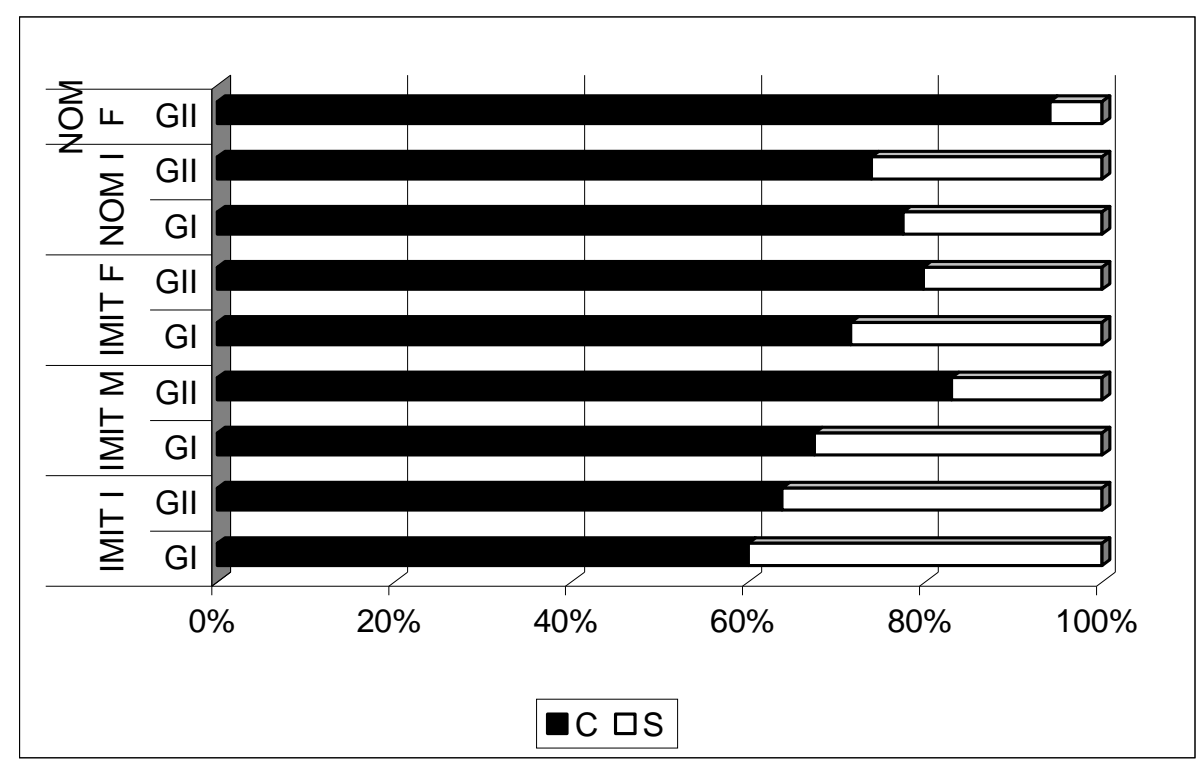


Comparando os tipos de erros com mais de dez ocorrências em pelo menos um dos grupos (Tabela 73), não houve diferença estatística entre as faixas etárias. Porém, o Gl obteve maior porcentagem destes erros que o Gll.

Tabela 73 - Comparação entre as faixas etárias para erros do fonema /g/.

\begin{tabular}{|c|c|c|c|c|c|c|c|c|c|}
\hline & & & & & & \multirow{2}{*}{\multicolumn{3}{|c|}{ GII }} & \multirow[b]{3}{*}{$\begin{array}{l}\text { Teste de } \\
\text { proporção }\end{array}$} \\
\hline & \multicolumn{3}{|c|}{$\mathrm{Gl}$} & & & & \\
\hline prova & sílaba & Tipo de erro & $\begin{array}{c}\text { № } \\
\text { erros }\end{array}$ & $\begin{array}{l}\text { possibi- } \\
\text { lidade }\end{array}$ & $\%$ & $\begin{array}{c}\text { № } \\
\text { erros }\end{array}$ & $\begin{array}{l}\text { possibi- } \\
\text { lidade }\end{array}$ & $\%$ & \\
\hline \multirow{3}{*}{ imitação } & inicial & $\mathrm{S} / \mathrm{k} /$ & 11 & 40 & 27.5 & 11 & 47 & 23.4 & 0.6614 \\
\hline & final & $\mathrm{S} / \mathrm{d} /$ & 11 & 81 & 13.6 & 7 & 94 & 7.4 & 0.1829 \\
\hline & final & $\mathrm{S} / \mathrm{k} /$ & 11 & 81 & 13.6 & 6 & 94 & 6.4 & 0.1089 \\
\hline nomeação & inicial & $S / k /$ & 6 & 40 & 15.0 & 10 & 69 & 14.5 & 0.943 \\
\hline
\end{tabular}

Legenda: S: substituição por um determinado fonema

A maior parte dos erros realizados, pelas crianças dos dois grupos, para o fonema / $/$ foi de substituição (Figura 16), sendo esta mais freqüente para o fonema /t/ (Anexo I).

Figura 16 - Erros para o fonema /k/.

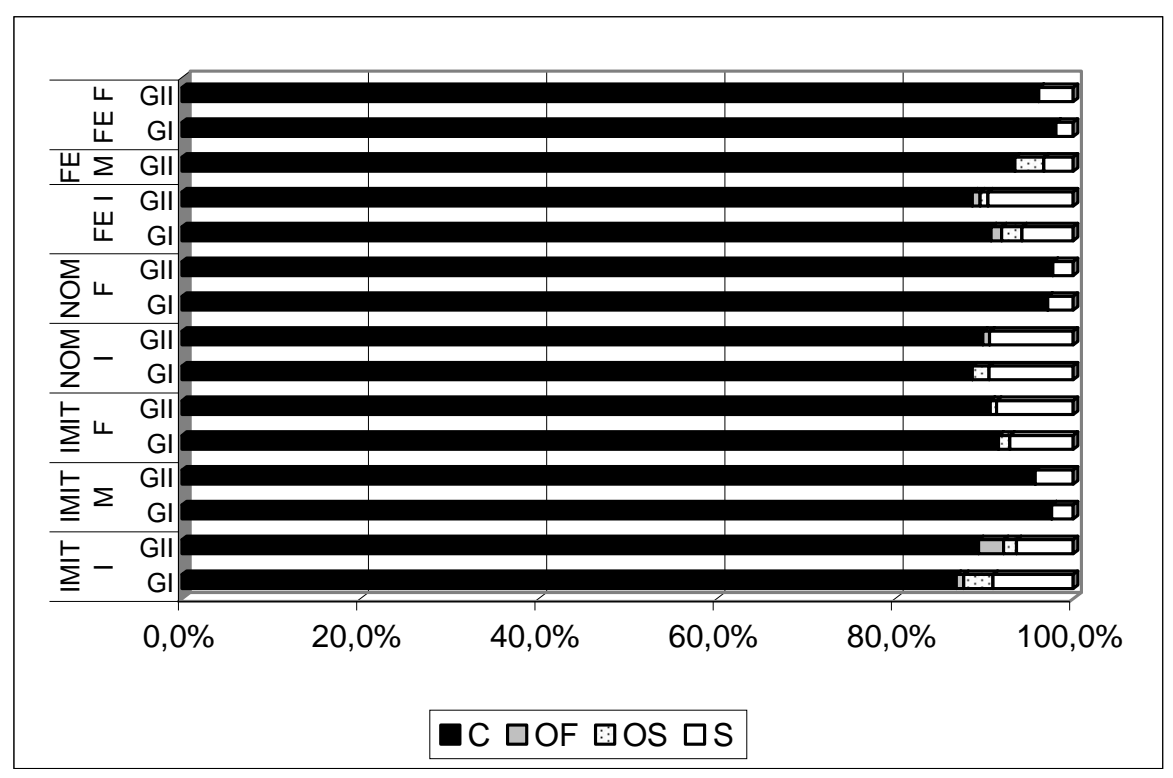

O único tipo de erro do fonema / $/ \mathrm{k}$ para o qual pôde ser realizado o teste de proporção foi a substituição por /t/, não havendo diferença entre as duas faixas etárias (Tabela 74). 
Tabela 74 - Comparação entre as faixas etárias para erros do fonema / $/ \mathrm{k}$.

\begin{tabular}{|c|c|c|c|c|c|c|c|c|c|}
\hline & & & \multicolumn{3}{|c|}{ Gl } & \multicolumn{3}{|c|}{ Gll } & \\
\hline prova & $\begin{array}{c}\text { Fonema/ } \\
\text { sílaba }\end{array}$ & $\begin{array}{l}\text { Tipo de } \\
\text { erro }\end{array}$ & $\begin{array}{c}\text { № } \\
\text { erros }\end{array}$ & $\begin{array}{l}\text { possibi- } \\
\text { lidade }\end{array}$ & $\%$ & $\begin{array}{c}\text { № } \\
\text { erros }\end{array}$ & $\begin{array}{l}\text { possibi- } \\
\text { lidade. }\end{array}$ & $\%$ & $\begin{array}{l}\text { Teste de } \\
\text { proporção }\end{array}$ \\
\hline $\begin{array}{c}\text { Fala } \\
\text { espontânea }\end{array}$ & inicial & $\mathrm{s} / \mathrm{t} /$ & 7 & 174 & 4.0 & 15 & 230 & 6.5 & 0.297 \\
\hline Imitação & final & $\mathrm{s} / \mathrm{t} /$ & 12 & 239 & 5.0 & 19 & 379 & 5.0 & 0.3921 \\
\hline Nomeação & inicial & $\mathrm{s} / \mathrm{t} /$ & 8 & 106 & 7.5 & 10 & 128 & 7.8 & 0.940 \\
\hline
\end{tabular}

Legenda: S: substituição por um determinado fonema

fricativas

A Figura 17 mostra os erros mais ocorrentes do fonema /z/. A maior parte deles foi de substituição, sendo que no Gl, este fonema foi mais substituído por/s/ e, no Gll, foi tanto para o /s/ como para o /Z/ (Anexo I).

Figura 17- Erros para o fonema /z/

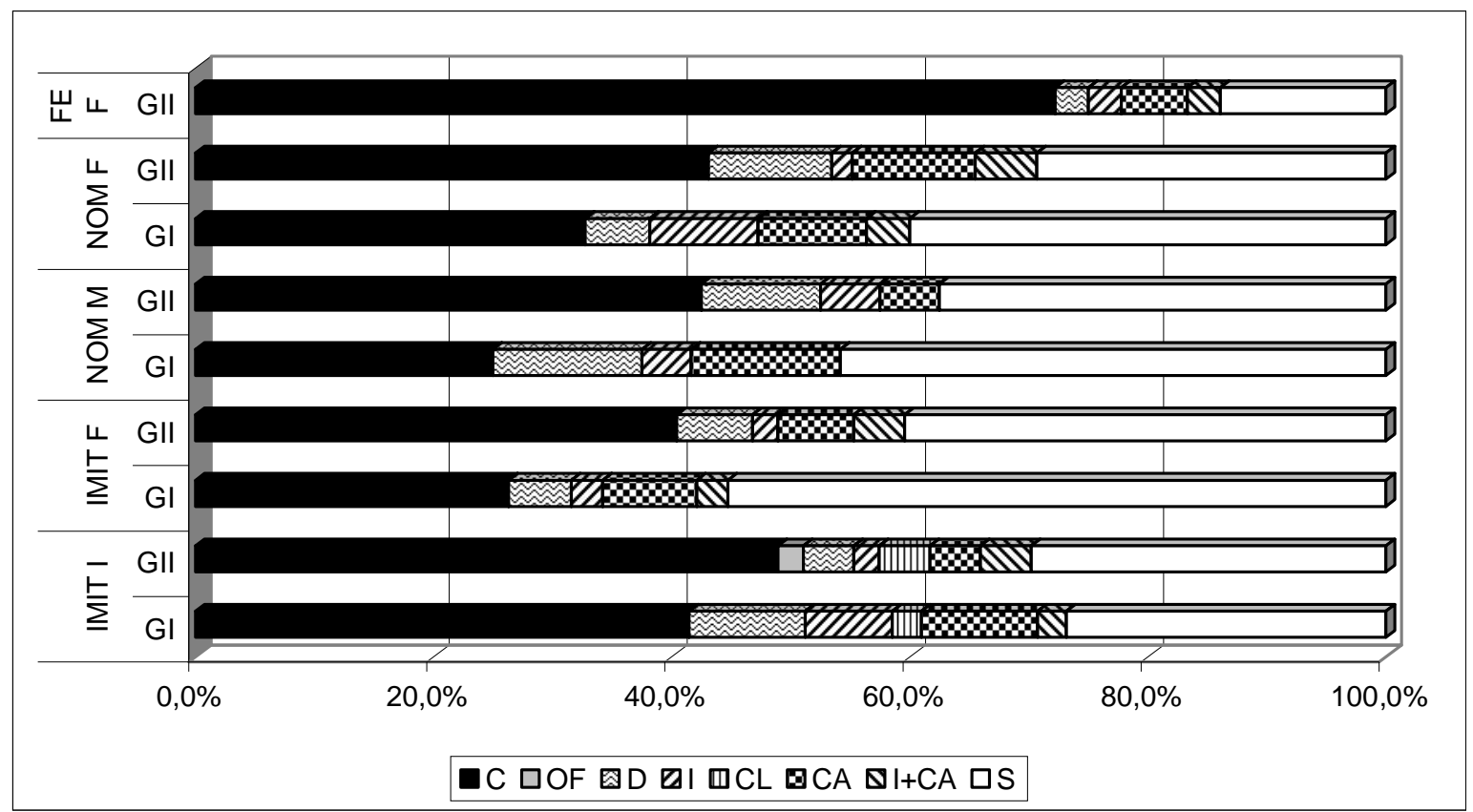

O teste de proporção para tipos de erros do fonema foi realizado apenas na nomeação, em sílaba final, para a substituição do /z/ pelo/s/. Não houve diferença entre as duas faixas etárias $(p=0,059)$, ressaltando-se que $\circ \mathrm{Gl}$ apresentou maior porcentagem deste erro que o Gll.

O fonema / $/$ / também apresentou como maior parte de seus erros a substituição (Figura 18), sendo as mais freqüentes pelo fonema $/ \Sigma /$ (Anexo I). Outras 
substituições também ocorreram, porém, os erros mais ocorrentes, após a substituição por $/ \Sigma /$, foram as distorções acústicas e articulatórias.

Figura 18 - Erros para o fonema /s/

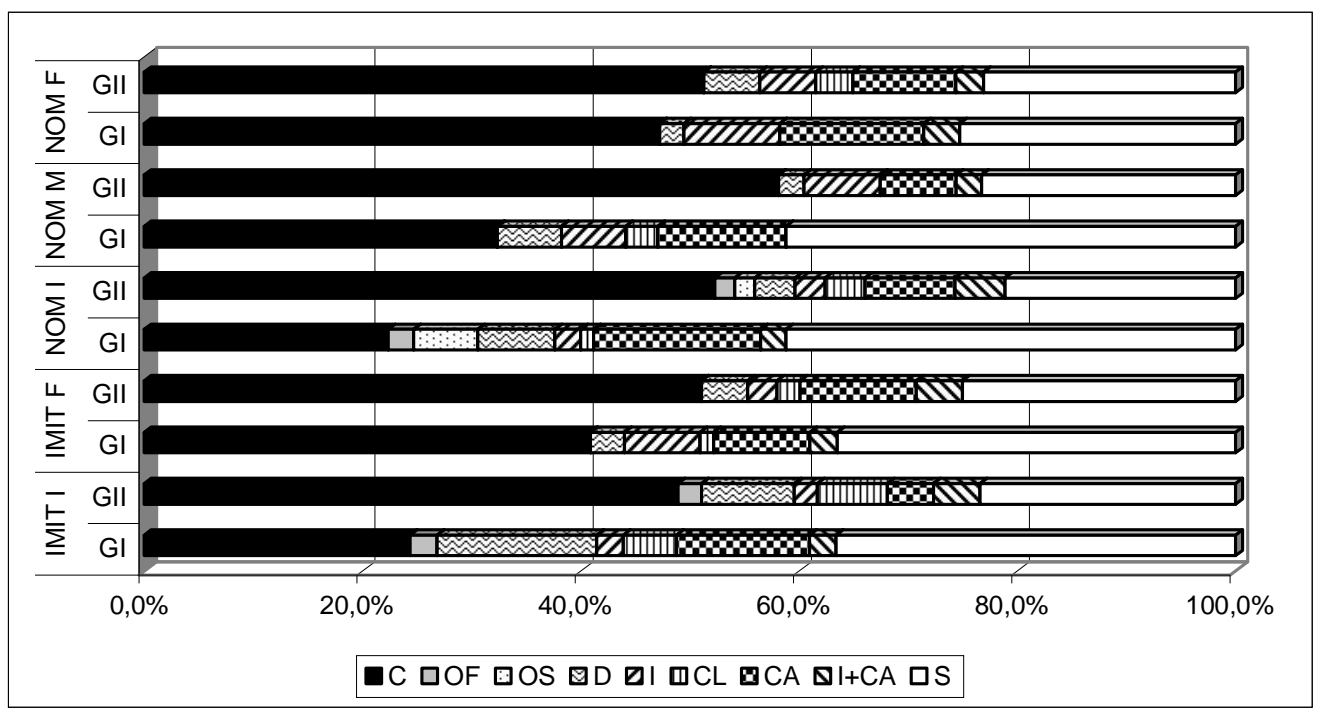

A Tabela 75 mostra os tipos de erros em que foi possível a realização do teste de proporção do fonema /s/. Houve diferença estatística entre as duas faixas etárias para a substituição por /t $\Sigma /$ na imitação, em sílaba final, e para a substituição por $/ \Sigma /$, na sílaba inicial, na nomeação. Nestas duas situações o Gl apresentou maior porcentagem destes erros.

Tabela 75 - Comparação entre as faixas etárias para erros do fonema /s/

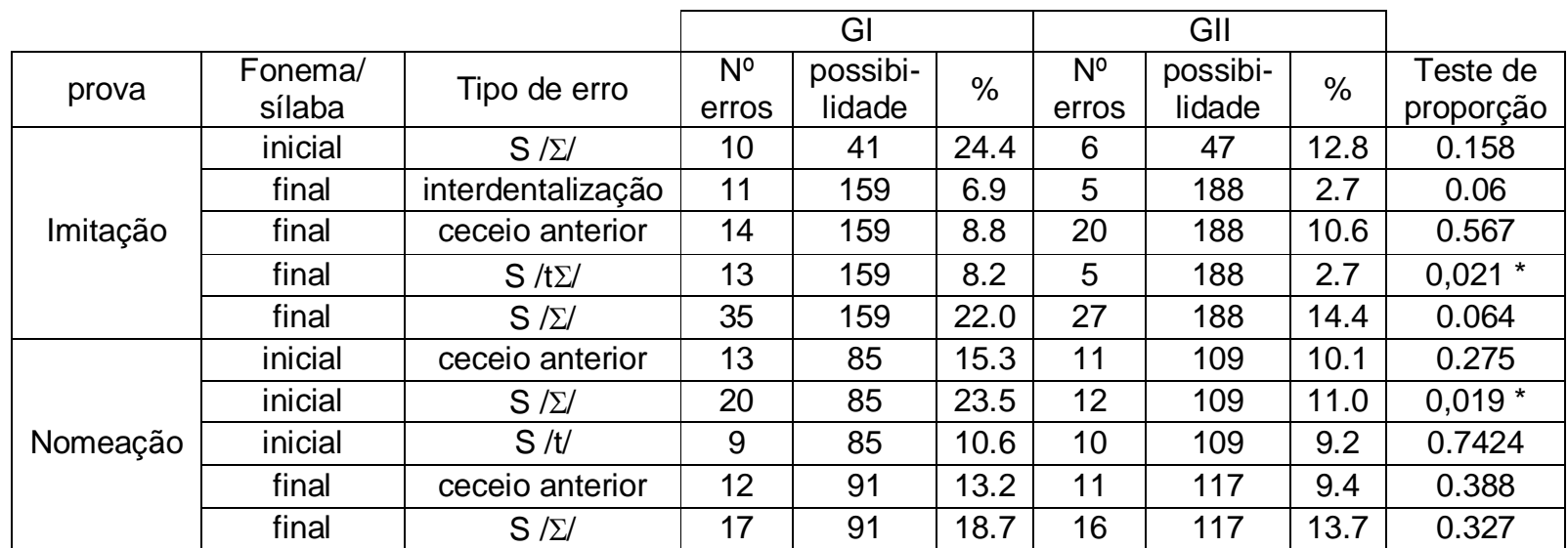

Legenda: S: substituição por um determinado fonema

O fonema /v/ apresentou como erro, basicamente, a substituição (Figura 19). Nas sílabas inicial e final, da prova de imitação, foi a substituição por /f/. Na sílaba medial da mesma prova, no GI, foi a substituição por /b/, e, no Gll, por /d/ e /vP/, 
sendo esta a posição de sílaba que mais mostrou diversidade de substituições para outros fonemas, nos dois grupos. Na nomeação, em sílaba inicial, foi evidente a maior parte dos erros ser de substituição por /b/ tanto nas crianças mais novas como nas mais velhas. Na fala espontânea, observada apenas em sílaba final do Gl, a substituição por /d/ foi o erro mais ocorrente (Anexo I).

Figura 19 - Erros para o fonema /v/

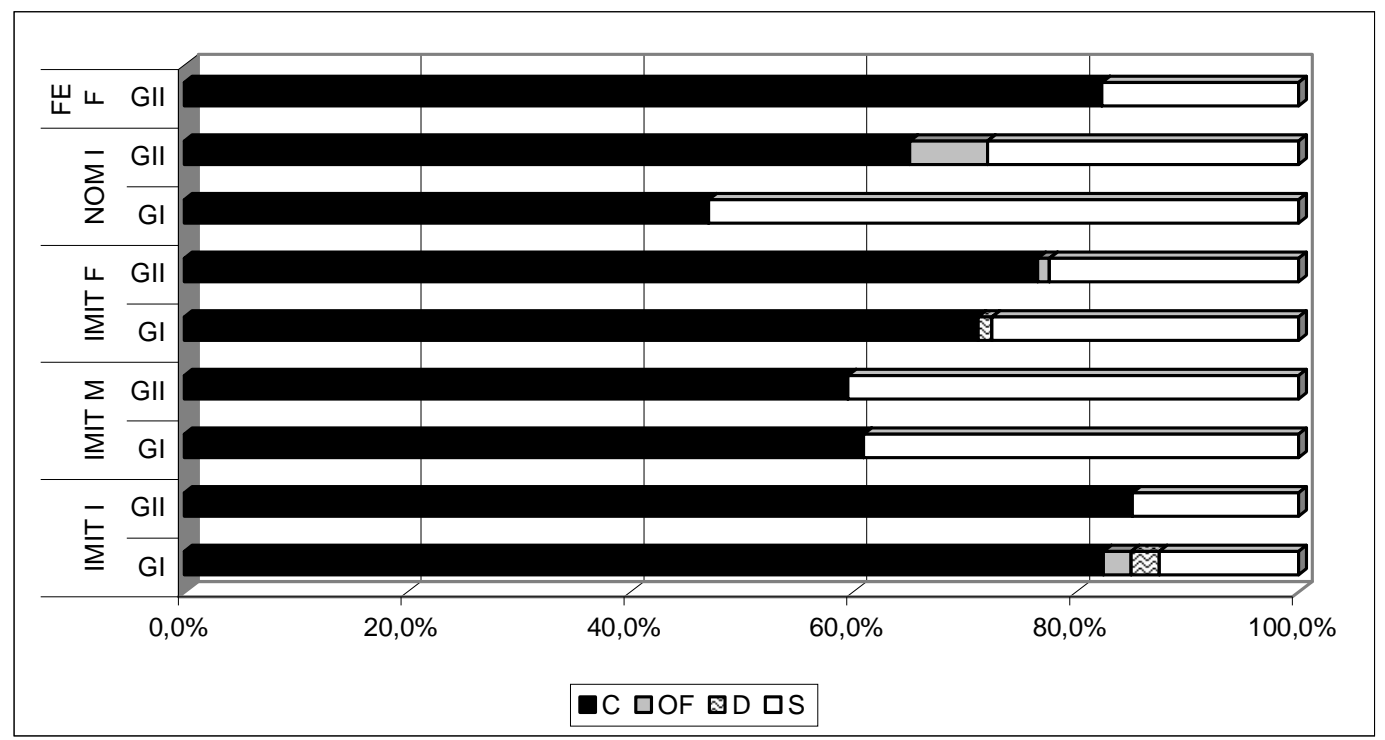

O teste de proporção foi aplicado na imitação em sílaba final para a substituição do /v/ pelo /f/, evidenciando diferença estatística significante entre as duas faixas etárias $(p=0,019)$, sendo que o Gl apresentou mais erro que o Gll. Na nomeação, foi possível a comparação para a substituição por /b/ em sílaba inicial, mostrando diferença entre os dois grupos $(p=0,003)$, também tendo $o \mathrm{Gl}$ apresentado maior porcentagem de erro que o Gll.

$\mathrm{O} / \mathrm{f} / \mathrm{mostrou}$ alta porcentagem de acerto pelas crianças dos dois grupos (Figura 20). Em relação ao tipo de erro, o mais observado foi substituição. Pode-se também notar que, em algumas situações, houve omissão da sílaba. Este erro foi o tipo mais observado na sílaba inicial dos dois grupos na prova de imitação. Nas demais situações, o Gl cometeu mais substituição por /p/ e o Gll, por /t/ (Anexo I). 
Figura 20 - Erros para o fonema /f/.

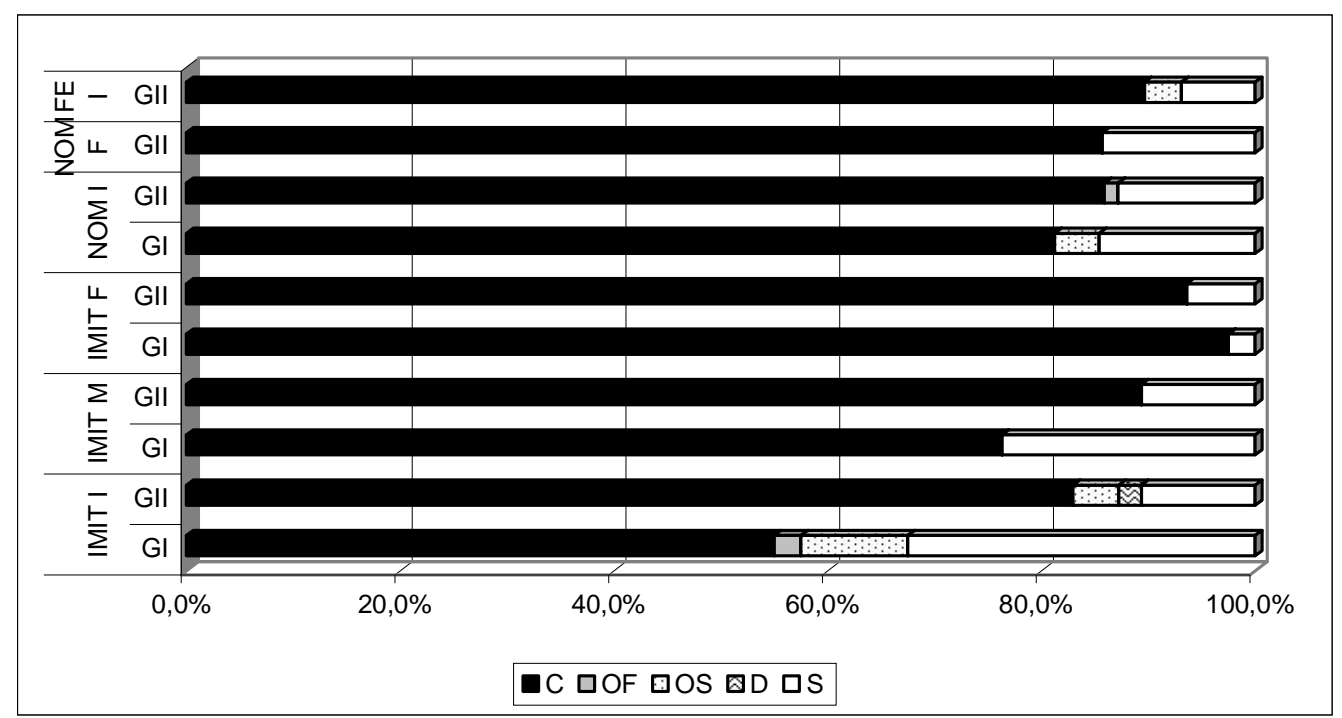

Não foi aplicado o teste de proporção para nenhum tipo de erro cometido quanto ao fonema /f/, pois não houve uma substituição em determinada situação com mais de dez ocorrências.

O fonema / $\mathrm{Z} /$ teve baixa porcentagem de acerto e a maior parte de erros foi de substituição (Figura 21). O erro mais freqüente na prova de imitação foi a substituição por $/ \Sigma /$, em sílaba medial e final, e omissão do fonema, em sílaba inicial, na imitação, no grupo de crianças mais novas. As crianças mais velhas tiveram a substituição por / z/ como erro mais freqüente em todas as sílabas nesta prova. $\mathrm{Na}$ nomeação, o erro mais comum no Gl foi a substituição para /s/ e no Gll, a substituição para /dZ/, sendo esta a única substituição (Anexo I). 
Figura 21 - Erros para o fonema /Z/.

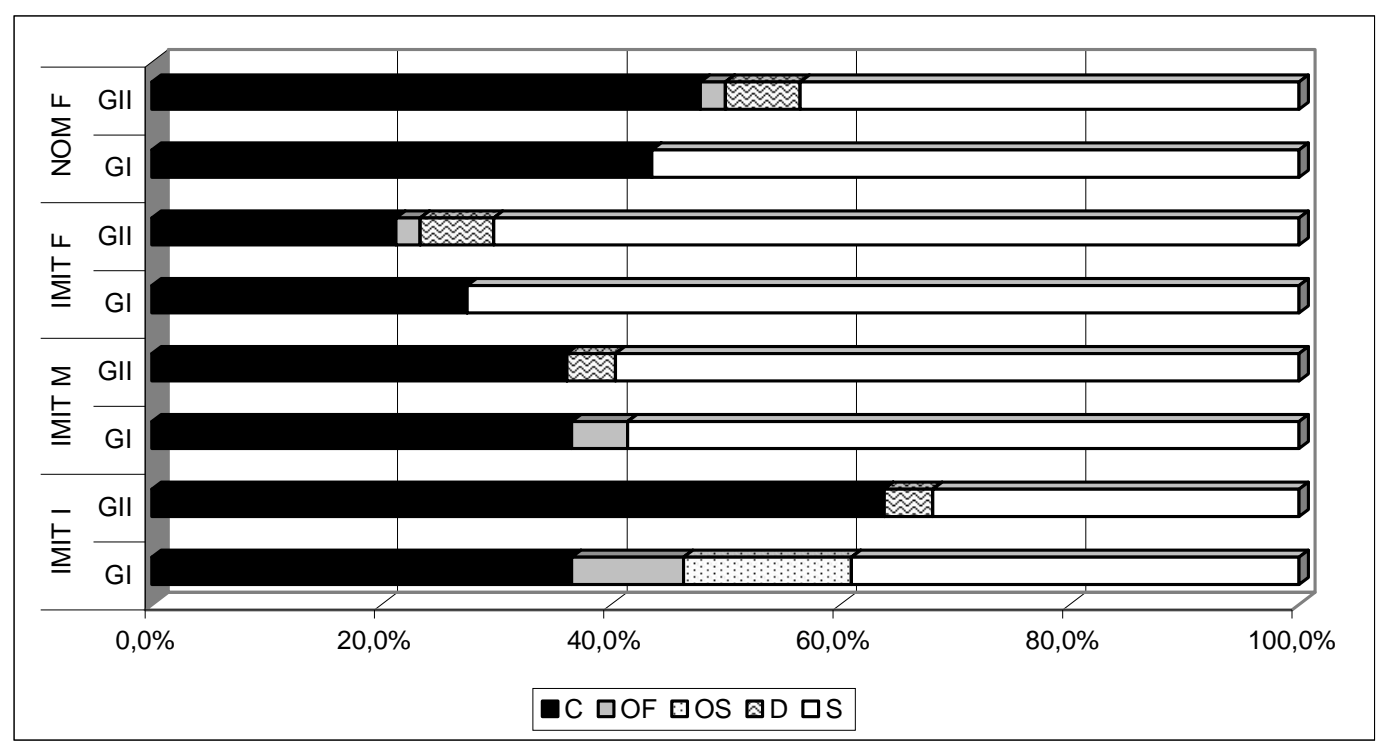

O teste de proporção foi usado nas comparações que se encontram na Tabela 76. Não houve diferença entre Gl e Gll quanto aos tipos de erros analisados.

Tabela 76 - Comparação entre as faixas etárias para erros do fonema /Z/.

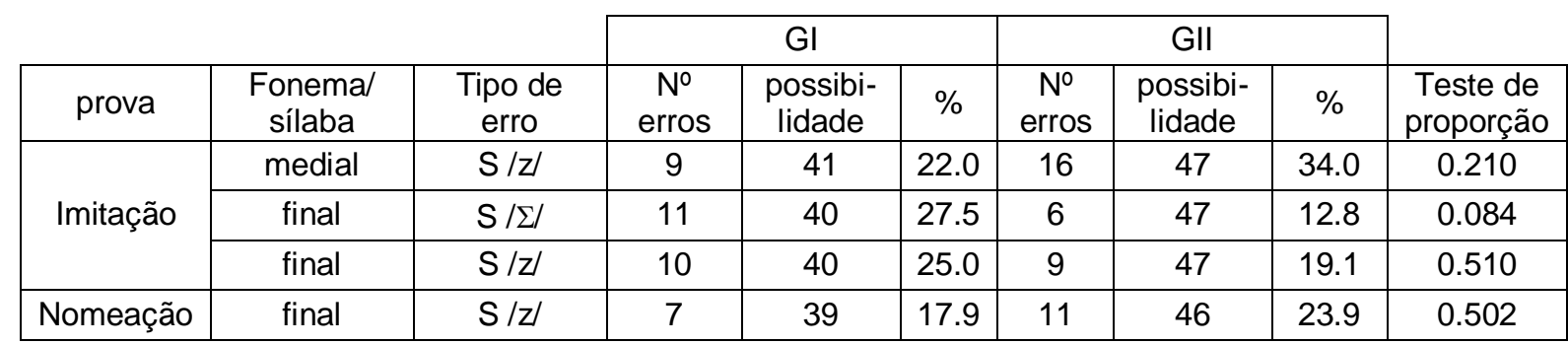

Legenda: S: substituição por um determinado fonema

$\mathrm{O}$ fonema $/ \Sigma /$ teve maior porcentagem de acerto que seu correspondente sonoro. A maior parte dos erros também é de substituição (Figura 22). No Gl, em todas as provas e sílabas analisadas, a maior parte de substituição foi para o $/ \mathrm{s} /$. As crianças mais velhas apresentaram a mesma substituição como erro mais freqüente, com exceção da imitação, em sílaba inicial, na qual elas substituíram mais por /t/ e, na sílaba final da nomeação em que a substituição por /s/ teve o mesmo número de ocorrência que a distorção do fonema (Anexo I). 
Figura 22 - Erros para o fonema $/ \Sigma /$.

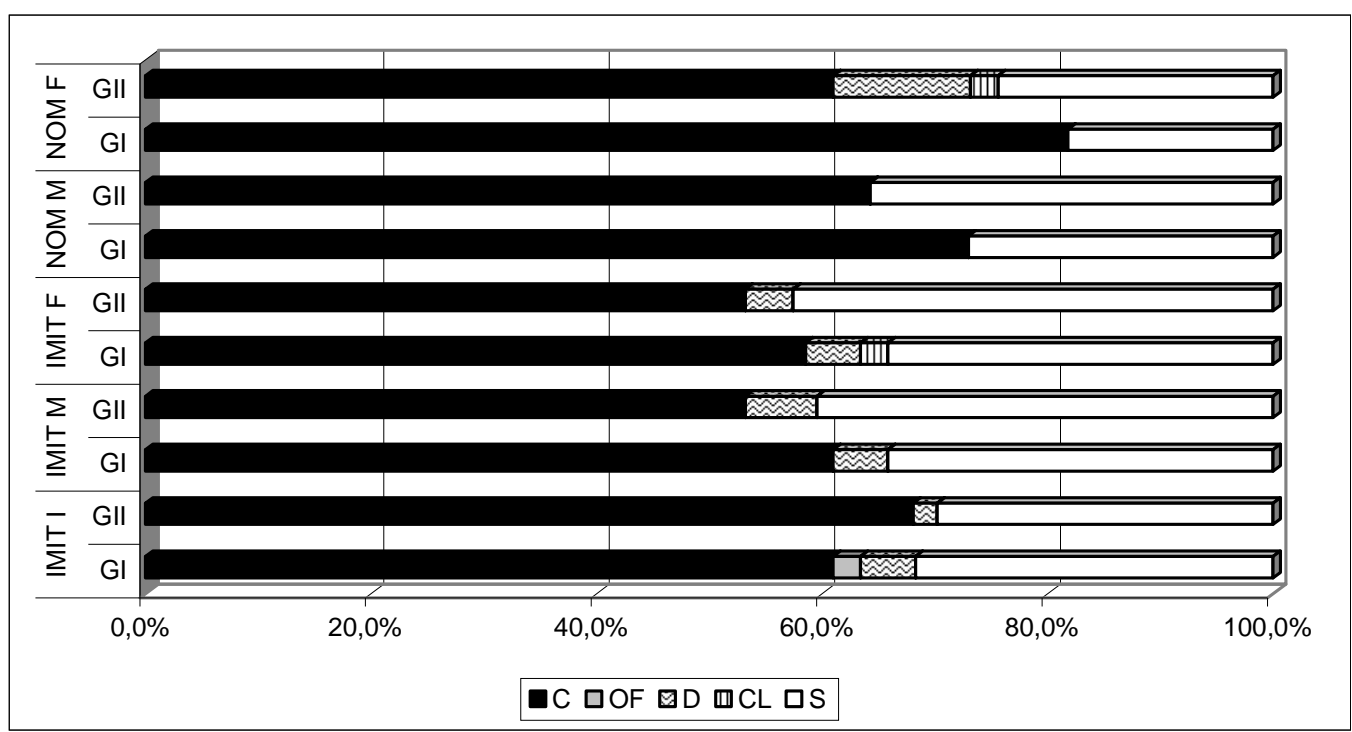

A substituição do fonema $/ \Sigma /$ por /s/ teve comparação entre os grupos apenas na imitação, em sílaba medial e final. Em nenhuma destas situações houve diferença entre as faixas etárias ( $p=0,232$ na medial e $p=0,404$ na final). Observa-se, entretanto, que as crianças mais velhas apresentam maior porcentagem de erro que as mais novas.

nasais

O fonema $/ \mathrm{m} /$ teve baixa porcentagem de erro como mostra a Figura 23 . Quando houve erro, este foi de omissão do fonema, como observado nos dois grupos na sílaba inicial da imitação, de substituição para /b/ ou $/ \mathrm{n} /$, entre outras (Anexo I). Não houve erro com mais de dez ocorrências em nenhum grupo para que fosse realizado o teste de proporção. 
Figura 23 - Erros para o fonema $/ \mathrm{m} /$.

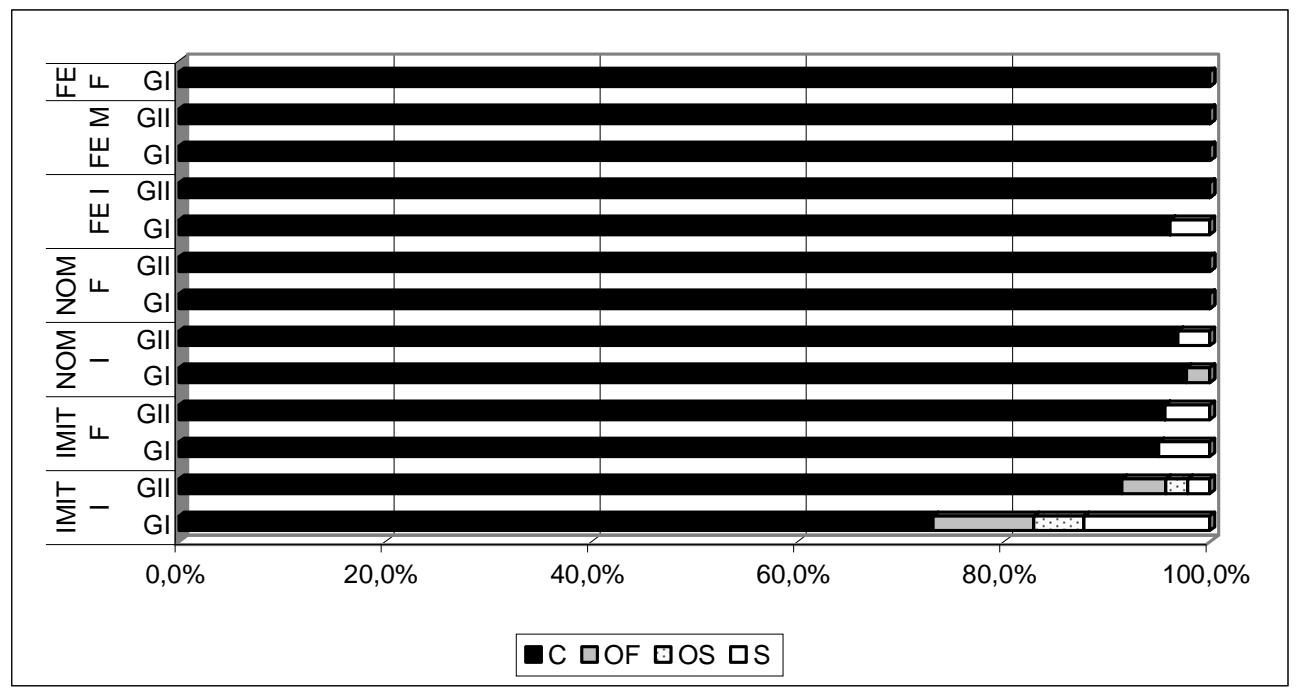

Quanto ao fonema /n/, não foi observado erro no Gll na prova de imitação, em sílaba final. Os demais erros englobaram substituição, interdentalização e omissão do fonema (Figura 24). As substituições mais observadas foram por /N/ e /// no Gl e por /m/e /// no Gll (Anexo I).

Não houve comparação dos erros por meio do teste de proporção para nenhuma situação com o /n/.

Figura 24 - Erros para o fonema /n/.

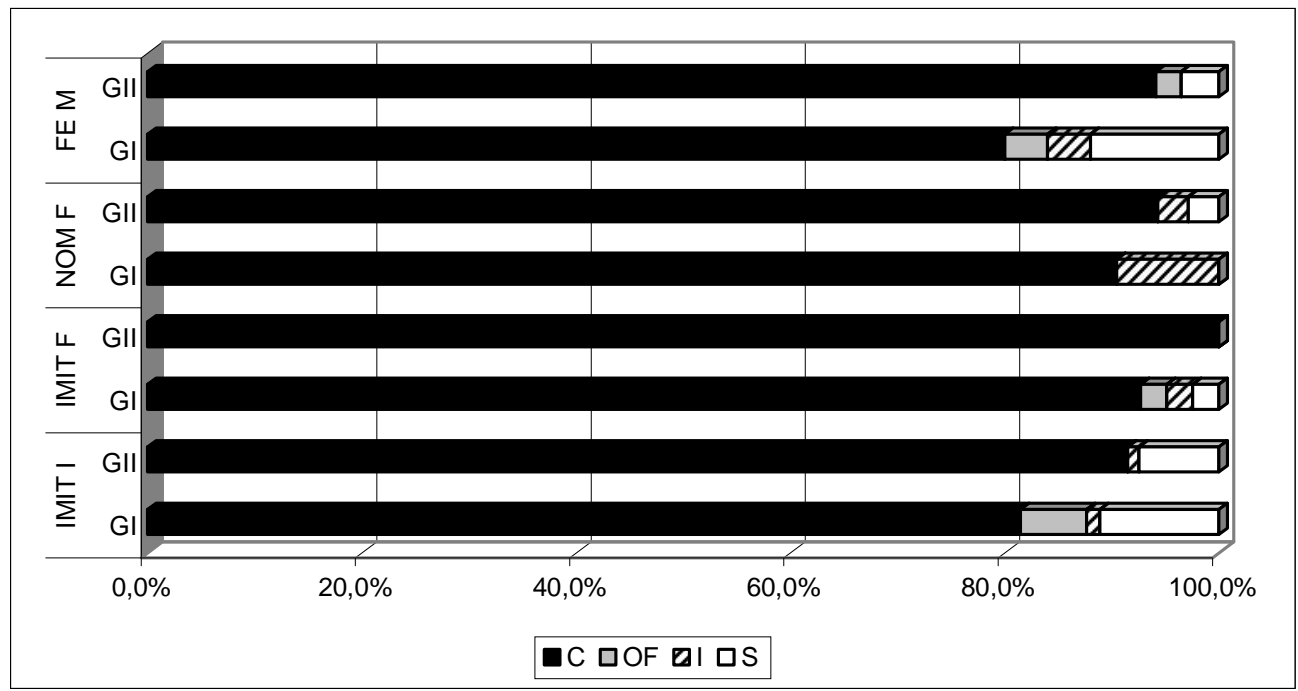


Por fim, a nasal /N/ obteve pouco erro e, quando isso ocorreu, foi observada apenas omissão do fonema (Figura 25). Não houve aplicação do teste de proporção para comparação das faixas etárias quanto a este tipo de erro.

Figura 25 - Erros para o fonema /N/.

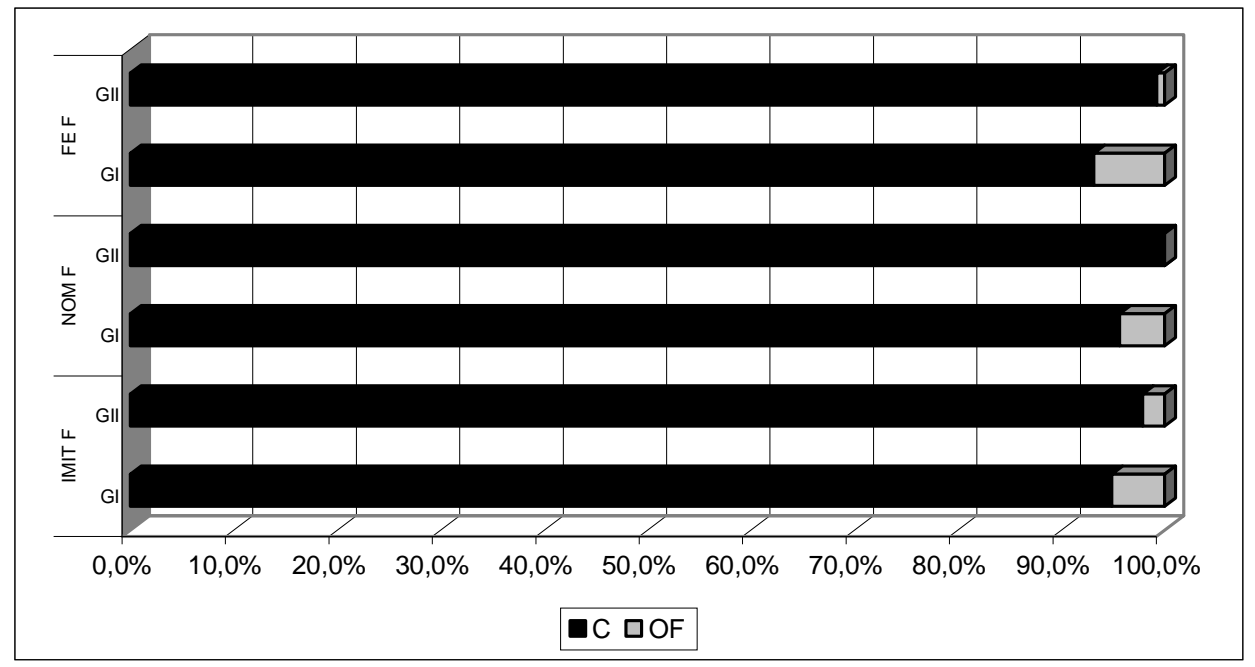

$\underline{\text { líquidas }}$

Em relação ao $/ / /$, os erros mais freqüentes foram omissão do fonema e interdentalização. Observa-se pouca ocorrência de substituição (Figura 26). Em todas as provas e sílabas, a omissão do fonema e a interdentalização foram os mais freqüentes nas crianças mais novas. No grupo de crianças mais velhas, estes também foram observados. No entanto, na sílaba final da imitação, o erro mais ocorrente foi a distorção e, na sílaba medial da fala espontânea, a substituição por /y/ (Anexo I).

Não foi realizado teste de proporção para nenhum tipo de erro cometido no fonema /l/. 
Figura 26 - Erros para o fonema ///.

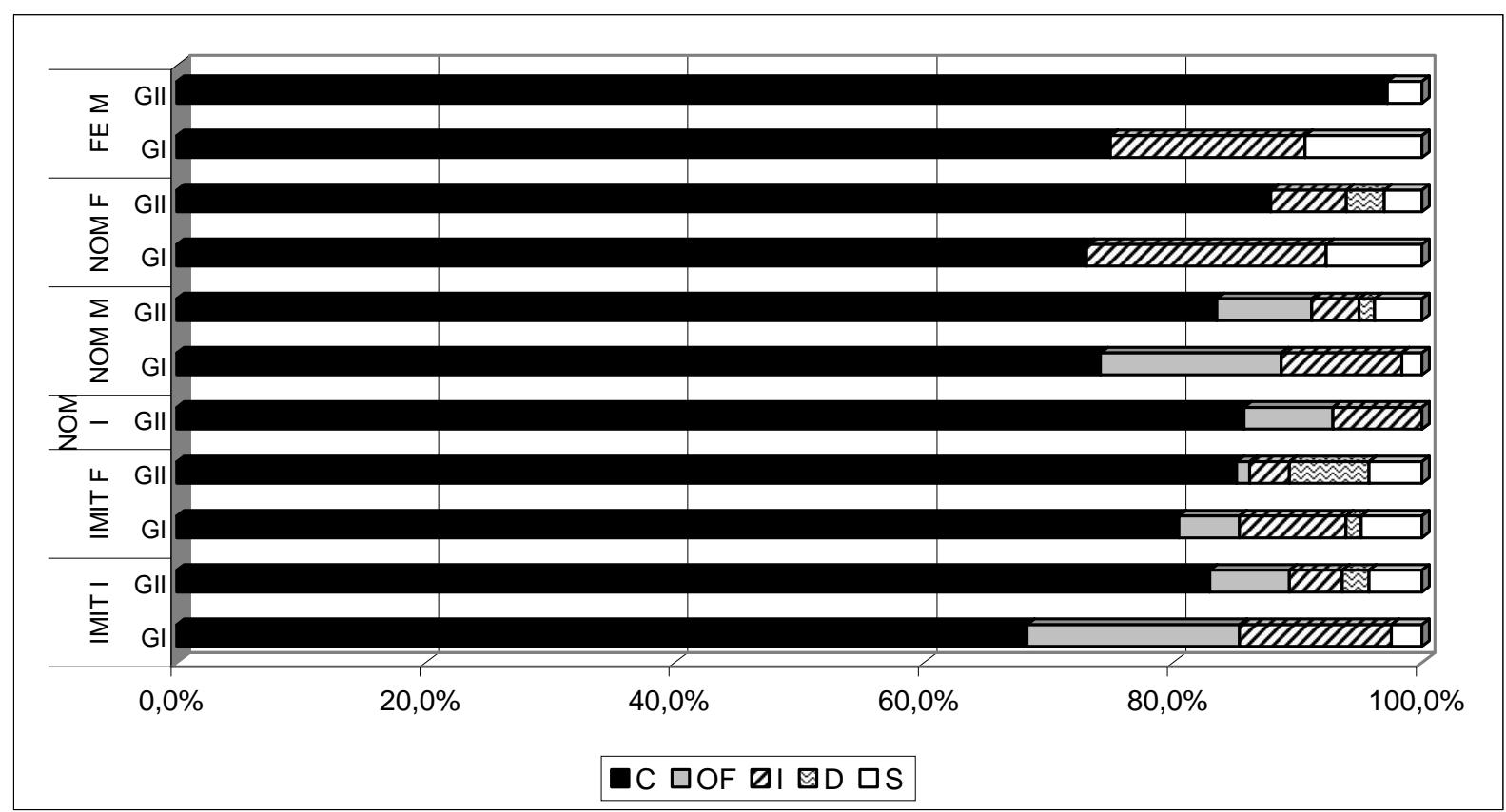

O fonema $/ \mathrm{P} /$ tem alta porcentagem de erro nas duas faixas etárias (Figura 27), sendo a maior parte de substituição por /// (Anexo I). Outros erros comumente encontrados são a omissão do fonema e a substituição para /y/.

Figura 27 - Erros para o fonema /P/.

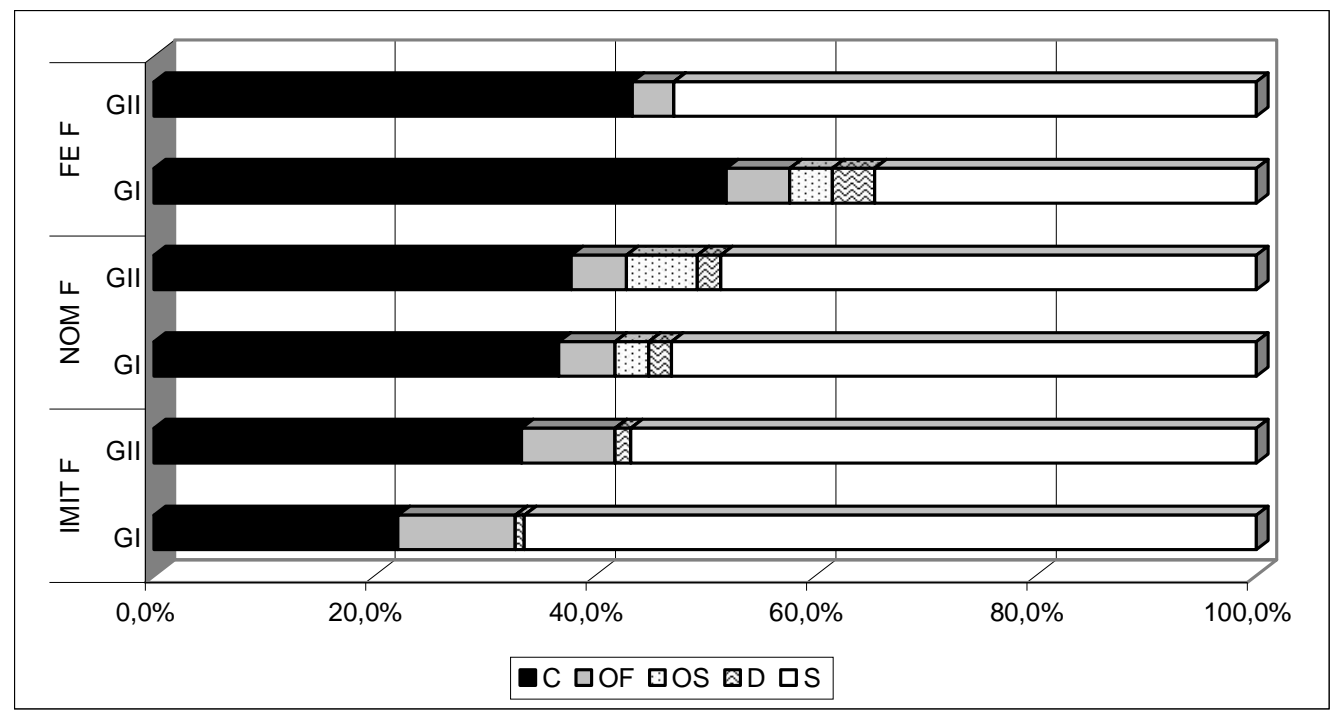

O teste de proporção para as situações demonstradas na Tabela 77 não indicam diferença entre os grupos para os erros. 
Tabela 77 - Comparação entre as faixas etárias para erros do fonema /P/.

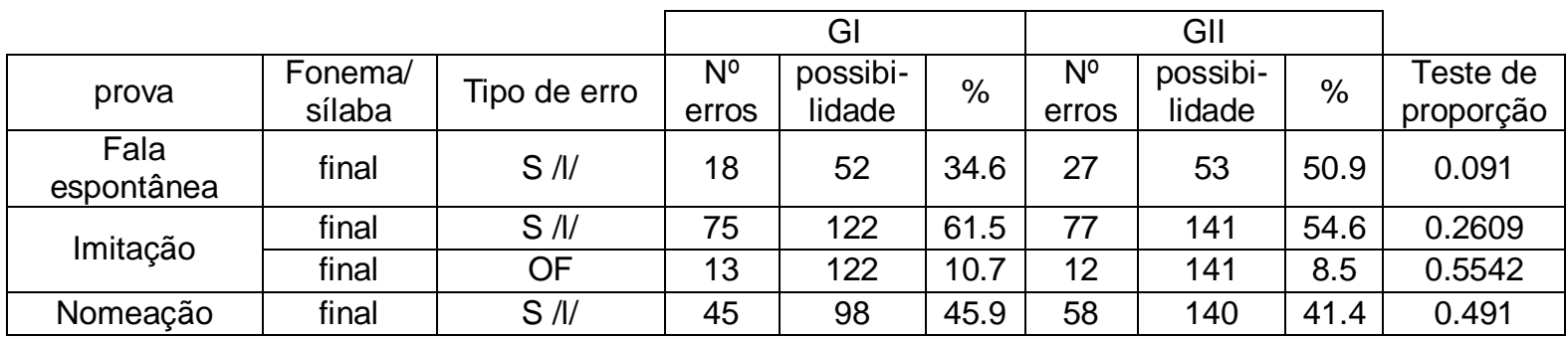

Legenda: S: substituição por um determinado fonema, OF: omissão de fonema

A líquida $/ x /$, representada na Figura 28 , também apresentou alta porcentagem de erro, sendo a maior parte deles de substituição para o /// (Anexo I). Outra substituição comum deste fonema é pela semivogal $/ y /$.

Figura 28 - Erros para o fonema $/ \times /$.

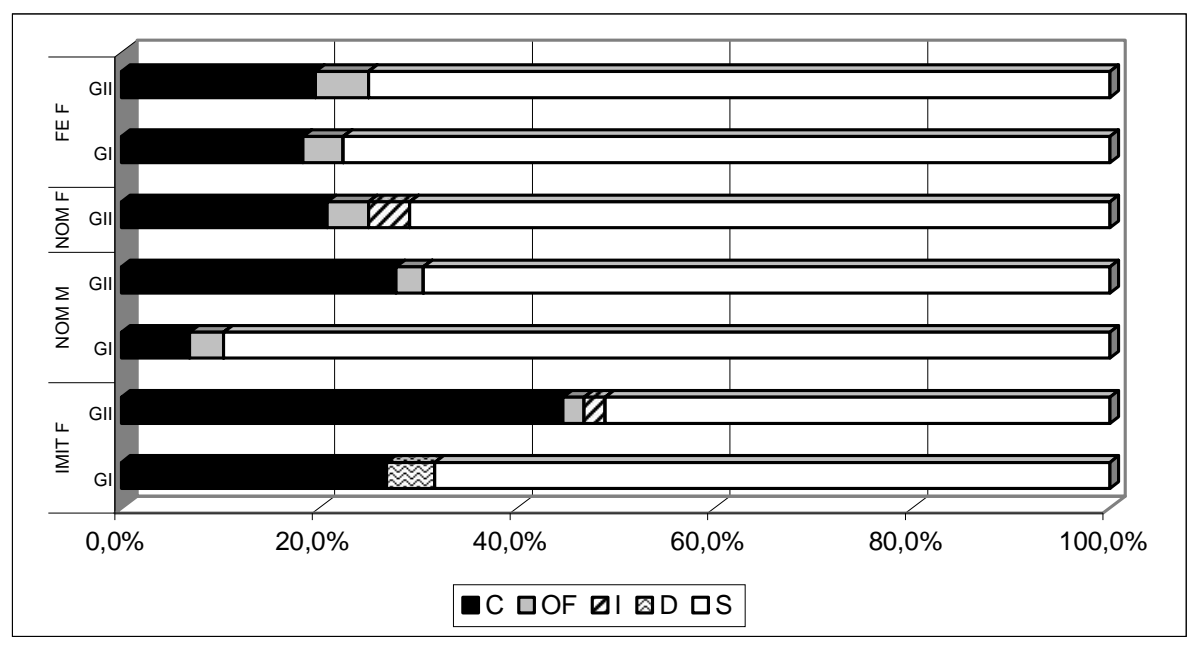

O teste de proporção mostrou diferença estatística na imitação, em sílaba final, para a substituição por /I/. As crianças do Gl tiveram maior porcentagem de erro que as do Gll (Tabela 78). 
Tabela 78 - Comparação entre as faixas etárias para erros do fonema $/ \times /$.

\begin{tabular}{|c|c|c|c|c|c|c|c|c|c|}
\hline & & & & & & \multirow{2}{*}{\multicolumn{3}{|c|}{ Gll }} & \multirow[b]{3}{*}{$\begin{array}{l}\text { Teste de } \\
\text { proporção }\end{array}$} \\
\hline & \multicolumn{3}{|c|}{$\mathrm{Gl}$} & & & & \\
\hline prova & sílaba & $\begin{array}{c}\text { Tipo } \\
\text { de erro }\end{array}$ & $\begin{array}{l}\text { № } \\
\text { erros }\end{array}$ & $\begin{array}{l}\text { possibi- } \\
\text { lidade }\end{array}$ & $\%$ & $\begin{array}{c}\text { № } \\
\text { erros }\end{array}$ & $\begin{array}{l}\text { possibi- } \\
\text { lidade }\end{array}$ & $\%$ & \\
\hline \multirow{2}{*}{$\begin{array}{c}\text { fala } \\
\text { espontânea }\end{array}$} & final & $\mathrm{S} / \mathrm{y} /$ & 5 & 49 & 10.2 & 10 & 56 & 17.9 & 0.264 \\
\hline & final & $\mathrm{S} / \mathrm{I} /$ & 33 & 49 & 67.3 & 30 & 56 & 53.6 & 0.151 \\
\hline \multirow{2}{*}{ imitação } & final & $\mathrm{S} / \mathrm{y} /$ & 8 & 41 & 19.5 & 11 & 47 & 23.4 & 0.6580 \\
\hline & final & $\mathrm{S} / \mathrm{I} /$ & 20 & 41 & 48.8 & 12 & 47 & 25.5 & 0,0237 * \\
\hline \multirow{3}{*}{ nomeação } & medial & $\mathrm{S} / \mathrm{I} /$ & 19 & 29 & 65.5 & 15 & 36 & 41.7 & 0.056 \\
\hline & medial & $S / y /$ & 7 & 29 & 24.1 & 10 & 36 & 27.8 & 0.740 \\
\hline & final & $S / I /$ & 9 & 15 & 60,0 & 13 & 24 & 54,2 & 0,721 \\
\hline
\end{tabular}

Legenda: S: substituição por um determinado fonema

$\underline{\text { fricativa velar }}$

$\mathrm{O} / \mathrm{X} /$ mostrou baixa porcentagem de acerto em todas as provas e sílabas analisadas (Figura 29). Nota-se que a maioria dos erros é de omissão do fonema (Anexo I), seguida de troca deste fonema por diversos outros, incluindo o /l/ e a semivogal /y/ como uma das mais ocorrentes.

Figura 29 - Erros para o fonema /X/.

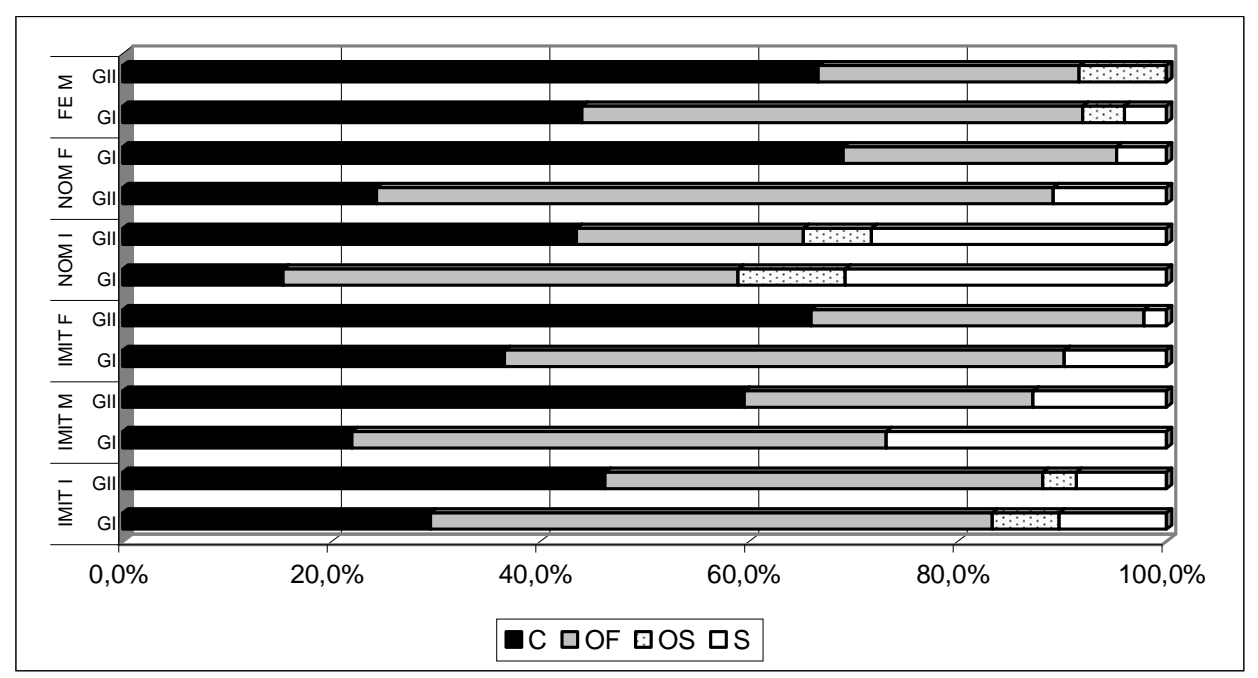

O teste de proporção mostrou diferença entre os erros na prova de nomeação e imitação apenas em sílaba medial e final. Observa-se que as crianças mais novas tiveram mais omissão do fonema que as mais velhas (Tabela 79). 
Tabela 79 - Comparação entre as faixas etárias para erros do fonema /X/.

\begin{tabular}{|c|c|c|c|c|c|c|c|c|c|}
\hline & & & \multicolumn{3}{|c|}{$\mathrm{Gl}$} & \multicolumn{3}{|c|}{ GII } & \\
\hline prova & sílaba & $\begin{array}{c}\text { Tipo } \\
\text { de erro }\end{array}$ & $\begin{array}{c}\text { № } \\
\text { erros }\end{array}$ & $\begin{array}{l}\text { possibi- } \\
\text { lidade }\end{array}$ & $\%$ & $\begin{array}{c}\text { № } \\
\text { erros }\end{array}$ & $\begin{array}{l}\text { possibi- } \\
\text { lidade. }\end{array}$ & $\%$ & $\begin{array}{c}\text { Teste de } \\
\text { proporção }\end{array}$ \\
\hline $\begin{array}{c}\text { fala } \\
\text { espontânea }\end{array}$ & medial & OF & 12 & 25 & 48.0 & 9 & 36 & 25.0 & 0.063 \\
\hline \multirow{3}{*}{ Imitação } & inicial & OF & 42 & 78 & 53.8 & 39 & 93 & 41.9 & 0.1203 \\
\hline & medial & OF & 21 & 41 & 51.2 & 13 & 47 & 27.7 & 0,0236 * \\
\hline & final & OF & 22 & 41 & 53.7 & 15 & 47 & 31.9 & 0,0393 * \\
\hline \multirow{2}{*}{ Nomeação } & inicial & OF & 17 & 39 & 43.6 & 10 & 46 & 21.7 & 0,031 * \\
\hline & final & OF & 24 & 37 & 64.9 & 11 & 42 & 26.2 & 0,001 * \\
\hline
\end{tabular}

Legenda: OF: omissão de fonema

arquifonemas

$\mathrm{O}$ arquifonema /R/ teve alto índice de erro nos dois grupos (Figura 30). $\mathrm{Na}$ imitação em sílaba final, o grupo mais novo não apresentou acerto. O erro mais freqüente foi omissão do fonema (Anexo I), seguido de substituição. Em algumas situações nota-se omissão da sílaba.

Outros erros incluem a substituição por /y/, por /P/ seguido de vogal (epêntese) e por /l/ seguido de vogal (troca da líquida acrescida de vogal).

Figura 30 - Erros para o arquifonema /R/.

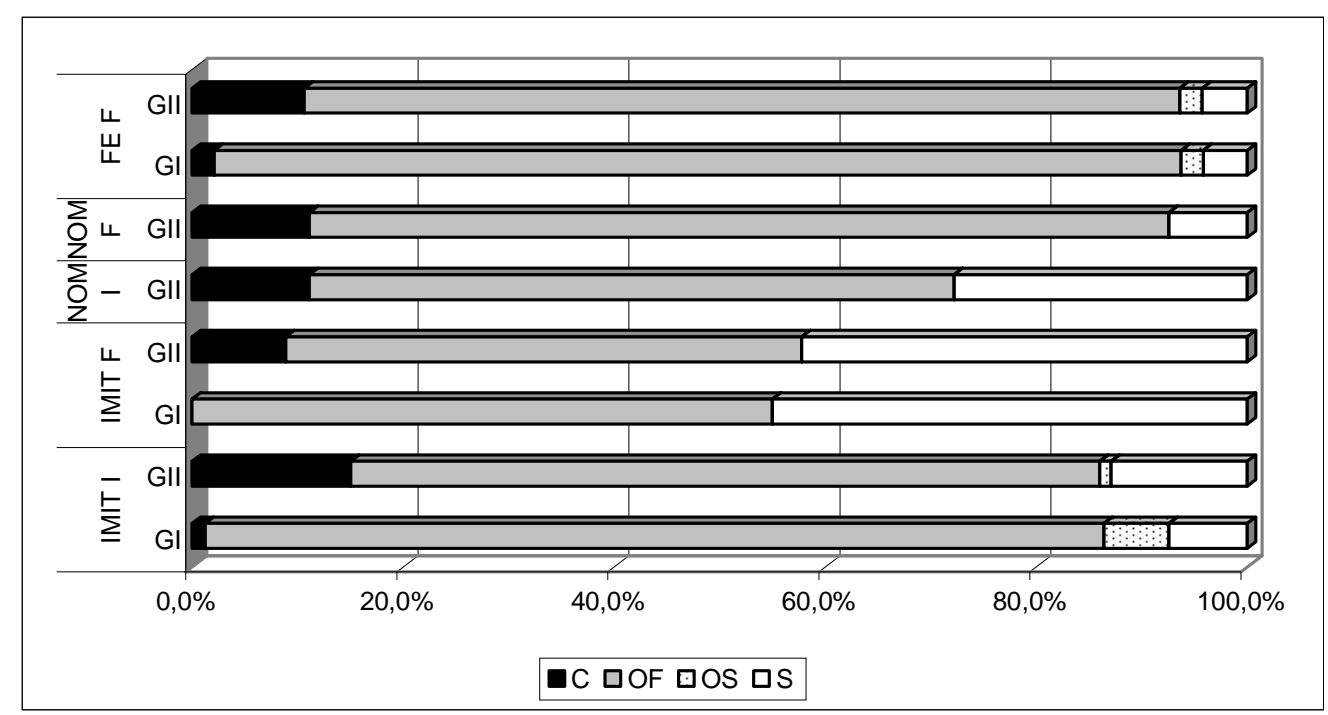

O teste de proporção entre os erros do arquifonema /R/ mostrou diferença entre as faixas etárias apenas em sílaba inicial, para omissão de fonema (Tabela 80). 
Tabela 80 - Comparação entre as faixas etárias para erros do arquifonema /R/.

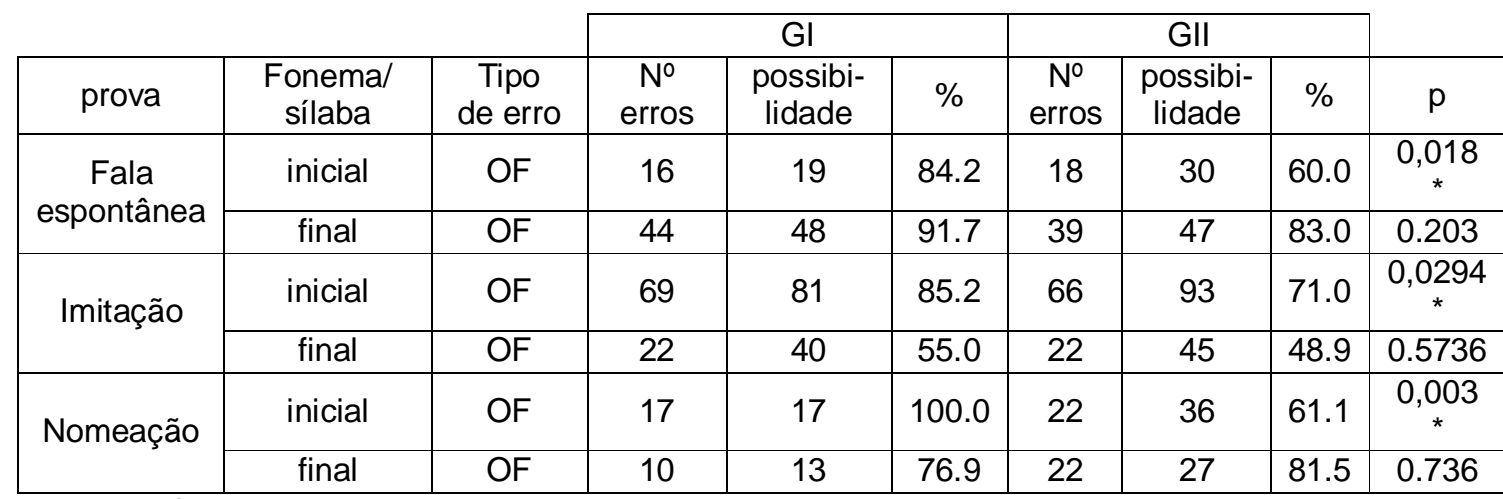

Legenda: OF: omissão de fonema

O arquifonema /S/ também apresentou alta porcentagem de erro (Figura 31). $\mathrm{Na}$ fala espontânea em sílaba inicial, este fonema foi analisado apenas no Gll e o tipo de erro mais observado foi a omissão de sílaba. Na sílaba inicial das provas de nomeação e imitação, as crianças apresentaram mais omissão do fonema comparada aos demais erros. Já em sílaba final da imitação, para os dois grupos, o erro mais freqüente foi a substituição do /S/ para o /z/ acrescido de vogal, formando a sílaba CV (Anexo I).

Figura 31 - Erros para o arquifonema /S/.

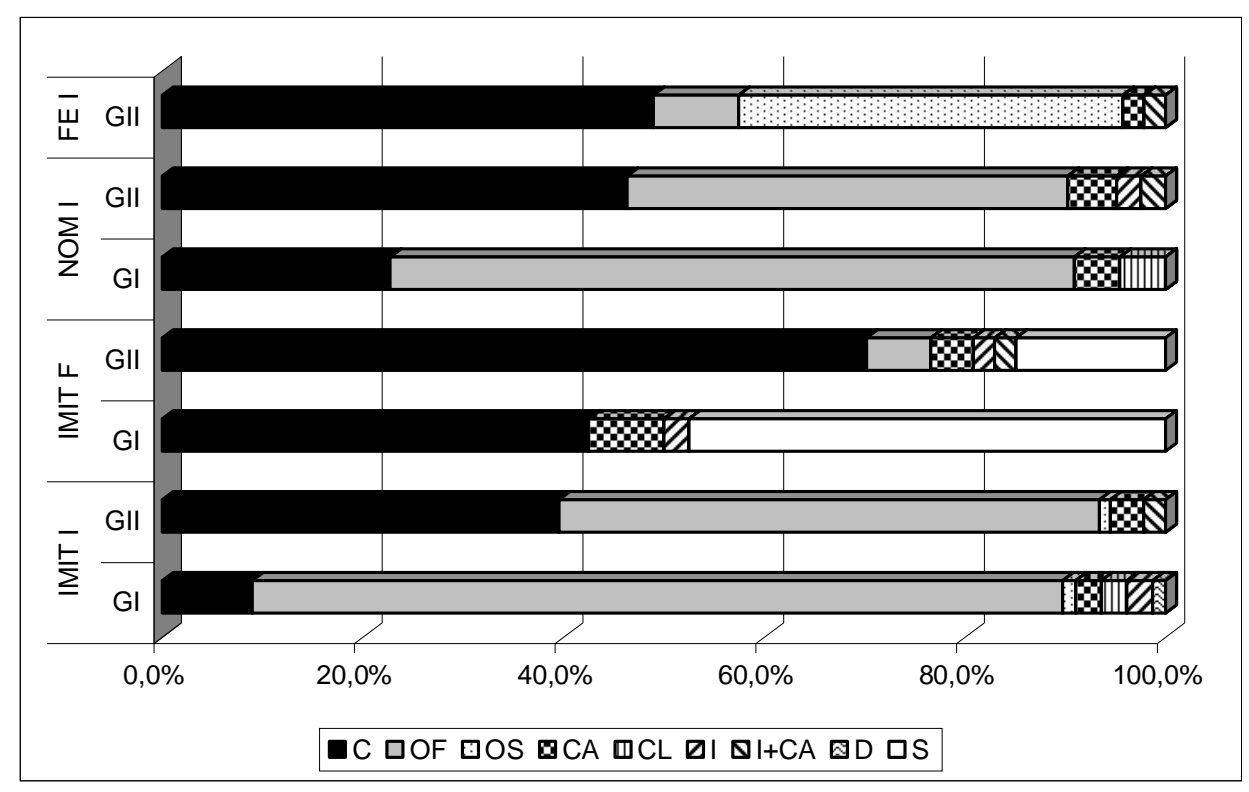

O teste de proporção mostrou diferença entre os grupos quanto aos erros, somente na prova de imitação, como mostra a Tabela 81. Em sílaba inicial, as 
crianças do Gl apresentaram mais omissão de fonema e, em sílaba final, mais substituição por /z/ acrescido de vogal.

Tabela 81 - Comparação entre as faixas etárias para erros do arquifonema /S/.

\begin{tabular}{|c|c|c|c|c|c|c|c|c|c|}
\cline { 3 - 10 } \multicolumn{2}{c|}{ prova } & $\begin{array}{c}\text { Fonema/ } \\
\text { sílaba }\end{array}$ & $\begin{array}{c}\text { Tipo } \\
\text { de erro }\end{array}$ & $\begin{array}{c}\text { № } \\
\text { erros }\end{array}$ & $\begin{array}{c}\text { possibi- } \\
\text { lidade }\end{array}$ & $\begin{array}{c}\text { № } \\
\text { erros }\end{array}$ & $\begin{array}{c}\text { possibi- } \\
\text { lidade }\end{array}$ & $\begin{array}{c}\text { Teste de } \\
\text { proporção }\end{array}$ \\
\hline $\begin{array}{c}\text { Fala } \\
\text { espontânea }\end{array}$ & inicial & OS & 7 & 20 & 35.0 & 18 & 47 & 38.3 & 0.798 \\
\hline \multirow{2}{*}{ Imitação } & inicial & OF & 63 & 78 & 80.8 & 49 & 91 & 53.8 & 0,0002 * \\
\cline { 2 - 10 } & final & $\begin{array}{c}\text { S /z/ + } \\
\text { vogal }\end{array}$ & 10 & 40 & 25.0 & 4 & 47 & 8.5 & 0,0370 * \\
\hline Nomeação & inicial & OF & 15 & 22 & 68.2 & 18 & 41 & 43.9 & 0.066 \\
\hline
\end{tabular}

Legenda: S: substituição por um determinado fonema, OS: omissão de sílaba, OF: omissão de fonema

- Estruturas silábicas

$\underline{\mathrm{CV}}$

A estrutura CV em palavras dissilábicas, trissilábicas e polissilábicas mostrou baixa porcentagem de erro (Tabelas 82 a 85).

Em palavras dissilábicas (Tabela 82), a omissão da consoante foi o erro mais freqüente em quase todas as provas e posições de sílabas, nos dois grupos. Observa-se, porém, que o Gll, em sílaba final da imitação, e o Gl, em sílaba final da nomeação, apresentaram a epêntese como erro mais freqüente. Na sílaba inicial da fala espontânea, o Gll mostrou apenas dois erros, sendo um de omissão da consoante e outro de troca para CVV. 
Tabela 82 - Erros observados na estrutura CV em dissílabos.

\begin{tabular}{|c|c|c|c|c|c|c|c|c|c|c|c|c|c|c|}
\hline & $\mathrm{N}$ & $P$ & C & $\%$ & $\mathrm{OC}$ & $\%$ & OS & $\%$ & VV & $\%$ & $\mathrm{E}$ & $\%$ & CVV & $\%$ \\
\hline \multirow{2}{*}{ IMI I } & GI $: 41$ & 447 & 430 & $96,20 \%$ & 16 & $3,58 \%$ & 1 & $0,22 \%$ & 0 & $0,00 \%$ & 0 & $0,00 \%$ & 0 & $0,00 \%$ \\
\hline & GII : 47 & 517 & 506 & $97,87 \%$ & 9 & $1,74 \%$ & 1 & $0,19 \%$ & 1 & $0,19 \%$ & 0 & $0,00 \%$ & 0 & $0,00 \%$ \\
\hline \multirow{2}{*}{ IMIT F } & Gl : 41 & 882 & 830 & $94,10 \%$ & 29 & $3,29 \%$ & 0 & $0,00 \%$ & 4 & $0,45 \%$ & 19 & $2,15 \%$ & 0 & $0,00 \%$ \\
\hline & GII, 47 & 1029 & 971 & $94,36 \%$ & 20 & $1,94 \%$ & 0 & $0,00 \%$ & 2 & $0,19 \%$ & 35 & $3,40 \%$ & 1 & $0,10 \%$ \\
\hline \multirow{2}{*}{ NOM I } & GI : 39 & 204 & 201 & $98,53 \%$ & 1 & $0,49 \%$ & 2 & $0,98 \%$ & 0 & $0,00 \%$ & 0 & $0,00 \%$ & 0 & $0,00 \%$ \\
\hline & GII: 47 & 301 & 297 & \begin{tabular}{|c|}
$98,67 \%$ \\
\end{tabular} & 4 & $1,33 \%$ & 0 & $0,00 \%$ & 0 & $0,00 \%$ & 0 & $0,00 \%$ & 0 & $0,00 \%$ \\
\hline \multirow{2}{*}{ NOM F } & $\begin{array}{l:ll} & \text { Gl } & 41\end{array}$ & 390 & 387 & $99,23 \%$ & 0 & $0,00 \%$ & 0 & $0,00 \%$ & 0 & $0,00 \%$ & 3 & $0,77 \%$ & 0 & $0,00 \%$ \\
\hline & GII: 47 & 521 & 517 & $99,23 \%$ & 1 & $0,19 \%$ & 0 & $0,00 \%$ & 3 & $0,58 \%$ & 0 & $0,00 \%$ & 0 & $0,00 \%$ \\
\hline \multirow{2}{*}{ FE I } & GI $: 38$ & 193 & 189 & $97,93 \%$ & 4 & $2,07 \%$ & 0 & $0,00 \%$ & 0 & $0,00 \%$ & 0 & $0,00 \%$ & 0 & $0,00 \%$ \\
\hline & GII : 44 & 191 & 189 & \begin{tabular}{|l|}
$98,95 \%$ \\
\end{tabular} & 1 & $0,52 \%$ & 0 & $0,00 \%$ & 0 & $0,00 \%$ & 0 & $0,00 \%$ & 1 & $0,52 \%$ \\
\hline \multirow{2}{*}{ FE F } & Gl $: 37$ & 177 & 174 & $98,31 \%$ & 3 & $1,69 \%$ & 0 & $0,00 \%$ & 0 & $0,00 \%$ & 0 & $0,00 \%$ & 0 & $0,00 \%$ \\
\hline & GII 44 & 230 & 224 & $97,39 \%$ & 4 & $1,74 \%$ & 0 & $0,00 \%$ & 2 & $0,87 \%$ & 0 & $0,00 \%$ & 0 & $0,00 \%$ \\
\hline
\end{tabular}

Legenda: IMI: imitação, NOM: nomeação, FE: fala espontânea, I: sílaba inicial, F: sílaba final, N: número de sujeitos, P: possibilidade, C: correta, OC: omissão de consoante, OS: omissão de sílaba, VV: troca para vogal-vogal, E: epêntese, CVV: troca para estrutura consoante-vogal-vogal

Quanto aos erros apresentados em palavras trissilábicas (Tabela 83), o mais ocorrente foi a omissão da consoante. Entretanto, na sílaba inicial da imitação e fala espontânea, o erro mais freqüente do Gl foi a omissão de sílaba e, na sílaba final da imitação, a troca para VV. Em sílaba inicial, na fala espontânea, a ocorrência de omissão de consoante foi igual à de omissão de sílaba.

As palavras polissilábicas ocorreram apenas na prova de fala espontânea (Tabela 84). Observa-se que não houve erro em sílaba final para nenhum grupo. Nas sílabas inicial e medial, o erro mais freqüente foi a omissão de sílaba nas duas faixas etárias. 
Tabela 83 - Erros observados na estrutura CV em trissílabos.

\begin{tabular}{|c|c|c|c|c|c|c|c|c|c|c|c|c|c|c|c|c|c|c|c|c|}
\hline & $\mathrm{N}$ & $P$ & $\mathrm{C}$ & $\%$ & $\mathrm{OC}$ & $\%$ & OS & $\%$ & $\mathrm{VV}$ & $\%$ & $E$ & $\%$ & $\mathrm{SVC}$ & $\%$ & $\mathrm{SVV}$ & $\%$ & ASS & $\%$ & ASA & $\%$ \\
\hline \multirow{2}{*}{ IMI I } & a 41 & 323 & 258 & $9,88 \%$ & 30 & ,29\% & 35 & $10,84 \%$ & 0 & $00 \%$ & 0 & $0,00 \%$ & 0 & $00 \%$ & 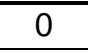 &, $00 \%$ & 0 &, $00 \%$ & 0 &, $00 \%$ \\
\hline & GII i 47 & 376 & 338 & $89,89 \%$ & 28 & $7,45 \%$ & 10 & $2,66 \%$ & 0 & $00 \%$ & 0 & $0,00 \%$ & $c$ & $00 \%$ & 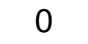 &, $00 \%$ & &, $00 \%$ & 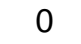 &, $00 \%$ \\
\hline \multirow{2}{*}{ IMI I } & GI i 41 & 522 & 487 & $93,30 \%$ & 25 & $4,79 \%$ & 3 & $0,57 \%$ & 4 & $0,77 \%$ & 2 & $0,38 \%$ & 1 & ,19\% & & ,00\% & &, $00 \%$ & &, $00 \%$ \\
\hline & GII, 47 & 609 & 582 & $95,57 \%$ & 13 & $2,13 \%$ & 2 & $0,33 \%$ & 3 & $0,49 \%$ & 8 & $1,31 \%$ & 0 &, $00 \%$ & 1 & $0,16 \%$ & c & $0,00 \%$ & 0 &, $00 \%$ \\
\hline \multirow{2}{*}{ IMI F } & GI, 41 & 522 & 501 & $95,98 \%$ & 7 & $1,34 \%$ & 2 & $0,38 \%$ & 12 & $2,30 \%$ & 0 & $0,00 \%$ & 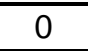 & $0,00 \%$ & ( & $0,00 \%$ & & $0,00 \%$ & & $0,00 \%$ \\
\hline & GII 47 & 609 & 586 & $96,22 \%$ & 4 & $0,66 \%$ & 2 & $0,33 \%$ & 14 & $2,30 \%$ & 0 & $0,00 \%$ & 0 & $0,00 \%$ & 0 & $0,00 \%$ & & $0,00 \%$ & $v$ & $0,00 \%$ \\
\hline \multirow{2}{*}{ NOM I } & \begin{tabular}{|c:c|c} 
GI & 41 \\
\end{tabular} & 293 & 259 & $88,40 \%$ & 20 & $6,83 \%$ & 13 & $4,44 \%$ & 0 & $0,00 \%$ & 1 & $0,34 \%$ & 0 & $0,00 \%$ & 0 & $0,00 \%$ & c & $0,00 \%$ & 0 & $0,00 \%$ \\
\hline & GII : 47 & 385 & 363 & $94,29 \%$ & 15 & $3,90 \%$ & 7 & $1,82 \%$ & 0 & $0,00 \%$ & 0 & $0,00 \%$ & 0 & $0,00 \%$ & $c$ & $0,00 \%$ & $c$ & $0,00 \%$ & 0 & $0,00 \%$ \\
\hline \multirow{2}{*}{ NOM M } & Gl : 41 & 201 & 182 & $90,55 \%$ & 11 & $5,47 \%$ & - & $00 \%$ & 7 & $3,48 \%$ & 1 & $0,50 \%$ & & $0,00 \%$ & & $0,00 \%$ & & $0,00 \%$ & & $0,00 \%$ \\
\hline & GII i 47 & 263 & 237 & $90,11 \%$ & 10 & $3,80 \%$ & 0 & $0,00 \%$ & 12 & $4,56 \%$ & 0 & $0,00 \%$ & 0 & $0,00 \%$ & 0 & $0,00 \%$ & r & $1,52 \%$ & 0 & $0,00 \%$ \\
\hline \multirow{2}{*}{ NOM F } & Gl : 41 & 254 & 211 & $83,07 \%$ & 30 & $11,81 \%$ & 3 & $1,18 \%$ & 10 & $3,94 \%$ & 0 & $0,00 \%$ & 0 & $0,00 \%$ & 0 & $0,00 \%$ & 0 & $0,00 \%$ & 0 & $0,00 \%$ \\
\hline & GII:47 & 341 & 302 & $88,56 \%$ & 18 & $5,28 \%$ & 5 & $1,47 \%$ & 11 & $3,23 \%$ & 0 & $0,00 \%$ & 0 & $0,00 \%$ & 0 & $0,00 \%$ & c & $0,00 \%$ & 4 & $1,47 \%$ \\
\hline \multirow{2}{*}{ FE I } & GI, 37 & 197 & 193 & $97,97 \%$ & 0 & $0,00 \%$ & 4 & $2,03 \%$ & 0 & $0,00 \%$ & 0 & $0,00 \%$ & $\pi$ & $0,00 \%$ & 0 & $0,00 \%$ & 0 & $0,00 \%$ & 0 & $0,00 \%$ \\
\hline & GII 43 & 241 & 236 & $97,93 \%$ & 2 & $0,83 \%$ & 2 & $0,83 \%$ & 0 & $0,00 \%$ & 0 & $0,00 \%$ & 0 & $0,00 \%$ & 1 & $0,41 \%$ & 0 & $0,00 \%$ & 0 & $0,00 \%$ \\
\hline \multirow{2}{*}{ FE M } & \begin{tabular}{|c:c} 
Gl & 38 \\
\end{tabular} & 193 & 173 & $89,64 \%$ & 18 & $9,33 \%$ & 1 & $0,52 \%$ & 1 & $0,52 \%$ & 0 & $0,00 \%$ & 0 & $0,00 \%$ & 0 & $0,00 \%$ & 0 & $0,00 \%$ & U & $0,00 \%$ \\
\hline & GII :44 & 251 & 235 & $93,63 \%$ & 12 & $4,78 \%$ & 1 & $0,40 \%$ & 3 & $1,20 \%$ & 0 & $0,00 \%$ & $c$ & $0,00 \%$ & ( & $0,00 \%$ & & $0,00 \%$ & & $0,00 \%$ \\
\hline \multirow{2}{*}{ FE F } & \begin{tabular}{|l:l} 
GI & 38 \\
\end{tabular} & 217 & 207 & $95,39 \%$ & 7 & $3,23 \%$ & 2 & $0,92 \%$ & 1 & $0,46 \%$ & 0 & $0,00 \%$ & 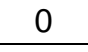 & $0,00 \%$ & 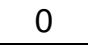 & $0,00 \%$ & 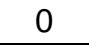 & $0,00 \%$ & 0 & $0,00 \%$ \\
\hline & GII ! 44 & 284 & 277 & $97,54 \%$ & 3 & $1,06 \%$ & 0 & $0,00 \%$ & 4 & $1,41 \%$ & 0 & $0,00 \%$ & 0 & $0,00 \%$ & 0 & $0,00 \%$ & 0 & $0,00 \%$ & 0 & $0,00 \%$ \\
\hline
\end{tabular}

Legenda: IMI: imitação, NOM: nomeação, FE: fala espontânea, I: sílaba inicial, F: sílaba final, M: sílaba medial, N: número de sujeitos, P: possibilidade, C: correta, OC: omissão de consoante, OS: omissão de sílaba, VV: troca para vogal-vogal, E: epêntese, CVC: troca para consonate-vogal-consoante, CVV: troca para estrutura consoante-vogal-vogal, ASS: aglutinação com sílaba seguinte, ASA: aglutinação com sílaba anterior. 
Tabela 84 - Erros observados na estrutura CV em polissílabos.

\begin{tabular}{|c|c|c|c|c|c|c|c|c|c|c|c|}
\cline { 2 - 10 } \multicolumn{2}{c|}{} & N & P & C & $\%$ & OC & $\%$ & OS & $\%$ & VV & $\%$ \\
\hline \multirow{2}{*}{ FE I } & GI & 24 & 42 & 39 & $92,86 \%$ & 0 & $0,00 \%$ & 3 & $7,14 \%$ & 0 & $0,00 \%$ \\
\cline { 2 - 11 } & GII & 31 & 76 & 73 & $96,05 \%$ & 0 & $0,00 \%$ & 3 & $3,95 \%$ & 0 & $0,00 \%$ \\
\hline \multirow{2}{*}{ FE M } & Gl & 26 & 84 & 67 & $79,76 \%$ & 3 & $3,57 \%$ & 13 & $15,48 \%$ & 1 & $1,19 \%$ \\
\cline { 2 - 10 } & GII 33 & 166 & 154 & $92,77 \%$ & 4 & $2,41 \%$ & 7 & $4,22 \%$ & 1 & $0,60 \%$ \\
\hline \multirow{2}{*}{ FE F } & Gl & 24 & 42 & 42 & $100,00 \%$ & 0 & $0,00 \%$ & 0 & $0,00 \%$ & 0 & $0,00 \%$ \\
\cline { 2 - 10 } & GIl 31 & 82 & 82 & $100,00 \%$ & 0 & $0,00 \%$ & 0 & $0,00 \%$ & 0 & $0,00 \%$ \\
\hline
\end{tabular}

Legenda: FE: fala espontânea, I: sílaba inicial, F: sílaba final, M: sílaba medial, N: número de sujeitos, P: possibilidade, C: correta, OC: omissão de consoante, OS: omissão de sílaba, VV: troca para vogalvogal.

O teste de proporção mostrou diferença estatística entre os grupos para omissão de sílaba tanto em sílaba medial, de palavras polissilábicas, na fala espontânea, como em sílaba inicial, de palavras trissilábicas, na imitação e nomeação (Tabela 85). Quanto ao erro de omissão da consoante, as duas faixas etárias tiveram porcentagem estatisticamente diferente em sílaba medial, de trissílabos, na imitação, e sílaba final, de trissílabos, na nomeação. Em todas estas situações, o Gl obteve mais erro que o Gll.

Tabela 85 - Comparação entre as faixas etárias para erros da estrutura CV.

\begin{tabular}{|c|c|c|c|c|c|c|c|c|c|}
\hline \multirow{3}{*}{ prova } & \multirow[b]{3}{*}{$\begin{array}{c}\text { Extensão / } \\
\text { sílaba }\end{array}$} & \multirow[b]{3}{*}{ erro } & \multirow{2}{*}{\multicolumn{3}{|c|}{ Gl }} & & & & \\
\hline & & & & & & \multicolumn{3}{|c|}{ GII } & \multirow[b]{2}{*}{$\begin{array}{l}\text { Teste de } \\
\text { proporção }\end{array}$} \\
\hline & & & $\begin{array}{c}\text { № } \\
\text { erros }\end{array}$ & $\begin{array}{l}\text { possibi- } \\
\text { lidade }\end{array}$ & $\%$ & $\begin{array}{c}\mathrm{N}^{0} \\
\text { erros }\end{array}$ & $\begin{array}{l}\text { possibi- } \\
\text { lidade }\end{array}$ & $\%$ & \\
\hline \multirow{2}{*}{$\begin{array}{c}\text { Fala } \\
\text { espontânea }\end{array}$} & $\begin{array}{c}\text { Trissílabo } \\
\text { medial }\end{array}$ & OC & 18 & 193 & 9.3 & 12 & 251 & 4.8 & 0.059 \\
\hline & $\begin{array}{c}\text { polissilabo } \\
\text { medial }\end{array}$ & OS & 13 & 84 & 15.5 & 7 & 166 & 4.2 & 0,002 * \\
\hline \multirow{7}{*}{ Imitação } & $\begin{array}{c}\text { dissilabo } \\
\text { inicial }\end{array}$ & $\mathrm{OC}$ & 16 & 447 & 3.6 & 9 & 517 & 1.7 & 0.0733 \\
\hline & dissilabo final & $\mathrm{OC}$ & 29 & 882 & 3.3 & 20 & 1029 & 1.9 & 0.0638 \\
\hline & dissilabo final & $E$ & 19 & 882 & 2.2 & 35 & 1029 & 3.4 & 0.1010 \\
\hline & $\begin{array}{c}\text { trissilabo } \\
\text { inicial }\end{array}$ & $\mathrm{OC}$ & 30 & 323 & 9.3 & 28 & 376 & 7.4 & 0.3790 \\
\hline & $\begin{array}{c}\text { trissilabo } \\
\text { inicial }\end{array}$ & OS & 35 & 323 & 10.8 & 10 & 376 & 2.7 & $<0,0001$ * \\
\hline & $\begin{array}{c}\text { trissilabo } \\
\text { medial }\end{array}$ & $\mathrm{OC}$ & 25 & 522 & 4.8 & 13 & 609 & 2.1 & 0,0135 * \\
\hline & trissilabo final & VV & 12 & 522 & 2.3 & 14 & 609 & 2.3 & 1.0000 \\
\hline
\end{tabular}

continua 
Continuação Tabela 85 - Comparação entre as faixas etárias para erros da estrutura CV.

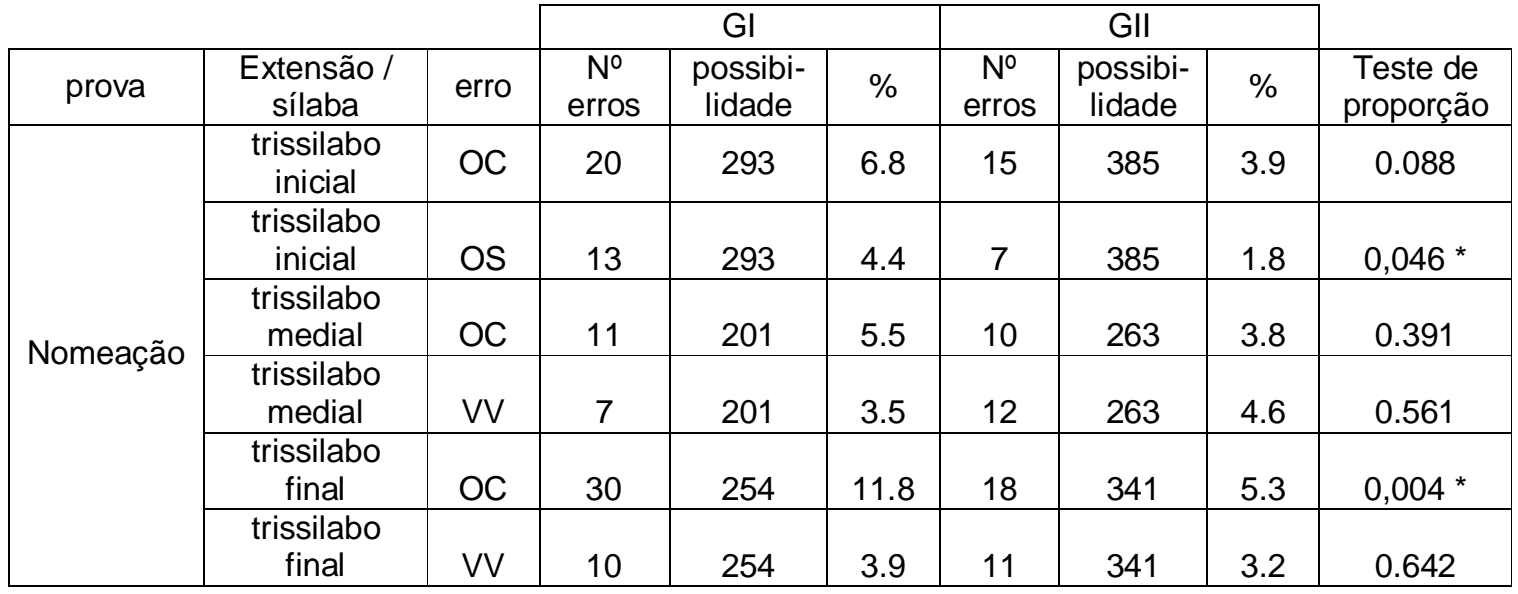

Legenda: OC: omissão da consoante, OS: omissão de sílaba, VV: troca para estrutura vogal-vogal $\underline{\mathrm{CCV}}$

Quanto à estrutura CCV com /P/, todos os grupos tiveram alta porcentagem de erro. A maior parte deles é a omissão da segunda consoante, ou seja, da líquida (Tabela 86). 
Tabela 86 - Erros observados na estrutura CCV com /P/.

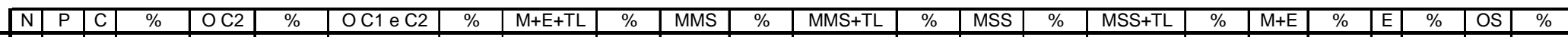

\begin{tabular}{|c|c|c|c|c|c|c|c|c|c|c|c|c|c|c|c|c|c|c|c|c|c|c|c|c|}
\hline \multirow{2}{*}{ IMI DIS I } & 111 & ותרת & T & & 2 & $00 \mathrm{cos}$ & & 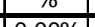 & 4 & 100 & $n$ & תחת & 0 & רחס & 5 & $200 \%$ & $\pi$ & $000 \%$ & 2 & $081 \%$ & 1 & $042 \%$ & $\pi$ & $000 \%$ \\
\hline & \begin{tabular}{|l|l|l|l|l} 
GII & 47 \\
\end{tabular} & \begin{tabular}{|l|}
283 \\
282 \\
\end{tabular} & \begin{tabular}{|l|}
69 \\
69 \\
\end{tabular} & \begin{tabular}{|l|}
$11,30 \%$ \\
$24,47 \%$ \\
\end{tabular} & $\frac{200}{198}$ & \begin{tabular}{|l|}
$83,68 \%$ \\
$70,21 \%$
\end{tabular} & $\frac{0}{1}$ & $|0,00 \%|$ & $\frac{4}{0}$ & $\begin{array}{l}7,6 / \% \\
0,00 \% \\
\end{array}$ & $\frac{0}{1}$ & \begin{tabular}{|l|}
$0,00 \%$ \\
$0,35 \%$ \\
\end{tabular} & $\frac{0}{1}$ & \begin{tabular}{|l|l|}
$0,00 \%$ \\
$0.35 \%$
\end{tabular} & $\frac{5}{8}$ & $\mid \frac{2,29 \%}{284 \%}$ & $\frac{0}{2}$ & \begin{tabular}{|l|}
$0,00 \%$ \\
$0,71 \%$ \\
\end{tabular} & $\frac{2}{0}$ & \begin{tabular}{|l|}
$0,04 \%$ \\
$0,00 \%$
\end{tabular} & $\frac{1}{1}$ & \begin{tabular}{|l|}
$0,4 \% \%$ \\
$0,35 \%$
\end{tabular} & 0 & $\frac{0,00 \%}{0,00 \%}$ \\
\hline \multirow{2}{*}{ NOM DIS I } & $\mathrm{Gl}^{+} 33$ & 60 & 5 & $8,33 \%$ & 53 & $88,33 \%$ & 0 & $0,00 \%$ & 0 & $0,00 \%$ & 0 & $0,00 \%$ & 0 & $0,00 \%$ & $\frac{2}{2}$ & $3,33 \%$ & 0 & $0,00 \%$ & 0 & $0,00 \%$ & 0 & \begin{tabular}{|l|}
$0,00 \%$ \\
\end{tabular} & 0 & $0,00 \%$ \\
\hline & $\begin{array}{|l:l|}\text { Gll } & 46 \\
\end{array}$ & \begin{tabular}{|l|}
92 \\
\end{tabular} & \begin{tabular}{|l|}
17 \\
\end{tabular} & $18,48 \%$ & 75 & \begin{tabular}{|l|}
$81,52 \%$ \\
\end{tabular} & 0 & $0,00 \%$ & 0 & $0,00 \%$ & 0 & $0,00 \%$ & 0 & $0,00 \%$ & 0 & \begin{tabular}{|l|}
$0,00 \%$ \\
\end{tabular} & 0 & $0,00 \%$ & 0 & \begin{tabular}{|l|}
$0,00 \%$ \\
\end{tabular} & 0 & \begin{tabular}{|l|}
$0,00 \%$ \\
\end{tabular} & 0 & $0,00 \%$ \\
\hline NOM DIS F & \begin{tabular}{|l|l|l|} 
GII & 28 \\
\end{tabular} & 29 & \begin{tabular}{|l|}
6 \\
\end{tabular} & $20,69 \%$ & 23 & $79,31 \%$ & $\overline{0}$ & \begin{tabular}{|l|l}
$0,00 \%$ \\
\end{tabular} & 0 & $0,00 \%$ & 0 & $0,00 \%$ & 0 & $0,00 \%$ & 0 & \begin{tabular}{|l|}
$0,00 \%$ \\
\end{tabular} & 0 & $0,00 \%$ & 0 & $0,00 \%$ & 0 & $0,00 \%$ & 0 & $0,00 \%$ \\
\hline \multirow{2}{*}{ IMI TRIS I } & GI I41 & \begin{tabular}{|l|}
41 \\
\end{tabular} & 3 & $7,32 \%$ & 33 & $80,49 \%$ & $\overline{0}$ & $0,00 \%$ & $\overline{0}$ & $0,00 \%$ & $\overline{0}$ & $0,00 \%$ & $\overline{0}$ & $0,00 \%$ & 2 & \begin{tabular}{|l|l}
$4,88 \%$ \\
\end{tabular} & 0 & \begin{tabular}{|l|}
$0,00 \%$ \\
\end{tabular} & 0 & \begin{tabular}{l|l|}
$0,00 \%$ \\
\end{tabular} & $\overline{0}$ & \begin{tabular}{|l|}
$0,00 \%$ \\
\end{tabular} & 3 & $7,32 \%$ \\
\hline & GII 47 & \begin{tabular}{|l|}
47 \\
\end{tabular} & 4 & $8,51 \%$ & 35 & $74,47 \%$ & 2 & $4,26 \%$ & 0 & $0,00 \%$ & 0 & $0,00 \%$ & 0 & $0,00 \%$ & 4 & $8,51 \%$ & 2 & $4,26 \%$ & 0 & $0,00 \%$ & 0 & $0,00 \%$ & 0 & $0,00 \%$ \\
\hline
\end{tabular}

Legenda: IMIT: imitação, NOM: nomeação, DIS: dissílabo, TRIS: trissílabo, I: sílaba inicial, F: sílaba final, N: número de sujeitos, P: possibilidade, C: correta, OC2: omissão da segunda consoante (líquida), O C1 e C2: omissão das duas consoantes, M: metátese, E: epêntese, TL: troca da líquida, MMS: metátese para a mesma sílaba, MSS: metátese para a sílaba seguinte, OS: omissão de sílaba. 
Foi realizado teste de proporção entre os erros e houve diferença entre os dois grupos apenas para palavras dissilábicas, em sílaba inicial, na imitação. As crianças do $\mathrm{Gl}$ apresentaram mais erros que as do Gll (Tabela 87).

Tabela 87 - Comparação entre as faixas etárias para erros da estrutura CCV com $/ \mathrm{P} /$.

\begin{tabular}{|c|c|c|c|c|c|c|c|c|c|}
\hline & & & & & & & & & \multirow[b]{3}{*}{$\begin{array}{c}\text { Teste de } \\
\text { proporção }\end{array}$} \\
\hline & & & \multicolumn{3}{|c|}{$\mathrm{Gl}$} & \multicolumn{3}{|c|}{ Gll } & \\
\hline prova & $\begin{array}{c}\text { Extensão / } \\
\text { sílaba }\end{array}$ & erro & $\begin{array}{c}\text { № } \\
\text { erros }\end{array}$ & $\begin{array}{l}\text { possibi- } \\
\text { lidade }\end{array}$ & $\%$ & $\begin{array}{c}\text { № } \\
\text { erros }\end{array}$ & $\begin{array}{l}\text { possibi- } \\
\text { lidade }\end{array}$ & $\%$ & \\
\hline \multirow{2}{*}{$\begin{array}{c}\text { Fala } \\
\text { espontânea }\end{array}$} & $\begin{array}{c}\text { dissílabo } \\
\text { inicial }\end{array}$ & OL & 9 & 12 & 75.0 & 16 & 19 & 84.2 & 0.527 \\
\hline & $\begin{array}{c}\text { trissílabo } \\
\text { inicial }\end{array}$ & $\mathrm{OL}$ & 8 & 11 & 72.7 & 13 & 17 & 76.5 & 0.823 \\
\hline \multirow{2}{*}{ Imitação } & $\begin{array}{c}\text { dissílabo } \\
\text { inicial }\end{array}$ & $\mathrm{OL}$ & 200 & 239 & 83.7 & 198 & 282 & 70.2 & 0,0003 * \\
\hline & $\begin{array}{c}\text { trissílabo } \\
\text { inicial }\end{array}$ & $\mathrm{OL}$ & 33 & 41 & 80.5 & 35 & 47 & 74.5 & 0.5015 \\
\hline \multirow{2}{*}{ Nomeação } & $\begin{array}{c}\text { dissílabo. } \\
\text { inicial }\end{array}$ & $\mathrm{OL}$ & 53 & 60 & 88.3 & 75 & 92 & 81.5 & 0.260 \\
\hline & $\begin{array}{c}\text { dissílabo } \\
\text { final }\end{array}$ & OL & 12 & 17 & 70.6 & 23 & 29 & 79.3 & 0.503 \\
\hline
\end{tabular}

Legenda: OL: omissão da líquida

A estrutura CCV com /// também apresentou baixa porcentagem de acerto. A eliminação da líquida também foi o erro mais freqüente em todas as provas e posições de sílabas, nos dois grupos. O segundo erro mais ocorrente foi a metátese para sílaba seguinte com troca da líquida (Tabela 88).

O teste de proporção mostrou que as crianças do $\mathrm{Gl}$ apresentaram a mesma porcentagem de omissão da líquida que as do Gll, em sílaba medial de polissílabos, na fala espontânea $(p=0,615)$, e em sílaba inicial de dissílabos, na imitação $(p=0,0681)$ e nomeação $(p=0,390)$. 
Tabela 88 - Erros observados na estrutura CCV com //.

\begin{tabular}{|c|c|c|c|c|c|c|c|c|c|c|c|c|c|c|c|c|c|c|c|c|c|c|c|}
\hline & & $\mathrm{N}$ & $\bar{P}$ & C & $\%$ & $\mathrm{OC1}$ & $\%$ & $\mathrm{OC2}$ & $\%$ & $\mathrm{OC} 1 \mathrm{e} \mathrm{C} 2$ & $\%$ & MMS & $\%$ & MMS+TL & $\%$ & MSS & $\%$ & $\mathrm{MSS}+\mathrm{TL}$ & $\%$ & $\mathrm{M}+\mathrm{E}$ & $\%$ & $\mathrm{M}+\mathrm{E}+\mathrm{TL}$ & $\%$ \\
\hline \multirow{2}{*}{ |MI DIS I } & GI & 40 & 117 & 14 & $11,97 \%$ & $\overline{3}$ & $2,56 \%$ & 85 & $72,65 \%$ & $\overline{3}$ & $2,56 \%$ & $\overline{0}$ & $0,00 \%$ & $\overline{0}$ & $0,00 \%$ & $\overline{6}$ & $5,13 \%$ & 5 & $4,27 \%$ & 1 & $0,85 \%$ & $\overline{0}$ & $0,00 \%$ \\
\hline & GII & 47 & 139 & 31 & $22,30 \%$ & 1 & $0,72 \%$ & 86 & $61,87 \%$ & 1 & $0,72 \%$ & 1 & $0,72 \%$ & 2 & $1,44 \%$ & 2 & $1,44 \%$ & 13 & $9,35 \%$ & 1 & $0,72 \%$ & 1 & $0,72 \%$ \\
\hline \multirow{2}{*}{ NOM DIS I } & $\mathrm{Gl}$ & 32 & 43 & 5 & $11,63 \%$ & $\overline{0}$ & $0,00 \%$ & 38 & $88,37 \%$ & $\overline{0}$ & $0,00 \%$ & $\overline{0}$ & $0,00 \%$ & $\overline{0}$ & $0,00 \%$ & $\overline{0}$ & $0,00 \%$ & $\overline{0}$ & $0,00 \%$ & $\overline{0}$ & $0,00 \%$ & 0 & $0,00 \%$ \\
\hline & Gll & 29 & 38 & 7 & $18,42 \%$ & 0 & $0,00 \%$ & 31 & $81,58 \%$ & 0 & $0,00 \%$ & $\overline{0}$ & $0,00 \%$ & 0 & $0,00 \%$ & $\overline{0}$ & $0,00 \%$ & 0 & $0,00 \%$ & 0 & $0,00 \%$ & 0 & $0,00 \%$ \\
\hline
\end{tabular}

Legenda: IMIT: imitação, NOM: nomeação, DIS: dissílabo, I: sílaba inicial, N: número de sujeitos, P: possibilidade, C: correta, OC1: Omissão da primeira consoante, OC2: omissão da segunda consoante (líquida), O C1 e C2: omissão das duas consoantes, MMS: metátese para a mesma sílaba, TL: troca de líquida, MSS: metátese para a sílaba seguinte, M: metátese, E: epêntese. 
$\underline{\text { CVC }}$

Em estrutura CVC com arquifonema /S/ (Tabela 89), o erro mais freqüente, em sílaba inicial, da nomeação e da imitação, é a omissão da coda silábica. Em sílaba final, observada apenas na imitação, o mais freqüente é a epêntese. Nesta posição de sílaba, as crianças também apresentaram menos erros que em sílaba inicial. Todas as comparações foram realizadas em palavras dissilábicas.

O teste de proporção mostrou diferença entre as faixas etárias para o erro de omissão do arquifonema, em sílaba inicial, na imitação ( $p=0,0042)$, e para o erro de epêntese, em sílaba final, na imitação $(p=0,0004)$. Na nomeação, o único erro comparado, omissão do arquifonema, não mostrou diferença entre os grupos ( $p=$ $0,118)$.

Tabela 89 - Erros observados na estrutura CVC com /S/.

\begin{tabular}{|c|c|c|c|c|c|c|c|c|c|c|c|c|}
\hline & $\mathrm{N}$ & $\mathrm{P}$ & $\mathrm{C}$ & $\%$ & $\mathrm{OC2}$ & $\%$ & $\mathrm{OC} 1 \mathrm{EC} 2$ & $\%$ & $E$ & $\%$ & OS & $\%$ \\
\hline \multirow[b]{2}{*}{ IMI DIS I } & \begin{tabular}{|l:l} 
GI & 40 \\
\end{tabular} & 40 & 11 & $27,50 \%$ & 28 & $70,00 \%$ & 0 & $0,00 \%$ & 0 & $0,00 \%$ & 1 & $2,50 \%$ \\
\hline & GII 46 & 46 & 26 & $56,52 \%$ & 18 & $39,13 \%$ & 1 & $2,17 \%$ & 0 & $0,00 \%$ & 1 & $2,17 \%$ \\
\hline \multirow[b]{2}{*}{ IMIT DIS F } & GI : 40 & 40 & 20 & $50,00 \%$ & 0 & $0,00 \%$ & 0 & $0,00 \%$ & 20 & $50,00 \%$ & 0 & $0,00 \%$ \\
\hline & GII $: 47$ & 47 & 37 & $78,72 \%$ & 3 & $6,38 \%$ & 0 & $0,00 \%$ & 7 & $14,89 \%$ & 0 & $0,00 \%$ \\
\hline \multirow[b]{2}{*}{ NOM DIS I } & Gl $: 22$ & 22 & 7 & $31,82 \%$ & 15 & $68,18 \%$ & 0 & $0,00 \%$ & 0 & $0,00 \%$ & 0 & $0,00 \%$ \\
\hline & GII 38 & 38 & 20 & $52,63 \%$ & 18 & $47,37 \%$ & 0 & $0,00 \%$ & 0 & $0,00 \%$ & 0 & $0,00 \%$ \\
\hline
\end{tabular}

Legenda: IMI: imitação; NOM: nomeação; DIS: dissílabo, N: número de sujeitos; P: possibilidade; C: correta; O C2: omissão da segunda consoante; O C1 E C2: omissão da primeira e segunda consoantes, E: epêntese; OS: omissão de sílaba.

A estrutura com arquifonema /R/ mostrou alta porcentagem de erro, sendo 0 mais ocorrente a omissão do arquifonema, seguido de troca da líquida por /y/, tornando a estrutura CV + semivogal (Tabela 90).

O teste de proporção mostrou diferença entre as faixas etárias para omissão do arquifonema, em sílaba inicial de palavras dissilábicas, na imitação e nomeação, e para CV + semivogal, em sílaba final de palavras dissilábicas, na nomeação (Tabela 91). Apenas para o erro de CV + semivogal, as crianças do GI apresentaram menos erros que as do Gll. 
Tabela 90 - Erros observados na estrutura CVC com /R/

\begin{tabular}{|c|c|c|c|c|c|c|c|c|c|c|c|c|c|c|c|c|c|c|c|c|c|c|}
\hline & $\mathrm{N}$ & $P$ & $\mathrm{C}$ & $\%$ & $\mathrm{OC}_{2}$ & $\%$ & $\mathrm{OC} 1$ e $\mathrm{C} 2$ & $\%$ & $\mathrm{CV}+\mathrm{SV}$ & $\%$ & $\mathrm{CV}+\mathrm{SV}+\mathrm{S}$ & $\%$ & $\mathrm{E}$ & $\%$ & MMS & $\%$ & $\mathrm{VV}+\mathrm{SV}$ & $\%$ & $\mathrm{~V}+\mathrm{SV}$ & $\%$ & OS & $\%$ \\
\hline \multirow[b]{2}{*}{ IMIT DIS | } & \begin{tabular}{|l|l|}
$\mathrm{Gl}$ & 40 \\
\end{tabular} & 40 & 1 & $2,50 \%$ & 34 & $85,00 \%$ & 0 & $0,00 \%$ & 3 & $7,50 \%$ & 0 & $0,00 \%$ & 1 & $2,50 \%$ & 1 & $2,50 \%$ & 0 & $0,00 \%$ & 0 & $0,00 \%$ & 0 & $0,00 \%$ \\
\hline & GII 46 & 46 & 10 & $21,74 \%$ & 25 & $54,35 \%$ & 0 & $0,00 \%$ & 8 & $17,39 \%$ & 0 & $0,00 \%$ & 0 & $0,00 \%$ & 3 & $6,52 \%$ & 0 & $0,00 \%$ & 0 & $0,00 \%$ & 0 & $0,00 \%$ \\
\hline \multirow[b]{2}{*}{ IMIT DIS F } & $\mathrm{Gl} 40$ & 40 & 0 & $0,00 \%$ & 22 & $55,00 \%$ & 0 & $0,00 \%$ & 10 & $25,00 \%$ & 0 & $0,00 \%$ & 8 & $20,00 \%$ & 0 & $0,00 \%$ & 0 & $0,00 \%$ & 0 & $0,00 \%$ & 0 & $0,00 \%$ \\
\hline & GII 45 & 45 & 4 & $8,89 \%$ & 22 & $48,89 \%$ & 0 & $0,00 \%$ & 8 & $17,78 \%$ & $\overline{1}$ & $2,22 \%$ & 9 & $20,00 \%$ & 1 & $2,22 \%$ & 0 & $0,00 \%$ & 0 & $0,00 \%$ & 0 & $0,00 \%$ \\
\hline NOM DIS I & GII | 36 & 36 & 4 & $11,11 \%$ & 22 & $61,11 \%$ & 0 & $0,00 \%$ & 10 & $27,78 \%$ & $\overline{0}$ & $0,00 \%$ & 0 & $0,00 \%$ & $\overline{0}$ & $0,00 \%$ & 0 & $0,00 \%$ & 0 & $0,00 \%$ & 0 & $0,00 \%$ \\
\hline NOM DIS F & GIII 24 & 27 & 3 & $11,11 \%$ & 21 & $77,78 \%$ & 0 & $0,00 \%$ & 2 & $7,41 \%$ & 0 & $0,00 \%$ & 0 & $0,00 \%$ & 1 & $3,70 \%$ & 0 & $0,00 \%$ & 0 & $0,00 \%$ & 0 & $0,00 \%$ \\
\hline FE DIS F & GI 30 & 42 & 0 & $0,00 \%$ & 32 & $76,19 \%$ & 4 & $9,52 \%$ & 2 & $4,76 \%$ & 0 & $0,00 \%$ & 0 & $0,00 \%$ & $\overline{0}$ & $0,00 \%$ & 0 & $0,00 \%$ & 4 & $9,52 \%$ & 0 & $0,00 \%$ \\
\hline \multirow[b]{2}{*}{ IMIT TRIS I } & \begin{tabular}{|l|l|}
$\mathrm{Gl}$ & 41 \\
\end{tabular} & 41 & 0 & $0,00 \%$ & 34 & $82,93 \%$ & 0 & $0,00 \%$ & 1 & $2,44 \%$ & 0 & $0,00 \%$ & 1 & $2,44 \%$ & 0 & $0,00 \%$ & 0 & $0,00 \%$ & 0 & $0,00 \%$ & 5 & $12,20 \%$ \\
\hline & GII 47 & 47 & 7 & $14,89 \%$ & 37 & $78,72 \%$ & 1 & $2,13 \%$ & 1 & $2.13 \%$ & 0 & $0,00 \%$ & 0 & $0,00 \%$ & 0 & $0,00 \%$ & 0 & $0,00 \%$ & 0 & $0,00 \%$ & 1 & $2,13 \%$ \\
\hline
\end{tabular}

Legenda: FE: fala espontânea, IMIT: imitação, NOM: nomeação, DIS: dissílabo, TRIS: trissílabo, I: sílaba inicial, F: sílaba final, N: número de sujeitos, P: possibilidade, C: correta, OC2: omissão da segunda consoante (líquida), O C1 e C2: omissão das duas consoantes, CV+SV: troca para estrutura consoante vogal + semivogal, CV+SV+S: troca para estrutura consoante vogal + semivogal seguida de /s/, E: epêntese, MMS: metátese para a mesma sílaba, VV+SV: troca para estrutura vogal-vogal + semivogal, V+SV: troca para vogal acrescida de semivogal, OS: omissão de sílaba. 
Tabela 91 - Comparação entre as faixas etárias para erros da estrutura CVC com $/ \mathrm{R} /$.

\begin{tabular}{|c|c|c|c|c|c|c|c|c|c|}
\hline & & & \multicolumn{3}{|c|}{$\mathrm{Gl}$} & \multicolumn{3}{|c|}{ GII } & \\
\hline prova & $\begin{array}{c}\text { Extensão / } \\
\text { sílaba }\end{array}$ & erro & $\begin{array}{l}\text { № } \\
\text { erros }\end{array}$ & $\begin{array}{l}\text { possibi- } \\
\text { lidade }\end{array}$ & $\%$ & $\begin{array}{l}\text { № } \\
\text { erros }\end{array}$ & $\begin{array}{l}\text { possibi- } \\
\text { lidade }\end{array}$ & $\%$ & $\begin{array}{c}\text { Teste de } \\
\text { proporção }\end{array}$ \\
\hline $\begin{array}{c}\text { Fala } \\
\text { espontânea }\end{array}$ & $\begin{array}{l}\text { dissílabo } \\
\text { final }\end{array}$ & $\mathrm{O}$ C2 & 32 & 42 & 76.2 & 22 & 29 & 75.9 & 0.975 \\
\hline \multirow{4}{*}{ Imitação } & $\begin{array}{c}\text { dissílabo } \\
\text { inicial }\end{array}$ & $\mathrm{O}$ C2 & 34 & 40 & 85.0 & 25 & 46 & 54.3 & 0,0023 * \\
\hline & $\begin{array}{l}\text { dissílabo } \\
\text { final }\end{array}$ & O C2 & 22 & 40 & 55.0 & 22 & 45 & 48.9 & 0.5736 \\
\hline & $\begin{array}{l}\text { dissílabo } \\
\text { final }\end{array}$ & $\begin{array}{c}\mathrm{CV}+ \\
\text { semivogal }\end{array}$ & 10 & 40 & 25.0 & 8 & 45 & 17.8 & 0.4159 \\
\hline & $\begin{array}{c}\text { trissílabo } \\
\text { inicial }\end{array}$ & $\mathrm{O} C 2$ & 34 & 41 & 82.9 & 37 & 47 & 78.7 & 0.6183 \\
\hline \multirow{3}{*}{ Nomeação } & $\begin{array}{c}\text { dissílabo } \\
\text { inicial }\end{array}$ & O C2 & 17 & 17 & 100.0 & 22 & 36 & 61.1 & 0,003 * \\
\hline & $\begin{array}{c}\text { dissílabo } \\
\text { inicial }\end{array}$ & $\begin{array}{c}\mathrm{CV}+ \\
\text { semivogal }\end{array}$ & 0 & 17 & 0.0 & 10 & 36 & 27.8 & 0,016 * \\
\hline & $\begin{array}{l}\text { dissílabo } \\
\text { final }\end{array}$ & O C2 & 10 & 13 & 76.9 & 21 & 27 & 77.8 & 0.952 \\
\hline
\end{tabular}

Legenda: O C2: omissão da segunda consoante, CV: estrutura consoante vogal 


\section{HIPÓTESE 6 - HÁ DIFERENÇA ENTRE OS ENCONTROS CONSONANTAIS, FONEMAS E ESTRUTURAS SILÁBICAS QUANTO À CLASSIFICAÇÃO DE AQUISIÇÃO, INDICANDO QUE AS CRIANÇAS DO GII APRESENTAM MAIOR PORCENTAGEM DE AQUISIÇÃO PARA TODOS OS FONEMAS.}

\section{HIPÓTESE PARCIALMENTE CONFIRMADA}

Conforme apontado no método, propôs-se uma classificação de aquisição para cada alvo que se apóia na porcentagem de crianças, em cada grupo, que tiveram um determinado fonema, encontro consonantal ou estrutura silábica adquirida, ou seja, com mais de $75 \%$ de acerto.

Se de $75 \%$ a $100 \%$ das crianças de um grupo tinham dominado o alvo, este era considerado adquirido, entre $50 \%$ e $75 \%$, em produção habitual, entre $25 \%$ e $50 \%$, em aquisição e, entre $0 \%$ a $25 \%$, não adquirido.

Ressalta-se que, para esta análise, pelo menos metade dos sujeitos do grupo teria que ter produzido o alvo. Assim, no Gl, foram considerados os alvos produzidos por 20 ou mais crianças e, no Gll, por 23 ou mais.

Inicialmente, serão apresentados os dados de fonemas e encontros consonantais, por prova. Por fim, as estruturas silábicas serão observadas.

\section{- Encontros consonantais e fonemas}

Os Quadros 6 a 8 mostram a aquisição dos fonemas e encontros consonantais analisados em cada uma das provas e em cada sílaba - inicial, medial e final - nas duas faixas etárias, indicando a porcentagem de crianças que tem os fonemas adquiridos.

\section{Fala Espontânea}

O Quadro 6 mostra os fonemas e a porcentagem de aquisição na fala espontânea.

Em relação aos encontros consonantais, não houve número de alvo suficiente para que eles pudessem ser analisados nas duas faixas etárias. 
O /p/ apareceu nas sílabas iniciais dos grupos e estava adquirido. $\mathrm{O} / \mathrm{b} /$ também foi analisado em posição inicial. No Gl encontra-se como produção habitual e no Gll como adquirido. A plosiva línguo-dental sonora apareceu somente nas sílabas medial e final. Nas crianças mais novas, nas duas sílabas, a produção foi habitual. Nas mais velhas, o /d/ estava adquirido. $\mathrm{O} / \mathrm{t} /$ foi analisado em sílaba final e está adquirido nos dois grupos. A velar / $\mathrm{k}$ só não foi analisada na sílaba medial do Gl. Porém, em todas as sílabas é considerada como adquirida. Sua correspondente sonora, /g/, não teve número de sujeito suficiente para análise.

Quanto às fricativas, menos de $50 \%$ das crianças emitiram palavras com o fonema /s/. Assim, ele não foi analisado nesta prova. $\mathrm{O} / \mathrm{z} /$ foi analisado apenas na sílaba final do Gll e se encontra como produção habitual. O /v/ também foi analisado somente na sílaba final do grupo mais velho e encontra-se adquirido. $O$ / $f$ / foi analisado no Gll em sílaba inicial, estando adquirido por este grupo. As fricativas palatais não tiveram número de sujeito suficiente para que fossem analisadas.

A nasal bilabial $/ \mathrm{m} /$ foi analisada em sílabas inicial e medial nos dois grupos e final somente no GI. O / / foi analisado na sílaba final dos grupos. Em todas estas ocasiões, estes fonemas encontram-se adquiridos. A nasal línguo-alveolar /n/ foi analisada em sílaba medial, encontra-se adquirida no Gll e, nos grupos de crianças mais novas, ainda está em produção habitual.

Quanto às líquidas, o / / não está adquirido em nenhum grupo na sílaba final, sendo esta a única sílaba analisada. $\mathrm{O} / \mathrm{P} /$ também foi analisado somente na sílaba final e se encontra em aquisição nos dois grupos. $\mathrm{O} / \mathrm{l} /$ foi analisado em sílaba medial e está adquirido nos grupos de crianças mais velhas. No Gl encontra-se em produção habitual.

$\mathrm{O} / \mathrm{X} /$ foi observado nas sílabas mediais, estando em aquisição no grupo de crianças mais novas e em produção habitual nas crianças mais velhas.

O arquifonema /R/ foi analisado em posição final e não está adquirido nos grupos. O arquifonema /S/ foi analisado em sílaba inicial apenas no Gll e encontrase em aquisição. 


\section{Imitação}

Na prova de imitação (Quadro 7), observa-se que os encontros consonantais apareceram apenas em sílabas iniciais. No Gl, a porcentagem de aquisição é inferior a $20 \%$, tanto para encontros com /P/ como com /// . No Gll, os encontros /bP/, /pP/ e /fP/ apresentaram porcentagem acima de $20 \%$, mas ainda são considerados como não adquiridos por terem valor abaixo de $25 \%$.

Quanto às plosivas, o /p/ está adquirido nas sílabas medial e final de todos os grupos. Em sílaba inicial, encontra-se em produção habitual. $\mathrm{O} / \mathrm{b} /$ está adquirido em sílaba medial nos dois grupos e em sílaba inicial nas crianças mais velhas. Na sílaba inicial do Gl e final nos dois grupos encontra-se em produção habitual.

As plosivas línguo-alveolares foram analisadas em todas as sílabas (inicial, medial e final). $\mathrm{O} / \mathrm{t} /$ encontra-se adquirido nas sílabas inicial e final nos dois grupos. Nas crianças mais novas em sílaba medial está em aquisição e nas mais velhas como produção habitual. $\mathrm{O} / \mathrm{d} /$ encontra-se como produção habitual no $\mathrm{Gl}$ e adquirido no Gll em todas as sílabas.

Em relação às plosivas velares, $0 / \mathrm{k} /$ encontra-se adquirido em todos os grupos e sílabas, com exceção da sílaba inicial do Gl, que aparece como produção habitual. Nas sílabas medial e final nos dois grupos, mais de $90 \%$ dos sujeitos o tem como adquirido. O /g/ mostra produção habitual em todas as sílabas do Gl e Gll, com exceção da medial do Gll, que é tido como dominado.

A fricativa /Z/ mostra-se em aquisição nas crianças mais novas. No grupo de crianças mais velhas, não está adquirida em sílaba final, em sílaba medial encontrase em aquisição e, em sílaba inicial, encontra-se em produção habitual. $O / \Sigma /$ apresenta-se em produção habitual nas três posições silábicas nos dois grupos.

As fricativas línguo-alveolares foram analisadas nas sílabas inicial e final. Aparecem em aquisição em todos os grupos, com exceção do Gl em sílaba inicial, que apresenta o /s/ como não adquirido. Nota-se que a porcentagem de crianças que o adquiriram está próxima do valor da categoria "em aquisição".

As fricativas lábio-dentais /f/ e /v/ apareceram nas sílabas inicial, medial e final. $\mathrm{O} / \mathrm{f} / \mathrm{mostra}$-se adquirido em todas as posições e em todos os grupos. Apenas 
em sílaba inicial do Gl encontra-se como produção habitual. O /v/ está adquirido em sílaba inicial e como produção habitual nas sílabas medial e final.

As nasais $/ \mathrm{n} / \mathrm{e} / \mathrm{m} /$ foram analisadas em sílabas inicial e final e o /// foi analisado somente em sílaba final. Todas as nasais estão adquiridas, com exceção da bilabial e línguo-alveolar no Gl, em sílaba inicial, que se apresentam como produção habitual.

Em relação às líquidas, $0 / \times /$ foi analisado apenas em sílaba final e nas duas faixas etárias encontra-se em aquisição. $\mathrm{O} / \mathrm{P} /$ também foi analisado somente em sílaba final, sendo que não está adquirido em nenhum dos grupos. O ///, analisado em sílabas inicial e final, teve produção habitual nas crianças mais novas e está adquirido nas crianças mais velhas.

O /X/ não está adquirido pelo Gl em sílaba inicial e medial e, em sílaba final, encontra-se em aquisição. No Gll, está em aquisição na sílaba inicial e, nas sílabas medial e final, encontra-se em produção habitual.

Nessa prova, não há análise dos arquifonemas em sílaba medial. O arquifonema /R/ ainda não está adquirido por nenhum grupo nas posições inicial e final. Quanto ao arquifonema /S/, em sílaba inicial, nos dois grupos, ainda não está adquirido, apesar da porcentagem de crianças no Gll ser maior que as no Gl. Em sílaba final, apresenta-se em aquisição no Gl e em produção habitual no Gll. 


\section{Nomeacão}

O Quadro 8 mostra a aquisição dos fonemas na prova de nomeação. Quanto aos encontros consonantais em sílaba inicial, foram analisados os encontros /pP/ e /bP/ nos dois grupos e o /bl/ no Gl. Em sílaba final, apenas o Gll teve análise do /vP/. Todos os encontros, em todas as sílabas, nos dois grupos foram considerados como não adquiridos.

Em relação às plosivas, a bilabial surda foi testada em todas as sílabas e a sonora em sílabas inicial e medial, nos dois grupos. Tanto $\circ / \mathrm{b} / \mathrm{como} \circ / \mathrm{p} /$ estão adquiridos em todos os grupos e sílabas testadas. $\mathrm{O} / \mathrm{d} / \mathrm{está}$ adquirido em todas as sílabas de ambos os grupos, com exceção apenas da sílaba final nas crianças mais novas, estando em produção habitual. $\mathrm{O} / \mathrm{t} /$ foi testado nas sílabas inicial e final de todos os grupos e se encontra adquirido no grupo de crianças mais velhas. No grupo mais novo, encontra-se em produção habitual. $\mathrm{O} / \mathrm{g} /$, em sílaba inicial, encontra-se em produção habitual no Gll, está adquirido na sílaba inicial do Gl e na final do Gll. Não há análise deste fonema em sílaba medial. $\mathrm{O} / \mathrm{k} /$ foi testado nas sílabas inicial $\mathrm{e}$ final e está adquirido nos dois grupos.

$\mathrm{O}$ /f/ foi analisado na sílaba inicial nos grupos e encontra-se adquirido. Em sílaba final, foi observado apenas no grupo de crianças mais novas, estando também adquirido. $O / \mathrm{v} /$ foi analisado somente em sílaba inicial, sendo que no Gl está em aquisição e no Gll em produção habitual. $\mathrm{O} / \mathrm{s} /$ foi testado em todas as sílabas e em todos os grupos. Ainda não está adquirido na sílaba inicial no Gl. Nas demais sílabas do Gl e do Gll, encontra-se em aquisição, com exceção da sílaba medial do Gll, que encontra-se em produção habitual. $\mathrm{O} / \mathrm{z} /$ foi testado nas sílabas medial e final e encontra-se em aquisição em todos os grupos. $\mathrm{O} / \Sigma /$ está adquirido na sílaba final do Gl e encontra-se em produção habitual na sílaba medial no Gl e nas sílabas medial e final no Gll. O /Z/ foi testado apenas em sílaba final. Nos dois grupos encontra-se em aquisição.

Quanto às nasais, somente $\mathrm{o} / \mathrm{m} /$ aparece em sílaba inicial e, em final, podese analisar as três nasais. Todas estão adquiridas nos dois grupos, independentemente da sílaba que aparecem.

Quanto às líquidas, o /P/ foi analisado apenas em sílaba final e não está adquirido no Gl. No Gll encontra-se em aquisição. $O / \times /$ em sílaba medial não está 
adquirido no Gl e no Gll está em aquisição. Em sílaba final foi somente analisado no Gll e não se encontra adquirido. $\mathrm{O} / \mathrm{l} /$ foi analisado em todas as sílabas com exceção da sílaba inicial no Gl. No Gl, encontra-se em produção habitual nas sílabas medial e final. O Gll parece ter adquirido este fonema nas três sílabas analisadas.

$\mathrm{O} / \mathrm{X} /$ foi testado em sílaba inicial e final. No GI não se encontra adquirido nas sílabas testadas. No Gll, está em aquisição na sílaba inicial e em produção habitual na sílaba final.

O arquifonema /S/ foi testado apenas em sílaba inicial. No GI, não está adquirido e no Gll encontra-se em aquisição. $O$ arquifonema /R/ foi analisado apenas no grupo de crianças mais velhas. Não houve número de sujeitos suficiente para análise no GI. Tanto em sílaba inicial como em final, ele não está adquirido. 


\section{- Estruturas silábicas}

No Quadro 9, observam-se todas as estruturas silábicas analisadas em relação à posição das sílabas na palavra. É importante lembrar que, pelo critério de aquisição adotado, pelo menos metade dos sujeitos de cada grupo teria que ter produzido ao menos uma vez o alvo.

Quanto à estrutura CV, em todas as sílabas e provas analisadas, nota-se que está adquirida, com exceção da estrutura CV em sílaba medial de palavra polissilábica, na fala espontânea, no Gl. Esta ainda se encontra em produção habitual.

Em relação à estrutura silábica CCV, com a segunda consoante sendo $0 / \mathrm{P} /$, não havia número suficiente de sujeitos ou não havia possível alvo para análise na fala espontânea. Na imitação, havia alvo apenas em sílaba inicial de palavras dissilábicas e trissilábicas, sendo que em nenhuma situação os grupos adquiriram esta estrutura. Na nomeação, havia alvo em palavras dissilábicas na sílaba inicial e, no Gll, também em palavras dissilábicas na sílaba final. Assim como na imitação, nenhum grupo adquiriu esta estrutura. Este fato mostra que menos de $25 \%$ das crianças tinham-na adquirido.

Pode-se observar que, quando a segunda consoante é $0 / 1 /$, os grupos também não adquiriram a estrutura CCV. Tal estrutura foi analisada somente na imitação e nomeação em sílaba inicial de palavras dissilábicas.

Analisando a estrutura CVC com arquifonema /R/, em todos os grupos, nas sílabas e provas analisadas, esta não estava adquirida. Ressalta-se que no GI não houve comparação na prova de nomeação.

Com o arquifonema /S/, a estrutura CVC foi observada apenas em palavras dissilábicas na imitação e nomeação. No Gl, nota-se que em sílaba inicial, nas duas provas, encontra-se em aquisição e, em sílaba final, com ocorrência apenas na imitação, a produção é habitual. Por outro lado, no grupo de crianças mais velhas, em sílaba inicial nas duas provas, apresenta-se como produção habitual e na sílaba final da prova imitação, como adquirida. 
Quadro 9 - Classificação de aquisição das estruturas silábicas

\begin{tabular}{|c|c|c|c|c|c|c|c|c|c|c|c|c|c|c|c|c|c|c|}
\hline & \multicolumn{9}{|c|}{ Gl } & \multicolumn{9}{|c|}{ GII } \\
\hline & \multicolumn{3}{|c|}{ FE } & \multicolumn{3}{|c|}{ IMIT } & \multicolumn{3}{|c|}{ NOM } & \multicolumn{3}{|c|}{ FE } & \multicolumn{3}{|c|}{ IMIT } & \multicolumn{3}{|c|}{ NOM } \\
\hline & I & $M$ & $F$ & $T$ & $M$ & $\bar{F}$ & $T$ & $\mathbf{M}$ & $\bar{F}$ & I & $\bar{M}$ & $F$ & $T$ & \begin{tabular}{|l|}
$\mathbf{M}$ \\
\end{tabular} & $\bar{F}$ & $T$ & $\mathrm{M}$ & $\Gamma$ \\
\hline $\mathrm{C} / \mathrm{V}$ - dis & * & --- & --- & NA & --- & --- & $N A$ & -- & * & * & --- & * & NA & $-{ }_{-1}$ & --- & NA & --- & NA \\
\hline $\mathrm{C} / \mathrm{V}$ - triss & & . & --- & NA & --- & --- & --- & --- & --- & * & * & --- & $\overline{N A}$ & $|--|$ & --- & --- & --- & -- \\
\hline$C / \% V$ & * & --- & --- & --- & --- & --- & --- & --- & --- & * & * & --- & --- & $|--|$ & --- & --- & --- & -- \\
\hline $\mathrm{C} / \mathrm{I} / \mathrm{V}$ & & $\overline{---}$ & $\overline{---}$ & NA & --- & $\overline{---}$ & $\overline{N A}$ & --- & --- & * & --- & $\overline{---}$ & $\overline{\mathrm{NA}}$ & \begin{tabular}{|l|}
--- \\
\end{tabular} & $\overline{---}$ & $\mathrm{NA}$ & $\overline{---}$ & - \\
\hline C/I/V - pol & ${ }^{\star}$ & --- & --- & $\begin{array}{ll}--- \\
\end{array}$ & --- & --- & --- & -- & --- & * & --- & --- & --- & \begin{tabular}{|l|}
-- \\
\end{tabular} & --- & --- & --- & --- \\
\hline ss & $A$ & $\begin{array}{c}-- \\
-\end{array}$ & $\bar{A}$ & A & $\begin{array}{l}-- \\
\end{array}$ & A & A & $\begin{array}{l}--- \\
\end{array}$ & $A$ & $A$ & ב--- & $A$ & $\mathrm{~A}$ & \begin{tabular}{|c|}
---1 \\
\end{tabular} & $A$ & $A$ & 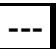 & $A$ \\
\hline CV - & A & $A$ & $A$ & $A$ & $A$ & A & $A$ & $A$ & $\mathrm{~A}$ & $A$ & $A$ & $A$ & $A$ & $A$ & $A$ & $A$ & $A$ & $A$ \\
\hline V- & $\mathrm{A}$ & $\mathrm{PH}$ & $\mathrm{A}$ & --- & --- & --- & --- & -- & -- & $A$ & $A$ & $\mathrm{~A}$ & --- & --- & --- & --- & --- & $\cdots$ \\
\hline CV/S/ - diss & & 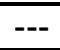 & * & $E A$ & --- & $\overline{\mathrm{PH}}$ & EA & \begin{tabular}{|c|}
-- \\
\end{tabular} & - & $*$ & --- & * & $\overline{\mathrm{PH}}$ & $-1--$ & A & $\mathrm{PH}$ & \begin{tabular}{|c|}
-- \\
\end{tabular} & - \\
\hline & & -- & * & --- & --- & --- & --- & --- & -- & * & --- & * & --- & --- & $\overline{---}$ & --- & --- & --- \\
\hline iss & 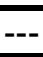 & $\overline{---}$ & $\overline{\mathrm{NA}}$ & NA & --- & $\overline{N A}$ & * & --- & 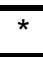 & * & --- & $\overline{N A}$ & $\overline{\mathrm{NA}}$ & --- & $\overline{N A}$ & NA & -- & $\overline{N A}$ \\
\hline CVR/ & - & -- & --- & NA & --- & --- & --- & -- & -- & * & * & * & $\overline{N A}$ & $-\cdots$ & --- & --- & --- & -- \\
\hline $\mathrm{CV} / \mathrm{R} /$ & & * & 7 & --- & - & --- & --- & 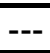 & -- & & * & * & --- & --- & --- & --- & -- & - \\
\hline
\end{tabular}

Legenda: FE: fala espontânea, IMIT: imitação, NOM: nomeação, I: sílaba inicial, M: sílaba medial, F: sílaba final, diss: dissílabo, triss: trissílabo, pol: polissílabo, NA: não adquirido, EA: em aquisição, $\mathrm{PH}$ : produção habitual, A: adquirido, *: número de alvo insuficiente 


\title{
HIPÓTESE 7 - AS CRIANÇAS DAS DUAS FAIXAS ETÁRIAS APRESENTAM DESEMPENHO DIFERENTE NAS TRÊS PROVAS (NOMEAÇÃO, IMITAÇÃO E FALA ESPONTÂNEA).
}

\author{
ENCONTROS CONSONANTAIS: HIPÓTESE NÃO CONFIRMADA \\ FONEMAS: HIPÓTESE PARCIALMENTE CONFIRMADA \\ ESTRUTURAS: \\ CV - HIPÓTESE PARCIALMENTE CONFIRMADA \\ CCV - HIPÓTESE NÃO CONFIRMADA \\ CVC - HIPÓTESE PARCIALMENTE CONFIRMADA
}

\section{- Encontros consonantais}

Todos os encontros consonantais foram agrupados para a realização da comparação entre as provas de nomeação, imitação e fala espontânea (ANOVA, n. sig. 0,05).

A comparação foi realizada somente em sílaba inicial e todas as provas tiveram porcentagem de acerto estatisticamente igual (Tabela 92).

Tabela 92 - Comparação entre as provas para encontros consonantais.

\begin{tabular}{|c|c|c|c|c|c|c|}
\hline & & & \multicolumn{3}{|c|}{ PROVA } & \multirow{2}{*}{$\begin{array}{l}\text { ANOVA } \\
(p)\end{array}$} \\
\hline Grupo & sílaba & Estatística & FE & IM & NO & \\
\hline \multirow{9}{*}{ GI } & \multirow{3}{*}{ Inicial } & Média & 18.94 & 8.46 & 9.71 & \multirow{3}{*}{0.236} \\
\hline & & Desvio-padrão & 37.20 & 27.85 & 29.75 & \\
\hline & & $\mathrm{n}$ & 22 & 473 & 103 & \\
\hline & \multirow{3}{*}{ Medial } & Média & 0.00 & --- & --- & \multirow{3}{*}{ não analisado } \\
\hline & & Desvio-padrão & 0.00 & --- & --- & \\
\hline & & $n$ & 15 & --- & --- & \\
\hline & \multirow{3}{*}{ Final } & Média & --- & --- & 29.41 & \multirow{3}{*}{ não analisado } \\
\hline & & Desvio-padrão & --- & --- & 46.97 & \\
\hline & & $n$ & --- & --- & 17 & \\
\hline \multirow{9}{*}{ GII } & \multirow{3}{*}{ Inicial } & Média & 8.57 & 14.67 & 12.78 & \multirow{3}{*}{0.541} \\
\hline & & Desvio-padrão & 25.68 & 35.41 & 33.52 & \\
\hline & & $\mathrm{n}$ & 35 & 559 & 133 & \\
\hline & \multirow{3}{*}{ Medial } & Média & 8.33 & --- & --- & \multirow{3}{*}{ não analisado } \\
\hline & & Desvio-padrão & 28.87 & --- & --- & \\
\hline & & $\mathrm{n}$ & 12 & --- & --- & \\
\hline & \multirow{3}{*}{ Final } & Média & 33.33 & --- & 17.24 & \multirow{3}{*}{ não analisado } \\
\hline & & Desvio-padrão & 57.74 & --- & 38.44 & \\
\hline & & $\mathrm{n}$ & 3 & --- & 29 & \\
\hline
\end{tabular}


- Fonemas

Assim como para a análise dos encontros consonantais, todos os fonemas foram agrupados para a realização da comparação entre as provas. Para essa análise foi usada a ANOVA (n. sig. 0,05).

No GI (Tabela 93), apenas em sílaba inicial houve diferença estatística entre as provas $(p<0,001)$. Assim, foi realizada comparação múltipla de Bonferroni entre elas. Os dados estatísticos confirmaram que cada uma das três provas é significantemente diferente das demais, sendo que a imitação foi a prova em que as crianças obtiveram o pior desempenho e, a fala espontânea, o melhor de todos (Tabela 94).

No grupo de crianças mais velhas, em todas as posições de sílaba, foi encontrada diferença significante entre as provas (Tabela 93). A comparação múltipla, em sílaba inicial, mostrou que imitação e nomeação apresentaram porcentagem estatisticamente igual quanto ao acerto em fonemas, mas em ambas as provas as crianças apresentaram mais erros que na fala espontânea. Quanto à sílaba medial, as crianças tiveram melhor desempenho na fala espontânea, seguida da imitação e nomeação. Porém, houve diferença significante apenas entre fala espontânea e nomeação. Em relação à sílaba final, o melhor desempenho também foi observado na fala espontânea, seguido da nomeação e, por último, da imitação. Nesta posição de sílaba, a fala espontânea obteve diferença estatística comparada à imitação (Tabela 94). 
Tabela 93 - Comparação entre as provas para fonemas.

\begin{tabular}{|c|c|c|c|c|c|c|}
\hline & & & & PROVA & & ANOVA \\
\hline grupo & sílaba & Estatística & FE & IM & $\mathrm{NO}$ & (p) \\
\hline \multirow{9}{*}{ Gl } & \multirow{3}{*}{ Inicial } & Média & 78.78 & 56.29 & 64.70 & \multirow{3}{*}{$<0,001$ * } \\
\hline & & Desvio-padrão & 36.80 & 47.34 & 46.52 & \\
\hline & & $\mathrm{n}$ & 221 & 734 & 458 & \\
\hline & \multirow{3}{*}{ Medial } & Média & 68.25 & 67.31 & 63.89 & \multirow{3}{*}{0.517} \\
\hline & & Desvio-padrão & 43.89 & 45.65 & 47.64 & \\
\hline & & $\mathrm{n}$ & 210 & 443 & 270 & \\
\hline & \multirow{3}{*}{ Final } & Média & 68.36 & 62.16 & 65.32 & \multirow{3}{*}{0.086} \\
\hline & & Desvio-padrão & 44.02 & 45.52 & 45.99 & \\
\hline & & $\mathrm{n}$ & 345 & 849 & 527 & \\
\hline \multirow{9}{*}{ Gll } & \multirow{3}{*}{ Inicial } & Média & 81.08 & 70.00 & 71.93 & \multirow{3}{*}{$<0,001$ * } \\
\hline & & Desvio-padrão & 36.74 & 43.28 & 43.24 & \\
\hline & & $\mathrm{n}$ & 303 & 845 & 614 & \\
\hline & \multirow{3}{*}{ Medial } & Média & 81.57 & 75.76 & 70.56 & \multirow{3}{*}{0,003 * } \\
\hline & & Desvio-padrão & 37.11 & 41.88 & 45.25 & \\
\hline & & $\mathrm{n}$ & 323 & 517 & 355 & \\
\hline & \multirow{3}{*}{ Final } & Média & 76.33 & 69.25 & 72.23 & \multirow{3}{*}{0,012 * } \\
\hline & & Desvio-padrão & 40.36 & 43.59 & 43.31 & \\
\hline & & $\mathrm{n}$ & 473 & 983 & 712 & \\
\hline
\end{tabular}

Tabela 94 - Comparação múltipla entre as provas para fonemas

\begin{tabular}{|c|c|c|}
\hline grupo & sílaba & $\begin{array}{l}\text { Comparações } \\
\text { múltiplas }(p)\end{array}$ \\
\hline \multirow{3}{*}{ GI } & \multirow{3}{*}{ inicial } & $\mathrm{FE} \times \operatorname{IM}\left(<0,001^{\star}\right)$ \\
\hline & & $\mathrm{FE} \times \mathrm{NO}\left(0,001^{*}\right)$ \\
\hline & & $\mathrm{IM} \times \mathrm{NO}\left(0,006^{*}\right)$ \\
\hline \multirow{9}{*}{ Gll } & \multirow{3}{*}{ inicial } & $\mathrm{FE} \times \operatorname{IM}\left(<0,001^{\star}\right)$ \\
\hline & & FE $\times$ NO $(0,006$ * $)$ \\
\hline & & IM x NO $(1,000)$ \\
\hline & \multirow{3}{*}{ medial } & FE $\times \operatorname{IM}(0,149)$ \\
\hline & & FE x NO $(0,002 *)$ \\
\hline & & $\mathrm{IM} \times \mathrm{NO}(0,213)$ \\
\hline & \multirow{3}{*}{ final } & FE $\times \operatorname{IM}\left(0,009^{*}\right)$ \\
\hline & & FE x NO $(0,318)$ \\
\hline & & $\mathrm{IM} \times \mathrm{NO}(0,475)$ \\
\hline
\end{tabular}

\section{- Estruturas silábicas}

$\underline{\mathrm{CV}}$

Para a comparação entre as provas quanto a acerto em estrutura CV (Tabela 95), as posições de sílabas foram analisadas separadamente (inicial, medial e final). Nos dois grupos as provas foram consideradas diferentes, com exceção da sílaba medial no grupo de crianças mais velhas. 
Tabela 95 - Comparação entre as provas para estrutura CV

\begin{tabular}{|c|c|c|c|c|c|c|}
\hline grupo & sílaba & estatística & FE & 1 & $\mathrm{~N}$ & ANOVA (p) \\
\hline \multirow{9}{*}{ GI } & \multirow{3}{*}{ Inicial } & Média & 97,02 & 88,10 & 93,05 & \multirow{3}{*}{$<0,001 *$} \\
\hline & & Desvio-padrão & 12,75 & 19,46 & 11,70 & \\
\hline & & $\mathrm{n}$ & 99 & 82 & 82 & \\
\hline & \multirow{3}{*}{ Medial } & Média & 83,80 & 93,26 & 90,65 & \multirow{3}{*}{0,049 * } \\
\hline & & Desvio-padrão & 28,38 & 5,75 & 12,81 & \\
\hline & & $\mathrm{n}$ & 64 & 41 & 41 & \\
\hline & \multirow{3}{*}{ Final } & Média & 97,36 & 95,01 & 90,75 & \multirow{3}{*}{$<0,001 *$} \\
\hline & & Desvio-padrão & 9,79 & 6,53 & 14,51 & \\
\hline & & $\mathrm{n}$ & 99 & 82 & 82 & \\
\hline \multirow{9}{*}{ Gll } & \multirow{3}{*}{ Inicial } & Média & 98,00 & 93,88 & 96,36 & \multirow{3}{*}{0,016 * } \\
\hline & & Desvio-padrão & 10,64 & 11,57 & 8,33 & \\
\hline & & $\mathrm{n}$ & 118 & 94 & 94 & \\
\hline & \multirow{3}{*}{ Medial } & Média & 91,79 & 95,55 & 91,13 & \multirow{3}{*}{0.226} \\
\hline & & Desvio-padrão & 17,57 & 4,77 & 12,22 & \\
\hline & & $\mathrm{n}$ & 77 & 47 & 47 & \\
\hline & \multirow{3}{*}{ Final } & Média & 98,61 & 95,29 & 94,08 & \multirow{3}{*}{$<0,001$ * } \\
\hline & & Desvio-padrão & 5,58 & 5,71 & 12,35 & \\
\hline & & $n$ & 119 & 94 & 94 & \\
\hline
\end{tabular}

Desta forma, foram realizadas comparações múltiplas de Bonferroni (n. sig. $0,05)$. Nota-se que, em sílaba inicial, para as crianças dos dois grupos (Tabela 96), a fala espontânea mostrou o mesmo desempenho que a nomeação, porém, teve resultado significativamente maior comparada à imitação. A nomeação e a imitação foram estatisticamente iguais, apesar de a primeira ter média maior de acerto.

Apesar da ANOVA mostrar diferença entre as provas na sílaba medial no Gl ( $p=0,049$ ), a comparação múltipla de Bonferroni não indicou diferença estatística significante entre elas. Isso ocorreu pelo fato do valor de $p$ ser próximo de 0,05. Considerando que o resultado de comparação geral seria o mais relevante, neste caso, pode-se considerar que a prova de fala espontânea é estatisticamente diferente da imitação, embora o $p$ valor seja 0,063. Nota-se que a imitação apresenta média de acerto maior que a fala espontânea. A nomeação mostrou ser estatisticamente igual à imitação e à fala espontânea (Tabela 96).

Em sílaba final no $\mathrm{Gl}$, as crianças tiveram desempenho igual em fala espontânea e imitação e ambas foram significantemente maiores que a nomeação. No Gll, as crianças tiveram resultado significantemente maior na fala espontânea comparada às provas de nomeação e imitação, sendo que as últimas foram consideradas iguais. 
Tabela 96 - Comparação múltipla entre as provas para estrutura CV.

\begin{tabular}{|c|c|c|}
\hline grupo & sílaba & comparação \\
\hline \multirow{9}{*}{ Gl } & \multirow{3}{*}{ Inicial } & $\mathrm{FE} \times \operatorname{IM}\left(<0,001^{*}\right)$ \\
\hline & & FE x NO $(0,225)$ \\
\hline & & $\mathrm{IM} \times \mathrm{NO}(0,102)$ \\
\hline & \multirow{3}{*}{ Medial } & FE $\times \operatorname{IM}(0,063)$ \\
\hline & & FE x NO $(0,280)$ \\
\hline & & $\mathrm{IM} \times \mathrm{NO}(1,000)$ \\
\hline & \multirow{3}{*}{ Final } & FE $\times \operatorname{IM}(0,434)$ \\
\hline & & FE $\times \mathrm{NO}\left(<0,001^{*}\right)$ \\
\hline & & $\mathrm{IM} \times \mathrm{NO}(0,035)$ \\
\hline \multirow{6}{*}{ Gll } & \multirow{3}{*}{ Inicial } & FE x IM $\left(0,012^{*}\right)$ \\
\hline & & FE x NO $(0,750)$ \\
\hline & & $\mathrm{IM} \times \mathrm{NO}(0,301)$ \\
\hline & \multirow{3}{*}{ Final } & FE x IM $\left(0,012^{*}\right)$ \\
\hline & & FE x NO $\left(<0,001^{*}\right)$ \\
\hline & & IM x NO $(0,956)$ \\
\hline
\end{tabular}

$\underline{\mathrm{CCV}}$

Houve comparação entre as provas somente para a sílaba inicial nos dois grupos. Nesta, não foi encontrada diferença estatística entre as provas (Tabela 97).

Tabela 97 - Comparação entre as provas para estrutura CCV.

\begin{tabular}{|c|c|c|c|c|c|c|}
\hline grupo & sílaba & estatística & FE & $\mathrm{I}$ & $\mathrm{N}$ & ANOVA (p) \\
\hline \multirow{9}{*}{ GI } & \multirow{3}{*}{ Inicial } & Média & 13.33 & 10.63 & 11.03 & \multirow{3}{*}{0.878} \\
\hline & & Desvio-padrão & 33.53 & 24.43 & 30.37 & \\
\hline & & $\mathrm{n}$ & 35 & 122 & 65 & \\
\hline & \multirow{3}{*}{ Medial } & Média & 0.00 & --- & --- & \multirow{3}{*}{ não analisado } \\
\hline & & Desvio-padrão & --- & --- & --- & \\
\hline & & $\mathrm{n}$ & 1 & --- & --- & \\
\hline & \multirow{3}{*}{ Final } & Média & $-\overline{--}$ & -- & 31.25 & \multirow{3}{*}{ não analisado } \\
\hline & & Desvio-padrão & --- & --- & 47.87 & \\
\hline & & $\mathrm{n}$ & --- & --- & 16 & \\
\hline \multirow{9}{*}{ Gll } & \multirow{3}{*}{ Inicial } & Média & 13.10 & 18.32 & 17.11 & \multirow{3}{*}{0.659} \\
\hline & & Desvio-padrão & 31.57 & 31.45 & 34.87 & \\
\hline & & $\mathrm{n}$ & 42 & 141 & 75 & \\
\hline & \multirow{3}{*}{ Medial } & Média & 0.00 & --- & --- & \multirow{3}{*}{ não analisado } \\
\hline & & Desvio-padrão & 0.00 & --- & --- & \\
\hline & & $\mathrm{n}$ & 2 & --- & --- & \\
\hline & \multirow{3}{*}{ Final } & Média & 50.00 & --- & 21.43 & \multirow{3}{*}{ não analisado } \\
\hline & & Desvio-padrão & 70.71 & --- & 41.79 & \\
\hline & & $\mathrm{n}$ & 2 & --- & 28 & \\
\hline
\end{tabular}


$\underline{\mathrm{CVC}}$

As provas foram comparadas quanto à estrutura CVC apenas em sílaba inicial e final.

Em sílaba inicial para ambas as faixas etárias, não houve diferença entre as provas. Porém, em sílaba final, as crianças tiveram desempenho estatisticamente diferente entre elas (Tabela 98).

Tabela 98 - Comparação entre as provas para estrutura CVC.

\begin{tabular}{|c|c|c|c|c|c|c|}
\hline grupo & sílaba & estatística & FE & I & $\mathrm{N}$ & ANOVA (p) \\
\hline \multirow{9}{*}{ Gl } & \multirow{3}{*}{ Inicial } & Média & 22.22 & 9.92 & 17.95 & \multirow{3}{*}{0.278} \\
\hline & & Desvio-padrão & 44.10 & 30.01 & 38.88 & \\
\hline & & $n$ & 9 & 121 & 39 & \\
\hline & \multirow{3}{*}{ Medial } & Média & 0.00 & --- & --- & \multirow{3}{*}{ não analisado } \\
\hline & & Desvio-padrão & 0.00 & --- & --- & \\
\hline & & $n$ & 3 & --- & --- & \\
\hline & \multirow{3}{*}{ Final } & Média & 5.26 & 25.00 & 0.00 & \multirow{3}{*}{0,007 * } \\
\hline & & Desvio-padrão & 22.63 & 43.57 & 0.00 & \\
\hline & & $\mathrm{n}$ & 38 & 80 & 12 & \\
\hline \multirow{9}{*}{ GII } & \multirow{3}{*}{ Inicial } & Média & 42.11 & 30.94 & 32.43 & \multirow{3}{*}{0.621} \\
\hline & & Desvio-padrão & 47.91 & 46.39 & 47.13 & \\
\hline & & $\mathrm{n}$ & 19 & 139 & 74 & \\
\hline & \multirow{3}{*}{ Medial } & Média & 27.27 & -- & --- & \multirow{3}{*}{ não analisado } \\
\hline & & Desvio-padrão & 46.71 & --- & --- & \\
\hline & & $\mathrm{n}$ & 11 & --- & --- & \\
\hline & \multirow{3}{*}{ Final } & Média & 10.42 & 44.57 & 10.42 & \multirow{3}{*}{$<0,001$ * } \\
\hline & & Desvio-padrão & 27.91 & 49.98 & 29.41 & \\
\hline & & $\mathrm{n}$ & 40 & 92 & 24 & \\
\hline
\end{tabular}

Desta forma, foi realizada comparação múltipla de Bonferroni entre as provas (Tabela 99). As crianças mais velhas tiveram desempenho significativamente melhor na imitação que nas demais provas. Na nomeação e fala espontânea, ambos os grupos obtiveram porcentagem de acerto estatisticamente iguais.

Nas crianças mais novas, observa-se que a média da imitação é a maior, seguida da fala espontânea e, por fim, da nomeação. Porém, ao se analisar as provas duas a duas, a imitação foi estatisticamente diferente da fala espontânea e 
quase diferente da nomeação. Este dado pode ter sido causado pelo baixo número amostral na nomeação. Sendo assim, pode-se dizer que a imitação, apesar de ter tido $p$-valor estatisticamente igual à nomeação, pode ser considerada diferente das demais provas (Tabela 99).

Tabela 99 - Comparação múltipla entre as provas para estrutura CVC em sílaba final.

\begin{tabular}{|c|c|}
\hline grupo & comparação \\
\hline \multirow{2}{*}{ GI } & $\mathrm{FE} \times \operatorname{IM}\left(0,021^{*}\right)$ \\
\cline { 2 - 2 } & $\mathrm{FE} \times \mathrm{NO}(1,000)$ \\
\cline { 2 - 2 } & $\operatorname{IM} \times \mathrm{NO}(0,086)$ \\
\hline \multirow{3}{*}{ GII } & $\mathrm{FE} \times \operatorname{IM}\left(<0,001^{*}\right)$ \\
\cline { 2 - 2 } & $\mathrm{FE} \times \mathrm{NO}(1,000)$ \\
\cline { 2 - 2 } & $\operatorname{IM} \times \mathrm{NO}\left(0,002^{*}\right)$ \\
\hline
\end{tabular}


DISCUSSÃO 


\section{HIPÓTESE 1}

A primeira hipótese era que não haveria diferença entre as posições silábicas com relação ao acerto em encontros consonantais, fonemas e estruturas silábicas.

Os resultados encontrados permitiram confirmar esta hipótese quanto aos encontros consonantais. Assim, na nomeação, única prova possível de comparação, não houve diferença entre as sílabas inicial e final.

O fato de não haver diferença entre as posições das sílabas demonstra que, para os encontros consonantais, que são uma estrutura ainda complexa para a faixa etária estudada, os acertos ocorrem em baixa freqüência, independentemente da posição silábica.

Como mostram algumas pesquisas, eles são uns dos últimos sons a serem adquiridos na fala das crianças em desenvolvimento (WERTZNER, 1994; RIBAS, 2003; 2004).

Possivelmente, estudos com crianças mais velhas adquirindo encontros consonantais, nos quais eles apareçam em maior porcentagem de acerto, possam definir alguma sílaba em que as crianças tenham melhor desempenho.

Já para os fonemas de forma geral, a hipótese foi parcialmente confirmada. Houve diferença entre as sílabas nas provas de fala espontânea e imitação. Na primeira, o Gl-M mostrou mais acertos na sílaba inicial comparada às demais provas. Na segunda, ambos os grupos de meninos mostraram diferença, sendo que para o GI-M a sílaba inicial teve menos acerto que as outras e, no Gll-M, a sílaba medial apresentou melhor desempenho que as demais.

A baixa porcentagem de acerto em fonemas, na sílaba inicial, pode estar relacionada com a eliminação da consoante inicial. Este é um processo fonológico comum durante a aquisição fonológica (INGRAM, 1976).

Em geral, o que parece é que a aquisição dos fonemas não é influenciada pela posição da sílaba dentro da palavra, embora algumas diferenças tenham sido observadas.

Quanto às estruturas silábicas, a hipótese também foi parcialmente confirmada. Na fala espontânea, as crianças de todos os grupos, com exceção dos meninos mais velhos, apresentaram porcentagem igual de acerto nas estruturas CV, em todas as sílabas. Na imitação, o único grupo que apresentou diferença foi o de meninas mais novas e, na nomeação, as sílabas não tiveram diferença estatística 
quanto aos acertos. Este fato pode ter ocorrido devido ao alto índice de acerto nesta estrutura, que é uma das primeiras a ser adquirida na fala das crianças (STOELGAMMON \& DUNN, 1985; TEIXEIRA \& DAVIS, 2002; STOEL-GAMMON \& PETER, no prelo).

A estrutura CCV foi comparada apenas nos grupos de crianças mais velhas, na nomeação. A hipótese foi confirmada, visto que não houve diferença entre as sílabas inicial e final. Este fato se relaciona com o baixo desempenho dos grupos na produção dos encontros consonantais, como mostrado anteriormente.

A estrutura CVC foi comparada apenas nos grupos de meninas mais velhas, na fala espontânea, em sílaba final e inicial. A hipótese não foi confirmada, visto que as crianças do GIll tiveram mais acerto em sílaba inicial, comparada com a final. Ao contrário, na imitação, as meninas mais novas tiveram pior desempenho na sílaba inicial que na final. Nos demais grupos, a porcentagem de acerto nas sílabas foi considerada igual, tanto na imitação como na nomeação, sendo que na segunda houve comparação apenas para o grupo de meninos mais velhos.

Este resultado pode demonstrar interferência da baixa porcentagem de acerto dos arquifonemas em todos os grupos nesta fase de desenvolvimento. Nota-se a importância da verificação em crianças mais velhas.

Finalizando, não houve diferença entre as sílabas quanto ao acerto de encontros consonantais e estrutura CCV. Em relação aos fonemas, estruturas CV e CVC, algumas diferenças foram encontradas. 


\section{HIPÓTESE 2}

A segunda hipótese era a de que não haveria diferença entre meninos e meninas da mesma faixa etária quanto a acerto de encontros consonantais, fonemas e estruturas silábicas.

Esta hipótese foi confirmada, mostrando que não houve diferença entre os gêneros em nenhuma comparação, com exceção da porcentagem de acerto, em fonemas, nas crianças mais velhas, em sílaba inicial da imitação. Nesta, as meninas tiveram mais acerto que os meninos.

Em estudo anterior, comparando o desempenho de meninos e meninas da mesma faixa etária quanto ao uso de processos fonológicos, GALEA (2003) não mostrou diferença entre os gêneros. Desta forma, a hipótese supunha que não haveria diferença entre meninos e meninas em todas as comparações.

$\mathrm{Na}$ presente pesquisa, foi realizada comparação apenas para o total de acertos em encontros consonantais, fonemas e estruturas. Futuros estudos poderiam verificar a diferença entre os gêneros para cada encontro, fonema e estrutura silábica isoladamente. Não há pesquisas que mostram a diferença entre os gêneros no total de acertos. A única comparação em relação a fonemas isolados, para o português, mostrou que meninas adquirem o arquifonema /R/ antes dos meninos e que meninos adquirem antes o arquifonema /S/, ambos dentro da palavra (MEZZOMO, 2007b). Estudos para a língua inglesa mostram diferença entre meninos e meninas durante a aquisição de fonemas (SMIT et al. 1990 ).

Desta forma, como apenas em uma comparação houve diferença entre os gêneros das crianças mais velhas, optou-se por agrupá-las em duas faixas etárias: Gl (crianças de 2:1 a 2:6 anos de idade) e Gll (crianças de 2:7 a 3:0 anos de idade). 


\section{HIPÓTESE 3}

A terceira hipótese era de que crianças mais velhas apresentariam mais acertos que as mais novas em relação a encontros consonantais, fonemas e estruturas silábicas. Esta hipótese foi confirmada em algumas situações, visto que em certos momentos, o desempenho das crianças mais velhas foi igual ao das crianças mais novas.

Quanto aos encontros consonantais, estrutura CCV e CVC, observados apenas em sílaba inicial ou final, as crianças do Gll tiveram melhor desempenho que as do Gl, apenas na prova de imitação. Tal fato indica que as crianças estão desenvolvendo a parte motora da fala, como demonstram alguns autores (STOELGAMMON \& DUNN, 1985; KENT, 1992; KENT \& VORPERIAN, 2006). Assim, seqüências de sons mais complexas são produzidas pelas crianças mais velhas com maior acerto. No entanto, como ainda não dominaram a regra da língua, nas demais provas em que não há o modelo do adulto, ainda não as produzem adequadamente.

Em relação aos fonemas e estrutura CV na imitação, as crianças menores também apresentaram menos acerto que as mais velhas, o que mais uma vez indica que o desenvolvimento do processamento motor da fala ainda está ocorrendo, sendo demonstrado pela maior dificuldade das crianças menores em produzir corretamente os sons. Porém, nestes alvos, também foi analisada a sílaba medial, mostrando diferença entre as faixas etárias. Isso pode ser decorrente das crianças mais velhas apresentarem melhor memória fonológica de trabalho, obtendo mais acertos em sílabas mediais, que são aquelas que não têm o efeito de rescência nem o de primazia, como também mostraram AGUILAR-MEDIAVILLA et al. (2002) .

Nota-se também que, analisando todos os fonemas juntamente, houve baixa porcentagem de acerto nos dois grupos. Tal fato pode estar relacionado com a aquisição, já que alguns dos fonemas são adquiridos mais tardiamente, como as líquidas (HERNADORENA \& LAMPRECHT, 1997; MEZZOMO \& RIBAS, 2004), a fricativa velar (HERNADORENA \& LAMPRECHT, 1997; WERTZNER et al, 2001a) e os arquifonemas (WERTZNER, 1994; MEZZOMO, 2004).

Os grupos também mostraram diferença na estrutura CV, na prova de nomeação, em sílaba inicial, fato que pode ser decorrente do erro de omissão da consoante inicial. 
Quanto aos fonemas, ainda foi observada diferença entre os grupos em sílaba final, na fala espontânea e na nomeação e, da sílaba inicial na nomeação, fatos que também serão discutidos a partir dos erros na quinta hipótese.

Posteriormente, cada encontro consonantal, fonema e estrutura silábica também serão discutidos. Mesmo nestas análises, em alguns alvos, as crianças mais novas apresentaram pior desempenho que as mais velhas. Isto reflete a fase de aquisição fonológica, pois neste período, as crianças estão adquirindo muitos contrastes da língua (INGRAM, 1976).

As diferenças entre os grupos, evidenciando que as crianças mais velhas apresentam melhor desempenho que as mais novas, era esperada, já que elas se encontram em fase de desenvolvimento fonológico, adquirindo as regras da língua e, conseqüentemente, procurando atingir a produção do adulto. Outros estudos já mostraram a diferença entre idade e desempenho fonológico (YAVAS, 1988; WERTZNER, 1992; GALEA, 2003).

$\mathrm{Na}$ presente pesquisa, a única exceção encontrada na qual o Gll teve pior desempenho que o Gl foi para o fonema $/ \Sigma /$, em sílaba final, da nomeação. Nesta, as crianças mais velhas tiveram pior desempenho que as mais novas. Este fato pode se justificar pela aquisição ser gradual e alguns vieses serem encontrados, como os da pesquisa de WERTZNER (1994).

Para que haja melhor discussão dos dados referentes a cada um dos encontros consonantais, fonemas e estruturas silábicas, estas diferenças serão abordadas juntamente com a discussão dos erros na hipótese 5.

De forma geral, as crianças mais velhas tiveram mais acerto que as mais novas em encontros consonantais, fonemas e estruturas silábicas. Algumas diferenças estatísticas foram encontradas, sendo que em todas as possibilidades, as crianças mais novas apresentaram mais erros que as mais velhas. 


\section{HIPÓTESE 4}

A hipótese 4 era a de que haveria diferença intragrupo no acerto do fonema /s/ em posição de onset e de coda silábica e que, em relação ao /P/, em onset e coda de sílaba, não haveria diferença.

Como pesquisas já realizadas mostraram que o /s/ em onset de sílaba é adquirido antes do arquifonema (WERTZNER, 1994), esperava-se que houvesse diferença entre estas duas posições. Porém, esta hipótese não foi confirmada. Notase que foi apresentada diferença apenas em sílaba final da imitação, mesmo assim, a coda teve mais acerto que o onset. Deve-se observar, porém, que muitos erros cometidos na produção dos grupos quanto ao /s/ em onset de sílaba foram as distorções. Talvez, se as considerássemos como acerto, houvesse diferença entre este fonema em onset e coda de sílaba. Já em coda, a maior parte dos erros foi de omissão de sílaba, mostrando ser um erro mais grave que compromete a fonologia da língua e, portanto, gera mais ininteligibilidade de fala.

Quanto à comparação do /P/ em onset e coda, era esperado que não houvesse diferença entre estas posições, visto que em onset, este fonema é um dos últimos a ser adquirido na classe das líquidas (WERTZNER, 1998; MEZZOMO \& RIBAS, 2004) assim como o arquifonema conforme citado em vários estudos (WERTZNER, 1994; MEZZOMO, 2003). Porém, a hipótese não foi confirmada. Houve diferença entre o fonema em onset e coda de sílaba, sendo que em onset, foi observado mais acerto. Esta diferença entre o fonema nas duas posições dentro da sílaba foi observada no estudo de WERTZNER (1992).

Crianças com transtorno fonológico apresentam como processos mais ocorrentes a simplificação de líquida e a simplificação da consoante final (WERTZNER et al., 2001b; 2006; WERTZNER, 2002). Este dado encontrado sobre crianças em desenvolvimento fonológico típico ajuda no tratamento de crianças com transtorno fonológico, visto que em algumas teorias, opta-se por iniciar o trabalho terapêutico com sons mais complexos do sistema fonológico das crianças (ELBERT \& GIERUT, 1986; ELBERT, 1992). Com base nestes dados, seria importante iniciar o tratamento com o /P/ em coda de sílaba, para uma maior eficácia terapêutica. 
Assim, de forma geral, notou-se que não houve diferença entre o /s/ em onset e coda silábica. Porém, quanto ao /P/, houve diferença entre as duas posições na sílaba, sendo que em onset as crianças dos dois grupos tiveram mais acertos. 


\section{HIPÓTESE 5}

A hipótese 5 era a de que haveria diferentes tipos de erros predominantes: em encontros consonantais aconteceria em função do /P/ e do /I/; nos fonemas, cada um apresentaria diferenças em função das categorias omissão, substituição e distorção e, nas estruturas silábicas, a diversidade ocorreria em função da extensão da palavra. Além disso, também se supunha que as crianças do Gl apresentariam mais ocorrência de erros que o Gll. Esta hipótese foi confirmada, como mostram os dados discutidos abaixo.

Em relação aos encontros consonantais, houve diferença entre os grupos apenas para /fP/ e /kP/, na imitação.

O erro mais encontrado ao se analisar os encontros consonantais é a omissão da líquida, restando apenas a primeira consoante. Este também é relatado em pesquisas anteriores que demonstram a aquisição dos encontros consonantais. Outro erro comumente encontrado neste trabalho é a substituição da líquida, também relatada nas pesquisas citadas anteriormente. Este erro foi mais observado no Gll, indicando que as crianças já apresentam a intenção de realizarem o encontro consonantal, porém, ainda não adquiriram a regra (RIBAS, 2003; 2004; RIBAS et al., 2003).

Analisando os erros nos dois grupos, houve diferença entre a substituição do /fP/ pelo /f/ nas duas faixas etárias, sendo que as crianças mais novas cometem mais este erro. Em relação à substituição do $/ \mathrm{kP} /$ para $/ \mathrm{k} /$, a porcentagem de erro nos dois grupos foi semelhante. No entanto, como houve diferença entre eles quanto à média de acerto do / kP/, pode-se inferir que o grupo mais novo faça outros tipos de erros que não aparecem no Gll ou a quantidade dos demais erros são mais altas no Gl.

O segundo erro mais freqüente para os encontros com $/ \mathrm{gP} /$ e $/ \mathrm{kP} /$ é a substituição para /d/ e /t/, respectivamente e, para os encontros /dP/ e /tP/, é a troca para $/ \mathrm{g} / \mathrm{e} / \mathrm{k} /$, respectivamente. Deve-se observar em fonema isolado se as crianças destas faixas etárias realizam a posteriorização dos fonemas línguo-alveolares e a frontalização dos velares. Este ponto será discutido quando os dados de fonemas plosivos forem mostrados. 
Analisando cada fonema separadamente, as plosivas não apresentaram diferença entre as faixas etárias, com exceção do /d/ em sílaba medial e final na fala espontânea e do /b/ na sílaba inicial na imitação. De fato, as crianças menores apresentaram mais substituição, omissão de sílaba e omissão de fonema do /b/ que as mais velhas, indicando que os processos de omissão de sílaba e de eliminação da consoante inicial vão sendo suprimidos com o aumento da idade (INGRAM, 1976; GALEA, 2003). Quanto ao /d/, observa-se que as interdentalizações predominam nas crianças mais novas, fato esperado devido ao desenvolvimento motor (STOELGAMMON \& DUNN, 1985; KENT, 1992; KENT e VORPERIAN, 2006).

As plosivas bilabiais apresentaram alta porcentagem de acerto, corroborando o fato delas serem as primeiras consoantes adquiridas por crianças, independentemente da comunidade lingüística em que se encontram (STOELGAMMON \& DUNN, 1985). O único erro de maior ocorrência e que houve comparação entre as faixas etárias, foi a substituição de /b/ para /bP/, como por exemplo em /'globuU/ para ['gobPu].

A grande quantidade desta substituição na imitação em sílaba final é relevante. Isto ocorreu, pois muitas crianças realizavam as palavras "clube" e "globo" cometendo metátese com troca da líquida. A metátese do encontro consonantal é vista durante o desenvolvimento (GALEA, 2003; RIBAS, 2003; 2004; RIBAS et al., 2003). Ressalta-se que os dois grupos realizam esta troca e que ambos têm médias estatisticamente iguais, embora a média de erro do Gll seja maior que a do Gl. Neste caso, a maior quantidade deste erro no grupo mais velho pode ser decorrente das crianças já demonstrarem conhecimento fonológico dessa estrutura e apresentarem processamento motor mais aprimorado que as mais novas na imitação, tentando produzir os encontros consonantais e, conseqüentemente, não conseguindo realizar o alvo corretamente, havendo a troca da líquida e de posição do encontro na palavra.

O fonema /p/ não teve substituição por um fonema específico. Apenas na nomeação em sílaba final algumas trocas por / $\mathrm{k} /$ foram constatadas. A palavra com este alvo seria "sapo", sendo que algumas crianças trocaram-na por /'saku/. Pode ter havido alguma dificuldade de discriminação das duas palavras que são foneticamente similares. 
Um dos erros mais freqüentes do fonema /t/ é a substituição por $/ \Sigma /$ e por $/ \mathrm{s} /$. O contexto em que isso ocorre é quando o /t/ encontra-se em sílaba que pode ser produzido com o alofone /t $\Sigma$ / como em "plástico", "tesoura" e "cortina".

Tanto o fonema /t/ como o /d/ não demonstraram muitos erros. Observa-se que, além das substituições, outro tipo de erro freqüente é a interdentalização. Novamente, as crianças mais novas apresentaram este tipo de erro em maior quantidade, indicando que com o aumento da idade, as distorções diminuem, devido a um melhor controle motor da fala.

Em algumas situações, observa-se que as plosivas linguodentais são substituídas pelas velares. Porém, os fonemas velares apresentam como maior categoria dos erros a substituição para as linguodentais. Desta forma, há tendência nas crianças dos dois grupos de ainda posteriorizarem e anteriorizarem durante a aquisição, mostrando instabilidade do sistema fonológico durante 0 desenvolvimento. Em pesquisa anterior, GALEA (2003) mostrou que as crianças desta faixa etária cometem mais o processo de frontalização de velar que o de posteriorização para velar. Estas substituições também foram observadas quando os encontros consonantais foram analisados. Além da omissão da líquida, as crianças cometeram frontalização e posteriorização do primeiro segmento.

Quanto às fricativas, na fala espontânea, o /z/ obteve diferença estatística, entre as faixas etárias em sílaba final, sendo que o Gl teve mais erros que o Gll. A diferença entre os grupos pode ter ocorrido devido ao pequeno número de alvos no Gl.

$\mathrm{Na}$ imitação, os fonemas fricativos que mostraram diferença de porcentagem entre o Gl e o Gll foram o /s/, /f/ e /Z/, na sílaba inicial. Na nomeação, foram os fonemas /s/, na sílaba medial e final, e o / $/$, na final. Nestas comparações, as crianças mais velhas mostraram mais erros que as mais novas quanto ao acerto do $/ \Sigma /$

Analisando cada um destes fonemas separadamente de acordo com o tipo de erro, a porcentagem de substituição de /s/ para / $/$ / é maior no Gl que no Gll. Esta diferença foi estatisticamente significante apenas na nomeação. Este fato mostra que as crianças estão em desenvolvimento fonológico, deixando de substituir o fonema. 
Quanto ao fonema /f/ na sílaba inicial, da imitação, a análise qualitativa demonstrou que o GI realiza mais substituições que o Gll. Esta foi a prova em que o Gl teve pior desempenho neste fonema, com média de acerto de 55\%.

O fonema /Z/ foi freqüentemente substituído por $/ \Sigma /$ nas crianças mais novas e por /z/ nas mais velhas. Porém, a quantidade de erro não foi diferente nas duas faixas etárias.

Por fim, analisando a última fricativa que mostrou diferença entre as faixas etárias, $/ \Sigma /$, na sílaba final da nomeação, as crianças mais novas apresentaram melhor desempenho que as mais velhas. Isto ocorreu, pois as crianças do Gll apresentaram mais substituições que as do Gl, além de terem cometido distorções acústicas e articulatórias não observadas no Gl. Neste fonema, parece que as distorções não diminuem com a idade, ao menos nesta faixa etária estudada.

O presente estudo indicou que, assim como na pesquisa de OLIVEIRA (2003), as fricativas que tiveram mais substituições foram o / $/$ e o /Z/. Estas foram mais substituídas para 0 /s/ e o /z/, como mostrado também em pesquisa mencionada.

Em estudo posterior, OLIVEIRA (2004) mostrou que o /s/ é mais substituído por $/ \Sigma /$ e 0 /z/ por /Z/, já as fricativas palatais eram mais substituídas pelas alveolares. Nesta pesquisa, com relação à alveolar surda, ela é mais substituída por $/ \Sigma /$ nas duas faixas etárias e, a sonora apresenta algumas diferenças entre os grupos. Nas crianças mais novas, é a mais substituída por/s/e, nas mais velhas, por /s/ ou /Z/. Quanto às palatais, a sonora é mais substituída pela correspondente surda no grupo mais novo e pela alveolar sonora no grupo mais velho. Já a palatal surda é mais substituída pelo /s/ nas duas faixas etárias.

O fato de haver muitas trocas entre $0 / \Sigma /$ e o /s/ por $/ \mathrm{s} / \mathrm{e} / \Sigma /$, respectivamente, mostra que durante o desenvolvimento as crianças podem escolher dois caminhos de aquisição das fricativas coronais, iniciando pelo /s/ ou pelo / $/$ / (MATZENAUER, 2003). Por isso, é observada tanto a troca do $/ \mathrm{s} / \mathrm{por} / \Sigma /$ como do $/ \Sigma /$ por $/ \mathrm{s} /$.

A fricativa labiodental sonora apresenta, em algumas provas e posições de sílabas, maior substituição pelo fonema /f/. Tal substituição mostra diferença significativa de ocorrência entre os grupos, sendo que o Gl comete este erro com maior porcentagem que o Gll. 
Esta troca de sonoridade, juntamente com as demais já especificadas anteriormente das fricativas coronais sonoras, está de acordo com pesquisa anterior que mostra que o processo de ensurdecimento ainda é ocorrente em crianças de 2:1 a 3:0 anos de idade, porém em baixa porcentagem. Além disso, nas três provas avaliadas, nomeação, imitação e fala espontânea, as crianças de 2:1 a 2:6 anos de idade apresentaram significativamente maior porcentagem de ensurdecimento de fricativas que as de 2:7 a 3:0 anos (GALEA, 2003). Desta forma, nota-se que o erro que envolve sonoridade ainda é visto nas crianças desta faixa etária, mas decrescem com o aumento da idade.

O fonema / $/$ também teve grande substituição pela plosiva /b/, na prova de nomeação, sendo que as crianças realizam-na significativamente mais vezes que as mais velhas. Isto ocorreu na palavra "vassoura", sendo uma troca que geralmente é vista como cultural. Além desse aspecto cultural, algumas crianças realizam esta substituição devido ao processo de plosivação de fricativas que ainda é observado em alguns sujeitos desta faixa etária.

Em geral, as fricativas são mais substituídas que omitidas e as crianças mais velhas apresentam mais acertos que as mais novas, com comprovação estatística. Mesmo quando os dois grupos eram considerados estatisticamente iguais, em poucas ocasiões as crianças mais velhas tiveram média de acerto menor que as mais novas. Estes dados comprovam estudos anteriores sobre aquisição das fricativas (WERTZNER \& CARVALHO, 2000; WERTZNER et al., 2002).

As nasais tiveram alta porcentagem de acerto, constatando também o fato da nasal bilabial ser uma das primeiras a surgir na fala de crianças (STOEL-GAMMON \& DUNN, 1985). Os grupos apresentam diferença significante para o fonema $/ \mathrm{n} / \mathrm{em}$ sílaba medial na fala espontânea e para o fonema $/ \mathrm{m} /$ em sílaba inicial na imitação.

$\mathrm{O} / \mathrm{m} /$ teve alta porcentagem de acerto em todas as provas e sílabas, mostrando mais erros na imitação em sílaba inicial, na qual foi encontrada diferença estatística entre as faixas etárias. O Gl apresentou omissão do fonema e de sílaba que não foram observadas no Gll, além de mais substituição que o grupo mais velho. Nota-se que a palavra em questão era "machado", podendo demonstrar mais uma vez a maior dificuldade do GI quanto à extensão de palavra.

$\mathrm{O} / \mathrm{n} /$ teve pior desempenho nas crianças mais novas, na sílaba medial, da fala espontânea. Apesar de não ter havido comparação entre os tipos de erros, as 
crianças do Gl apresentaram qualitativamente, mais substituições que as do Gll, além de omissão do fonema e interdentalização, não observadas no Gll.

$\mathrm{Na}$ nomeação, não houve diferença entre os grupos quanto ao acerto das nasais.

Quanto às líquidas, nota-se que 0 /// tem mais acerto que as demais, corroborando com achados de outras pesquisas (WERTZNER, 1992: MEZZOMO \& RIBAS, 2004). Os fonemas $/ x /$ e $/ \mathrm{P} /$ tiveram baixa porcentagem de acerto nos dois grupos.

As crianças do Gl apresentaram estatisticamente mais erros do /// que as do Gll em sílaba medial na fala espontânea. Em nenhuma das provas foi realizado teste de proporção entre os erros deste fonema, indicando baixa ocorrência entre eles. Mesmo assim, nesta situação, as crianças mais novas mostraram mais substituições e interdentalizações que as mais velhas. Mais uma vez, demonstrando aquisição fonológica neste período além da maturação do sistema motor.

$\mathrm{Na}$ imitação, não foi observada diferença entre as faixas etárias para nenhuma líquida. Este fato pode estar relacionado à alta porcentagem de acerto do fonema /// nos dois grupos e ao baixo índice de acerto nas demais líquidas nas duas faixas etárias.

$\mathrm{Na}$ nomeação em sílaba medial, as crianças do Gl obtiveram significativamente mais erros do $/ x /$ que as do Gll. Analisando os erros com mais de dez ocorrências, substituição do / $/$ / por /// e por /y/, não houve diferença entre as faixas etárias. Porém, o teste estatístico mostrou que o p-valor da comparação entre as faixas etárias para a substituição de / / / para /// está próximo do nível de significância. Além disso, este fato pode indicar que as crianças do Gl cometem mais ocorrências de outros tipos de erros, tornando a diferença significante entre os grupos.

Apesar de não haver diferença entre os grupos quanto ao acerto na imitação, em sílaba final, houve diferença estatística quanto à substituição do $/ \times /$ por $/ / /$, mostrando que as crianças mais novas realizam-no com maior ocorrência. Isto indica que as crianças do Gll também cometem outros tipos de erros que, no total, não fazem diferença com a média do Gl. 
Observa-se que as líquidas ainda são substituídas por /l/, no caso do /P/ e / / /, ou eliminadas da fala das crianças de 2:1 a 3:0 anos de idade. A pesquisa de WERTZNER (1998) também mostrou este fato.

Os erros mais observados, tanto do $/ x /$ como do $/ \mathrm{P} /$, nos dois grupos, foi a substituição por /I/. A substituição pela líquida é um erro freqüentemente observado durante a aquisição (WERTZNER, 1998). A substituição do /P/ pelo /// também é vista em outros estudos (RIGATTI ET al., 2001; MEZZOMO \& RIBAS, 2004). Já a substituição do / $x /$ é relatada no estudo de MEZZOMO \& RIBAS (2004) como mais freqüente por $/ y /$, além de terem observado omissão deste fonema.

A fricativa velar teve baixa porcentagem de acerto nesta pesquisa, sendo que o erro mais cometido foi a omissão, encontrando poucas substituições deste fonema. Estes erros também foram relatados na pesquisa de WERTZNER et al. (2001a) e GALEA (2003). MEZZOMO \& RIBAS (2004) mostraram que outro erro comumente encontrado é a substituição por / $/$. Em alguns momentos, este erro também foi observado nesta pesquisa, mas com baixa ocorrência.

As crianças mais novas tiveram estatisticamente menos acertos que as mais velhas em todas as sílabas da imitação e nomeação quanto ao $/ X / . \mathrm{Na}$ fala espontânea, só houve comparação entre as faixas etárias na sílaba medial. Apesar das crianças do Gl terem cometido mais erros, não houve diferença estatística entre os grupos. Este fato pode ser devido às crianças dos dois grupos terem apresentado grande quantidade de erro na estrutura CV em sílaba medial, devido à extensão da palavra polissilábica, o que será discutido posteriormente.

Esta diferença entre as faixas etárias é também comprovada com a maior porcentagem de erro de omissão do fonema no Gl comparado ao Gll. Nas provas de nomeação e imitação, em sílabas medial e final, isto foi comprovado estatisticamente.

Os arquifonemas ainda são produzidos com baixa porcentagem de acerto pelas crianças dos dois grupos. Um dos erros mais freqüentes é a omissão, também observada em pesquisas anteriores (MEZZOMO, 2003; 2004).

Outro dado relevante encontrado, e que está de acordo com MEZZOMO (2004), é que em sílaba final as crianças cometem mais erro de epêntese do arquifonema /S/. Este fato mostra que as crianças apresentam tendência a manterem a estrutura CV nesta fase de aquisição. 
O arquifonema /S/ teve diferença quanto a acertos nas duas faixas etárias somente na prova de imitação, tanto em sílaba inicial como final. Os dados condizem com comparação do erro de omissão de fonema entre os dois grupos, mostrando que as crianças mais novas apresentam maior porcentagem deste erro. Tal fato pode estar relacionado com as crianças mais velhas terem melhor desempenho motor que as mais novas, conseguindo imitar com mais precisão um padrão do adulto.

Com relação ao arquifonema /R/, em todas as sílabas e provas, a maior parte dos erros é de omissão, corroborando com os dados de pesquisa que mostram ser este o erro mais freqüente em sílaba dentro da palavra (MEZZOMO, 2004). Porém, em final de palavra, os erros da pesquisa anterior mostram com mais freqüência a substituição por /y/ ou pela líquida lateral. Na presente pesquisa também aparecem erros de substituição por /y/ e de substituição por /P/ acrescido de vogal, como visto no arquifonema /S/, na tentativa de manter a sílaba CV.

Houve diferença entre as duas faixas etárias em sílaba inicial da nomeação e imitação, sendo que o grupo mais novo teve menos acertos que o mais velho. Além disso, observou-se que a omissão do fonema é mais realizada pelo Gl, mostrando que as crianças encontram-se em desenvolvimento.

Outro ponto que merece atenção é o grande número de distorções acústicas e articulatórias encontradas nesta pesquisa. Quanto às plosivas, foi observada interdentalização dos fonemas /t/ e /d/. As fricativas /s/, /z/ e arquifonema /S/ mostraram ocorrência de ceceio anterior e lateral, interdentalização, entre outras distorções. Pôde-se observar distorção em pouca quantidade e em apenas algumas posições de sílabas para os fonemas /f/ e /v/. As fricativas palatais mostraram distorção e o ceceio lateral foi observado apenas no $/ \Sigma /$. Quanto às nasais, o fonema /n/ apresentou interdentalização e, quanto às líquidas, todas mostraram distorção acústica, inclusive o arquifonema $/ \mathrm{P} /$, sendo que $0 / / /$ e $0 / \times /$ também mostraram interdentalização.

Estes erros são comuns durante o desenvolvimento, como mostram estudos com fricativas (WERTZNER, 1994; JUNQUEIRA \& GUILHERME, 1996; PEREIRA et al., 2003; TOMÉ et al., 2004; WERTZNER, et al., 2005; AMARO, 2006) e líquidas (CASTRO, 2004; GALEA \& WERTZNER, 2005a; AMARO, 2006). Muitas destas pesquisas indicam diminuição das distorções com o aumento da idade. No presente 
estudo, houve comparação entre as faixas etárias apenas da interdentalização nos fonemas /t/ e /s/ e do ceceio anterior do fonema /s/, indicando que os grupos são estatisticamente semelhantes. Observa-se que, na sílaba final da imitação, as crianças mais velhas apresentaram mais ocorrência de ceceio anterior que as mais novas. Nas demais comparações, as crianças do Gl cometeram mais estes tipos de erros que as do Gll, indicando possível eliminação destas distorções.

Resumindo, quando há diferença entre as faixas etárias, as crianças do Gl apresentam menos acerto que as do Gll, indicando que com o aumento da idade, há diminuição dos erros.

Além disso, as crianças realizam mais substituições que omissões, com exceção dos encontros consonantais, arquifonemas e fonema /X/. Isto indica que elas já percebem que há algum segmento nos lugares especificados e tentam produzi-lo. Na tentativa de produção, cometem substituições que acontecem por alvos dentro da mesma classe de fonemas. Em poucas ocasiões, a substituição foi realizada para fonemas de outras classes. Quando isso ocorreu, houve, em muitos momentos, influência dos demais segmentos das palavras em questão.

Quanto à estrutura silábica CCV, houve diferença entre as faixas etárias apenas na imitação. Este ponto também foi observado quando os encontros consonantais foram analisados. Ressalta-se que, para a análise da estrutura CCV, mesmo quando havia troca da líquida, ela era considerada correta, diferentemente da análise dos encontros consonantais. Para os encontros, quando havia troca da líquida, considerava-se substituição. Como foi mostrada a mesma diferença tanto nos encontros como na estrutura CCV, pode-se inferir que as crianças tiveram mais erros do tipo omissão da segunda consoante.

Este erro foi o mais observado em todas as sílabas de diferentes extensões de palavras, nas três provas. Assim, parece que para esta estrutura silábica, não há efeito de extensão de palavra. O baixo índice de acerto desta estrutura pode ter colaborado para este fato.

Na prova de imitação em que foi encontrada diferença entre as faixas etárias, as crianças imitam a partir de um estímulo fornecido pela avaliadora,. Este fato pode indicar que as crianças não apenas apresentam desenvolvimento fonológico durante a aquisição, mas também mostram desenvolvimento motor, conseguindo imitar estruturas mais complexas da fala. $\mathrm{Na}$ fala espontânea e na nomeação, os dois 
grupos ainda são muito semelhantes, quando se tem a produção sem padrão do adulto.

Separando os encontros com /// e /P/, observa-se que houve diferença entre os grupos apenas para palavras dissilábicas com /P/, em sílaba inicial da imitação. Analisando a proporção dos erros, a omissão da segunda consoante mostrou ter ocorrência maior no GI comparado ao Gll.

Nas palavras trissilábicas da prova de imitação e de fala espontânea e nas palavras polissilábicas da fala espontânea não há diferença entre os grupos, mostrando que as crianças ainda apresentam dificuldade em imitar quando a extensão da palavra é maior.

O encontro com /I/ não mostrou diferença de acerto entre as crianças e a ocorrência do tipo de erro mais freqüente, omissão da segunda consoante, também não apresentou porcentagem de erro diferente entre os grupos, indicando que as duas faixas etárias mostram dificuldade com esta estrutura.

A estrutura CV apresentou alta porcentagem de acerto nos dois grupos. Como esta estrutura é a mais ocorrente no português do Brasil (TEIXEIRA \& DAVIS, 2002; MATZENAUER, 2004), a freqüência desta na língua pode influenciar a porcentagem de acerto. Além disso, ela é o primeiro tipo de estrutura que aparece na fala das crianças desde o balbucio (STOEL-GAMMON \& DUNN, 1985).

Deve-se lembrar que, quando a criança realizou corretamente a estrutura CV, não necessariamente, ela tenha produzido a consoante alvo desta estrutura, porém, manteve a estrutura CV.

$\mathrm{Na}$ imitação e na nomeação em sílaba inicial, as crianças mais novas tiveram desempenho estatisticamente pior que as mais velhas. Ao analisar a estrutura CV de acordo com a extensão da palavra, esta diferença foi encontrada em palavras trissilábicas. O erro mais freqüente foi o de omissão do fonema, com exceção do Gl na imitação, cujo erro mais ocorrente foi omissão de sílaba. O teste de proporção não encontrou diferença entre os grupos quanto à omissão de consoante, porém a omissão da sílaba foi mais freqüente no Gl.

$\mathrm{Na}$ imitação, as crianças mais novas também mostraram porcentagem de acerto menor em sílaba medial. O tipo de erro mais freqüente nas duas faixas etárias, omissão de fonema, mostrou diferença entre os grupos, sendo que o Gl apresentou mais erros que o Gll. Este fato mostra que as crianças também estão em 
desenvolvimento, melhorando seu desempenho motor e conseguindo imitar com mais acerto a sílaba medial.

Em outras comparações, houve diferença estatística entre as crianças dos dois grupos para omissão de sílaba e de fonema. As crianças do Gl tiveram mais erros destes tipos que as mais velhas. Porém, nestas mesmas situações, não houve diferença entre as faixas etárias para porcentagem de acerto, indicando que as crianças do Gll podem apresentar outros tipos de erros que não são observados nas mais novas ou realizam outros tipos de erros que as mais novas cometem com menos ocorrência.

Na fala espontânea, como não há palavras definidas para produção, ou seja, as crianças podem falar em situação livre, houve mais produção de palavras de três ou mais sílabas. Estes dados estão de acordo com estudos que mostram maior incidência de palavras polissilábicas na língua portuguesa (TEIXEIRA \& DAVIS, 2002; MATZENAUER, 2004).

Quanto aos polissílabos, ocorrentes apenas em fala espontânea, observa-se a tendência das crianças omitirem sílabas iniciais e mediais, porém, mantendo as sílabas finais com porcentagem de acerto de 100\%. Mesmo assim, observa-se que as sílabas mediais tiveram porcentagem de acerto menor que as iniciais.

Em relação aos erros, tanto em dissílabos como em trissílabos e polissílabos, a maioria ocorreu devido à omissão de consoante ou de sílaba.

A omissão de sílaba pode ter ocorrido devido à extensão da palavra, pois foi observada mais freqüentemente em palavras trissilábicas e polissilábicas. Em todas as situações, a ocorrência foi em sílaba átona, o que está de acordo com estudos de diversas línguas (AGUILAR-MEDIAVILLA et al., 2002; DODD et al., 2003; GALEA, 2003; JAMES, 2007).

Já a omissão de consoante, ou seja, substituição da estrutura CV em V, demonstra erro fonológico de omissão de fonemas durante a aquisição fonológica. Este tipo de erro foi mais freqüente devido à omissão de consoante inicial, sendo comum e esperado durante o desenvolvimento (INGRAM, 1976). Outros erros de omissão de consoantes englobaram as líquidas, que são uns dos últimos sons a serem adquiridos durante a aquisição do português do Brasil, (WERTZNER, 1992; PAGAN, 2003) e a omissão da fricativa velar, também comum durante o desenvolvimento (WERTZNER et al., 2001a; GALEA, 2003). 
A estrutura CVC mostrou baixa porcentagem de acerto em todos os grupos. $\mathrm{Na}$ imitação, o grupo de crianças mais novas apresentou desempenho estatisticamente mais baixo que as mais velhas, o que não foi observado na nomeação e na fala espontânea. Isto mostra que as crianças são estimuláveis, melhorando o desempenho motor com o aumento da idade.

Separando a estrutura CVC em coda com /S/ e com /R/, a diferença entre os dois grupos na imitação ocorreu em todas as comparações, isto é, dissílabos com arquifonema /S/ e /R/ e trissílabos com arquifonema /R/, mais uma vez demonstrando melhora no desempenho motor com o aumento da idade.

Apesar de não ter havido diferença entre os grupos na nomeação para acerto desta estrutura, analisando os arquifonemas separadamente, houve diferença em dissílabos com arquifonema /R/ em sílaba inicial. Quando os arquifonemas foram analisados, observou-se que as crianças do Gl cometeram mais omissão deste fonema que as do Gll, tendo influenciado na produção correta da estrutura CVC.

Quanto à estrutura CVC com arquifonema /S/, os erros mais freqüentemente encontrados em sílaba inicial são as omissões e, em final, a epêntese, dados que também ocorreram na população estudada por MEZZOMO (2004, 2007a). Nas situações em que houve diferença na porcentagem de acerto na imitação, as crianças mais velhas apresentaram estatisticamente menos erros que as mais novas, indicando desenvolvimento fonológico e maturação motora exigida na produção de estruturas mais complexas.

Com o arquifonema /R/, na imitação, em sílaba inicial, houve diferença quanto ao erro de omissão da coda. Em sílaba final não houve diferença entre os grupos quanto aos erros testados. Nota-se que, nas duas faixas etárias, houve baixa porcentagem de acerto. Na nomeação em sílaba inicial, houve diferença quanto à omissão da consoante da coda e de uso de CV+/y/, ou seja, substituição da coda/R/ por /y/. Ressalta-se que este último erro teve maior ocorrência no Gll, mostrando que as crianças mais velhas parecem preencher o espaço da coda com outra consoante, ao invés de omiti-la. Os erros de omissão em sílaba inicial e de substituição para a estrutura CVV, sendo a segunda, uma semivogal, também foi encontrada nos estudos de MEZZOMO (2004, 2007a).

Resumindo, como mostrado no quadro do Anexo I, cada encontro consonantal, fonema e estrutura silábica apresenta um determinado tipo de erro predominante. Os encontros consonantais apresentam como maior parte dos erros a 
eliminação da líquida. Quanto aos fonemas, eles são mais substituídos por outro da mesma classe, com exceção do /x/ e arquifonemas /S/ e /R/, que apresentam na maioria dos erros a omissão e, dos fonemas /d/ e /t/, que mostraram em grande parte dos erros a interdentalização.

Em relação às estruturas silábicas, a CCV apresentou com maior freqüência a omissão da segunda líquida, a CV omissão de fonema e de sílaba e a CVC omissão do arquifonema.

Quanto aos erros, as crianças mais novas apresentaram significativamente maior porcentagem que as mais velhas em alguns encontros consonantais, fonemas e estruturas silábicas, porém, apenas para $0 / \Sigma /$, as crianças mais velhas tiveram menos acerto que as mais novas.

Os erros com mais de dez ocorrências foram comparados entre as faixas etárias. Observou-se diferença entre os grupos para: substituição de /fP/ para /f/ em sílaba inicial na imitação, substituição de /s/ para /t $\Sigma /$ em sílaba final na imitação, substituição de /s/ para / $\Sigma$ / em sílaba inicial na nomeação, substituição de /v/ para /b/ em sílaba inicial na nomeação, substituição do /×/ por /// em sílaba final na imitação, omissão do /X/ em sílaba medial e final na imitação e em sílaba inicial e final na nomeação, omissão do arquifonema /R/ em sílaba inicial nas três provas, omissão do arquifonema /S/ em sílaba inicial na imitação e substituição deste arquifonema por /z/ seguido de vogal, sendo que em todas estas situações o Gl apresentou estes erros com maior porcentagem que o Gll.

O único erro na estrutura CCV que teve comparação entre as faixas etárias foi omissão da líquida em sílaba inicial de palavras dissilábicas na imitação. Os erros em CV analisados foram: omissão da sílaba em sílaba medial de palavras polissilábicas na fala espontânea e em sílaba inicial de palavra trissilábicas, tanto na imitação como na nomeação; omissão da consoante em sílaba medial na imitação e em sílaba final na nomeação de palavras trissilábicas. Na estrutura CVC, os erros que mostraram diferença entre os dois grupos foram a omissão da segunda consoante em sílaba inicial de palavras dissilábicas na fala espontânea e nomeação e a substituição de CVC para CV seguido de semivogal em sílaba inicial de palavras dissilábicas na nomeação. Como nos fonemas e encontros consonantais, em todas estas situações em que foram observadas diferenças estatísticas, as crianças mais novas comentem erros em maior porcentagem que as mais velhas. 


\section{HIPÓTESE 6}

A sexta hipótese mostrada foi a de que haveria diferença entre os encontros consonantais, fonemas e estruturas silábicas quanto à classificação de aquisição, indicando que as crianças do Gll encontram-se numa faixa de maior porcentagem de aquisição para todos os fonemas.

Esta hipótese foi parcialmente confirmada, visto que para algumas situações, o critério de aquisição foi o mesmo para as duas faixas etárias, como mostrou os Quadros 6 a 8 nos resultados.

Vale ressaltar que na prova de fala espontânea, muitos fonemas do português não foram analisados. Este fato ocorreu por ser uma situação de brincadeira, não tendo controle sobre as palavras emitidas pelas crianças

Os encontros consonantais ainda não estão adquiridos em nenhum dos grupos. Eles são um dos últimos a serem dominados na fonologia de crianças falantes do português do Brasil (YAVAS, 1988; WERTZNER, 1994).

Observa-se, entretanto, que algumas crianças da pesquisa já os produzem de forma correta. Segundo RIBAS (2003; 2004), eles aparecem na fala da criança de $1: 8$ ano de idade.

A plosiva bilabial surda mostra-se adquirida em todas as situações, com exceção das sílabas iniciais da imitação, que se encontra em produção habitual nos dois grupos. Já a sonora, está adquirida em sílaba medial em todas as situações, portanto, sendo adquirida aos 2:1 anos ou anteriormente. Em sílaba inicial, encontrase adquirida no Gll, porém no Gl, está adquirida apenas na nomeação. Assim, podese dizer que ela é adquirida aos 2:6 anos. Na sílaba final, analisada apenas na imitação, encontra-se em produção habitual, nos dois grupos, sendo adquirida aos 3:0 anos de idade.

Analisando os dados que foram encontrados em relação aos fonemas, outro tipo de discussão pertinente é se a freqüência de ocorrência de um determinado fonema na língua seria um facilitador para a produção mais correta de um determinado alvo. Pode-se observar que o fonema /p/ é um dos mais ocorrentes no português do Brasil (ALBANO, 2001), porém, o /b/ não é tão freqüente. A bilabial sonora, na nomeação, está em sílaba tônica, mas na imitação, nem sempre isso ocorre. O fonema /p/ ocorre tanto em sílaba tônica como átona em palavras de diferentes extensões silábicas. Mas, como discutido anteriormente, elas são uns dos 
primeiros fonemas a serem adquiridos na fala de crianças de qualquer comunidade lingüística (STOEL-GAMMON \& DUNN, 1985).

Quanto às línguodentais, o /t/ parece ser dominado em sílaba inicial e final antes da medial, nos dois grupos de crianças. Na imitação, pode-se observar as três posições de sílabas, sendo que a medial é a que tem menos de $75 \%$ dos sujeitos com o alvo dominado nos grupos. Nas demais posições da imitação, ele se encontra adquirido. Nota-se que, na nomeação, as crianças mais novas o produzem como produção habitual e as mais velhas como adquirido, nas sílabas inicial e final, únicas analisadas nesta prova. Na fala espontânea, nos dois grupos está adquirido em sílaba final. Pode-se dizer que, desta forma, o /t/ é adquirido nesta pesquisa em sílaba inicial e final aos 2:1, mas que em medial ainda apresenta erros até os 3:0 anos, sendo adquirido nesta idade, como mostra WERTZNER (1994). A autora observou que este fonema já estava adquirido aos três anos de idade.

A línguodental sonora é adquirida aos 2:6 anos nesta pesquisa, visto que nas crianças do $\mathrm{Gl}$ encontra-se em produção habitual e nas crianças do Gll, adquirida. $\mathrm{A}$ única situação em que se encontra adquirido no Gl é em sílaba medial na nomeação.

Os dois fonemas linguodentais aparecem em grande ocorrência no português do Brasil (ALBANO, 2001). Vale ressaltar que, apesar das crianças terem adquirido o /t/ primeiramente em sílaba inicial e final, na inicial, aparecia somente em sílaba átona. Na medial, apesar dele se encontrar em sílaba tônica, em duas das três palavras, todas eram trissilábicas, podendo ter influenciado na aquisição proposta nesta pesquisa. Neste caso, parece que a extensão da palavra exerce maior controle na aquisição que a tonicidade da sílaba.

O fonema / $\mathrm{k}$ parece ser adquirido em sílaba medial e final antes da inicial, já que a porcentagem de crianças que o tinham dominado nos dois grupos era maior nestas posições de sílabas. $\mathrm{O} / \mathrm{g} /$ está na fase de produção habitual e de aquisição, parecendo ter comportamento igual nos dois grupos de crianças. Pode-se dizer que ele é adquirido aos 3:0 anos, como mostrou WERTZNER (1994). Não se observa uma determinada posição de sílaba em que ele é dominado primeiro.

O /k/ aparece em sílaba átona de sílaba medial e final,; já na inicial, apresenta-se em átona e tônica, não parecendo ser esta a influência na aquisição. $A$ extensão da palavra também parece não influenciar, pois nas três posições ele aparece também em palavras trissilábicas. Neste caso, como é um dos fonemas 
mais ocorrentes no português (ALBANO, 2001), a freqüência na língua pode ter colaborado para a aquisição precoce. $\mathrm{O} / \mathrm{g} /$ não é tão freqüente na língua portuguesa, mas aparece em sílaba tônica inicial e medial da imitação. Na sílaba final, encontra-se em situação átona, além da primeira sílaba das duas palavras dissilábicas conterem encontro consonantal, dificultando a produção da palavra. Apesar deles se encontrarem na mesma categoria de aquisição nas diferentes sílabas, produção habitual, a sílaba medial apresenta menos sujeitos com o fonema adquirido.

Os dados da presente pesquisa não corroboram com os achados de FREITAS (2004), em que todas as plosivas são adquiridas entre 1:6 e 1:8 ano de idade. Vale ressaltar que a autora usou o índice de aquisição de $80 \%$ a $86 \%$ das consoantes serem produzidas corretamente para que fossem consideradas adquiridas. Nesta pesquisa, mesmo tendo sido considerada porcentagem inferior, as crianças ainda não haviam adquirido todas as plosivas entre 2:1 e 3:0 anos.

Com relação à idade de aquisição das fricativas, a única considerada adquirida neste trabalho é o /f/, confirmando pesquisas que mostram esta fricativa como adquirida até os três anos de idade (WERTZNER \& CARVALHO, 2000; OLIVEIRA, 2003). As demais ainda estão no percurso de aquisição, não corroborando com os achados sobre aquisição da pesquisa de OLIVEIRA (2003), na qual $0 / \mathrm{v} /$ estaria adquirido ao 1:8 ano, o / $/ /$ aos 2:10 e $0 / \mathrm{Z} /$ aos 2:6 anos. $\mathrm{O} / \Sigma /$ encontra-se em produção habitual. Neste estudo, se a faixa etária de 2:7 a 3:0 anos fosse dividida por mês, talvez ele já fosse considerado adquirido nas crianças de 2:11 ou 3:0 anos de idade. Novamente, deve-se considerar que o estudo de OLIVEIRA (2203) adotou o índice de $85 \%$ para que um determinado alvo fosse considerado adquirido.

O /f/ não é um dos fonemas mais ocorrentes no português e aparece tanto em sílaba tônica como átona nas provas de nomeação e imitação. Assim, pode-se dizer que a facilidade de produção pode ter influenciado sua aquisição na pesquisa. $O / v /$ aparece em sílaba tônica apenas na imitação em sílaba medial. Nas demais situações, aparece em sílaba átona e em palavras de diferentes extensões.

$\mathrm{O} / \mathrm{Z} /$, além de ser um dos fonemas menos freqüentes na língua portuguesa, aparece para testagem apenas em palavras trissilábicas na nomeação e imitação. Estes dois fatores podem ter colaborado para a aquisição. Sua correlata sonora, é 
também uma das menos ocorrentes na língua e, aparece nas provas de fonologia em palavras de diferentes extensões e tonicidade de sílaba.

As fricativas alveolares ainda estão na fase de aquisição em praticamente todos os grupos e sílabas analisadas. O fato das crianças ainda realizarem distorções freqüentemente nestes dois fonemas, pode ter contribuído para que muitas crianças não os tivessem dominado. Pesquisa anterior (OLIVEIRA, 2004) mostrou que o /s/ é adquirido aos 2:6 e o /z/ aos 2:0 anos, o que não corrobora com os dados da presente pesquisa. Apesar das pesquisas terem utilizado valores de porcentagem diferentes para o critério de aquisição, há também o fato dos estudos terem sido realizados em diferentes regiões do Brasil, mostrando a diferença da aquisição nas diferentes partes do país.

Todas as nasais estão adquiridas de acordo com o critério adotado neste estudo, com exceção do /n/ e do /m/ no Gl, em sílaba inicial na imitação e do /n/ em sílaba inicial na fala espontânea. Nestas situações, eles são produzidos de forma habitual e a porcentagem de sujeitos que os adquiriu está próximo do critério para considerá-lo adquirido. Assim, pode-se considerar que estão dominados aos 2:1 anos, concordando com dados do estudo de FREITAS (2004), que mostra estas nasais adquiridas entre 1:6 e 1:8 anos de idade.

A nasal palatal $/ \mathrm{N} /$ está adquirida em todos os contextos, que aparece corroborando com os dados de HERNANDORENA (1999), que mostra este fonema adquirido aos dois anos de idade, e de FREITAS (2004), que constatou a idade de aquisição com 1:7 ano. Apesar disso, ele é um dos fonemas menos freqüentes no português (ALBANO, 2001).

De acordo com o critério de aquisição aqui proposto, o ///, tanto em sílaba inicial como medial e final, é adquirido aos 2:6 anos, visto que antes desta idade, este fonema encontra-se em produção habitual e, nas crianças mais velhas, está adquirido. Na pesquisa relatada por HERNANDORENA \& LAMPRECHT (1997), o /// é adquirido no meio da palavra entre 3:0 e 3:1 anos e em início, entre 2:8 e 2:9 anos. MEZZOMO \& RIBAS (2004) mostraram que no início da palavra é adquirido aos 2:6 anos, como observado na presente pesquisa.

Neste fonema, o que pode ter contribuído para o pior desempenho do Gl em comparação ao Gll foi que, em muitas palavras em que ele aparecia, elas eram trissilábicas, mostrando que as crianças menores ainda apresentam dificuldade na emissão de palavras com maior extensão. 
Segundo o critério de aquisição adotado na presente pesquisa, as demais líquidas ainda não estão adquiridas aos três anos de idade. O estudo de MEZZOMO \& RIBAS (2004) mostrou que elas são adquiridas posteriormente. No entanto, a pesquisa de HERNADORENA (1999) constatou a aquisição do / $/$ / aos 2:6/2:7 anos.

Para o português, um dos sons mais freqüentes na língua, segundo estudo realizado por ALBANO (2001), tanto em vocábulos do Minidicionário Aurélio como de coleta de fala de adultos, é o/P/. Nesta pesquisa, foi visto que este fonema não está adquirido até os 3:0 anos de acordo com o critério proposto. Poder-se-ia pensar, então, que a tonicidade das sílabas influenciaria a produção deste fonema. $\mathrm{Na}$ imitação, das três palavras que contém o /P/, uma aparece nesta prova apenas em sílaba final e duas o contém em sílaba tônica. Mesmo assim, para os dois grupos de crianças, este fonema não estava adquirido. Na nomeação, são quatro palavras que contém este fonema, sendo que em todas, ele se encontra em sílaba átona final de trissílabos. Assim, o /P/ também não está adquirido nos dois grupos. Neste caso, parece que a complexidade articulatória para a produção deste fonema influencia sua produção, ainda não sendo possível sua correta produção.

Para o fonema $/ x /$, a freqüência deste som na língua pode ter influenciado na sua aquisição, já que ele é um dos menos freqüentes no português.

Embora tenha havido diferença estatística entre os grupos de faixas etárias diferentes, ao se analisar o fonema $/ \mathrm{X} /$, indicando que aumentando a idade, há diminuição do erro, assim como relatado por WERTZNER et al. (2001a) e GALEA (2003), este fonema ainda não está adquirido aos 3:0 anos. Demais pesquisas mostram que eles são adquiridos após esta idade (HERNANDORENA \& LAMPRECHT, 1997; WERTZNER et al., 2001a; GALEA, 2003; MEZZOMO \& RIBAS, 2004).

$\mathrm{O} / \mathrm{X} /$, além de não ser freqüente na língua, aparecendo em apenas uma palavra, encontra-se em sílaba tônica e a maioria delas é trissilábica. Assim, muitos fatores podem estar envolvidos na sua aquisição.

Nota-se que 0 arquifonema /S/ apresenta mais acerto que $\mathrm{o} / \mathrm{R} / \mathrm{em}$ todas as provas e grupos analisados, demonstrando ser adquirido antes.

$\mathrm{O} / \mathrm{S} /$ parece ser adquirido primeiramente em sílaba final, pois a aquisição mostrou mais crianças que o dominaram nesta posição de sílaba, na imitação. Esta é a única prova que tem aquisição para este fonema nas duas sílabas e é possível 
haver comparação. Apesar da pesquisa de MEZZOMO (2004) ter mostrado que este fonema é adquirido primeiro em sílaba final, como parece ser na presente pesquisa, a autora mostrou que as crianças já o dominam aos 2:6 anos, em sílaba final, e aos 3:0 anos, em sílaba inicial. Isto não foi observado com base no critério de aquisição aqui adotado.

Com relação arquifonema /R/, ele ainda não está adquirido pelos grupos em nenhuma prova e posição de sílaba. Pesquisas anteriores mostram que ele é adquirido em idades mais avançadas (YAVAS, 1988; WERTZNER, 1992; 1994; MEZZOMO, 2004).

Da mesma forma que o arquifonema /S/, embora não esteja adquirido por nenhum dos grupos, parece que é adquirido antes em sílaba final, já que mais crianças o dominaram nesta posição de sílaba comparada à sílaba inicial, corroborando com os achados de WERTZNER (1992).

A tonicidade da sílaba parece não influenciar a aquisição dos arquifonemas na amostra analisada, já que estes se encontram em sílaba tônica. A extensão da palavra também não parece ser fator relevante, visto que a maior parte das palavras é dissilábica, sendo observados nas trissilábicas apenas na imitação. Assim, eles podem ser influenciados pela complexidade articulatória.

Quanto às estruturas silábicas, a CCV não está adquirida em nenhuma das provas, posições de sílabas e grupos analisados, corroborando com os dados da análise dos encontros consonantais, os quais também não estão adquiridos.

De acordo com o critério de aquisição adotado, a sílaba CV mostrou estar dominada em todos os grupos, ou seja, mais de $75 \%$ dos sujeitos de cada grupo a adquiriram. A única exceção encontrada é na sílaba medial, de polissílabos na fala espontânea. Nesta situação, as crianças mais novas ainda a realizam de forma considerada "produção habitual", ou seja, entre $50 \%$ e $75 \%$ de domínio pelo grupo. Este dado condiz com o fato das crianças do GI terem dificuldade de produção de palavras mais extensas, já que na faixa etária seguinte, ela se encontra dominada, indicando desenvolvimento.

A estrutura CVC com /R/ não está adquirida em nenhum dos grupos e eventos analisados. Este dado também foi observado ao se analisar o arquifonema /R/ separadamente.

Já em relação à coda /S/, esta estrutura parece ser adquirida antes em sílaba final. Observa-se que, nas crianças mais novas, encontra-se em aquisição nas 
sílabas iniciais e, na final, em produção habitual. Já nas mais velhas, encontra-se em produção habitual nas sílabas iniciais e, na final, como adquirida.

Sugestão para futura pesquisa seria a comprovação de vogal antecedente ou seguinte que facilitaria a produção ou aquisição de um certo fonema. Além disso, seria de grande importância fazer correlação entre tonicidade da sílaba e extensão da palavra com a aquisição de determinado alvo.

Finalizando, os encontros consonantais não estão adquiridos nesta faixa etária. Quanto aos fonemas, os que estão adquiridos são: /b/ aos 2:1 anos ou anteriormente em sílaba medial e final e aos 3:0 anos em inicial; /p/ aos 2:1 anos ou anteriormente em sílaba medial, aos 2:6 anos em inicial e aos 3:0 anos em final; /t/ aos 2:1 anos em sílaba inicial e final e aos 3:0 anos em sílaba medial; /d/ aos 2:6 anos; /k f m n l/ aos 2;1 anos ou anteriormente; /g/ aos 3:0 anos; /// aos 2:6 anos e $/ \mathrm{X} /$ aos 3:0 anos. Em relação às estruturas silábicas, apenas a estrutura CV está adquirida aos 2:1 anos. Já a estrutura CVC com arquifonema /S/ é adquirida aos 2:6 anos apenas em sílaba final. 


\section{HIPÓTESE 7}

A sétima hipótese seria a de que as crianças das duas faixas etárias apresentariam desempenho diferente nas três provas (nomeação, imitação e fala espontânea).

Em relação aos encontros consonantais, a hipótese não foi confirmada. Não houve diferença entre as provas, o que pode ter ocorrido pelo fato das crianças dos dois grupos terem apresentado muito erros.

Quanto a fonemas, a hipótese foi parcialmente confirmada. As crianças mais novas não apresentaram diferença entre as provas em sílaba medial e final. $\mathrm{Na}$ inicial, a fala espontânea demonstrou o melhor desempenho das crianças. As crianças mais velhas apresentaram desempenho diferente nas três sílabas, sendo que na fala espontânea sempre houve o maior índice de acerto que nas demais provas, seguida da nomeação em sílaba final e na imitação em sílaba inicial e medial.

Como mostrado no parágrafo anterior, nas sílabas em que foi encontrada diferença entre as provas, as crianças tiveram melhor desempenho na fala espontânea. Isto pode ter ocorrido pelo fato das crianças nesta prova escolherem as palavras que desejam emitir evitando aquelas de maior complexidade e com sons que ainda não sabem produzir (STOEL-GAMMON \& DUNN, 1985).

GALEA \& WERTZNER (2005c) mostraram que a nomeação apresentava resultado similar à fala espontânea e à imitação, sendo que a imitação era diferente da fala espontânea quanto ao uso de processos fonológicos. Os dados de fonemas da presente pesquisa não mostraram esta característica. Em alguns momentos, a nomeação era parecida com a fala espontânea, porém, em outros momentos, a fala espontânea era similar à imitação.

Quanto à estrutura CV, a hipótese foi parcialmente confirmada. No Gl, em sílaba medial, a fala espontânea tem o menor índice de acerto dentre as provas, tendo a imitação o maior de todas. Como na fala espontânea, as crianças produziram mais palavras polissilábicas, a dificuldade em lidar com extensão da palavra pode ter dificultado a produção e favorecido o erro. No Gll não houve diferença estatística entre as provas, mas se observa que na imitação as crianças apresentam melhor porcentagem de acerto, indicando que elas melhoram 0 desempenho quando há padrão do adulto. 
Na sílaba inicial da fala espontânea as crianças obtiveram melhor resultado, seguido da nomeação e imitação. Estas duas são iguais, porém, somente a nomeação é igual à fala espontânea, resultado similar ao de processos fonológicos (GALEA \& WERTZNER, 2005c).

Na sílaba final, a fala espontânea mostrou melhor desempenho das crianças, seguida da imitação e, por fim, da nomeação.

A estrutura CCV mostrou o mesmo desempenho que a análise dos encontros consonantais, não confirmando a hipótese.

Quanto à estrutura CVC, ela não apresentou diferença entre as provas em sílaba inicial, devido à baixa porcentagem de acerto. Porém, na sílaba final, a imitação apresentou melhor desempenho que as demais, indicando que frente a uma estrutura mais complexa, as crianças tendem a produzi-la mais corretamente quando há padrão do adulto. Desta forma, considera-se a hipótese parcialmente confirmada.

Finalizando, para encontros consonantais e estrutura CCV, as provas foram consideradas iguais. Quanto a fonemas, estruturas CV e CVC, algumas diferenças foram encontradas. Para todas as sílabas e em cada uma das faixas etárias, as crianças tiveram melhor desempenho de acerto dos fonemas na fala espontânea, mesmo quando não foi constatada diferença estatística entre todas as provas. Em geral, o mesmo comportamento é observado na estrutura CV, sendo que apenas na sílaba medial dos dois grupos a imitação apresentou melhor desempenho que nas demais provas. Na estrutura CVC, em sílaba inicial, a fala espontânea obteve melhores resultados, porém, em sílaba final, a imitação atingiu maior porcentagem de acerto em ambos os grupos. 
Neste trabalho, foi exposto o percurso de aquisição fonológica de crianças dos 2:1 aos 3:0 anos de idade. Estes dados são de grande importância para a clínica fonoaudiológica. Além de demonstrar a idade em que fonemas, encontros consonantais e estruturas silábicas são dominados, características sobre esta aquisição foram relatadas, como diferença entre as posições de sílabas, erros mais apresentados e diferenças entre as provas de fonologia. Tais parâmetros auxiliam na avaliação de crianças com queixa de transtorno fonológico, bem como fornecem pistas para a decisão sobre a melhor escolha dos alvos a serem trabalhados em terapia.

Ainda mais, foi demonstrado que a aquisição, além de ser um aprendizado das regras fonológicas de determinada língua, apresenta outros fatores que podem influenciar este domínio, como maturação motora da fala, freqüência de ocorrência do alvo na língua, extensão da palavra, tonicidade e ambiente fonético. Estes fatores não foram o objetivo da pesquisa apresentada, por este motivo, foram pouco discutidos. Mas, abrem a oportunidade de serem mais pesquisados, visto que não são muito explorados na literatura do português do Brasil.

Estudos com crianças de faixas etárias menores que as da presente pesquisa também são necessários, visto que o diagnóstico de determinada alteração deve ser realizado o mais precocemente possível para evitar futuras complicações sociais e escolares destes indivíduos. 
REFERÊNCIAS BIBLIOGRÁFICAS 
AGUILAR-MEDIAVILLA, E. M.; SANZ-TORRENT, M.; SERRA-RAVENTO, M. A comparative study of the phonology of pre-school children with specific language impairment (SLI), language delay (LD) and normal acquisition. Clinical Linguistics \& Phonetics. v. 16, n. 8, p. 573-596, 2002.

ALBANO, E. C. O Gesto e Suas Bordas - esboço de fonologia acústico-articulatória do português brasileiro. Campinas: Mercado de Letras: Associação de Leitura do Brasil - ALB; São Paulo: Fapesp, 2001.

AMARO, L. Estudo da categorização de distorções dos sons em crianças com e sem transtorno fonológico. Dissertação (Mestrado em Lingüística) - Faculdade de Filosofia, Letras e Ciências Humanas da Universidade de São Paulo, São Paulo, 2006.

AMAYREH, M. M.; DYSON, A. T. Phonetic inventories of young Arabic-speaking children. Clinical Linguistics \& Phonetics, v. 14, n. 3, p. 193-215, 2000.

BECHARA, E. Moderna Gramática Portuguesa. 32ª ed. São Paulo: Companhia Editora Nacional, 1988.

BEFI-LOPES, D. M. Vocabulário. In: ANDRADE, C. R. F.; BEFI-LOPES, D. M.; FERNANDES, F. D. M.; WERZNER, H. F. ABFW - teste de linguagem infantil nas áreas de fonologia, vocabulário, fluência e pragmática. Carapicuíba: Pró-Fono, 2000, cap. 2.

BEFI-LOPES, D. M.; FERREIRA, K. I. Aspectos da Aquisição Lexical em Crianças entre 2:0 e 2:11 anos. (Relatório encaminhado à FAPESP - conclusão de pesquisa) - Universidade de São Paulo, 2000.

BEFI-LOPES, D. M.; SERRA, V. C. Aspectos da Aquisição Lexical em Crianças entre 3:0 e 3:11 anos. (Relatório encaminhado à FAPESP - conclusão de pesquisa) - Universidade de São Paulo, 2000.

BERNHARDT, B. H.; STEMBERGER, J. P. Workbook in Nonlinear Phonology for Clinical Application. Austin, Texas: Pro-Ed, 2000.

BISOL, L. Os Constituintes Prosódicos. In: BISOL, L. Introdução a Estudos de Fonologia do Português Brasileiro. 3aㅡ ed. Porto Alegre: EDIPUCRS, 2001, cap 6.

CÂMARA JÚNIOR, J. M. Estrutura da Língua Portuguesa. 34ª ed. Petrópolis: Editora Vozes, 2001.

CASTRO, M. M. Estudo da Estimulabilidade de Crianças com Desenvolvimento Típico e com Distúrbio Fonológico para os fonemas Líquidos Laterais e Vibrante Simples. Dissertação (Mestrado em Lingüística) - Faculdade de Filosofia, Letras e Ciências Humanas da Universidade de São Paulo, São Paulo, 2004.

CASTRO, M. M.; WERTZNER, H. F. Vocabulário Fundamental de Crianças de 5:0 a 8:11 Anos de Idade: fonemas líquidos laterais e vibrantes simples do português brasileiro. Revista Brasileira de Lingüística. São Paulo. v. 12, n. 1, p. 121-135, 2003. 
COLLISCHONN, G. A Sílaba em Português. In: BISOL, L. Introdução a Estudos de Fonologia do Português Brasileiro. 3를. ed. Porto Alegre: EDIPUCRS, 2001a, cap 2.

. O Acento em Português. In: BISOL, L. Introdução a Estudos de Fonologia do Português Brasileiro. $3^{\mathrm{a}}$ ed. Porto Alegre: EDIPUCRS, 2001b, cap 3.

CUNHA, C. Gramática do Português Contemporâneo, de acordo com a Nomenclatura Gramatical Brasileira. 8 ed. Rio de Janeiro: Padrão, 1980.

DODD, B.; HOLM, A.; HUA, Z.; CROSBIE, S. Phonological development: a normative study of British English-speaking children. Clinical Linguistics \& Phonetics. v. 17, n. 8, p. $617-643,2003$.

EDWARDS, J.; GIBBON, F.; FOUKARIS, M. On Discrete Changes in the Acquisition of the Alveolar/Velar Stop Consonant Contrast. Language and Speech. v. 40, n. 2, p. 203-210, 1997.

ELBERT, M. Clinical Forum: phonological assessment and treatment: consideration of error types: a response to Fey. Language, Speech, and Hearing Services in Schools. v. 23, p. 241-246, 1992.

ELBERT, M.; GIERUT,J. Handbook of Clinical Phonology: Approaches to assessment and treatment. $2^{\mathrm{a}}$ ed. Austin: Pro-ed. 1986.

FONSECA, R. A.; TUCCI, T. A.; RODRIGUEZ, R. C. L.; GOMES, I. C. D.; BIANCHINI, E. M. G. A correlação entre ceceio frontal e o crescimento infantil. Revista da Sociedade Brasileira de Fonoaudiologia. v. 10, n. 4, p. 211-7, 2005.

FREITAS, G. C. M. Sobre a Aquisição das Plosivas e Nasais. In: LAMPRECHT, R.R. Aquisição Fonológica do Português: perfil de desenvolvimento e subisídios para a terapia. Porto Alegre: Artmed, 2004, cap 4.

GALEA, D. E. S. Análise do sistema fonológico em crianças de 2;1 a 3;0 anos de idade. São Paulo. Dissertação (Mestrado em Semiótica e Lingüística Geral) Faculdade de Filosofia Letras e Ciências Humanas Universidade de São Paulo, 2003.

GALEA, D. E. S.; WERTZNER, H. F. Análise das Consoantes Líquidas no Desenvolvimento Fonológico Típico. In: CONGRESSO BRASILEIRO DE FONOAUDIOLOGIA, 13, 2005, Santos. Anais... São Paulo: [s. n.], 2005a.

GALEA, D. E. S.; WERTZNER, H. F. Phonological Processes of Syllabic Structure in Typical Developing Brazilian Children. In: ASHA CONVENTION, 2005, San Diego. Anais....[s. n.], 2005b.

GALEA, D. E. S.; WERTZNER, H. F. Comparação de Processos Fonológicos em Três Tipos de Coleta de Fala. Temas sobre Desenvolvimento, São Paulo, v. 14, n. 83 , p. 20-25, 2005c. 
GOLDSTEIN, B.; FABIANO, L.; IGLESIAS, A. Spontaneous and imitated productions in Spanish-speaking children with phonological disorders. Language Speech and Hearing Services in Schools, v. 35, n. 1, p. 5-15, 2004.

HAWKINS, P. Acquisition, Normal and Delayed. In: Introducing Phonology. London: Routledge, 1995. cap. 10.

HERNADORENA, C. L. M. Aquisição da Fonologia e implicações teóricas: um estudo sobre as soantes palatais. In: LAMPRECHT, R. R. Aquisição da Linguagem questões e análises. Porto Alegre: EDIPUCRS, 1999. p. 81-94.

HERNADORENA, C. L. M.; LAMPRECHT, R. R. A Aquisição das Consoantes Líquidas do Português. Letras de Hoje. v. 32, n. 4, p. 7-22, 1997.

HERNADORENA, C. L. M. Aquisição da Fonologia e implicações teóricas: um estudo sobre as soantes palatais. In: LAMPRECHT, R. R. Aquisição da Linguagem questões e análises. Porto Alegre: EDIPUCRS, 1999. p. 81-94.

HODSON, B. W. APP-R The Assessment of Phonological Processes (Examiner's Manual). Austin, Texas: Pro-ed., 1986.

HOFFMAN, P. R.; NORRIS, J. A. Phonological assessment as an integral part of language assessment. American Journal of Speech-Language Pathology. v. 11, n. 3, p. 230-235, 2002.

INGRAM, D. Phonological Disability in Children. London: Edward Arnold, 1976.

JAMES, D. Does the number of syllables in words affect weak syllable deletion in typically developing children aged 3 to 7 years speaking Australian English. In: WORLD CONGRESS OF THE INTERNATIONAL ASSOCIATION OF LOGOPEDICS AND PHONIATRICS, 27, 2007, Copenhagen, Dinamarca. Anais... International Association of Logopedics and Phoniatrics, 2007. p. 69.

JONHSON, C. A.; WESTON, A. D.; BAIN, A. B. An objective and time efficient method for determining severity of childhood speech delay. American Journal of Speech-Language Pathology. v.13, p. 55-65, 2004.

JUNQUEIRA, P.; GUILHERME, A. Ocorrência de Sigmatismo Interdental em Crianças de Três a Oito Anos e sua Relação com Idade e Oclusão Dental. In: MARCHESAN, I. (Org). Tópicos em Fonoaudiologia. São Paulo: Lovise, 1996, cap. 18.

KENT, R. The Biology of Phonological Development. In: FERGURSON, C.A., MENN, L. e STOEL-GAMMON, C. Phonological Development. Models, Research, Implications. Baltimore, Maryland: York Press, 1992, cap. 2. 
KENT, R.; VOPERIAN, H. K. In the mouths of babes: anatomic, motor, and sensory foundations of speech development in children. In: Paul, R. (ed.) Language Disorders from a Developmental Perspective. Mahwah, NJ: Lawrence Erlbaum, 2006, cap 2.

KIRK, C.; DEMUTH, K. Asymmetries in the acquisition of word-initial and word-final consonant clusters. Journal of Child Language, v. 32, n. 4, p 709-734, 2005.

KUNNARI, S.; SAVINAINEN-MAKKONEN, T.; PAAVOLA, L. Phonetic skills of 2year-old Finnish-speaking children. In: WORLD CONGRESS OF THE INTERNATIONAL ASSOCIATION OF LOGOPEDICS AND PHONIATRICS, 27, 2007, Copenhagen, Dinamarca. Anais... International Association of Logopedics and Phoniatrics, 2007. p. 68.

MACNEILAGE, P. F. The frame/content theory of evolution of speech production. Behavioral and Brain Sciences, v. 21, n. 4, p. 499-546, 1998.

MACNEILAGE, P. F.; DAVIS, B.L. Origin of the internal structure of words. Science, v. 288, n. 7 , p. 527-531, 2000.

MACNEILAGE, P. F.; DAVIS, B.L. Motor mechanisms in speech ontogeny: Phylogenetic and neurobiological and linguistic implications. Current Opinion in Neurobiology, v.11, n. 6, p. 696-700, 2001.

MAGALHÃES, J. S. A Metátese da Líquida não-lateral na aquisição: evidência do pé-troqueu. Letras de Hoje. Porto Alegre. v. 38, n. 2, p. 83-95, 2003.

MALDANER, R. D.; RAMOS, A. P. F. A Influência do Alemão na Aquisição dos Róticos em Duas Crianças Brasileiras. Revista da Sociedade Brasileira de Fonoaudiologia. v. 6, n. 2, p. 34-38, 2001.

MATZENAUER, C. L. B. A aquisição das fricativas coronais com base em restrições. Letras de Hoje. Porto Alegre. v. 38, n. 2, p. 123-135, 2003.

Bases para o Entendimento da Aquisição Fonológica. In: LAMPRECHT, R.R. Aquisição Fonológica do Português: perfil de desenvolvimento e subisídios para a terapia. Porto Alegre: Artmed, 2004, cap 2.

MCLEOD, S.; DOORN, J. V.; REED, V. A. Consonant Cluster Development in TwoYear-Olds: General Trends and Individual Difference. Journal of Speech and Hearing Research. v. 44, n. 5, p. 1144-1171, 2001 a.

MCLEOD, S.; DOORN, J. V.; REED, V. A. Normal Acquisition of Consonant Clusters. American Journal of Speech-Language Pathology. v. 10, n. 2, p. 99-110, 2001b.

MEZZOMO, C. L. A Análise Acústica como Subsídio para a Descrição da Aquisição do Constituinte Coda. Letras de Hoje. Porto Alegre. v. 38, n. 2, p. 75-82, 2003. 
Sobre a Aquisição da Coda. In: LAMPRECHT, R. R. Aquisição Fonológica do Português: perfil de desenvolvimento e subisídios para a terapia. Porto Alegre: Artmed, 2004, cap 8.

- A epêntese e a metátese na fala de crianças adquirindo o português brasileiro. In: CONGRESSO BRASILEIRO DE FONOAUDIOLOGIA, 15; CONGRESSO INTERNACIONAL DE FONOAUDIOLOGIA, 7, 2007, Gramado. Anais... São Paulo: [s. a.], 2007a.

O papel das variantes extralingüísticas, idade e gênero, no desenvolvimento da coda silábica. In: CONGRESSO BRASILEIRO DE FONOAUDIOLOGIA, 15; CONGRESSO INTERNACIONAL DE FONOAUDIOLOGIA, 7, 2007, Gramado. Anais... São Paulo: [s. a.], 2007b.

MEZZOMO, C. L.; RIBAS, L. P. Sobre a Aquisição das Líquidas. In: LAMPRECHT, R.R. Aquisição Fonológica do Português: perfil de desenvolvimento e subisídios para a terapia. Porto Alegre: Artmed, 2004, cap 6.

MICCIO, A. W. Components of Phonological Assessment. In: KAMHI, A. G.; POLLOCK, K. E. Phonological Disorders in Children: clinical decision making in assessment and intervention. Baltimore: Paul Brookes Publishing Co., 2005, cap. 3.

MIRANDA, A. R. M. A Representação das Consoantes Róticas nos Sistemas de Crianças Brasileiras e Argentinas Letras de Hoje. Porto Alegre. v. 38, n. 2, p. 111122, 2003.

MUNSON, B. Variability in /s/ production in children and adults: evidence from dynamic measures of spectral mean. Journal of Speech, Language, and Hearing Research. v.. 47, p. 58-69, 2004.

OLIVEIRA, C. C. Perfil da Aquisição das fricativas /f/, $/ \mathrm{V} /, \Sigma /$ e $/ \mathrm{Z}$ do Português Brasileiro: um estudo quantitativo. Letras de Hoje. Porto Alegre. v. 38, n. 2, p. 97110, 2003.

Sobre a Aquisição das Fricativas. In: LAMPRECHT, R.R. Aquisição Fonológica do Português: perfil de desenvolvimento e subisídios para a terapia. Porto Alegre: Artmed, 2004, cap 5.

OWENS, R. E. Jr. Language Development - An Introduction. 4ª ed. Boston: Allyn and Bacon, 1996.

PAGAN, L. O. Estudo das líquidas laterais e vibrantes em crianças com distúrbio fonológico : análise acústica e articulatória. Dissertação (Mestrado em Semiótica e Lingüística Geral) - Faculdade de Filosofia Letras e Ciências Humanas Universidade de São Paulo, 2003.

PEÑA-BROOKS, A.; HEDGE, M. N. Development of Articulation and Phonological Skills. In: Assessment and Treatment of Articulation and Phonological Disorders in Children. Austin: Pro Ed, 2000, cap. 3. 
PEREIRA, M. M. B.; BIANCHINI, E. M. G.; CARVALHO, G. T.; JARDIM, Z. M. G. Investigação da Ocorrência e Caracterização de Distorções do [s] em crianças de 3 a 10 anos. Revista da Sociedade Brasileira de Fonoaudiologia. v. 8, n. 1, p. 10-18, 2003.

PORTER, J. H.; HODSON, B. W. Collaborating to Obtain Phonological Acquisition Data for Local Schools. Language, Speech, and Hearing Services in Schools. v. 32, n. 3, p. 165-171, Jul. 2001.

RAMOS, A. P. F. Aquisição dos Róticos em um Dialeto do Português Brasileiro: Discussão de Aspectos Fonéticos e Fonológicos e suas Implicações para a Clínica Fonoaudiológica. Revista da Sociedade Brasileira de Fonoaudiologia. v. 4, n. 6, p. 31-35, 2000.

RIGATTI, A. P.; FONSECA, R. P.; RAMOS, A. P. F. Aquisição Normal e Desviante do Rótico Alveolar Simples em Dois Dialetos do Português Brasileiro. Pró-Fono Revista de Atualização Científica. v. 13, n. 2, p. 157-164, 2001.

RIBAS, L. Onset Complexo: características da aquisição. Letras de Hoje. Porto Alegre. v. 38, n. 2, p. 23-31, 2003.

Sobre a Aquisição do Onset Complexo. In: LAMPRECHT, R.R. Aquisição Fonológica do Português: perfil de desenvolvimento e subisídios para a terapia. Porto Alegre: Artmed, 2004, cap 9.

RIBAS, L.; BONILLA, G.; LAMPRECHT, R. Hierarquias de Restrições e Estratégias de Reparo: aquisição do onset complexo. Letras de Hoje. Porto Alegre. v. 38, n. 2, p. 33-44, 2003.

SHRIBERG, L. D. Epidemiologic and diagnostic profiles for five developmental phonological disorders. Seminar presented at the Annual Convention or the American Speech-Language-Hearing Association, San Francisco, November, 1999. (http://www.waisman.wisc.edu/phonology).

SHRIBERG, L. D.; KWIATKOWSKI, J. Continuous Speech Sampling for Phonologic Analysis of Speech-Delayed Children. Journal of Speech and Hearing Disorders. v. 50, p. 323-334, 1985.

SILVA, T. C. Fonética e Fonologia do português - roteiro de estudos e guia de exercícios. $2^{a}$ ed. São Paulo: Contexto, 1999.

SMIT, A. B. Phonologic Error Distributions in the lowa-Nebraska Articulation Norms Project: Consonant Clusters. Journal of Speech and Hearing Research. v. 36, p. 931947, 1993.

SMIT, A. B.; HAND, L.; FREILINGER, J. J.; BERNTHAL, J. E.; BIRD, A. The lowa Articulation Norms Project and its Nebraska Replication. Journal of Speech and Hearing Disorders. v. 55, p. 779-798, 1990. 
SOSA, A.; STOEL-GAMMON, C. Patterns of intra-word phonological variability during the second year of life. Journal of Child Language. v. 33, p. 31-50, 2006.

STOEL-GAMMON, C.; DUNN, C. Normal and Disordered Phonology in Children. Austin, Texas: Pro-ed., 1985.

STOEL-GAMMON, C.; PETER, B. Syllables, segments, and sequences: Phonological patterns in the words of young children acquiring American English. In: DAVIS, B.; ZAJDÓ, K. Syllable Development: The Frame/Content Theory and Beyond. Mahwah, NJ: Lawrence Erlbaum Associates, Inc., no prelo.

STOKES, S. F.; WONG, I. M. Vowel and diphthong development in Cantonesespeaking children. Clinical Linguistics \& Phonetics. v. 16, n. 8, p. 597-617, 2002.

STOKES, S. F.; SURENDRAN D. Articulatory Complexity, Ambient Frequency, and Functional Load as Predictors of Consonant Development in Children. Journal of Speech, Language and Hearing Research. v. 48, p. 577-591, 2005.

TEIXEIRA, E. R.; DAVIS, B. L. Early Sound Patterns in the Speech of Two Brazilian Portuguese Speakers. Language and Speech. v. 45, n. 2, p. 179-204, 2002.

TOMÉ, M. C.; FARIAS, S. R.; ARAÚJO, S. M.; SCHIMITT, B. E. Ceceio interdental e alterações oclusais em crianças de 03 a 06 anos. Pró-Fono Revista de Atualização Científica. v.16, n. 1, p. 19-30, 2004.

WERTZNER, H. F. Articulação: Aquisição do Sistema Fonológico dos três aos Sete Anos. Tese (Doutorado - Departamento de Lingüística) - Faculdade de Filosofia, Letras e Ciências Humanas da Universidade de São Paulo, São Paulo, 1992.

Aquisição da Articulação: um estudo em crianças de três a sete anos. Estudos de Psicologia. v.11, n. 1,2, p.11-21, 1994.

Typical Substitutions of the Liquids Phonemes in the Phonological Acquisition of Brazilian Children. Proceedings of Speech Pathology Australia National Conference, School of Speech and Hearing Sciences, and Curtin Printing Services, Curtin University of Technology, 1998, p. 175-180.

Fonologia. In: ANDRADE, C. R. F.; BEFI-LOPES, D. M.; FERNANDES, F. D. M.; WERZNER, H. F. ABFW; teste de linguagem infantil nas áreas de fonologia, vocabulário, fluência e pragmática. Carapicuíba: Pró-Fono, 2000, cap 1.

. O Distúrbio Fonológico em Crianças Falantes do Português: descrição e medidas de severidade. Tese (Livre Docência - Departamento de Fisioterapia, Fonoaudiologia e Terapia Ocupacional) - Faculdade de Medicina da Universidade de São Paulo, São Paulo, 2002.

WERTZNER, H. F.; CARVALHO, I. A. M. Ocorrências de "erros" nos fonemas fricativos durante o processo de aquisição do sistema fonológico. Jornal Brasileiro de Fonoaudiologia. v. 2, n. 2, p. 67-74, 2000. 
WERTZNER, H. F.; GALEA, D. E. S.; ALMEIDA, R. C. Uso do Processo Fonológico de Simplificação de Velar em Crianças de 2;1 a 3;0 anos de idade. Jornal Brasileiro de Fonoaudiologia. v. 8, n. 2, p. 233-238, 2001 a.

WERTZNER, H. F.; HERRERO, S. F.; PIRES, S. C.. F.; IDERIHA, P. N. Classificação do distúrbio fonológico por meio de duas medidas de análise: Porcentagem de Consoantes Corretas (PCC) e índice de ocorrência dos processos (PDI). Pró-Fono Revista de Atualização Científica. v. 13, n. 1, p. 90-97, 2001 b.

WERTZNER, H. F.; GALEA, D. E. S.; TERUYA, N. M. Acquisition of the Fricative Phonemes in Brazilian Children. The ASHA Leader. American Speech- LanguageHearing Association. v.7, n. 15, 2002, p. 158.

WERTZNER, H. F.; PAPP, A. C. C. S.; GALEA, D. E. S. Provas de nomeação e Imitação como instrumentos de diagnóstico do transtorno fonológico. Pró-Fono Revista de Atualização Científica, Barueri, v. 18, n.3, p:303-312, 2006.

WERTZNER, H. F.; SOTELO, M. B.; AMARO, L. Analysis of Distortions in Children with and without Phonological Disorders. Clinics. v. 60, n. 2, p. 93-102, 2005.

YAVAS, M. Padrões de Aquisição da Fonologia do Português. Letras de Hoje. Porto Alegre, v. 23, p. 7-30, 1988. 
ANEXOS 
Anexo A - Aprovação da Comissão de Ética para Análise de Projetos de Pesquisa

\section{HOSPITAL DAS CLINICAS \\ DA \\ FACULDADE DE MEDICINA DA UNIVERSIDADE DE SÁO PAULO \\ DIRETORIA CLINATCA}

\section{Comissão de Ética para Análise de Projetos de}

\section{Pesquisa}

\section{APROVACẼO}

A Comissão de Ética para Análise de Projetos de Pesquisa - CAPPesq da Diretoria Clínica do Hospital das Clínicas e da Faculdade de Medicina da Universidade de São Paulo, em sessão de 08.08.01, APROVOU o Protocolo de Pesquisa $n^{\circ} 358 / 01$, intitulado: "Características do sistema fonológico em crianças com desenvolvimento normal de 2:1 a 3:0 anos de idade", do Departamento de Fisioterapia, Fonoaudiologia e Terapia Ocupacional, bem como o Termo de Consentimento Livre e Esclarecido.

Pesquisador Responsável: Profa. Dra. Haydée Fiszbein Wertzner Pesquisador Executante: Sra. Daniela Evaristo dos Santos Galea

CAPPesq, 9 de agosto de 2001.

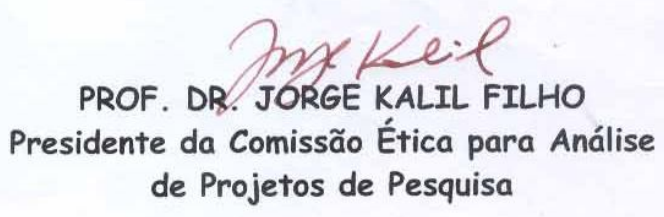

OBSERVAÇÃO: Cabe ao pesquisador elaborar e apresentar à CAPPesq, os relatórios parciais e final sobre a pesquisa (Resolução do Conselho Nacional de Saúde $n^{\circ} 196$, de 10.10.1996, inciso IX.2, letra "c") 
Anexo B - Creches na ordem em que foram utilizadas na pesquisa e número de crianças que passaram por cada uma das etapas

\begin{tabular}{|c|c|c|c|c|c|c|c|c|c|}
\hline \multirow[b]{2}{*}{ creche } & \multirow[b]{2}{*}{ classe } & \multirow[b]{2}{*}{ número de crianças } & \multirow[b]{2}{*}{ pais não localizados } & \multirow[b]{2}{*}{ otite } & \multirow[b]{2}{*}{ bilingüe } & \multirow[b]{2}{*}{ outras complicações } & \multicolumn{3}{|c|}{ Vocabulário } \\
\hline & & & & & & & não quiseram/não falaram & \begin{tabular}{|c|}
\multicolumn{2}{|c|}{ fizer } \\
alteradas
\end{tabular} & ram \\
\hline \multirow{3}{*}{ Frei Luis Amigó } & módulo 1 & 16 & 0 & 0 & 0 & 0 & 8 & 3 & 5 \\
\hline & módulo 2 & 19 & 0 & 1 & 0 & 0 & 5 & 1 & 12 \\
\hline & módulo 3 & 9 & 0 & 0 & 0 & 0 & 0 & 3 & 6 \\
\hline \multirow{4}{*}{ Nossa Senhora dos Pobres } & $\operatorname{mini} \mathrm{A}$ & 24 & 1 & 2 & 1 & 0 & 5 & 3 & 12 \\
\hline & $\operatorname{mini} B$ & 15 & 1 & 7 & 1 & 0 & 1 & 0 & 5 \\
\hline & $\operatorname{mini} \mathrm{C}$ & 19 & 0 & 4 & 0 & 0 & 3 & 2 & 10 \\
\hline & barçário maior & 10 & 0 & 4 & 0 & 0 & 3 & 1 & 2 \\
\hline \multirow{3}{*}{ Maria de Nazaré } & $\operatorname{mini} \mathrm{A}$ & 9 & 4 & 0 & 0 & 0 & 1 & 1 & 3 \\
\hline & $\operatorname{mini} B$ & 13 & 2 & 0 & 0 & 0 & 5 & 1 & 5 \\
\hline & $\operatorname{mini} \mathbf{C}$ & 10 & 0 & 1 & 0 & 0 & 0 & 0 & 9 \\
\hline \multirow{3}{*}{ Paulo de Tarso } & mini-grupo 1 & 9 & 0 & 0 & 0 & 0 & 4 & 0 & 5 \\
\hline & mini-grupo 2 & 12 & 1 & 1 & 0 & 0 & 1 & 3 & 6 \\
\hline & mini-grupo 3 & 1 & 0 & 0 & 0 & 0 & 0 & 0 & 1 \\
\hline \multirow{4}{*}{ Sinhazinha Meireles } & berçário maior I & 11 & 2 & 1 & 0 & 0 & 4 & 1 & 3 \\
\hline & berçário maior III & 6 & 0 & 0 & 0 & 0 & 1 & 1 & 4 \\
\hline & mini-grupo I & 3 & 0 & 1 & 0 & 1 & 0 & 0 & 1 \\
\hline & mini-grupo II & 6 & 2 & 1 & 0 & 0 & 0 & 1 & 2 \\
\hline \multirow{2}{*}{ Vila Nova Jaguaré } & berçário maior & 2 & 0 & 0 & 0 & 0 & 1 & 0 & 1 \\
\hline & mini-grupo & 4 & 0 & 0 & 0 & 0 & 1 & 0 & 3 \\
\hline
\end{tabular}


Anexo C - Anamnese

\section{ANAMNESE}

Data:

Nome:

D.N: Idade: Natural de:

Nome do Pai:

Natural de: D.N: Profissão:

Nome da Mãe:

Natural de: D.N:

Profissão:

Irmãos (idade e sexo):

DESENVOLVIMENTO DA LINGUAGEM:

Balbucio: Primeiras Palavras:

Era compreendida? Por Quem?

ATUALMENTE: Quantidade de Fala:

Qualidade da Fala:

Há antecedente de linguagem? (parentesco e alteração)

Bilíngüe?

DOENÇAS:

Ouvido: quantos episódios e em que idade?.

Rebaixamento auditivo:

Respiratória? 


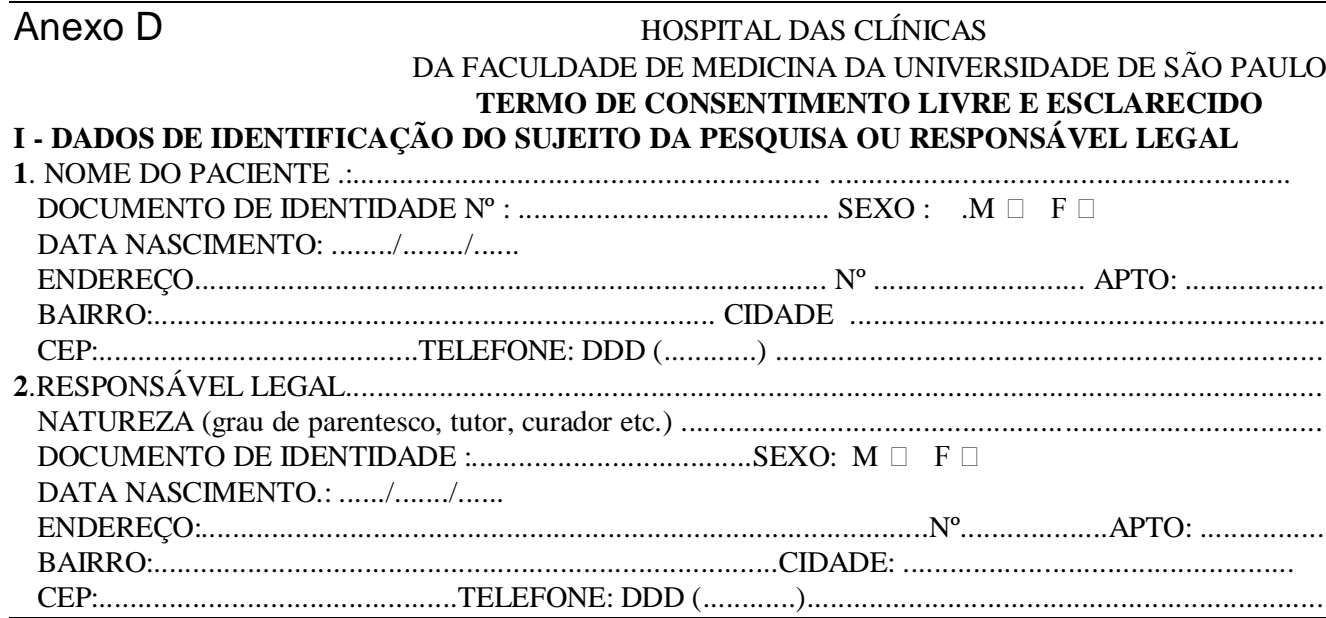

\section{II - DADOS SOBRE A PESQUISA CIENTÍFICA}

1. TÍtUlo Do PROTOCOLO DE PESQUISA : Características do Sistema Fonológico em Crianças com Desenvolvimento Normal de $2 ; 1$ a $3 ; 0$ anos de idade

PESQUISADOR: $\operatorname{Prof}^{a}{ }^{a} r^{a}$ Haydée Fiszbein Wertzner CARGO/FUNÇÃO: Profa. Assistente Dra -MS3

INSCRIÇÃO CONSELHO REGIONAL N ${ }^{\circ}$ CRFa. 0941

UNIDADE DO HCFMUSP: Departamento de Fisioterapia, Fonoaudiologia e Terapia Ocupacional

3. AVALIAÇÃO DO RISCO DA PESQUISA:

$\begin{array}{llll}\text { SEM RISCO } & \mathrm{x} & \text { RISCO MÍNIMO } & \text { RISCO MÉDIO } \\ \text { RISCO BAIXO } & \square & \text { RISCO MAIOR } & \square\end{array}$

(probabilidade de que o indivíduo sofra algum dano como consequência imediata ou tardia do estudo)

4.DURAÇÃO DA PESQUISA : 24 meses

\section{III - REGISTRO DAS EXPLICAÇÕES DO PESQUISADOR AO PACIENTE OU SEU REPRESENTANTE LEGAL SOBRE A PESQUISA CONSIGNANDO:}

1. justificativa e os objetivos da pesquisa: O conhecimento sobre o desenvolvimento normal dos sons da fala das crianças é importante para ajudar o tratamento daquelas crianças que possuem alguma alteração.

2. procedimentos que serão utilizados e propósitos, incluindo a identificação dos procedimentos que são experimentais: Serão aplicadas para cada criança uma prova de imitação de palavras e de nomeação de objetos, além de uma situação de brincadeira livre. Essas provas serão gravadas em fitas cassete e de video.

3. desconfortos e riscos esperados: Não é esperado nenhum risco nem desconforto durante a aplicação dessas provas.

4. benefícios que poderão ser obtidos: Melhorar o diagnóstico e tratamento da criança com fala incompreensível.

5. procedimentos alternativos que possam ser vantajosos para o indivíduo: se, durante a aplicação das provas, a criança apresentar alguma alteração no desenvolvimento da linguagem, ela será encaminhada para atendimento fonoaudiológico.

\section{IV - ESCLARECIMENTOS DADOS PELO PESQUISADOR SOBRE GARANTIAS DO SUJEITO DA PESQUISA CONSIGNANDO:}

1. acesso, a qualquer tempo, às informações sobre procedimentos, riscos e benefícios relacionados à pesquisa, inclusive para dirimir eventuais dúvidas: a qualquer momento o responsável pela criança poderá procurar a pesquisadora para tirar quaisquer dúvidas quanto às provas usadas na testagem, bem como às gravações realizadas.

2. liberdade de retirar seu consentimento a qualquer momento e de deixar de participar do estudo, sem que isto traga prejuízo à continuidade da assistência: a qualquer momento o responsável pela criança poderá decidir não fazer parte do estudo, sendo que a criança continuará recebendo o tratamento fonoaudiológico da forma habitual, quando necessário.

3. salvaguarda da confidencialidade, sigilo e privacidade: os dados da criança serão utilizados somente para a pesquisa sendo mantido o sigilo e a privacidade.

4. disponibilidade de assistência no HCFMUSP, por eventuais danos à saúde, decorrentes da pesquisa: não é esperado nenhum dano á saúde com a aplicação das provas de imitação, de nomeação e de situação de brincadeira livre, sendo garantido o tratamento fonoaudiológico posterior ao diagnóstico do distúrbio fonológico.

V. INFORMAÇÕES DE NOMES, ENDEREÇOS E TELEFONES DOS RESPONSÁVEIS PELO ACOMPANHAMENTO DA PESQUISA, PARA CONTATO EM CASO DE INTERCORRÊNCIAS CLÍNICAS E REAÇÕES ADVERSAS.

Prof Dr ${ }^{a}$ Haydée Fiszbein Wertzner: $\quad$ Rua Cipotanea ,51 - Cidade Universitária - Butantã - São Paulo Fone: 38187455 e 38187453

\section{OBSERVAÇÕES COMPLEMENTARES:}

\section{VII - CONSENTIMENTO PÓS-ESCLARECIDO}

Declaro que, após convenientemente esclarecido pelo pesquisador e ter entendido o que me foi explicado, consinto em participar do presente Protocolo de Pesquisa

$$
\text { São Paulo, } \quad \text { de de 200_ }
$$


Anexo $\mathrm{E}$ - Carta de encaminhamento às creches

São Paulo, de de 2002

À Creche

$\mathrm{A} / \mathrm{C}$

Prezada Sra.,

Como aluna regular do curso de pós-graduação em Semiótica e Lingüística Geral na FFLCH USP, estou realizando a seguinte pesquisa para a dissetação de mestrado "Características do Sistema Fonológico em Crianças com Desenvolvimento Normal de 2;1 a 3;0 anos de idade", sob a orientação da $\operatorname{Prof}^{\mathrm{a}} \operatorname{Dr}^{\mathrm{a}}$ Haydée Fiszbein Wertzner.

O projeto da pesquisa foi aprovado pela comissão de ética da Faculdade de Medicina da Universidade de São Paulo e se encontra em anexo. O termo de consentimento pós informação, o qual também se encontra em anexo, contém a explicação da pesquisa e será entregue para o responsável de cada criança participante, antes da coleta dos dados.

Seria de grande interesse para a realização dessa pesquisa contar com o auxílio dessa Creche para aplicação dos protocolos em questão nas crianças entre dois e tres anos. Assim, solicito autorização para tanto.

Desde já agradeço a colaboração.

Atenciosamente,

Daniela Evaristo dos Santos Galea

CRFa. 10.204 


\section{Anexo Fa - Rodízio das provas no Gl-F}

\begin{tabular}{|c|c|c|c|}
\hline sujeito número & idade & 1 $^{\text {a }}$ etapa & 2 $^{\text {a }}$ etapa \\
\hline 1 & $02 ; 01$ & $\mathrm{~N} / \mathrm{I}$ & $\mathrm{FE}$ \\
\hline 2 & $02 ; 01$ & $\mathrm{~N} / \mathrm{FE}$ & $\mathrm{I}$ \\
\hline 3 & $02 ; 01$ & $\mathrm{I} / \mathrm{FE}$ & $\mathrm{N}$ \\
\hline 4 & $02 ; 01$ & $\mathrm{FE} / \mathrm{N}$ & $\mathrm{I}$ \\
\hline 5 & $02 ; 02$ & $\mathrm{~N} / \mathrm{l}$ & $\mathrm{FE}$ \\
\hline 6 & $02 ; 02$ & $\mathrm{~N} / \mathrm{FE}$ & $\mathrm{I}$ \\
\hline 7 & $02 ; 02$ & $\mathrm{I} / \mathrm{FE}$ & $\mathrm{N}$ \\
\hline 8 & $02 ; 02$ & $\mathrm{FE} / \mathrm{l}$ & $\mathrm{I}$ \\
\hline 9 & $02 ; 03$ & $\mathrm{I} / \mathrm{N}$ & $\mathrm{FE}$ \\
\hline 10 & $02 ; 03$ & $\mathrm{I} / \mathrm{FE}$ & $\mathrm{N}$ \\
\hline 11 & $02 ; 03$ & $\mathrm{FE} / \mathrm{l}$ & $\mathrm{N}$ \\
\hline 12 & $02 ; 04$ & $\mathrm{~N} / \mathrm{I}$ & $\mathrm{FE}$ \\
\hline 13 & $02 ; 04$ & $\mathrm{I} / \mathrm{N}$ & $\mathrm{FE}$ \\
\hline 14 & $02 ; 04$ & $\mathrm{I} / \mathrm{FE}$ & $\mathrm{N}$ \\
\hline 15 & $02 ; 04$ & $\mathrm{FE} / \mathrm{l}$ & $\mathrm{N}$ \\
\hline 16 & $02 ; 05$ & $\mathrm{~N} / \mathrm{FE}$ & $\mathrm{I}$ \\
\hline 17 & $02 ; 05$ & $\mathrm{I} / \mathrm{N}$ & $\mathrm{FE}$ \\
\hline 18 & $02 ; 05$ & $\mathrm{FE} / \mathrm{N}$ & $\mathrm{I}$ \\
\hline 19 & $02 ; 05$ & $\mathrm{FE} / \mathrm{l}$ & $\mathrm{N}$ \\
\hline 20 & $02 ; 06$ & $\mathrm{~N} / \mathrm{FE}$ & $\mathrm{I}$ \\
\hline 21 & $02 ; 06$ & $\mathrm{I} / \mathrm{N}$ & $\mathrm{FE}$ \\
\hline 22 & $02 ; 06$ & $\mathrm{FE} / \mathrm{N}$ & $\mathrm{I}$ \\
\hline 23 & $02 ; 06$ & $\mathrm{FE} / \mathrm{I}$ & $\mathrm{N}$ \\
\hline
\end{tabular}

Legenda: N: nomeação, I: imitação, FE: fala espontânea 
Anexo Fb - Rodízio das provas no Gl-M

\begin{tabular}{|c|c|c|c|}
\hline sujeito número & idade & 1 $^{\text {a }}$ etapa & 2 $^{\text {a }}$ etapa \\
\hline 1 & $02 ; 01$ & $\mathrm{~N} / \mathrm{I}$ & $\mathrm{FE}$ \\
\hline 2 & $02 ; 02$ & $\mathrm{~N} / \mathrm{I}$ & $\mathrm{FE}$ \\
\hline 3 & $02 ; 02$ & $\mathrm{~N} / \mathrm{FE}$ & $\mathrm{I}$ \\
\hline 4 & $02 ; 03$ & $\mathrm{~N} / \mathrm{I}$ & $\mathrm{FE}$ \\
\hline 5 & $02 ; 03$ & $\mathrm{I} / \mathrm{N}$ & $\mathrm{FE}$ \\
\hline 6 & $02 ; 03$ & $\mathrm{I} / \mathrm{FE}$ & $\mathrm{N}$ \\
\hline 7 & $02 ; 04$ & $\mathrm{~N} / \mathrm{I}$ & $\mathrm{FE}$ \\
\hline 8 & $02 ; 04$ & $\mathrm{I} / \mathrm{N}$ & $\mathrm{FE}$ \\
\hline 9 & $02 ; 04$ & $\mathrm{I} / \mathrm{FE}$ & $\mathrm{N}$ \\
\hline 10 & $02 ; 04$ & $\mathrm{FE} / \mathrm{l}$ & $\mathrm{N}$ \\
\hline 11 & $02 ; 05$ & $\mathrm{~N} / \mathrm{FE}$ & $\mathrm{I}$ \\
\hline 12 & $02 ; 05$ & $\mathrm{I} / \mathrm{N}$ & $\mathrm{FE}$ \\
\hline 13 & $02 ; 05$ & $\mathrm{FE} / \mathrm{N}$ & $\mathrm{I}$ \\
\hline 14 & $02 ; 05$ & $\mathrm{FE} / \mathrm{l}$ & $\mathrm{N}$ \\
\hline 15 & $02 ; 06$ & $\mathrm{~N} / \mathrm{FE}$ & $\mathrm{I}$ \\
\hline 16 & $02 ; 06$ & $\mathrm{I} / \mathrm{N}$ & $\mathrm{FE}$ \\
\hline 17 & $02 ; 06$ & $\mathrm{FE} / \mathrm{N}$ & $\mathrm{I}$ \\
\hline 18 & $02 ; 06$ & $\mathrm{FE} / \mathrm{I}$ & $\mathrm{N}$ \\
\hline
\end{tabular}

Legenda: N: nomeação, l: imitação, FE: fala espontânea 
Anexo Fc - Rodízio das provas no Gll-F

\begin{tabular}{|c|c|c|c|}
\hline sujeito número & idade & 1 $^{\mathbf{a}}$ etapa & 2 $^{\mathbf{a}}$ etapa \\
\hline 1 & $02 ; 07$ & $\mathrm{~N} / \mathrm{l}$ & $\mathrm{FE}$ \\
\hline 2 & $02 ; 07$ & $\mathrm{~N} / \mathrm{FE}$ & $\mathrm{I}$ \\
\hline 3 & $02 ; 07$ & $\mathrm{I} / \mathrm{FE}$ & $\mathrm{N}$ \\
\hline 4 & $02 ; 07$ & $\mathrm{FE} / \mathrm{N}$ & $\mathrm{I}$ \\
\hline 5 & $02 ; 08$ & $\mathrm{~N} / \mathrm{l}$ & $\mathrm{FE}$ \\
\hline 6 & $02 ; 08$ & $\mathrm{~N} / \mathrm{FE}$ & $\mathrm{I}$ \\
\hline 7 & $02 ; 08$ & $\mathrm{I} / \mathrm{FE}$ & $\mathrm{N}$ \\
\hline 8 & $02 ; 08$ & $\mathrm{FE} / \mathrm{l}$ & $\mathrm{I}$ \\
\hline 9 & $02 ; 09$ & $\mathrm{~N} / \mathrm{l}$ & $\mathrm{FE}$ \\
\hline 10 & $02 ; 09$ & $\mathrm{I} / \mathrm{N}$ & $\mathrm{FE}$ \\
\hline 11 & $02 ; 09$ & $\mathrm{I} / \mathrm{FE}$ & $\mathrm{N}$ \\
\hline 12 & $02 ; 09$ & $\mathrm{FE} / \mathrm{l}$ & $\mathrm{N}$ \\
\hline 13 & $02 ; 10$ & $\mathrm{~N} / \mathrm{l}$ & $\mathrm{FE}$ \\
\hline 14 & $02 ; 10$ & $\mathrm{I} / \mathrm{N}$ & $\mathrm{FE}$ \\
\hline 15 & $02 ; 10$ & $\mathrm{I} / \mathrm{FE}$ & $\mathrm{N}$ \\
\hline 16 & $02 ; 10$ & $\mathrm{FE} / \mathrm{l}$ & $\mathrm{N}$ \\
\hline 17 & $02 ; 11$ & $\mathrm{~N} / \mathrm{FE}$ & $\mathrm{I}$ \\
\hline 18 & $02 ; 11$ & $\mathrm{I} / \mathrm{N}$ & $\mathrm{FE}$ \\
\hline 19 & $02 ; 11$ & $\mathrm{FE} / \mathrm{N}$ & $\mathrm{I}$ \\
\hline 20 & $02 ; 11$ & $\mathrm{FE} / \mathrm{l}$ & $\mathrm{N}$ \\
\hline 21 & $03 ; 00$ & $\mathrm{~N} / \mathrm{FE}$ & $\mathrm{I}$ \\
\hline 22 & $03 ; 00$ & $\mathrm{I} / \mathrm{N}$ & $\mathrm{FE}$ \\
\hline 23 & $03 ; 00$ & $\mathrm{FE} / \mathrm{N}$ & $\mathrm{I}$ \\
\hline 24 & $03 ; 00$ & $\mathrm{FE} / \mathrm{l}$ & $\mathrm{N}$ \\
\hline & & & \\
\hline
\end{tabular}

Legenda: N: nomeação, l: imitação, FE: fala espontânea 
Anexo Fd - Rodízio das provas no Gll-M

\begin{tabular}{|c|c|c|c|}
\hline sujeito número & idade & 1 $^{\text {a }}$ etapa & 2 $^{\text {a }}$ etapa \\
\hline 1 & $02 ; 07$ & $\mathrm{~N} / \mathrm{I}$ & $\mathrm{FE}$ \\
\hline 2 & $02 ; 07$ & $\mathrm{~N} / \mathrm{FE}$ & $\mathrm{I}$ \\
\hline 3 & $02 ; 07$ & $\mathrm{I} / \mathrm{FE}$ & $\mathrm{N}$ \\
\hline 4 & $02 ; 07$ & $\mathrm{FE} / \mathrm{N}$ & $\mathrm{I}$ \\
\hline 5 & $02 ; 08$ & $\mathrm{~N} / \mathrm{I}$ & $\mathrm{FE}$ \\
\hline 6 & $02 ; 08$ & $\mathrm{~N} / \mathrm{FE}$ & $\mathrm{I}$ \\
\hline 7 & $02 ; 08$ & $\mathrm{I} / \mathrm{FE}$ & $\mathrm{N}$ \\
\hline 8 & $02 ; 09$ & $\mathrm{~N} / \mathrm{I}$ & $\mathrm{FE}$ \\
\hline 9 & $02 ; 09$ & $\mathrm{I} / \mathrm{N}$ & $\mathrm{FE}$ \\
\hline 10 & $02 ; 09$ & $\mathrm{I} / \mathrm{FE}$ & $\mathrm{N}$ \\
\hline 11 & $02 ; 09$ & $\mathrm{FE} / \mathrm{I}$ & $\mathrm{N}$ \\
\hline 12 & $02 ; 10$ & $\mathrm{~N} / \mathrm{I}$ & $\mathrm{FE}$ \\
\hline 13 & $02 ; 10$ & $\mathrm{I} / \mathrm{N}$ & $\mathrm{FE}$ \\
\hline 14 & $02 ; 10$ & $\mathrm{I} / \mathrm{FE}$ & $\mathrm{N}$ \\
\hline 15 & $02 ; 10$ & $\mathrm{FE} / \mathrm{l}$ & $\mathrm{N}$ \\
\hline 16 & $02 ; 11$ & $\mathrm{~N} / \mathrm{FE}$ & $\mathrm{I}$ \\
\hline 17 & $02 ; 11$ & $\mathrm{I} / \mathrm{N}$ & $\mathrm{FE}$ \\
\hline 18 & $02 ; 11$ & $\mathrm{FE} / \mathrm{N}$ & $\mathrm{I}$ \\
\hline 19 & $02 ; 11$ & $\mathrm{FE} / \mathrm{l}$ & $\mathrm{N}$ \\
\hline 20 & $03 ; 00$ & $\mathrm{~N} / \mathrm{FE}$ & $\mathrm{I}$ \\
\hline 21 & $03 ; 00$ & $\mathrm{I} / \mathrm{N}$ & $\mathrm{FE}$ \\
\hline 22 & $03 ; 00$ & $\mathrm{FE} / \mathrm{N}$ & $\mathrm{I}$ \\
\hline 23 & $03 ; 00$ & $\mathrm{FE} / \mathrm{I}$ & $\mathrm{N}$ \\
\hline
\end{tabular}

Legenda: N: nomeação, I: imitação, FE: fala espontânea 
Anexo G - Número possível de fonemas na prova de imitação e nomeação, em sílaba medial.

\begin{tabular}{|c|c|c|}
\hline Fonema & Nomeação & Imitação \\
\hline $\mathrm{b}$ & 1 & 1 \\
\hline $\mathrm{p}$ & 1 & 1 \\
\hline $\mathrm{d}$ & 1 & 1 \\
\hline $\mathrm{t}$ & 0 & 3 \\
\hline $\mathrm{g}$ & 0 & 1 \\
\hline $\mathrm{k}$ & 1 & 1 \\
\hline $\mathrm{z}$ & 1 & 0 \\
\hline $\mathrm{s}$ & 1 & 0 \\
\hline $\mathrm{v}$ & 0 & 1 \\
\hline $\mathrm{f}$ & 0 & 1 \\
\hline $\mathrm{Z}$ & 0 & 1 \\
\hline$\Sigma$ & 1 & 1 \\
\hline $\mathrm{l}$ & 2 & 0 \\
\hline $\mathrm{P}$ & 1 & 0 \\
\hline $\mathrm{x}$ & 1 & 0 \\
\hline $\mathrm{x}$ & 0 & 1 \\
\hline $\mathrm{m}$ & 0 & 0 \\
\hline $\mathrm{n}$ & 0 & 0 \\
\hline ) & 0 & 0 \\
\hline & & \\
\hline
\end{tabular}

OBS: não há alvo medial para arquifonemas e encontros consonantais 
Anexo H - Número possível de cada estrutura silábica, na prova de imitação e nomeação.

\begin{tabular}{|c|c|c|c|c|c|c|}
\hline \multirow{2}{*}{ estrutura } & \multicolumn{3}{|c|}{ Nomeação } & \multicolumn{3}{c|}{ Imitação } \\
\cline { 2 - 7 } & inicial & medial & final & inicial & medial & final \\
\hline CV dis & 11 & --- & 15 & 11 & --- & 22 \\
\hline CV tris & 11 & 8 & 10 & 8 & 13 & 13 \\
\hline CVC R dis & 1 & --- & 2 & 1 & --- & 1 \\
\hline CVC R tris & --- & --- & --- & 1 & --- & --- \\
\hline CVC S dis & 1 & --- & --- & 1 & --- & 1 \\
\hline CCV R dis & 3 & --- & 2 & 6 & --- & --- \\
\hline CCV R tris & --- & --- & --- & 1 & --- & --- \\
\hline CCV L dis & 2 & --- & --- & 3 & --- & --- \\
\hline
\end{tabular}


Anexo I a - Erro mais comum quanto a fonemas no Gl

\begin{tabular}{|c|c|c|c|c|c|c|c|c|c|}
\hline & \multicolumn{9}{|c|}{ GI } \\
\hline & \multicolumn{3}{|c|}{ FALA ESPONTÂNEA } & \multicolumn{3}{|c|}{ IMITAÇÃO } & \multicolumn{3}{|c|}{ NOMEAÇÃO } \\
\hline & INICIAL & MEDIAL & FINAL & INICIAL & MEDIAL & FINAL & INICIAL & MEDIAL & FINAL \\
\hline$b$ & $\mathrm{~S} / \mathrm{m} /$ & * & --- & OS & $\mathrm{S} / \mathrm{p} /+\mathrm{S} / \mathrm{d} / \mathrm{UNI}$ & $\mathrm{S} / \mathrm{br} /$ & $\mathrm{S} / \mathrm{p} / \mathrm{UNI}$ & SEM ERRO & * \\
\hline$p$ & $\mathrm{~S} / \mathrm{pr} / \mathrm{UNI}$ & * & * & OS & $\mathrm{S} / \mathrm{b} / \mathrm{UNI}$ & S /t/ UNI & $\mathrm{S} / \mathrm{f} /$ & SEM ERRO & $\mathrm{S} / \mathrm{k} / \mathrm{UNI}$ \\
\hline d & * & I & I & $s / t /$ & $\mathrm{s} / \mathrm{t} /$ & $\mathrm{s} / \mathrm{t} /$ & $\mathrm{s} / \mathrm{t} /$ & I & I \\
\hline $\mathrm{t}$ & * & * & 1 & OS & $\mathrm{S} / \mathrm{s} /+\mathrm{S} / \Sigma /$ & $\mathrm{I}$ & $\mathrm{OS}+\mathrm{I}+\mathrm{S} / \Sigma /$ & --- & 1 \\
\hline$g$ & * & * & * & $\mathrm{S} / \mathrm{k} /$ & $\mathrm{S} / \mathrm{d} /$ & $\mathrm{S} / \mathrm{d} /+\mathrm{S} / \mathrm{k} /$ & $\mathrm{S} / \mathrm{k} /$ & --- & $\mathrm{S} / \mathrm{d} / \mathrm{UNI}$ \\
\hline k & $\mathrm{s} / \mathrm{t}$ & * & $\mathrm{S} / \mathrm{t} / \mathrm{UNI}$ & $s / t /$ & $\mathrm{S} / \mathrm{t} / \mathrm{UNI}$ & $\mathrm{s} / \mathrm{t}$ & $\mathrm{s} / \mathrm{t} /$ & * & $\mathrm{S} / \mathrm{t} / \mathrm{UNI}$ \\
\hline$z$ & --- & * & * & $C A+S / Z /$ & --- & $\mathrm{S} / \mathrm{s} /$ & * & $\mathrm{S} / \mathrm{s} /$ & $\mathrm{S} / \mathrm{s} /$ \\
\hline $\mathrm{s}$ & * & * & * & $\mathrm{S} / \Sigma /$ & --- & $\mathrm{S} / \Sigma /$ & $\mathrm{S} / \Sigma /$ & $\mathrm{S} / \Sigma /$ & $\mathrm{S} / \Sigma /$ \\
\hline $\mathrm{v}$ & * & * & * & $\mathrm{S} / \mathrm{f} /$ & $\mathrm{S} / \mathrm{b} /$ & $\mathrm{S} / \mathrm{f} /$ & $\mathrm{S} / \mathrm{b} /$ & --- & * \\
\hline$f$ & * & --- & * & OS & $\mathrm{S} / \mathrm{p} /$ & $\mathrm{S} / \mathrm{s} / \mathrm{UNI}$ & $S / p /$ & --- & * \\
\hline Z & * & --- & * & OS & $\mathrm{S} / \Sigma /$ & $\mathrm{S} / \Sigma /$ & * & --- & $\mathrm{S} / \mathrm{s} /$ \\
\hline$\Sigma$ & * & * & * & $\mathrm{S} / \mathrm{s} /$ & $\mathrm{S} / \mathrm{s} /$ & $\mathrm{S} / \mathrm{s} /$ & * & $\mathrm{S} / \mathrm{s} /$ & $\mathrm{S} / \mathrm{s} /$ \\
\hline $\mathrm{m}$ & $\mathrm{S} / \mathrm{b} / \mathrm{UNI}$ & SEM ERRO & SEM ERRO & OF & --- & $\mathrm{S} / \mathrm{b} /+/ \mathrm{n} /+/ \mathrm{g} /+/ \mathrm{l} / \mathrm{UNI}$ & OF UNI & --- & SEM ERRO \\
\hline $\mathrm{n}$ & * & $\mathrm{OF}+\mathrm{l}+\mathrm{S} / \mathrm{l} /$ & * & OF & --- & $\mathrm{OF}+\mathrm{I}+\mathrm{S} / \mathrm{l}$ & * & --- & $\mathrm{I}$ \\
\hline | & --- & * & OF UNI & --- & --- & OF UNI & --- & --- & OF UNI \\
\hline I & ${ }^{*}$ & 1 & * & $\mathrm{OF}$ & --- & 1 & * & OF & 1 \\
\hline$r$ & --- & * & $\mathrm{S} / / /$ & --- & --- & $\mathrm{S} / / /$ & --- & * & $\mathrm{S} / / /$ \\
\hline$\times$ & --- & * & $\mathrm{S} / / /$ & --- & --- & $\mathrm{S} / \mathrm{l} /$ & --- & $\mathrm{S} / / /$ & * \\
\hline$x$ & * & OF & * & OF & OF & OF & OF & --- & OF \\
\hline Arqui $\mathrm{R}$ & * & * & OF & OF & --- & OF & * & --- & * \\
\hline Arqui S & * & --- & * & OF & --- & $\mathrm{S}|z|+$ vogal & OF & --- & --- \\
\hline
\end{tabular}

Legenda: OS: omissão de sílaba, S: substituição, I: interdentalização, OF: omissão de fonema, CA: ceceio anterior, UNI: único tipo de erro, *: sem número suficiente de alvo. 
Anexo I b - Erro mais comum quanto a encontros consonantais no Gl

\begin{tabular}{|c|c|c|c|c|c|c|c|c|c|}
\hline & \multicolumn{9}{|c|}{$\mathrm{Gl}$} \\
\hline & \multicolumn{3}{|c|}{ FALA ESPONTÂNEA } & \multicolumn{3}{|c|}{ IMITAÇÃO } & \multicolumn{3}{|c|}{ NOMEAÇÃO } \\
\hline & INICIAL & MEDIAL & FINAL & INICIAL & MEDIAL & FINAL & INICIAL & MEDIAL & FINAL \\
\hline bl & --- & --- & --- & $\mathrm{S} / \mathrm{b} /$ & --- & --- & $\mathrm{S} / \mathrm{b} /$ & --- & --- \\
\hline $\mathrm{pl}$ & --- & --- & --- & $\mathrm{S} / \mathrm{p} /$ & --- & --- & * & --- & --- \\
\hline gl & --- & --- & --- & $\mathrm{S} / \mathrm{g} /$ & $\begin{array}{ll}-- \\
\end{array}$ & $\begin{array}{ll}-- \\
\end{array}$ & --- & --- & --- \\
\hline $\mathrm{kl}$ & $\begin{array}{ll}-- \\
\end{array}$ & * & --- & $\mathrm{S} / \mathrm{k}$ & $\begin{array}{ll}-- \\
\end{array}$ & $\begin{array}{l}-- \\
\end{array}$ & $\begin{array}{ll}--- \\
\end{array}$ & --- & $\begin{array}{ll}-- \\
\end{array}$ \\
\hline $\mathrm{fl}$ & * & --- & $\begin{array}{ll}-- \\
\end{array}$ & $S / f /$ & --- & $\begin{array}{ll}-- \\
\end{array}$ & --- & --- & --- \\
\hline $\mathrm{bP}$ & * & --- & $\begin{array}{ll}-- \\
\end{array}$ & $\mathrm{S} / \mathrm{b} /$ & --- & --- & $\mathrm{S} / \mathrm{b} /$ & --- & * \\
\hline $\mathrm{pP}$ & * & * & $\begin{array}{cl}-- \\
\end{array}$ & $\mathrm{S} / \mathrm{p} /$ & --- & --- & $\mathrm{S} / \mathrm{p} /$ & --- & --- \\
\hline $\mathrm{fP}$ & * & --- & --- & $\mathrm{S} / \mathrm{f} /$ & --- & --- & --- & --- & --- \\
\hline $\mathrm{dP}$ & --- & --- & --- & $\mathrm{S} / \mathrm{d} /$ & --- & --- & --- & --- & --- \\
\hline tP & --- & --- & --- & $\mathrm{S} / \mathrm{t} /$ & --- & --- & * & --- & --- \\
\hline $\mathrm{gP}$ & --- & --- & --- & $\mathrm{S} / \mathrm{g} /$ & --- & --- & --- & --- & --- \\
\hline $\mathrm{kP}$ & --- & --- & --- & $\mathrm{S} / \mathrm{k}$ & --- & --- & --- & --- & --- \\
\hline VP & --- & --- & --- & --- & --- & --- & --- & --- & * \\
\hline
\end{tabular}

Legenda: S: substituição, *: sem número suficiente de alvo 
Anexo I c - Erro mais comum quanto a fonemas no Gll

\begin{tabular}{|c|c|c|c|c|c|c|c|c|c|}
\hline & \multicolumn{9}{|c|}{ GII } \\
\hline & \multicolumn{3}{|c|}{ FALA ESPONTÂNEA } & \multicolumn{3}{|c|}{ IMITAÇÃO } & \multicolumn{3}{|c|}{ NOMEAÇÃO } \\
\hline & INICIAL & MEDIAL & FINAL & INICIAL & MEDIAL & FINAL & INICIAL & MEDIAL & FINAL \\
\hline b & OS & * & --- & $\mathrm{s} / \mathrm{p} /$ & $\mathrm{S} / \mathrm{p} /+\mathrm{S} / \mathrm{v} / \mathrm{UNI}$ & $\mathrm{S} / \mathrm{br} /$ & $\mathrm{S} / \mathrm{p} /$ & SEM ERRO & * \\
\hline $\mathrm{p}$ & $\mathrm{S} / \mathrm{b} / \mathrm{UNI}$ & * & * & $\mathrm{s} / \mathrm{t} /$ & $\mathrm{S} / \mathrm{f} / \mathrm{UNI}$ & $\mathrm{S} / \mathrm{pP} / \mathrm{UNI}$ & $S / b /$ & SEM ERRO & $\mathrm{S} / \mathrm{k} / \mathrm{UNI}$ \\
\hline$d$ & * & I UNI & $I+S / t /$ & $\mathrm{s} / \mathrm{t} /$ & $S / t /+I$ & $S / t /+1$ & 1 & $\mathrm{I}$ & 1 \\
\hline$t$ & * & * & $\mathrm{I}+\mathrm{S} / \Sigma / \mathrm{UNI}$ & $\mathrm{OF}+\mathrm{I}$ & $\mathrm{S} / \mathrm{s} /+\mathrm{S} / \Sigma /$ & 1 & $\mathrm{OS}+\mathrm{S} / \Sigma /+\mathrm{S} / \mathrm{s} /$ & --- & 1 \\
\hline $\mathrm{g}$ & * & * & * & $\mathrm{S} / \mathrm{k} /$ & $\mathrm{S} / \mathrm{d} /$ & $\mathrm{S} / \mathrm{d} /$ & $\mathrm{S} / \mathrm{k} /$ & --- & $\mathrm{S} / \mathrm{d} / \mathrm{UNI}$ \\
\hline $\mathrm{k}$ & $\mathrm{S} / \mathrm{t} /$ & $\mathrm{OS}+\mathrm{S} / \mathrm{t} /$ & $\mathrm{S} / \mathrm{t} / \mathrm{UNI}$ & $\mathrm{s} / \mathrm{t} /$ & $S / p /+S / t /$ & $\mathrm{s} / \mathrm{t} /$ & $\mathrm{s} / \mathrm{t} /$ & * & $\mathrm{S} / \mathrm{t} / \mathrm{UNI}$ \\
\hline$z$ & --- & * & $\mathrm{CA}+\mathrm{S} / \mathrm{s} /$ & $\mathrm{S} / \mathrm{d} /$ & --- & $\mathrm{S} / \mathrm{Z} /$ & * & $\mathrm{S} / \mathrm{Z} /$ & $\mathrm{D}+\mathrm{CA}+\mathrm{S} / \mathrm{Z} /+\mathrm{s} /$ \\
\hline$s$ & ${ }^{*}$ & * & ${ }^{*}$ & $\mathrm{~S} / \Sigma /$ & --- & $\mathrm{S} / \Sigma /$ & $\mathrm{S} / \Sigma /$ & $\mathrm{S} / \Sigma /$ & $\mathrm{S} / \Sigma /$ \\
\hline $\mathrm{v}$ & * & * & $\mathrm{S} / \mathrm{d} /$ & $S$ /f/ & $\mathrm{S} / \mathrm{d} /+\mathrm{S} / \mathrm{vr} /$ & $S$ /f/ & $\mathrm{S} / \mathrm{b} /$ & --- & * \\
\hline$f$ & OS+S/p/+S/t/ UNI & * & * & $\mathrm{OS}+\mathrm{S} / \mathrm{p} /$ & $S / t /+S / s /$ & $\mathrm{s} / \mathrm{t} /$ & $\mathrm{s} / \mathrm{t} /$ & --- & $\mathrm{s} / \mathrm{t}$ \\
\hline $\mathrm{Z}$ & * & * & * & $\mathrm{S} / \mathrm{z} /$ & $\mathrm{S} / \mathrm{z} /$ & $\mathrm{S} / \mathrm{z} /$ & * & --- & $\mathrm{S} / \mathrm{z} /$ \\
\hline$\Sigma$ & * & * & * & $\mathrm{S} / \mathrm{t} /$ & $\mathrm{S} / \mathrm{s} /$ & $\mathrm{S} / \mathrm{s} /$ & * & $\mathrm{S} / \mathrm{s} /$ & $D+S / s /$ \\
\hline $\mathrm{m}$ & SEM ERRO & SEM ERRO & * & OF & --- & $\mathrm{S} / \mathrm{n} /$ & $S / b /+S / t /$ & --- & SEM ERRO \\
\hline $\mathrm{n}$ & * & $\mathrm{OF}+\mathrm{S} / \mathrm{I} /$ & * & $\mathrm{S} / \mathrm{m} /$ & --- & SEM ERRO & * & --- & $\mathrm{I}+\mathrm{S} / \mathrm{m} / \mathrm{UNI}$ \\
\hline | & --- & * & OF UNI & --- & --- & OF UNI & --- & --- & SEM ERRO \\
\hline $\mathrm{I}$ & * & $\mathrm{S} / \mathrm{y} / \mathrm{UNI}$ & * & OF & --- & $\mathrm{D}$ & OF + I UNI & OF & $\mathrm{I}$ \\
\hline$r$ & --- & * & $\mathrm{S} / \mathrm{I}$ & --- & --- & $\mathrm{S} / \mathrm{I} /$ & --- & * & $\mathrm{S} / / /$ \\
\hline$x$ & --- & * & $S / / /$ & --- & --- & $\mathrm{S} / \mathrm{l} /$ & --- & $\mathrm{S} / \mathrm{I} /$ & $\mathrm{S} / / /$ \\
\hline$x$ & * & OF & * & OF & OF & OF & OF & --- & OF \\
\hline Arqui $R$ & * & * & OF & OF & --- & OF & OF & --- & OF \\
\hline Arqui S & OS & --- & * & $\mathrm{OF}$ & --- & $\mathrm{S} / \mathrm{z} /+$ VOGAL & OF & --- & --- \\
\hline
\end{tabular}

Legenda: OS: omissão de sílaba, S: substituição, I: interdentalização, OF: omissão de fonema, CA: ceceio anterior, D: distorção, UNI: único tipo de erro, *: sem número suficiente de alvo. 
Anexo I d - Erro mais comum quanto a encontros consonantais no GII

\begin{tabular}{|c|c|c|c|c|c|c|c|c|c|}
\hline & \multicolumn{9}{|c|}{ Gl } \\
\hline & \multicolumn{3}{|c|}{ FALA ESPONTÂNEA } & \multicolumn{3}{|c|}{ IMITAÇÃO } & \multicolumn{3}{|c|}{ NOMEAÇÃO } \\
\hline & INICIAL & MEDIAL & FINAL & INICIAL & MEDIAL & FINAL & INICIAL & MEDIAL & FINAL \\
\hline $\mathrm{bl}$ & --- & --- & --- & $\mathrm{S} / \mathrm{b} /$ & --- & --- & * & --- & --- \\
\hline $\mathrm{pl}$ & * & --- & --- & $S / p /$ & --- & --- & * & --- & --- \\
\hline $\mathrm{gl}$ & --- & --- & --- & $\mathrm{S} / \mathrm{g} /$ & --- & --- & --- & --- & --- \\
\hline $\mathrm{kl}$ & --- & * & --- & $\mathrm{S} / \mathrm{k} /$ & --- & --- & --- & --- & --- \\
\hline $\mathrm{fl}$ & * & --- & --- & $S$ /f/ & --- & --- & --- & --- & $-\cdots$ \\
\hline $\mathrm{bP}$ & * & --- & * & $\mathrm{S} / \mathrm{b} /$ & --- & --- & $\mathrm{S} / \mathrm{b} /$ & --- & * \\
\hline $\mathrm{pP}$ & * & --- & --- & $\mathrm{S} / \mathrm{p} /$ & --- & --- & $S / p /$ & --- & --- \\
\hline fP & --- & --- & --- & $S / f /$ & --- & --- & --- & --- & --- \\
\hline $\mathrm{dP}$ & --- & * & * & $\mathrm{S} / \mathrm{d} /$ & --- & --- & --- & --- & --- \\
\hline tP & * & --- & * & $S / t /$ & --- & --- & * & --- & --- \\
\hline $\mathrm{gP}$ & --- & --- & --- & $S / g /$ & --- & --- & --- & --- & --- \\
\hline $\mathrm{kP}$ & * & --- & --- & $\mathrm{S} / \mathrm{k} /$ & --- & --- & * & --- & $-\cdots$ \\
\hline $\mathrm{VP}$ & --- & --- & --- & -- & --- & --- & --- & --- & $\mathrm{S} / \mathrm{v} /$ \\
\hline
\end{tabular}

Legenda: S: substituição, *: sem número suficiente de alvo 